\title{
SISTEMA INTEGRADO DE DIAGNOSE E RECOMENDAÇÃO (DRIS) PARA AVALIAÇÃO DO ESTADO NUTRICIONAL DA MACIEIRA NO SUL DO BRASIL
}

\author{
GILMAR RIBEIRO NACHTIGALL
}

Tese apresentada à Escola Superior de Agricultura "Luiz de Queiroz", Universidade de São Paulo, para obtenção do título de Doutor em Agronomia, Área de Concentração: Solos e Nutrição de Plantas.

P I R A C I C A B A

Estado do São Paulo - Brasil

$$
\text { Junho - } 2004
$$




\title{
SISTEMA INTEGRADO DE DIAGNOSE E RECOMENDAÇÃO (DRIS) PARA AVALIAÇÃO DO ESTADO NUTRICIONAL DA MACIEIRA NO SUL DO BRASIL
}

\author{
GILMAR RibEIRo NACHTIGALL \\ Engenheiro Agrônomo
}

Orientador: Prof. Dr. ANTONIO ROQUE DECHEN

\begin{abstract}
Tese apresentada à Escola Superior de Agricultura "Luiz de Queiroz", Universidade de São Paulo, para obtenção do título de Doutor em Agronomia, Área de Concentração: Solos e Nutrição de Plantas.
\end{abstract}

\author{
P I R A C I C A B A \\ Estado do São Paulo - Brasil \\ Junho - 2004
}


Dados Internacionais de Catalogação na Publicação (CIP)
DIVISÃO DE BIBLIOTECA E DOCUMENTAÇÃO - ESALQ/USP

Nachtigall, Gilmar Ribeiro

Sistema integrado de diagnose e recomendação (DRIS) para avaliação do estado nutricional da macieira no sul do Brasil / Gilmar Ribeiro Nachtigall. - Piracicaba, 2004. 141 p. : il.

Tese (doutorado) - - Escola Superior de Agricultura Luiz de Queiroz, 2004. Bibliografia.

1. Balanço de nutriente 2. Diagnose foliar 3. Maçã 4. Sistema Integrado de Diagnose e Recomendação I. Título

CDD 634.11 


\section{Á minha esposa Heliane, Aos meus filhos Matheus e Lucase Aos meus pais \\ Pelo carinho, apoio e incentivo}

\section{DEDICO}




\section{AGRADECIMENTOS}

- Ao Professor Dr. Antonio Roque Dechen, pelo apoio, confiança, orientação e, principalmente, amizade dispensados não só na realização deste trabalho mas, também, durante o curso;

- À Embrapa (Empresa Brasileira de Pesquisa Agropecuária), em especial a Embrapa Uva e Vinho, pela confiança e apoio financeiro;

- À Escola Superior de Agricultura “Luiz de Queiroz”, em especial ao Departamento de Solos e Nutrição de Plantas, pela oportunidade concedida para a realização do curso de Doutorado;

- Às empresas produtoras de maçã Rasip Agro Pastoril S.A., Agropecuária Schio Ltda, Tedesco S.A., Renar Maçãs S.A., Agrícola Fraiburgo S.A., e aos produtores Marcos Palombini, Sebastião Rioytsu Fukushima, Paulo Mindru Okamoto, Nelson Iida e Makoto Umemiya, pela colaboração e facilidades proporcionadas para a condução dos trabalhos de campo;

- Aos Pesquisadores George Wellington Bastos de Melo, Gilberto Nava e Cláudio José da Silva Freire pelo auxílio ao trabalho;

- Aos Professores do Curso de Pós Graduação em Solos e Nutrição de Plantas, pelos ensinamentos, colaborações e amizade; 
- Ao Professor Dr. Luis Reynaldo Ferracciú Alleoni, pela amizade e oportunidade concedida para a execução de trabalhos pesquisa;

- Aos Funcionários do Departamento de Solos e Nutrição de Plantas, pela colaboração e amizade;

- Aos Funcionários da Biblioteca da ESALQ/USP, em especial a bibliotecária Eliane Maria Garcia Sabino, pela colaboração, correções das referências bibliográficas e amizade;

- Aos amigos(as) do Curso, em especial: Aline Marques Genú, Antonio Xavier de Campos, Camila Beig Jordão, Cindy Silva Moreira, Eros Artur Bohac Francisco, José Egídio Flori, Márcio Roberto Soares, Maria Ligia de Souza Silva, Michel Alexandro Cambri, Paulo Furtado Mendes Filho, Simão Lindoso de Souza e Suzana Pereira de Melo, pela convivência, amizade e pelos bons momentos;

- Às graduandas em agronomia da ESALQ, Roberta Corrêa Nogueirol, Cíntia Masuco Lopes, Martha Monteiro Chaddad e Heloisa Rangel Carraro, pela amizade e convivência. 


\section{SUMÁRIO}

Página

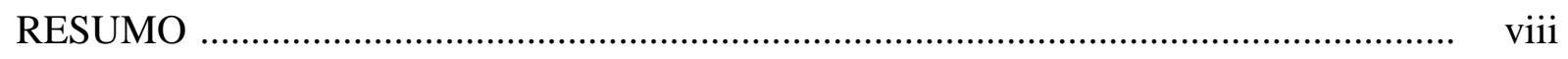

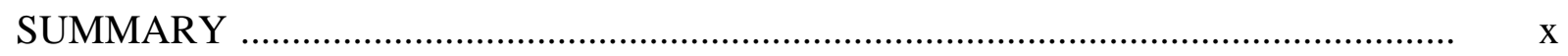

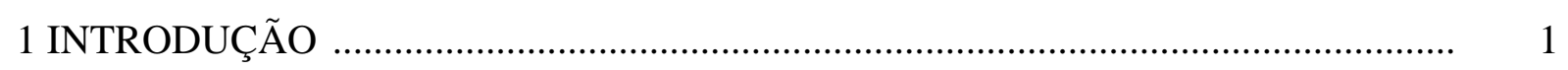

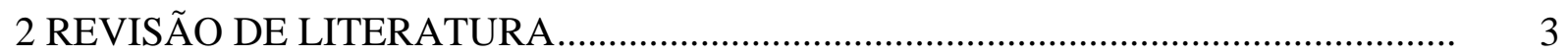

2.1 A cultura da macieira no Brasil ......................................................................... 3

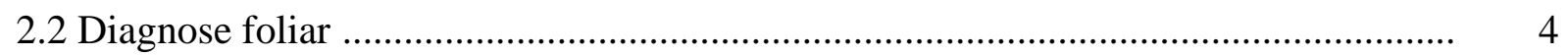

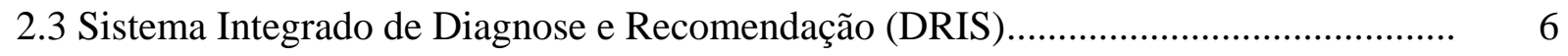

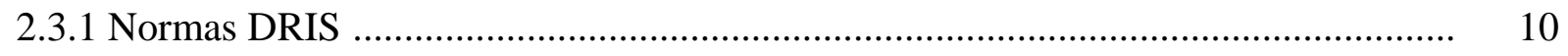

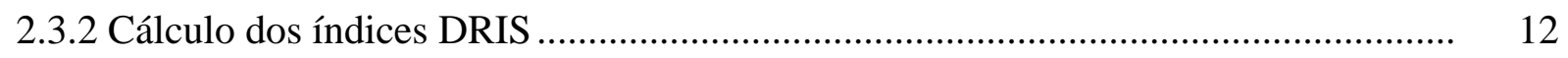

2.3.3 Aplicação do método DRIS em fruticultura ........................................................ 14

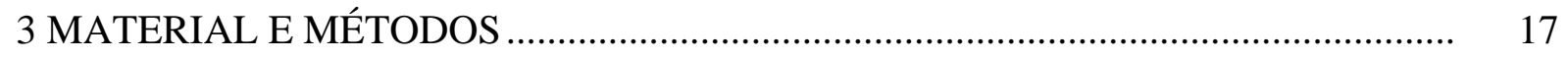

3.1 Estabelecimento das normas DRIS para a cultura da macieira no Sul do Brasil......... 17

3.1.1 Localização e descrição dos pomares estudados ................................................... 17

3.1.2 Amostragem e análise de folhas e solo ............................................................... 20

3.1.3 Formação do banco de dados............................................................................... 21

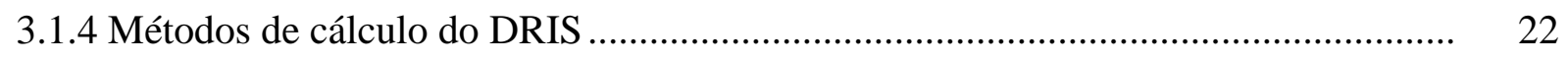

3.1.4.1 Escolha da ordem da razão dos nutrientes ....................................................... 22

3.1.4.2 Cálculo dos índices DRIS e índice de balanço nutricional .................................... 23

3.2 Avaliação da eficiência do método DRIS ............................................................. 26

3.3 Avaliação da época de amostragem de folhas de macieira para o método DRIS......... 30

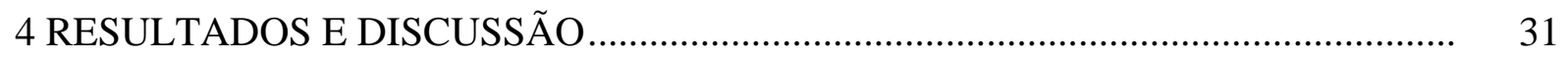

4.1 Descrição da população avaliada ......................................................................... 31

4.2 Estabelecimento das normas DRIS para a cultura da macieira no Sul do Brasil......... . 46 
4.3 Avaliação dos métodos de cálculo do DRIS ........................................................... 51

4.4 Avaliação da eficiência dos métodos de cálculo do DRIS ...................................... 64

4.5 Avaliação da época de amostragem de folhas de macieira para o método DRIS......... 83

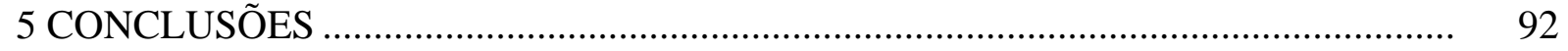

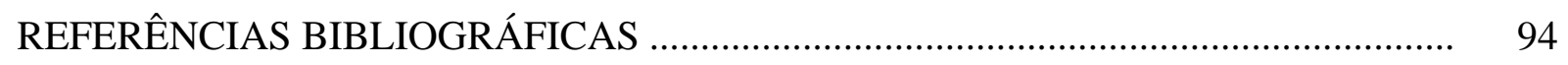

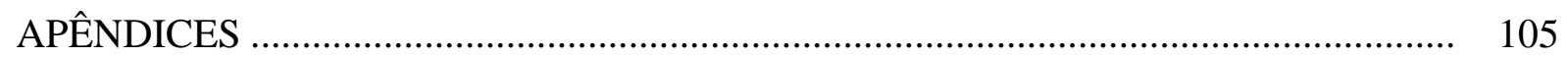




\title{
SISTEMA INTEGRADO DE DIAGNOSE E RECOMENDAÇÃO (DRIS) PARA AVALIAÇÃO DO ESTADO NUTRICIONAL DA MACIEIRA NO SUL DO BRASIL
}

\author{
Autor: GILMAR RIBEIRO NACHTIGALL \\ Orientador: Prof. Dr. ANTONIO ROQUE DECHEN
}

\section{RESUMO}

O manejo nutricional adequado é fator determinante na produtividade e na qualidade dos frutos de macieira. Dentre os métodos para diagnóstico nutricional das plantas, destacam-se o critério de faixa de suficiência e o sistema integrado de diagnose e recomendação (DRIS). Este trabalho teve por objetivo avaliar o DRIS como método de interpretação de resultados de análises de folhas de plantas de macieira, estabelecendo normas adequadas para a cultura, e compará-lo com o método de diagnose nutricional, baseado no critério de faixa de suficiência, atualmente utilizado no Sul do Brasil. Buscou-se determinar, também a melhor época de amostragem de folhas de macieira para a aplicação do método DRIS. O estudo foi realizado na região produtora de maçã dos Campos de Cima da Serra, no Rio Grande do Sul, e nas regiões do Alto Vale do Rio do Peixe e Planalto Serrano, em Santa Catarina, em 70 pomares selecionados quanto à produtividade e técnicas de manejo do pomar, onde foram obtidas informações sobre a produtividade, espaçamento, porta-enxertos e realizada a amostragem de folhas e solo. 
Foram determinadas as concentrações de nitrogênio, fósforo, potássio, cálcio, magnésio, boro, cobre, ferro, manganês e zinco nas amostras de folhas e os valores de pH e os teores de matéria orgânica, fósforo, potássio, cálcio e magnésio nas amostras de solos. Também foram utilizados resultados de experimentos de adubação potássica e nitrogenada para avaliar a eficiência dos métodos DRIS, bem como de resultados de sazonalidade de nutrientes em três cultivares de macieira, para avaliar a época adequada de coleta de folhas para o método DRIS. Os índices DRIS foram calculados utilizandose dois critérios para a escolha da ordem da razão dos nutrientes (Letzsch, 1985 e Walworth et al., 1986; Nick, 1998) e três formas de cálculo das funções dos nutrientes (Beaufils, 1973; Jones, 1981; Elwali \& Gascho, 1984). Os resultados indicaram que: (i) A concentração dos nutrientes apresentou correlação positiva e significativa $(p<0,01)$ com os respectivos índices DRIS, com exceção do N; (ii) O critério do "valor F" (Letzsch, 1985 e Walworth et al., 1986) mostrou-se mais eficiente que o "valor R" (Nick, 1998) para a escolha da ordem da razão dos nutrientes para a cultura da macieira; (iii) O Índice de Balanço Nutricional (IBN), calculado a partir das normas geradas, apresentou correlação negativa e significativa $(\mathrm{p}<0,01)$ com a produtividade para a população de referência, em todas as combinações de métodos testados; (iv) O método DRIS descrito por Elwali \& Gascho (1984), utilizando o "valor F”, quando comparado com o critério de faixas de suficiência, apresentou diagnóstico nutricional mais eficiente que os demais métodos de cálculo do DRIS; (v) O método de cálculo do DRIS, com base no somatório das funções, descrito por Elwali \& Gascho (1984), utilizando o "valor F” é o mais indicado para a cultura da macieira, por apresentar valores de IBN que melhor indicam o estado nutricional das plantas e pela eficiência no diagnóstico nutricional da cultura; (vi) A melhor época de coleta de folhas para o método DRIS esta situada entre a quinta e a décima quinta semana após a plena floração; (vii) As normas DRIS geradas neste trabalho foram adequadas para o diagnóstico nutricional da macieira, para as condições do Sul do Brasil. 


\title{
DIAGNOSIS AND RECOMMENDATION INTEGRATED SYSTEM (DRIS) TO EVALUATION OF NUTRITIONAL STATUS OF APPLE IN SOUTHERN BRAZIL
}

\author{
Author: GILMAR RIBEIRO NACHTIGALL \\ Adviser: Prof. Dr. ANTONIO ROQUE DECHEN
}

\section{SUMMARY}

The appropriate nutritional management is a decisive factor in fruit productivity and quality of apple trees. Among the several methods for nutritional diagnosis of the plants, the most important are the sufficiency range approach and the diagnosis and recommendation integrated system (DRIS). The objective of this work was evaluate DRIS as an interpretation method of results of analyses of apple tree leaves, establishing appropriate norms for the culture and comparing it with the sufficiency range approach currently used in the Southern Brazil, and determine the best sampling time of apple tree leaves for the application of the DRIS method. The study was carried out in the apple producing area of Campos de Cima da Serra (RS, Brazil), and in the areas of Alto Vale do Rio do Peixe and Planalto Serrano (SC, Brazil), in 70 orchards selected on basis of productivity and management techniques, where information on productivity, spacing, rootstock was obtained and leaf and soil sampling were performed. The concentrations of nitrogen, phosphorus, potassium, calcium, magnesium, boron, copper, iron, manganese and zinc were determined in the leaf 
samples as well as the $\mathrm{pH}$ values and the concentrations of organic matter, phosphorus, potassium, calcium and magnesium in the samples of soils. Results of fertilization experiments with potassium and nitrogen were also used to evaluate the efficiency of DRIS methods, as well as results of nutrient seasonally in three apple tree cultivars, to evaluate the appropriate leaf collection time for the DRIS method. The DRIS indices were calculated using two criteria to choose the order of the nutrient ratio (Letzsch, 1985 and Walworth et al., 1986; Nick, 1998) and three forms of calculating of the nutrient functions (Beaufils, 1973; Jones, 1981; Elwali \& Gascho, 1984). The results indicated that: (i) the nutrient concentration presented positive and significant correlation $(\mathrm{p}<0.01)$ with the respective DRIS indices, except for N; (ii) the criterion of the "F value" (Letzsch, 1985 and Walworth et al., 1986) was shown to be more efficient than the "R value" (Nick, 1998) to choose the order of the nutrient ratio for apple tree culture; (iii) the Nutritional Balance Index (NBI), calculated from the generated norms, presented a negative and significant correlation $(\mathrm{p}<0.01)$ with productivity for the reference population in all combinations of methods tested; (iv) the DRIS method described by Elwali \& Gascho (1984), using the "F value", when compared with the sufficiency range approach, presented a more efficient nutritional diagnosis than the other methods of DRIS calculation; (v) the method of DRIS calculation, based on the sum of the functions, described by Elwali \& Gascho (1984), using the "F value" is the most suitable for apple tree culture, for presenting NBI values that best indicate the nutritional state of the plants and for the efficiency in the nutritional diagnosis of the culture; (vi) the best leaf sampling time for the DRIS method is between the fifth and the fifteenth week after full blossom; (vii) The DRIS norms generated in this work were appropriate for the nutritional diagnosis of apple trees, for the conditions of Southern Brazil. 


\section{INTRODUÇÃO}

O Brasil possui atualmente cerca de 31.000 ha cultivados com macieira, dos quais aproximadamente 13.600 ha no Rio Grande do Sul, localizados principalmente na região fisiográfica dos Campos de Cima da Serra, e aproximadamente 16.000 ha em Santa Catarina, situados nas regiões do Alto Vale do Rio do Peixe e do Planalto Serrano. Os solos destas regiões se caracterizam por serem ácidos e de fertilidade natural baixa, o que exige o uso de adubação adequada para a obtenção de boas produções.

O desenvolvimento vegetativo e produtivo do pomar de macieira, a incidência de pragas e doenças e a qualidade do fruto são reflexos do estado nutricional das plantas, o que define a importância do conhecimento do estado nutricional do pomar, tanto para minimizar estes efeitos como para racionalizar a aplicação de fertilizantes.

A recomendação de adubação utilizada para a cultura da macieira estabelece uma adubação de pré-plantio, baseada na análise do solo, a qual é um bom indicador da acidez e do teor de nutrientes disponíveis no solo, aliada a uma adubação de manutenção, estabelecida em função de vários fatores. Entre estes se destaca a diagnose foliar, que é uma forma de avaliar o estado nutricional das plantas frutíferas.

O diagnóstico nutricional da cultura da macieira no Brasil é realizado, através da análise foliar, seguindo o método inicialmente desenvolvido na Michigan State University, onde os valores analíticos dos nutrientes são transformados para índices do balanço de cada nutriente. Posteriormente, estes índices de balanço foram simplificados, chegando, atualmente, ao uso de tabelas de interpretação de concentrações de nutrientes da cultura da macieira. Por esta metodologia, as folhas completas (limbo com pecíolo) devem ser colhidas da porção média dos ramos do ano, posicionados em altura facilmente acessível, sem o uso de escada, nos quatro lados das plantas, no período de 15 de janeiro a 15 de fevereiro, cujos resultados são comparados com padrões 
nutricionais. Esta metodologia apresenta algumas limitações práticas: a) não permite a interpretação de resultados de amostras coletadas fora do período indicado; b) o resultado da análise foliar, mesmo realizado em um curto espaço de tempo, não permite corrigir problemas nutricionais na mesma safra.

O Sistema Integrado de Diagnose e Recomendação (DRIS) é um método de diagnóstico nutricional de plantas baseado na comparação de índices, calculados através das relações entre nutrientes. Esta técnica apresenta algumas vantagens: a) permite uma interpretação menos dependente de variações de amostragens, relativas à fase de desenvolvimento, idade e origem do material analisado; b) permite ordenar os fatores limitantes de produção e destacar a importância do balanço de nutrientes; c) as normas de referência para o equilíbrio nutricional de uma determinada cultura podem ser extrapoladas para diversas regiões do país.

Como ainda não existem informações referentes a este método para a cultura da macieira, nas condições brasileiras, a introdução desta técnica, associada aos conceitos tradicionais, relativos aos níveis críticos e faixas de suficiência, poderá trazer informações importantes para a avaliação do estado nutricional da macieira.

O objetivo deste trabalho foi avaliar o DRIS como método de interpretação de resultados de análises de folhas de plantas de macieira, estabelecendo normas adequadas para a cultura, e compará-lo com o método de diagnose nutricional, baseado no critério de faixa de suficiência, atualmente utilizado no Sul do Brasil, buscou-se determinar, também, a melhor época de amostragem de folhas de macieira para a aplicação do método DRIS. 


\section{REVISÃO DE LITERATURA}

\subsection{A cultura da macieira no Brasil}

Os primeiros pomares comerciais no Brasil surgiram na Região de Fraiburgo, SC, em 1969, atraídos pela Lei de Incentivos Fiscais para reflorestamento, que incluía a macieira no programa. No início da década de 70, através do incentivo da Secretaria da Agricultura do Estado, foi criado o PROFIT (Programa de Fruticultura de Clima Temperado), que beneficiava pequenos e médios produtores. A experiência do PROFIT foi posteriormente levada ao Paraná e Rio Grande do Sul (Boneti et al., 1999).

A produção de maçã está concentrada na Região Sul do Brasil, que é responsável por 98\% da produção nacional. Em 1972, a área plantada no Brasil era insignificante (931 ha), passando a 18.941 ha em 1980 e a 31.070 ha em 2002. O principal Estado produtor é Santa Catarina com 15.907 ha, seguido do Rio Grande do Sul com 13.639 ha, Paraná com 1.300 ha e São Paulo com 224 ha. A evolução da área plantada com macieira no Brasil, de 1986 a 2002, mostra que o maior incremento de área nos últimos anos se deu no Estado do Rio Grande do Sul (Associação Brasileira dos Produtores de Maçã - ABPM, 2004).

A produção de maçã no Brasil, em 1973 atingia 1.528 toneladas, passando a 48.715 toneladas em 1980 e 857.340 toneladas em 2002 (ABPM, 2004). Enquanto a área plantada teve um aumento de 62\% de 1980 a 1990, a produção aumentou, neste mesmo período, 1.394\%. Considerando o período de 1990 a 2003, o incremento da área foi de 15\% e a produção de 106,84\%. Estes indicadores mostram um incremento significativo na eficiência produtiva da maçã no Brasil (Borges Júnior, 1998). 
A maior parte da produção brasileira provém dos cultivares Gala, Golden Delicious e Fuji. A Gala, a mais precoce (colhida em fevereiro), responde por 46\% da produção total; a Golden Delicious, colhida em março, representa 6\% da produção total e a Fuji, cuja colheita ocorre em abril, participa com $45 \%$ da produção e outras com 3\% (ABPM, 2004).

Tem-se verificado nos últimos anos forte tendência ao plantio de pomares de macieira em altas densidades de cultivo sobre porta-enxertos anões. Para pomares de alta densidade (superior a 1200 plantas/ha) são utilizados os porta-enxertos M-9 e M-26 e para densidades menores (entre 800 e 1200 plantas/ha) os porta-enxertos M-7 e MM-106 (Petri et al., 2003).

A maior parte da produção de maçã provém de grandes empresas, que cultivam extensas áreas, com avançado nível de integração vertical nas estruturas de classificação, de câmaras frias e de comercialização. Parte dos pequenos e médios produtores associam-se às grandes empresas atuando sob contrato, beneficiando-se da infraestrutura dessas empresas e outra parte está organizada em associações ou cooperativas e apresentam infra-estrutura para armazenagem, classificação e embalagem.

A capacidade de armazenamento de maçã atual é de 504.190 t, ou seja, cerca de 75\% da produção nacional. Desta capacidade, 47\% utiliza tecnologia convencional e 53\% atmosfera controlada. O Estado de Santa Catarina detém a maior capacidade de armazenamento e a maior proporção em atmosfera controlada (Boneti et al., 1999).

\subsection{Diagnose foliar}

Considerando que a análise de tecidos da planta constitui-se em um critério mais direto que a análise do solo para avaliar o estado nutricional das plantas, este método necessita envolver a análise de uma parte representativa da planta (Hallmark \& Beverly, 1991). Para fins de diagnose nutricional, dentre os diversos tecidos considerados para a análise, as folhas constituem o principal tecido amostrado em 
plantas, técnica conhecida como diagnose foliar (Bataglia et al., 1996; Terblanche \& Du Plessis, 1992).

A utilização das folhas para avaliar o estado nutricional das plantas leva em conta que estas são o principal órgão de metabolismo da planta, que as mudanças no suprimento de nutrientes se refletem na composição mineral das folhas, que as mudanças na composição mineral são mais acentuadas em certos estádios de crescimento que em outros e, que a concentração de nutrientes nas folhas em estádios específicos está relacionada com a performance da cultura (Basso et al., 1986).

Beaufils (1971) destacou que a maior vantagem da diagnose foliar está no fato de se considerar a própria planta como o extrator dos nutrientes no solo, e permitir uma avaliação direta de seu estado nutricional e, desse modo, avaliar as concentrações e as relações entre os nutrientes, constituindo, assim, uma forma indireta de avaliação da fertilidade do solo.

A análise foliar pode ser uma ferramenta de grande utilidade para o diagnóstico nutricional das plantas, contudo é necessário que sejam utilizados procedimentos disponíveis e adequados para a análise e interpretação dos resultados analíticos. Deve-se considerar que a diagnose foliar pode-se tornar uma técnica de difícil entendimento e utilização prática, já que a composição foliar apresenta natureza dinâmica, influenciada pela idade e maturação do tecido, bem como pelas interações que envolvem a absorção e translocação de nutrientes (Walworth \& Summer, 1987).

Para as plantas frutíferas em geral, a análise de tecidos da parte aérea tem se mostrado muito útil na avaliação do estado nutricional das culturas e nas recomendações de adubação (Marschner, 1995), uma vez que as concentrações dos nutrientes nas plantas são resultantes da ação e interação dos fatores envolvidos na sua disponibilidade no solo e na absorção pela planta (Mengel \& Kirkby, 2001).

Diversos métodos para diagnose nutricional utilizando-se da análise foliar têm sido propostos e utilizados, incluindo o método do valor crítico, o método de faixas de suficiência e o sistema integrado de diagnose e recomendação (DRIS).

A diagnose foliar, baseada em métodos padronizados de amostragem, é o 
critério mais eficaz na avaliação do estado nutricional de plantas frutíferas (Faust, 1989). Contudo, podem ocorrer situações que dificultem a interpretação dos resultados, já que nem sempre é possível obter as informações necessárias através da analise foliar, bem como nem sempre é possível estabelecer boa relação entre as concentrações dos nutrientes no solo e aqueles existentes nas folhas, existindo variação quanto ao cultivar, época do ano, porta-enxerto, densidade de plantio e outros (Schneider et al., 1978; Poling \& Oberly, 1979; Sharma \& Chauhan, 1991; Tagliavini et al., 1992; Basso \& Suzuki, 2000; Marangoni, 2000).

Pela dificuldade de interpretação dos resultados numéricos da análise foliar por parte do usuário, Kenworthy (1973) desenvolveu um sistema para plantas frutíferas, onde todos os valores analíticos dos nutrientes são transformados para um único índice, denominado de índice de balanço, através de equações matemáticas. Para a cultura da macieira no Brasil, estes índices de balanço foram simplificados por Nogueira \& Magnani (1981), resultando em uma única equação. Contudo, este sistema de apresentação de resultados apresenta a desvantagem de ter uma mesma faixa de interpretação, bem como os índices de balanço nutricional não são inferiores aos coeficientes de variação do nutriente, o que levou a criação da tabela de interpretação de concentrações de nutrientes da cultura da macieira (Comissão de Fertilidade do Solo, 1995).

Esta metodologia apresenta algumas limitações práticas: a) não permite a interpretação de resultados de amostras coletadas fora do período indicado; b) o resultado da análise foliar, mesmo realizado em um curto espaço de tempo, não permite corrigir problemas nutricionais na mesma safra.

\subsection{Sistema Integrado de Diagnose e Recomendação (DRIS)}

O Sistema Integrado de Diagnose e Recomendação (DRIS) é um método de diagnose nutricional de plantas que se baseia no cálculo de índice para cada nutriente, considerando sua relação com os demais, e comparando cada relação com as relações 
médias de uma população de referência (Beaufils, 1971).

O equilíbrio nutricional para um dado nutriente na planta é definido pelo método DRIS quando os valores dos índices estiverem mais próximos de zero, para valores negativos pode-se assumir que ocorre deficiência do nutriente em relação ao demais e, valores positivos indicam excesso. Desta forma, é possível classificar os nutrientes em ordem de importância de limitação na produção, bem como estabelecer uma indicação de intensidade de exigência de um nutriente pelas plantas (Beaufils, 1971, Davee et al., 1986).

O método DRIS está baseado em várias suposições relativas ao modo como o estado nutricional afeta o rendimento da cultura: a) As relações entre os nutrientes são, freqüentemente, melhores indicadores de deficiências nutricionais do que valores isolados de concentração de nutrientes; b) Algumas relações entre nutrientes são mais importantes ou significativas do que outras; c) Produtividades máximas são atingidas apenas quando os valores de relações nutricionais importantes são observados próximos aos valores ideais ou ótimos, que são médias de valores determinados em populações selecionadas, com alta produtividade; d) Pelo fato de que relações nutricionais importantes devem apresentar valores próximos aos obtidos em populações de alta produtividade, a variância de uma relação nutricional importante é menor em uma população de alta produtividade (população de referência) do que em populações de baixa produtividade; e) Os índices DRIS podem ser calculados individualmente, para cada nutriente, utilizando-se o desvio médio de cada relação nutricional desse nutriente com os demais em relação aos valores ótimos dessa determinada relação nutricional (Jones, 1981; Walworth \& Summer, 1987).

Vários estudos de comparação entre o método DRIS e o método do nível crítico foliar foram desenvolvidos utilizando diversas culturas (Beaufils, 1971, 1973; Beverly et al., 1984; Davee et al., 1986; Bataglia \& Santos, 1990). Estes autores concluíram que o DRIS apresentou vantagens sobre o nível crítico foliar no diagnóstico nutricional visando a recomendação de adubação: a) A indicação de deficiências nutricionais é, freqüentemente, melhor definida quando se utilizam as relações das concentrações dos nutrientes, dois a dois, do que a concentração do nutriente isolado; 
b) Sendo o equilíbrio nutricional um fator crítico e importante na determinação da produtividade das plantas, principalmente em altos níveis de produção, o diagnóstico considerando o equilíbrio nutricional com base em padrões ou normas tem vantagens sobre o diagnóstico através do nível crítico de cada nutriente; c) As normas ou padrões de referência para o equilíbrio nutricional de uma cultura podem ser extrapolados para diversas regiões do país; d) Os nutrientes que estão limitando a produção, tanto por excesso como por deficiência, podem ser prontamente identificados e ordenados em função de sua importância na limitação da produtividade; e) O diagnóstico pode ser realizado em diferentes estádios de desenvolvimento da cultura, bem como independentemente de cultivar.

Esta última vantagem e contestada por outros autores. É conhecido que em função da maturação dos tecidos da planta, a concentração de nutrientes é alterada significativamente, onde, geralmente, as concentrações de nitrogênio, fósforo, potássio e enxofre tendem a diminuir e as concentrações de cálcio e magnésio tendem a aumentar com a maturação dos tecidos. Assim, esta condição dinâmica da composição mineral nos tecidos das plantas tende a impor algumas limitações ao uso da análise foliar para fins de diagnostico nutricional. Por esta razão, os métodos de diagnose baseados no valor crítico e em faixas de suficiência utilizam estágios de desenvolvimento da planta bem definidos para a amostragem.

Pelos resultados obtidos por Beaufils (1973), as concentrações no tecido foliar de nitrogênio, fósforo e potássio decresceram com a maturação dos tecidos, de modo que as relações N/P, N/K e P/K (ou as relações inversas) permanecem constantes, enquanto que as concentrações de cálcio e magnésio decresceram com a maturação, originando relações $\mathrm{Ca} / \mathrm{Mg}$ ou $\mathrm{Mg} / \mathrm{Ca}$ constantes. Além disso, o produto de dois nutrientes como o nitrogênio e o cálcio ( $\mathrm{N}$ x Ca), onde o primeiro diminui e o segundo aumenta com a maturação dos tecidos, deve permanecer constante. Baldock \& Schulte (1996), contestaram essa vantagem do método DRIS, pois observaram que, em diversos casos, o método DRIS, aplicado para algumas culturas, mostrou-se ser sensível à maturação dos tecidos e idade da planta quanto comparado com o método de faixas de suficiência. 
Outras desvantagens ou erros no diagnóstico pelo método DRIS foram descritos por Hallmark \& Beverly (1991), contudo muitos deles não mostraram ser importantes para a eficiência do método. Segundo estes autores, além do diagnóstico pelo método DRIS poder ser sensível a idade do tecido amostrado, pode apresentar os seguintes erros: a) O DRIS indica qual o nutriente é relativamente mais deficiente, mas não indica a probabilidade de resposta ou a quantidade a aplicar; b) As funções são calculadas usando uma (linear) ou duas (linear e não linear) equações; c) Alternativas formas de expressão dos nutrientes não são consistentes quanto à assimetria da relação; d) Alternativas formas de expressão não têm equivalentes coeficientes de variação (CV); e) Diferentes tamanhos de população apresentam diferentes normas; f) O método DRIS usa normas a partir de populações de alta produtividade (normas), mas também de populações gerais; g) O método proposto por Jones (1981) é sensível à forma de expressão dos nutrientes.

Desenvolvido por Beaufils $(1971,1973)$ para a cultura da seringueira, o método previa, originalmente, envolver o máximo de fatores envolvidos na produção, para diagnosticar as causas primárias e secundárias que afetam a produtividade. Contudo, atualmente o sistema está evoluindo como um sistema de avaliação do estado nutricional das plantas. Seu uso tem mostrado ser um método útil neste tipo de diagnóstico para diversas culturas, como trigo (Sumner, 1977a), soja (Sumner, 1977b; Beverly et al., 1986), citros (Beverly et al., 1984; Cerda et al., 1995; Rodriguez et al., 1997), videiras (Chelvan et al., 1984; Schaller et al., 1995; Bhargava \& Raghpathi, 1996), pessegueiros (Sanz et al., 1992; Monge et al., 1995), milho (Elwali et al., 1985), pastagens (Bailey et al., 1997), cerejeiras (Davee et al., 1986) e bananeiras (Angeles et al., 1993), entre outras.

No Brasil, os estudos e o desenvolvimento desse sistema ainda envolvem poucas culturas, como café (Leite, 1993; Wadt et al., 1999a; Reis Júnior et al., 2002; Silva et al., 2003), cana-de-açúcar (Zambello Júnior, 1979; Reis Júnior \& Monnerat, 2002), citros (Bataglia, 1989; Creste \& Nakagawa, 1997; Santos, 1997; Veloso et al., 2000; Mourão Filho \& Azevedo, 2003), soja (Leandro et al., 1996; Maeda, 2003), eucalipto (Wadt et al., 1999b), mamoeiro (Costa, 1995), banana (Teixeira et al., 2002) e 
videira (Gergoletti, 1995; Guilherme, 1995; Costa, 1998), contudo, esta técnica vem sendo divulgada em eventos técnicos como uma ferramenta alternativa e útil no diagnóstico nutricional das plantas (Bataglia \& Dechen, 1986; Malavolta \& Malavolta, 1988).

\subsubsection{Normas DRIS}

O método DRIS utiliza as relações binárias entre os nutrientes, incorporando o conceito de índices primários, o que o diferencia dos métodos tradicionais de diagnose foliar como o nível crítico e faixas de suficiência (Costa, 1999). O cálculo dos índices DRIS depende, inicialmente, do estabelecimento de valores padrões ou normas de referência. Para isto, é necessário selecionar uma população de alta produtividade (população de referência), partindo-se da premissa de que existe uma relação significativa entre o suprimento de nutrientes e seus teores na planta, de modo que aumentos ou decréscimos nas suas concentrações proporcionam variação na produção.

A partir de uma população maior, cujo conjunto de resultados foi criteriosamente selecionados, é feita a seleção da população de referência. Os bancos de dados para a obtenção das normas podem ter tamanhos variáveis em função das premissas a serem adotadas no método e devem ser uniformes quanto às características da cultura. Normas obtidas a partir de um grande banco de dados, geradas de diferentes tipos de variáveis, normalmente não podem ser generalizadas, e serão consideradas representativas apenas se incluírem toda a variabilidade da população. Deve-se, portanto, definir esses atributos para, então, reunir e formar o banco de dados (Letzsch \& Summer, 1984).

A população escolhida para a obtenção das normas deve ser subdividida em duas subpopulações ou categorias: a) Plantas não anormais ou população de referência, que não são influenciadas por condições adversas e que apresentam produtividade significativamente superior a um nível arbitrariamente estabelecido; b) Plantas anormais ou população não referência, que são influenciadas por outros fatores, com 
produtividade menor que o estabelecido (Beaufils, 1973; Beverly, 1991; Walworth \& Summer, 1987).

Diversas pesquisas têm revelado que o sucesso e eficiência do método DRIS é dependente da seleção da população de referência. Letzsch \& Summer (1984) citam que a população de referência contenha, pelo menos, $10 \%$ das observações do banco de dados geral. Walworth \& Summer (1987) descrevem que o ponto de referência para separar as subpopulações de referência e não referência deve ser escolhido de forma arbitrária, pois as mesmas subpopulações deverão apresentar distribuição normal. Malavolta \& Malavolta (1989) recomendam que a população de referência seja obtida com resultados com níveis de 80\% da produção máxima.

Uma vez definida a população de referência, são obtidas as normas que são constituídas das relações entre todos os pares de nutrientes e seus respectivos desvios padrões e coeficientes de variação. A relação entre um par de nutrientes pode ser tanto direta como inversa, por exemplo, N/P e P/N, respectivamente.

Nos cálculos do método DRIS apenas um tipo de relação é utilizado para cada par de nutrientes. Diversos critérios para selecionar a relação mais adequada têm sido propostos. Bataglia \& Santos (1990) avaliaram as relações entre nutrientes tanto na ordem direta como na ordem inversa e concluíram que a ordem das relações pode interferir nos resultados de cálculo dos índices de nutrientes em citros, especialmente se as funções forem obtidas pelo método de cálculo de Jones (1981).

Um dos critérios mais utilizados para a seleção da relação entre nutrientes é o critério da maior relação de variâncias entre as populações de baixa e alta produtividade (Letzsch, 1985; Walworth \& Summer, 1987). Nick (1998) propôs o critério denominado "Valor r" para a escolha da ordem da razão dos nutrientes na aplicação do DRIS em cafeeiros podados, em que é escolhida a ordem da razão que resultar no mais alto valor absoluto do coeficiente de correlação (r) entre os valores da variável resposta da planta e a razão entre os pares de nutrientes, tanto na ordem direta como inversa.

Uma vez definidas as normas e selecionadas as relações para cada par de nutrientes, é possível calcular os índices DRIS para os teores de nutrientes de uma 
amostra. Assim, o cálculo de índices DRIS depende, inicialmente, do estabelecimento dos valores padrões ou normas, obtidos para todos os nutrientes dois a dois, onde se utiliza uma população de alta produtividade como população de referência (Bataglia \& Santos, 1990). O sucesso do DRIS depende da seleção da população normal (Beaufils, 1973), bem como do método de seleção das relações entre nutrientes, envolvendo o maior número de relações possíveis (Alkoshab et al., 1988).

\subsubsection{Cálculo dos índices DRIS}

O índice DRIS para um determinado nutriente é definido como a média das funções de todas as relações contendo esse nutriente. Os componentes dessa média são ponderados pelas recíprocas dos coeficientes de variação das respectivas relações da população de referência (Walworth \& Summer, 1987).

No método para o cálculo dos índices DRIS proposto originalmente por Beaufils (1973) as funções dos nutrientes são estabelecidas a partir das relações entre os pares de nutrientes e são impostas restrições quando a relação na amostra é maior ou menor que a relação média da população de referência. As funções são ponderadas através da recíproca dos coeficientes de variação das respectivas relações da população de referência. Para esse método, o valor da função é igual a zero quando a relação na amostra apresenta o mesmo valor da população de referência, independente de sua variabilidade. Esta metodologia resulta em índices DRIS para os nutrientes em maior deficiência, destacando deste modo às deficiências nutricionais.

A partir da metodologia de Beaufils (1973), diversas modificações na forma de cálculo dos índices DRIS foram propostas. Elwali \& Gascho (1984) propuseram uma modificação que, de modo geral, reduz o valor absoluto do índice DRIS, já que não inclui nos cálculos pequenos desvios da razão das concentrações de nutrientes na amostra em relação à razão média das concentrações dos nutrientes na população de referência, o que pode levar a uma maior sensibilidade na interpretação do estado nutricional. Esta metodologia consiste em considerar dois nutrientes balanceados se a 
relação entre os pares de nutrientes estiver dentro da faixa constituída pela média da relação na população de referência mais ou menos seu desvio padrão, assim, a função da relação assume valor zero em toda a faixa. Os procedimentos para os cálculos são os mesmos do método proposto por Beaufils (1973).

Já a modificação proposta por Jones (1981) apresenta uma base na formalidade estatística, semelhante à utilizada no controle estatístico de qualidade em indústrias, constituindo-se em uma simplificação do método de Beaufils. Este método não considera se a relação na amostra é maior ou menor que a relação na população de referência e utiliza a recíproca do desvio padrão para ponderar a variabilidade das relações.

Diversos trabalhos têm avaliado a eficiência destas três metodologias de cálculo dos índices DRIS. Bataglia \& Santos (1990), concluíram que os métodos propostos Beaufils (1973) e por Elwali \& Gascho (1984) apresentaram resultados semelhantes entre si, enquanto que o método proposto por Jones (1981) mostrou depender da ordem da relação de cada par de nutrientes estudados para a cultura da seringueira. Trabalhando com cafeeiros podados, Nick (1998) concluiu que o método proposto por Jones (1981) resultou em índices DRIS mais precisos que os gerados pelos métodos de Beaufils (1973) e Elwali \& Gascho (1984). Para Mourão Filho et al. (2002), o método de cálculo do DRIS proposto por Jones (1981) apresentou melhor correlação com a produtividade do que os métodos propostos por Beaufils (1973) e Elwali \& Gascho (1984), para a laranjeira “Caipira” e “Trifoliata”.

Um índice adicional pode ser obtido com o somatório dos valores absolutos dos índices DRIS, denominado Índice de Balanço Nutricional (IBN) (Baldock \& Schulte, 1996). Este índice pode ser um indicativo do estado nutricional da planta, contudo, não estabelece suas causas. Quanto menor o valor da soma, menor será o desequilíbrio entre nutrientes e, portanto, maior será a produtividade da cultura (Walworth \& Summer, 1987). Diversos trabalhos mostram que o IBN apresenta correlação negativa alta com a produtividade (Creste \& Nakagawa, 1997; Veloso et al., 2000; Mourão Filho et al., 2002; Silva et al., 2003). 


\subsubsection{Aplicação do método DRIS em fruticultura}

Atualmente o método DRIS tem evoluindo como um sistema de avaliação do estado nutricional das plantas. Seu uso têm mostrado ser um método útil neste tipo de diagnóstico para diversas culturas frutíferas, como citros (Beverly et al., 1984; Wallace, 1990; Beverly, 1992; Woods \& Villiers, 1992; Cerda et al., 1995; Rodriguez et al., 1997), videiras (Chelvan et al., 1984; Schaller et al., 1995; Bhargava \& Raghpathi, 1996), mangueiras (Schaffer et al., 1988; Raghupathi \& Bhargava, 1999), pessegueiros (Sanz et al., 1992; Monge et al., 1995), cerejeiras (Davee et al., 1986; Righetti et al., 1988), abacaxizeiros (Angeles et al., 1990), avelãs (Alkoshab et al., 1988; Righetti et al., 1988), bananeiras (Angeles et al., 1993; Wortmann et al., 1994), mamoeiros (Bowen, 1992), entre outras.

No Brasil, os estudos e o desenvolvimento desse método de diagnóstico nutricional ainda envolvem poucas culturas frutíferas, como citros (Bataglia, 1989; Creste \& Nakagawa, 1997; Santos, 1997; Creste \& Grassi Filho, 1998; Veloso et al., 2000; Salvo, 2001; Mourão Filho \& Azevedo, 2003), videiras (Gergoletti, 1995; Guilherme, 1995; Costa, 1998), bananeiras (Teixeira et al., 2002) mamoeiros (Costa, 1995).

Para a cultura da macieira ainda são poucos os estudos com o método DRIS, embora alguns resultados tenham sido obtidos no Canadá (Parent \& Granger, 1989), na Hungria (Szücs et al., 1990; Szücs \& Kállay, 1990), Nova Zelândia (Goh \& Malakouti, 1992) e Índia (Singh et al., 2000). Em todos os estudos o método DRIS mostrou-se adequado para o diagnóstico nutricional da cultura da macieira. No Brasil, ainda não existem estudos sobre a utilização deste método para a diagnose nutricional da macieira.

Parent \& Granger (1989) avaliaram o método DRIS para pomares adensados de macieiras no Canadá, utilizando o cultivar Morspur McIntosh enxertado sobre os porta-enxertos ananizantes M.7, M.26, Ott.3 e M.9. Para o estabelecimento das normas, utilizaram 1113 amostras de folhas coletadas em quatro anos, definindo como população de referência aquelas com produções superiores a 15,6 t ha ${ }^{-1}$. O trabalho foi realizado em 
experimento de adubação com doses de N, P, K, Ca e Mg. Os autores constaram que ocorreram variações nas normas, ano a ano, o que levou à definição das mesmas anualmente e concluíram que produções anuais podem ser utilizadas em vez de produções acumuladas para a geração das normas DRIS, especialmente após o sexto ano de plantio. A incorporação do índice de matéria seca nas equações de balanço nutricional (M-DRIS) foi importante para melhorar a definição entre nutrientes limitantes e não limitantes.

Na Hungria, Szucs et al. (1990), determinaram as relações padrão para DRIS em macieira. Para o estabelecimento das normas, utilizaram 190 amostras de folhas do cultivar Jonathan, coletadas em 18 pomares por três anos, definindo como população de referência aquelas com produções superiores a 33,5 $\mathrm{t} \mathrm{ha}^{-1}$. Os autores observaram que através do cálculo convencional do método DRIS, os índices indicaram excesso de $\mathrm{K}$ e carência de $\mathrm{P}$, enquanto os teores de $\mathrm{N}$ estiveram adequados. Normas estimadas por regressão quadrática para N/P, N/K e K/P mostraram excesso de K e relativa deficiência de $\mathrm{N}$ e $\mathrm{P}$, sugerindo que as normas obtidas por análise de regressão podem apresentar relações entre nutrientes mais extremas do que o método tradicional.

Goh \& Malakouti (1992) compararam a eficiência das normas desenvolvidas por Parent \& Granger (1989) no Canadá com as estabelecidas para a Nova Zelândia. A base de dados utilizada pelos autores foi constituída por experimento com o cultivar Golden Delicious, onde coletas de amostras de folhas foram feitas mensalmente, por experimento de adubação com N e $\mathrm{K}$ com o cultivar Golden Delicious e, por experimento de amostragem, no verão por três anos, em quatro pomares com os cultivares Golden Delicious e Braeburn. Os autores compararam o método diagnóstico com o método de faixas de suficiência e concluíram que os dois métodos apresentam eficiências semelhantes. Desequilíbrios referentes ao excesso de $\mathrm{N}$ e deficiência de Ca foram identificados, indicando que o método DRIS apresenta uma boa indicação das necessidades de nutrientes pela cultura. A melhor época de amostragem para fins de diagnose foliar foi constatada como de três a cinco meses após o florescimento.

Na Índia, Singh et al. (2000), determinaram as relações padrão para o DRIS em macieira, utilizando 1800 amostras de folhas do cultivar Jonathan, para o 
estabelecimento das normas, coletadas em 25 pomares por dois anos, definindo como população de referência aquelas com produções superiores a $25 \mathrm{t} \mathrm{ha}^{-1}$. Os autores observaram que o método DRIS realizou diagnóstico nutricional correto, revelando nutrientes insuficientes, em faixa normalmente considerada suficiente. Os autores concluíram que, na avaliação do balanço de nutrientes, a precisão é aumentada pelo método DRIS, já que o método do nível crítico não identificou certas deficiências. 


\section{MATERIAL E MÉTODOS}

\subsection{Estabelecimento das normas DRIS para a cultura da macieira no Sul do Brasil}

\subsubsection{Localização e descrição dos pomares estudados}

O trabalho foi realizado na região produtora de maçã dos Campos de Cima da Serra, no Rio Grande do Sul, e nas regiões do Alto Vale do Rio do Peixe e Planalto Serrano, em Santa Catarina. Os solos predominantes nestas regiões são Latossolo Bruno alumínico câmbico e Cambissolo Húmico alumínico típico.

Para a coleta de dados, foram selecionadas propriedades (grandes, médias e pequenas) produtoras de maçã com as seguintes características: a) estarem localizadas nas principais áreas produtoras de maçã do Rio Grande do Sul e Santa Catarina; b) possuírem histórico de produtividade superior à média regional; c) serem gerenciadas por especialista da área agronômica; d) possuírem levantamento detalhado de produtividade das áreas; e) apresentarem diversidade de cultivar, porta-enxerto e espaçamento de plantio; f) possuírem pomares plantados entre 1991 e 1998 e g) possuírem registros do manejo cultural utilizado anualmente.

Com base nestas características, foram selecionados 70 pomares de macieira, cuja descrição é apresentada na Tabela 1. Para cada pomar, tanto na safra 2002 como na safra 2003, foram coletadas informações do histórico da área, produção, cultivar, portaenxerto, espaçamento, ano de plantio, práticas culturais, manejo de pragas e doenças e manejo de fertilizantes e corretivos, através de questionário preenchido pelo técnico responsável pelo pomar. 
Tabela 1. Descrição dos locais, cultivares, porta-enxertos, ano de plantio, espaçamento entre plantas e número de plantas por hectare das amostras coletadas em 70 pomares de macieira no Rio Grande do Sul e Santa Catarina

\begin{tabular}{|c|c|c|c|c|c|c|}
\hline Amostra & Local & Cultivar & Porta-enxerto & $\begin{array}{l}\text { Ano de } \\
\text { Plantio } \\
\end{array}$ & $\begin{array}{c}\text { Espaçamento } \\
\text { (m) }\end{array}$ & Plantas/ha \\
\hline 1 & São Joaquim & Fuji & MARUBAKAIDO & 1985 & $4,00 \times 6,5$ & 384,62 \\
\hline 2 & São Joaquim & Fuji & MARUBAKAIDO & 1985 & $4,00 \times 6,5$ & 384,62 \\
\hline 3 & São Joaquim & Fuji & MARUBAKAIDO & 1992 & $3,00 \times 6,0$ & 555,56 \\
\hline 4 & São Joaquim & Fuji & MARUBAKAIDO & 1992 & $3,00 \times 6,0$ & 555,56 \\
\hline 5 & São Joaquim & Fuji & MARUBAKAIDO & 1993 & $3,00 \times 6,0$ & 555,56 \\
\hline 6 & São Joaquim & Fuji & MARUBAKAIDO & 1989 & $3,00 \times 6,0$ & 555,56 \\
\hline 7 & Vacaria & Royal Gala & EM-7 & 1998 & $1,50 \times 4,5$ & 1481,48 \\
\hline 8 & Vacaria & Fuji & EM-7 & 1998 & $2,00 \times 4,5$ & 1111,11 \\
\hline 9 & Vacaria & Royal Gala & EM-9 & 1998 & $0,80 \times 3,5$ & 3571,43 \\
\hline 10 & Vacaria & Gala & MM-106 & 1991 & $2,50 \times 5,0$ & 800,00 \\
\hline 11 & Vacaria & Fuji & EM-27 & 1993 & $2,00 \times 5,0$ & 1000,00 \\
\hline 12 & Vacaria & Fuji & MM-106 & 1991 & $2,50 \times 5,0$ & 800,00 \\
\hline 13 & Vacaria & Gala & EM-7 & 1988 & $1,80 \times 4,5$ & 1234,57 \\
\hline 14 & Vacaria & Fuji & EM-7 & 1988 & $2,00 \times 4,5$ & 1111,11 \\
\hline 15 & Vacaria & Gala & EM-7 & 1988 & $1,80 \times 4,5$ & 1234,57 \\
\hline 16 & Vacaria & Fuji & EM-7 & 1987 & $1,80 \times 4,5$ & 1234,57 \\
\hline 17 & Vacaria & Fuji & MM-106 & 1987 & $1,80 \times 4,5$ & 1234,57 \\
\hline 18 & Vacaria & Gala & EM-7 & 1987 & $1,80 \times 4,5$ & 1234,57 \\
\hline 19 & Vacaria & Fuji & EM-7 & 1988 & $2,00 \times 4,5$ & 1111,11 \\
\hline 20 & Vacaria & Gala & MM-106 & 1989 & $1,80 \times 4,5$ & 1234,57 \\
\hline 21 & Vacaria & Fuji & EM-7 & 1987 & $2,00 \times 4,5$ & 1111,11 \\
\hline 22 & Vacaria & Fuji & EM-7 & 1987 & $2,00 \times 4,5$ & 1111,11 \\
\hline 23 & Vacaria & Royal Gala & EM-7 & 1993 & $1,80 \times 4,5$ & 1234,57 \\
\hline 24 & Vacaria & Gala & MM-106 & 1989 & $1,80 \times 4,5$ & 1234,57 \\
\hline 25 & Vacaria & Royal Gala & EM-7 & 1993 & $2,50 \times 4,5$ & 888,89 \\
\hline 26 & Vacaria & Royal Gala & MM-111 & 1995 & $1,80 \times 4,5$ & 1234,57 \\
\hline 27 & Vacaria & Royal Gala & MM-111 & 1994 & $1,80 \times 4,5$ & 1234,57 \\
\hline 28 & Vacaria & Royal Gala & EM-9 & 1995 & $0,80 \times 3,5$ & 3571,43 \\
\hline 29 & Vacaria & Fuji & EM-9 & 1995 & $1,00 \times 4,0$ & 2500,00 \\
\hline 30 & Vacaria & Royal Gala & EM-9 & 1995 & $0,80 \times 3,5$ & 3571,43 \\
\hline 31 & Vacaria & Fuji & EM-9 & 1995 & $1,00 \times 4,0$ & 2500,00 \\
\hline 32 & Vacaria & Fuji & EM-9 & 1995 & $1,00 \times 4,0$ & 2500,00 \\
\hline 33 & Vacaria & Imperial Gala & EM-9 & 1995 & $0,80 \times 3,5$ & 3571,43 \\
\hline 34 & Vacaria & Imperial Gala & EM-7 & 1995 & $1,50 \times 4,5$ & 1481,48 \\
\hline 35 & Vacaria & Fuji & EM-7 & 1995 & $2,00 \times 4,5$ & 1111,11 \\
\hline
\end{tabular}


Tabela 1. Descrição locais, dos cultivares, porta-enxertos, ano de plantio, espaçamento entre plantas e número de plantas por hectare das amostras coletadas em 70 pomares de macieira no Rio Grande do Sul e Santa Catarina

\begin{tabular}{|c|c|c|c|c|c|c|}
\hline Amostra & Local & Cultivar & Porta-enxerto & $\begin{array}{l}\text { Ano de } \\
\text { Plantio } \\
\end{array}$ & $\begin{array}{c}\begin{array}{c}\text { Espaçamento } \\
\text { (m) }\end{array} \\
\end{array}$ & Plantas/ha \\
\hline 36 & Vacaria & Imperial Gala & EM-7 & 1995 & $1,25 \times 4,5$ & 1777,78 \\
\hline 37 & Vacaria & Fuji & EM-7 & 1995 & $2,00 \times 4,5$ & 1111,11 \\
\hline 38 & Vacaria & Imperial Gala & EM-7 & 1995 & $1,50 \times 4,5$ & 1481,48 \\
\hline 39 & Vacaria & Fuji & EM-7 & 1995 & $2,00 \times 4,5$ & 1111,11 \\
\hline 40 & Vacaria & Royal Gala & MM-106 & 1991 & $2,00 \times 4,5$ & 1111,11 \\
\hline 41 & Vacaria & Fuji & MM-106 & 1991 & $2,00 \times 4,5$ & 1111,11 \\
\hline 42 & Vacaria & Royal Gala & EM-7 & 1995 & $1,00 \times 4,0$ & 2500,00 \\
\hline 43 & Vacaria & Fuji & EM-7 & 1995 & $1,00 \times 4,0$ & 2500,00 \\
\hline 44 & Vacaria & Royal Gala & EM-9 & 1995 & $0,40 \times 3,5$ & 7142,86 \\
\hline 45 & Vacaria & Fuji & EM-9 & 1995 & $0,70 \times 4,0$ & 3571,43 \\
\hline 46 & Vacaria & Royal Gala & M-26 & 1995 & $0,50 \times 3,5$ & 5714,29 \\
\hline 47 & Vacaria & Royal Gala & MM-106 & 1995 & $0,50 \times 3,5$ & 5714,29 \\
\hline 48 & Vacaria & Royal Gala & EM-9 & 1995 & $0,50 \times 3,5$ & 5714,29 \\
\hline 49 & Vacaria & Fuji & EM-9 & 1995 & $0,70 \times 4,0$ & 3571,43 \\
\hline 50 & Vacaria & Royal Gala & EM-9 & 1995 & $1,00 \times 3,5$ & 2857,14 \\
\hline 51 & Vacaria & Royal Gala & EM-9 & 1995 & $0,50 \times 3,5$ & 5714,29 \\
\hline 52 & Vacaria & Fuji & EM-9 & 1995 & $0,70 \times 4,0$ & 3571,43 \\
\hline 53 & Fraiburgo & Fuji & EM-7 & 1991 & $2,50 \times 5,0$ & 800,00 \\
\hline 54 & Fraiburgo & Gala & EM-7 & 1991 & $1,60 \times 4,5$ & 1388,89 \\
\hline 55 & Fraiburgo & Fuji & EM-7 & 1991 & $2,50 \times 5,0$ & 800,00 \\
\hline 56 & Fraiburgo & Gala & EM-7 & 1991 & $1,60 \times 4,5$ & 1388,89 \\
\hline 57 & Fraiburgo & Gala & EM-7 & 1991 & $1,60 \times 4,5$ & 1388,89 \\
\hline 58 & Fraiburgo & Gala & EM-7 & 1991 & $1,60 \times 4,5$ & 1388,89 \\
\hline 59 & Fraiburgo & Fuji & MM-106 & 1991 & $2,50 \times 5,0$ & 800,00 \\
\hline 60 & Fraiburgo & Gala & MM-106 & 1989 & $2,50 \times, 50$ & 800,00 \\
\hline 61 & Fraiburgo & Fuji & MM-106 & 1989 & $2,50 \times 5,0$ & 800,00 \\
\hline 62 & Fraiburgo & Royal Gala & EM-7 & 1990 & $1,50 \times 4,5$ & 1481,48 \\
\hline 63 & Fraiburgo & Royal Gala & EM-7 & 1996 & $1,50 \times 4,5$ & 1481,48 \\
\hline 64 & Fraiburgo & Royal Gala & EM-7 & 1995 & $1,00 \times 3,8$ & 2631,58 \\
\hline 65 & Fraiburgo & Fuji & EM-7 & 1985 & $2,00 \times 4,5$ & 1111,11 \\
\hline 66 & Fraiburgo & Fuji & EM-7 & 1985 & $2,00 \times 4,5$ & 1111,11 \\
\hline 67 & Fraiburgo & Royal Gala & EM-7 & 1993 & $1,50 \times 4,5$ & 1481,48 \\
\hline 68 & Fraiburgo & Royal Gala & EM-7 & 1990 & $1,50 \times 4,5$ & 1481,48 \\
\hline 69 & Fraiburgo & Fuji & EM-7 & 1985 & $2,00 \times 4,5$ & 1111,11 \\
\hline 70 & Fraiburgo & Fuji & EM-7 & 1985 & $2,00 \times 4,5$ & 1111,11 \\
\hline
\end{tabular}




\subsubsection{Amostragem e análise de folhas e solo}

Em cada pomar foram selecionadas 20 plantas quanto à uniformidade, para a amostragem de solo (nas profundidades de $0-20 \mathrm{~cm}$ e $20-40 \mathrm{~cm}$ ) e amostragem de folhas. A coleta de amostras de folhas foi realizada no período de 15 de janeiro a 15 de fevereiro, que é considerada a época padrão do diagnóstico foliar da macieira (Magnani et al., 1997). Estas amostras foram compostas por 50 folhas completas (limbo com pecíolo) da porção média dos ramos do ano, posicionados em altura facilmente acessível, sem o uso de escada, nos quatro lados das plantas. A coleta de amostras de solos, realizada na mesma época da amostragem de folhas, foi realizada na projeção da copa das plantas de macieira, utilizando trado tipo holandês. Cada amostra foi acondicionada em saco de papel e de plástico, para folha e solo, respectivamente, e preparadas para os procedimentos analíticos.

Foram determinados os valores de $\mathrm{pH}$ e os teores de matéria orgânica, fósforo, potássio, cálcio e magnésio nas amostras de solos e as concentrações de nitrogênio, fósforo, potássio, cálcio, magnésio, boro, cobre, ferro, manganês e zinco nas amostras de folhas. Os procedimentos analíticos foram realizados no Laboratório de Solos e Nutrição de Plantas da Embrapa Uva e Vinho.

O nitrogênio nas folhas foi determinado pelo método semi-micro Kjeldahl, enquanto os extratos para a determinação das concentrações de fósforo, potássio, cálcio e magnésio nas folhas foram obtidos através da digestão nitroperclórica e a concentração determinada por espectrofotometria visível, fotometria de chama e espectrofotometria de absorção atômica, respectivamente. Os extratos para a determinação das concentrações de cobre, ferro, manganês e zinco nas folhas foram obtidos através da mistura de digestão (ácidos nítrico, sulfúrico e perclórico) e as concentrações determinadas por espectrofotometria de absorção atômica. A digestão para a determinação de boro das

folhas foi feita por via seca, e a concentração determinada por espectrofotometria visível, através da azometina H (Freire, 1998).

Para as análises de solo foi utilizada a metodologia descrita por Freire (1998). 
$\mathrm{O} \mathrm{pH}$ do solo foi determinado no extrato em água, na proporção 1:1 (10 $\mathrm{mL}$ de amostra de solo para $10 \mathrm{~mL}$ de água destilada), através de potenciômetro. $\mathrm{O}$ teor de matéria orgânica foi estimado, a partir da concentração de carbono do solo, pelo método Walkley-Black. Os extratos para a determinação dos teores de fósforo e potássio do solo foram obtidos através do método Mehlich I e os teores determinados por espectrofotometria visível e fotometria de chama, respectivamente. Os extratos para a determinação dos teores de cálcio e magnésio do solo foram obtidos através de extração com cloreto de potássio $1 \mathrm{M}$ e os teores determinados por espectrofotometria de absorção atômica.

Os resultados de concentrações de nutrientes nas folhas foram submetidos à análise estatística descritiva, utilizando o procedimento "Univariate" do pacote estatístico SAS (SAS Institute, 1985). Para os valores de $\mathrm{pH}$ e os teores de matéria orgânica, fósforo, potássio, cálcio e magnésio nas amostras de solos, utilizou-se a mesma metodologia descrita para os resultados de concentração de nutrientes nas folhas. Para avaliar o efeito de cultivar, porta-enxerto e espaçamento de plantio nas concentrações de nutrientes nas folhas, os resultados foram submetidos à análise de variância, considerando significância a 5\%. Para a comparação de médias, aplicou-se o teste de Tukey a 5\%, utilizando o procedimento "General Linear Models" (GLM) do pacote estatístico SAS (SAS Institute, 1985).

\subsubsection{Formação do banco de dados}

O banco de dados foi composto com os resultados de análise de folhas e de produtividade dos 70 pomares de macieira, das safras 2002 e 2003, organizados com discriminações para local, cultivar, porta-enxerto, ano de plantio, espaçamento e número de plantas/ha. Este banco de dados foi dividido em duas sub-populações $(A=$ alta produtividade e $\mathrm{B}=$ baixa produtividade) em função da produtividade de frutos. Considerando que a cultura da macieira apresenta alternância de produção, optou-se por definir como pomares de alta produtividade aqueles que apresentaram produção superior 
a $40 \mathrm{t} \mathrm{ha}^{-1}$ na safra normal e produção superior a $30 \mathrm{t} \mathrm{ha}^{-1}$ na safra com alternância.

\subsubsection{Métodos de cálculo do DRIS}

\subsubsection{Escolha da ordem da razão dos nutrientes}

Foi obtido a média, o desvio padrão e o coeficiente de variação dos valores das relações das concentrações dos nutrientes, dois a dois, das amostras de folhas das safras 2002 e 2003 das populações de alta e baixa produtividade. Para as duas populações foram excluídos os resultados referentes às concentrações de ferro, manganês e zinco, cujos valores extrapolaram a concentração considerada acima do normal para a cultura (Basso et al., 1986).

Para a escolha da ordem da razão dos nutrientes foram avaliados dois critérios. O primeiro critério, proposto por Nick (1998), denominado de "valor R", consiste no cálculo dos coeficientes de correlação (r) entre os valores de produtividade e a relação entre os pares de nutrientes, tanto na ordem direta como inversa. É selecionada a ordem da relação que apresentar maior valor absoluto do coeficiente de correlação (r):

se: $\left|\mathrm{r}_{\mathrm{A} / \mathrm{B}}\right|>\left|\mathrm{r}_{\mathrm{B} / \mathrm{A}}\right| \quad$ então: relação na norma $=\mathrm{A} / \mathrm{B}$

se: $\left|\mathrm{r}_{\mathrm{A} / \mathrm{B}}\right|<\left|\mathrm{r}_{\mathrm{B} / \mathrm{A}}\right| \quad$ então: relação na norma $=\mathrm{B} / \mathrm{A}$

em que:

$\left|\mathrm{r}_{\mathrm{A} / \mathrm{B}}\right|=$ Valor absoluto do coeficiente de correlação entre a produtividade e a razão entre as concentrações dos nutrientes A e B da população;

$\left|\mathrm{r}_{\mathrm{B} / \mathrm{A}}\right|=$ Valor absoluto do coeficiente de correlação entre a produtividade e a razão entre as concentrações dos nutrientes B e A da população; 
O segundo critério, descrito por Letzsch (1985) e Walworth et al. (1986), denominado de "valor F", consiste no cálculo da razão de variância das relações entre nutrientes entre o grupo de referência ( $\mathrm{r}$ ) e de baixa produtividade (b), tanto na ordem direta como inversa. É selecionada a ordem da relação que apresentar maior razão de variância entre o grupo de alta e o de baixa produtividade:

$\begin{array}{ll}\text { se: }\left[\mathrm{s}^{2}(\mathrm{~A} / \mathrm{B})_{\mathrm{b}} / \mathrm{s}^{2}(\mathrm{~A} / \mathrm{B})_{\mathrm{r}}\right]>\left[\mathrm{s}^{2}(\mathrm{~B} / \mathrm{A})_{\mathrm{b}} / \mathrm{s}^{2}(\mathrm{~B} / \mathrm{A})_{\mathrm{r}}\right] & \text { então: relação na norma }=\mathrm{A} / \mathrm{B} \\ \text { se: }\left[\mathrm{s}^{2}(\mathrm{~A} / \mathrm{B})_{\mathrm{b}} / \mathrm{s}^{2}(\mathrm{~A} / \mathrm{B})_{\mathrm{r}}\right]<\left[\mathrm{s}^{2}(\mathrm{~B} / \mathrm{A})_{\mathrm{b}} / \mathrm{s}^{2}(\mathrm{~B} / \mathrm{A})_{\mathrm{r}}\right] & \text { então: relação na norma }=\mathrm{B} / \mathrm{A}\end{array}$

em que:

$\mathrm{s}^{2}(\mathrm{~A} / \mathrm{B})_{\mathrm{r}}=$ Variância da razão entre as concentrações dos nutrientes $\mathrm{A}$ e $\mathrm{B}$ da população de referência;

$\mathrm{s}^{2}(\mathrm{~A} / \mathrm{B})_{\mathrm{b}}=$ Variância da razão entre as concentrações dos nutrientes $\mathrm{A}$ e $\mathrm{B}$ da população de baixa produtividade;

$\mathrm{s}^{2}(\mathrm{~B} / \mathrm{A})_{\mathrm{r}}=$ Variância da razão entre as concentrações dos nutrientes B e A da população de referência;

$\mathrm{s}^{2}(\mathrm{~B} / \mathrm{A})_{b}=$ Variância da razão entre as concentrações dos nutrientes $\mathrm{B}$ e A da população de baixa produtividade.

\subsubsection{Cálculo dos índices DRIS e índice de balanço nutricional}

Os Índices DRIS para os nutrientes foram calculados pelos procedimentos propostos por Beaufils (1973), Elwali \& Gascho (1984) e Jones (1981). Desta forma, foi obtido o índice DRIS $\mathrm{I}_{\mathrm{A}}$, para o nutriente A da seguinte forma: 


$$
\mathrm{I}_{\mathrm{A}}=\quad \begin{array}{lll}
\mathrm{m} & & \mathrm{n} \\
\sum_{\mathrm{f}} \mathrm{f}\left(\mathrm{A} / \mathrm{B}_{\mathrm{i}}\right) & - & \sum_{\mathrm{f}\left(\mathrm{B}_{\mathrm{j}} / \mathrm{A}\right)} \\
\mathrm{i}=1 & & \mathrm{j}=1 \\
\mathrm{~m}+\mathrm{n} &
\end{array}
$$

Beaufils (1973):

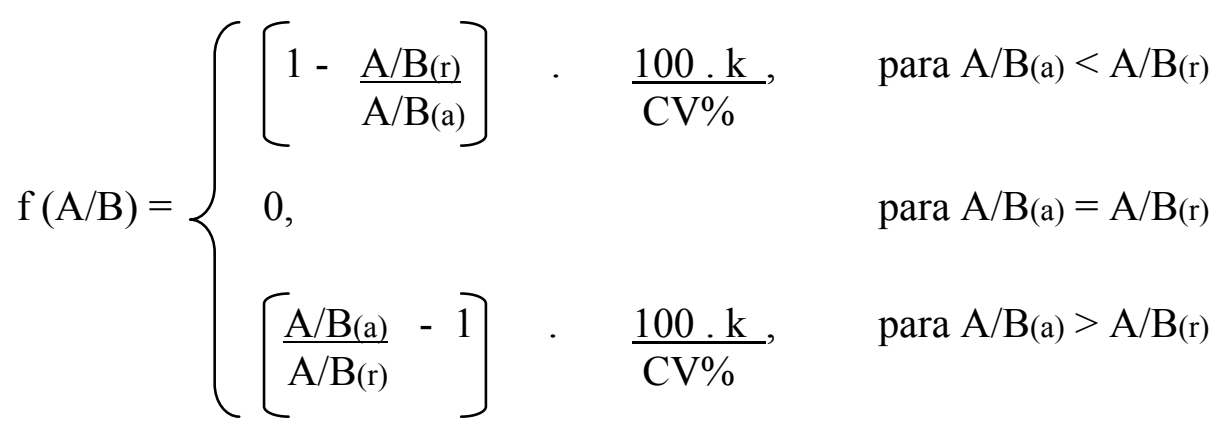

Elwali \& Gascho (1984):

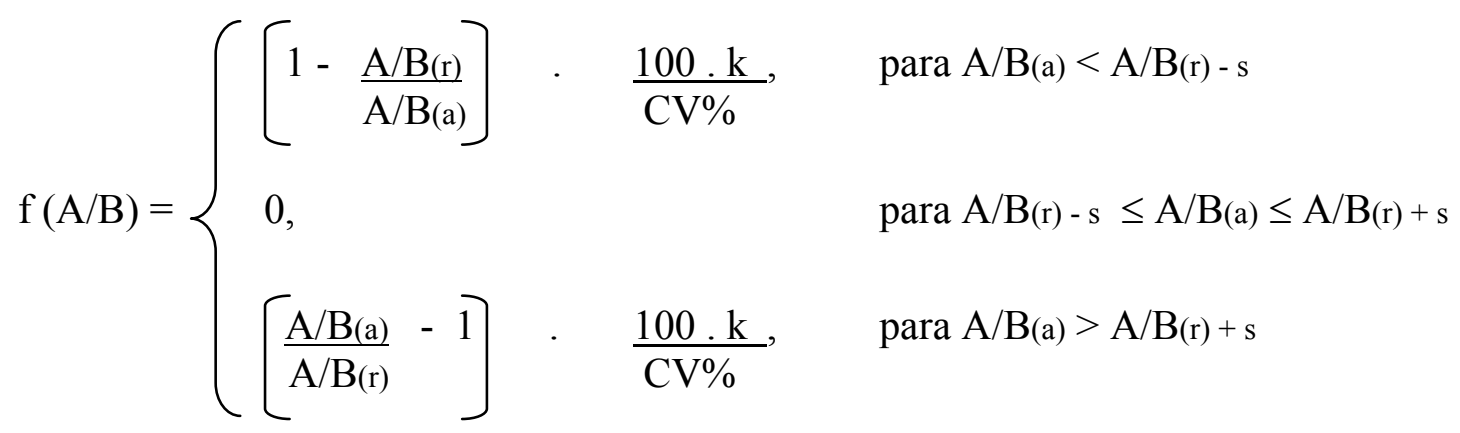


Jones (1981):

$\mathrm{f}(\mathrm{A} / \mathrm{B})=(\mathrm{A} / \mathrm{B}(\mathrm{a})-\mathrm{A} / \mathrm{B}(\mathrm{r})) \mathrm{k} / \mathrm{s}$

em que:

$\mathrm{A} / \mathrm{B}(\mathrm{a})=$ relação entre a concentração do nutriente $\mathrm{A}$ e $\mathrm{B}$ na amostra;

$\mathrm{A} / \mathrm{B}(\mathrm{r})$ = relação entre a concentração do nutriente $\mathrm{A}$ e $\mathrm{B}$ na população de referência;

$\mathrm{CV} \%=$ coeficiente de variação para a relação, $\%$;

$\mathrm{S}=$ desvio padrão da relação;

$\mathrm{k} \quad=$ constante de sensibilidade.

O Índice de Balanço Nutricional (IBN) foi calculado através da somatória dos valores absolutos dos índices gerados para a amostra, obtidos para cada nutriente de cada pomar, conforme a equação:

$$
\mathrm{IBN}=\mid \text { Índice } \mathrm{A}|+| \text { Índice } \mathrm{B}|+\ldots .+| \text { Índice } \mathrm{N} \mid
$$

Foi, também, obtido o Índice de Balanço Nutricional Médio (IBNm), calculado através da somatória dos valores absolutos dos índices gerados para cada nutriente, obtidos para cada amostra, dividido pelo número de nutrientes que participam do cálculo, conforme a equação:

$$
\mathrm{IBNm}=(\mid \text { Índice } \mathrm{A}|+| \text { Índice } \mathrm{B}|+\ldots .+| \text { Índice } \mathrm{N} \mid) / \mathrm{N}
$$

Os cálculos dos Índices DRIS, do IBN e do IBNm foram feitos utilizando a planilha do software Microsoft Excel $^{\mathrm{TM}}$. Para avaliar a eficiência dos três métodos empregados, considerando os dois critérios de para a escolha da ordem da razão dos 
nutrientes, os Índices DRIS para cada nutriente foram relacionados com as concentrações dos respectivos nutrientes e verificada a significância da correlação, bem como foram relacionados os valores de IBN com a produtividade de frutos.

\subsection{Avaliação da eficiência do método DRIS}

Para avaliar a eficiência do método DRIS no diagnóstico nutricional da cultura, utilizou-se dos resultados de dois experimentos de campo de longa duração, conduzidos na Estação Experimental de Vacaria da Embrapa Uva e Vinho.

O primeiro experimento, que trata de doses de adubo potássico em pré-plantio e em manutenção, foi instalado no ano de 1991, utilizando mudas livres de vírus do cultivar Gala sobre o porta-enxerto MM 106, no espaçamento 2,5 x 5,0 m. O experimento está localizado em solo da Unidade de Mapeamento Vacaria, classificado como Latossolo Bruno alumínico câmbico (Streck et al., 2002). O teor inicial de potássio trocável no solo era de $1,15 \mathrm{mmol}_{\mathrm{c}} \mathrm{dm}^{-3}$. O delineamento experimental utilizado foi de blocos ao acaso, com 12 tratamentos, quatro repetições e três plantas úteis por parcela experimental, constituído dos seguintes tratamentos:

1- $0 \mathrm{~kg} / \mathrm{ha}$ de $\mathrm{K}_{2} \mathrm{O}+0 \mathrm{~kg} / \mathrm{ha} /$ ano de $\mathrm{K}_{2} \mathrm{O}$

2- $0 \mathrm{~kg} / \mathrm{ha}$ de $\mathrm{K}_{2} \mathrm{O}+50 \mathrm{~kg} / \mathrm{ha} /$ ano de $\mathrm{K}_{2} \mathrm{O}$

3- $0 \mathrm{~kg} / \mathrm{ha}$ de $\mathrm{K}_{2} \mathrm{O}+100 \mathrm{~kg} / \mathrm{ha} /$ ano de $\mathrm{K}_{2} \mathrm{O}$

4- $0 \mathrm{~kg} / \mathrm{ha}$ de $\mathrm{K}_{2} \mathrm{O}+150 \mathrm{~kg} / \mathrm{ha} /$ ano de $\mathrm{K}_{2} \mathrm{O}$

5- $50 \mathrm{~kg} / \mathrm{ha}$ de $\mathrm{K}_{2} \mathrm{O}+0 \mathrm{~kg} / \mathrm{ha} /$ ano de $\mathrm{K}_{2} \mathrm{O}$

6- $50 \mathrm{~kg} / \mathrm{ha}$ de $\mathrm{K}_{2} \mathrm{O}+50 \mathrm{~kg} / \mathrm{ha} /$ ano de $\mathrm{K}_{2} \mathrm{O}$

7- $50 \mathrm{~kg} / \mathrm{ha}$ de $\mathrm{K}_{2} \mathrm{O}+100 \mathrm{~kg} / \mathrm{ha} /$ ano de $\mathrm{K}_{2} \mathrm{O}$

8- $50 \mathrm{~kg} / \mathrm{ha}$ de $\mathrm{K}_{2} \mathrm{O}+150 \mathrm{~kg} / \mathrm{ha} /$ ano de $\mathrm{K}_{2} \mathrm{O}$

9- $100 \mathrm{~kg} / \mathrm{ha}$ de $\mathrm{K}_{2} \mathrm{O}+0 \mathrm{~kg} / \mathrm{ha} /$ ano de $\mathrm{K}_{2} \mathrm{O}$

10- $100 \mathrm{~kg} / \mathrm{ha}$ de $\mathrm{K}_{2} \mathrm{O}+50 \mathrm{~kg} / \mathrm{ha} /$ ano de $\mathrm{K}_{2} \mathrm{O}$

$11-100 \mathrm{~kg} / \mathrm{ha}$ de $\mathrm{K}_{2} \mathrm{O}+100 \mathrm{~kg} / \mathrm{ha} /$ ano de $\mathrm{K}_{2} \mathrm{O}$

12- $100 \mathrm{~kg} / \mathrm{ha}$ de $\mathrm{K}_{2} \mathrm{O}+150 \mathrm{~kg} / \mathrm{ha} /$ ano de $\mathrm{K}_{2} \mathrm{O}$ 
As quantidades de potássio foram aplicadas na queda das pétalas (estádio $\mathrm{H}$ ). Para os três primeiros anos as doses foram diferenciadas: $25 \%$ da dose estabelecida de $\mathrm{K}$ para o $1^{\circ}$ ano; $50 \%$ da dose de $\mathrm{K}$ para o $2^{\circ}$ ano e; $75 \%$ da dose de $\mathrm{K}$ para o $3^{\circ}$ ano. Os demais nutrientes foram aplicados conforme a necessidade estabelecida pela análise foliar e a recomendação de adubação para a macieira. Os tratos culturais e fitossanitários para a formação e manutenção do pomar foram os normais utilizados para a cultura da macieira.

No período de 1995 a 2000, foram coletados resultados de produção de frutos, bem como determinadas as concentrações de nitrogênio, fósforo, potássio, cálcio, magnésio, boro, cobre, ferro, manganês e zinco nas amostras de folhas, conforme metodologia descrita por Freire (1998).

$\mathrm{O}$ segundo experimento, que trata de fontes e doses de adubo nitrogenado em manutenção, foi instalado no ano de 1991, utilizando mudas livres de vírus do cultivar Fuji sobre o porta-enxerto MM 106, no espaçamento 2,5 x 5,0 m. O experimento está localizado em solo da Unidade de Mapeamento Vacaria, classificado como Latossolo Bruno alumínico câmbico (Streck et al., 2002). O teor inicial de matéria orgânica no solo era de $51 \mathrm{~g} \mathrm{dm}^{-3}$. O delineamento experimental utilizado foi de blocos ao acaso, com nove tratamentos, quatro repetições e duas plantas úteis por parcela experimental, constituído dos seguintes tratamentos:

1- Testemunha (sem aplicação de nitrogênio)

2- $50 \mathrm{~g} / \mathrm{planta} /$ ano de $\mathrm{N}$ na forma de uréia

3- $100 \mathrm{~g} /$ planta/ano de $\mathrm{N}$ na forma de uréia

4- $50 \mathrm{~g} / \mathrm{planta} / \mathrm{ano}$ de $\mathrm{N}$ na forma de sulfato de amônio

5- $100 \mathrm{~g} / \mathrm{planta} /$ ano de $\mathrm{N}$ na forma de sulfato de amônio

6- $50 \mathrm{~g} / \mathrm{planta} / \mathrm{ano}$ de $\mathrm{N}$ na forma de nitrato de potássio

7- $100 \mathrm{~g} / \mathrm{planta} /$ ano de $\mathrm{N}$ na forma de nitrato de potássio

8- $50 \mathrm{~g} / \mathrm{planta} / \mathrm{ano}$ de $\mathrm{N}$ na forma de nitrato de cálcio

9- $100 \mathrm{~g} / \mathrm{planta} / \mathrm{ano}$ de $\mathrm{N}$ na forma de nitrato de cálcio 
As quantidades de nitrogênio foram aplicadas em duas épocas: a) metade da dose na queda das pétalas (estádio $\mathrm{H}$ ) e; b) o restante após a colheita. Para os três primeiros anos as doses foram diferenciadas: $20 \mathrm{~g} /$ planta/ano de $\mathrm{N}$ e $40 \mathrm{~g} / \mathrm{planta} /$ ano de $\mathrm{N}$ no $1^{\circ}$ ano; $25 \mathrm{~g} /$ planta/ano de $\mathrm{N}$ e $50 \mathrm{~g} /$ planta/ano de $\mathrm{N}$ no $2^{\circ}$ ano e; $30 \mathrm{~g} /$ planta/ano de $\mathrm{N}$ e $60 \mathrm{~g} /$ planta/ano de $\mathrm{N}$ no $3^{\circ}$ ano. Os demais nutrientes foram aplicados conforme a necessidade estabelecida pela análise foliar e a recomendação de adubação para a macieira. Os tratos culturais e fitossanitários para a formação e manutenção do pomar foram os normais utilizados para a cultura da macieira.

No período de 1996 a 1999, foram coletados resultados de produção de frutos, bem como determinadas as concentrações de nitrogênio, fósforo, potássio, cálcio, magnésio, boro, cobre, ferro, manganês e zinco nas amostras de folhas, conforme metodologia descrita por Freire (1998).

Foram determinados, para os dois experimentos e para cada ano, os Índices DRIS para cada nutriente e o IBN, considerando os resultados médios de cada tratamento, utilizando as combinações de critérios de escolha das razões entre nutrientes (valor R e F) e os métodos Beaufils (1973), Elwali \& Gascho (1984) e Jones (1981).

Os cálculos dos Índices DRIS, do IBN e do IBNm foram feitos utilizando a planilha do software Microsoft Excel ${ }^{\mathrm{TM}}$. Para avaliar a eficiência dos três métodos empregados, os Índices DRIS para $\mathrm{K}$ e para $\mathrm{N}$ e o IBN, foram relacionadas com a produtividade de frutos e verificadas as significâncias da correlação. A significância da correlação entre o Índice DRIS para K e para N e a concentração de K e de N nas folhas também foi avaliada.

A diagnose ou avaliação da concentração foliar de nutrientes para a cultura da macieira foi realizada utilizando o critério de faixas de concentração de nutrientes (Tabela 2), adotado no Rio Grande do Sul e Santa Catarina, e pelo DRIS, através dos três métodos DRIS empregados. A consistência da diagnose foi testada através da comparação entre os diferentes critérios de diagnóstico. Para o critério de faixas de concentração de nutrientes, foram utilizadas apenas três faixas (deficiência, normal e excesso). Para a diagnose nutricional utilizando o método DRIS, foi utilizada a 
metodologia proposta por Wadt (1996), onde foram utilizadas, também, três faixas, estabelecidas a partir do Índice DRIS do nutriente ( $\mathrm{I}_{\text {Nut. }}$ ) e do Índice de Balanço Nutricional Médio (IBNm), assumindo:

$$
\begin{array}{llll}
\text { Deficiente } & =\mathrm{I}_{\text {Nut. }}<0 \quad \text { e } & \left|\mathrm{I}_{\text {Nut. }}\right|>\operatorname{IBNm} \\
\text { Normal } & =\left|\mathrm{I}_{\text {Nut. }}\right| \leq \mathrm{IBNm} & & \\
\text { Em excesso } & =\mathrm{I}_{\text {Nut. }}>0 \quad \text { e } & \left|\mathrm{I}_{\text {Nut. }}\right|>\mathrm{IBNm}
\end{array}
$$

\begin{tabular}{|c|c|c|c|c|c|}
\hline NUTRIENTE & INSUFICIENTE & $\begin{array}{c}\text { ABAIXO DO } \\
\text { NORMAL }\end{array}$ & NORMAL & $\begin{array}{c}\text { ACIMA DO } \\
\text { NORMAL }\end{array}$ & EXCESSO \\
\hline $\mathrm{N} \quad\left(\mathrm{g} \mathrm{kg}^{-1}\right)$ & $<17,0$ & 17,0 a 19,9 & 20,0 a 25,0 & 25,1 a 30,0 & $>30,0$ \\
\hline $\mathrm{P} \quad\left(\mathrm{g} \cdot \mathrm{kg}^{-1}\right)$ & $<1,0$ & 1,0 a 1,4 & 1,5 a 3,0 & $>3,0$ & -- \\
\hline $\mathrm{K} \quad\left(\mathrm{g} \mathrm{kg}^{-1}\right)$ & $<8,0$ & 8,0 a 11,9 & 12,0 a 15,0 & 15,1 a 20,0 & $>20,0$ \\
\hline $\mathrm{Ca} \quad\left(\mathrm{g} \mathrm{kg}^{-1}\right)$ & $<8,0$ & 8,0 a 10,9 & 11,0 a 17,0 & $>17,0$ & -- \\
\hline $\operatorname{Mg} \quad\left(\mathrm{g} \mathrm{kg}^{-1}\right)$ & $<2,0$ & 2,0 a 2,4 & 2,5 a 4,5 & $>4,5$ & -- \\
\hline $\mathrm{Fe} \quad\left(\mathrm{mg} \mathrm{kg}^{-1}\right)$ & -- & $<50$ & 50 a 250 & $>250$ & -- \\
\hline $\operatorname{Mn}\left(\mathrm{mg} \mathrm{kg}^{-1}\right)$ & $<20$ & 20 a 29 & 30 a 130 & 131 a 200 & $>200$ \\
\hline $\mathrm{Zn}\left(\mathrm{mg} \mathrm{kg}^{-1}\right)$ & $<15$ & 15 a 19 & 20 a 100 & $>100$ & -- \\
\hline $\mathrm{Cu}\left(\mathrm{mg} \mathrm{kg}^{-1}\right)$ & $<3$ & 3 a 4 & 5 a 30 & 31 a 50 & $>50$ \\
\hline B $\quad\left(\mathrm{mg} \mathrm{kg}^{-1}\right)$ & $<20$ & 20 a 29 & 30 a 50 & 51 a 140 & $>140$ \\
\hline
\end{tabular}

Tabela 2. Faixas de concentração de nutrientes para a cultura da macieira no Rio Grande do Sul e Santa Catarina

Fonte: Basso et al. (1986) modificado. 


\subsection{Avaliação da época de amostragem de folhas de macieira para o método DRIS}

Para avaliar a melhor época de amostragem de folhas para o método DRIS, utilizou-se resultados analíticos coletados previamente ao início do curso de pósgraduação, já que para se obter maior exatidão seriam necessários resultados de mais de uma safra agrícola. O trabalho foi realizado nas safras agrícolas de 1998/99, 1999/00 e 2000/01, na Estação Experimental de Vacaria da Embrapa Uva e Vinho, utilizando os cultivares de macieira Gala, Golden Delicious e Fuji, enxertadas sobre EM VII, plantados em 1982 em Latossolo Bruno alumínico câmbico. Os tratos culturais e fitossanitários para a formação e manutenção dos pomares foram os normais utilizados para a cultura da macieira.

Para acompanhar a concentração sazonal de nutrientes nas folhas de macieira, foram coletadas semanalmente amostras, cujas coletas iniciaram a partir da primeira ou segunda semana após a plena floração, conforme o cultivar, e prolongaram-se até quatro semanas após a colheita. O início da coleta na safra 1998/99 foi em 29/10/98 e prolongou-se por 21, 24 e 29 semanas, para os cultivares Gala, Golden Delicious e Fuji, respectivamente. Na safra 1999/00 a coleta teve início em 11/10/99 e prolongou-se por 22, 24 e 30 semanas para os cultivares Gala, Golden Delicious e Fuji, respectivamente. Na última safra avaliada, a coleta iniciou em 19/10/00 e prolongou-se por 21, 25 e 25 semanas para os cultivares Gala, Golden Delicious e Fuji, respectivamente.

A amostragem das folhas foi feita no terço médio dos ramos do ano e nos quatro quadrantes das plantas, onde foram coletadas 30 folhas, oriundas de 10 plantas, por amostra. As folhas foram secas em estufa a $60^{\circ} \mathrm{C}$ até peso constante. Foram determinadas as concentrações de nitrogênio, fósforo, potássio, cálcio, magnésio, boro, cobre, ferro, manganês e zinco nas amostras de folhas, conforme metodologia descrita por Freire (1998). Os procedimentos analíticos foram realizados no Laboratório de Solos e Nutrição de Plantas da Embrapa Uva e Vinho.

Foram determinados, para os três cultivares e para cada época de coleta, os Índices DRIS para cada nutriente e o IBN, considerando os resultados médios das três safras, utilizando o método DRIS selecionado pela validação do método DRIS. 


\section{RESULTADOS E DISCUSSÃO}

\subsection{Descrição da população avaliada}

As distribuições de freqüência das concentrações de macro e micronutrientes em folhas de macieira de 70 pomares do Rio Grande do Sul e Santa Catarina, considerando os dados das safras 2002 e 2003, são apresentadas nas Figuras 1 e 2 e os resultados da análise estatística descritiva na Tabela 3. Mesmo considerando que os pomares selecionados são representativos de áreas de alta produtividade e qualidade, apresentando bom nível tecnológico de manejo do pomar, observou-se alta variabilidade nas concentrações de $\mathrm{Fe}, \mathrm{Mn}$ e $\mathrm{Zn}$ (valores de variância da amostra e coeficiente de variação), isto pode ser atribuído à contaminação da amostra por produtos fitossanitários, utilizados para o controle de doenças e pragas, ou adubação foliar com micronutrientes. Para os demais nutrientes estudados, a variabilidade observada pode ser considerada adequada, apresentando valores de desvio padrão, variância da amostra, coeficiente de variação e de coeficientes de curtose e assimetria adequados para o tipo de estudo proposto.

Observou-se que a concentração de $\mathrm{N}$ nas folhas de macieira, considerando as safras 2002 e 2003, variou de 18,5 a 26,9 $\mathrm{g} \mathrm{kg}^{-1}$, a de P entre 1,00 e 2,60 $\mathrm{g} \mathrm{kg}^{-1}$, a de K entre 8,0 e 27,2 $\mathrm{g} \mathrm{kg}^{-1}$, a de Ca entre 7,8 e 17,0 $\mathrm{g} \mathrm{kg}^{-1}$, a de $\mathrm{Mg}$ entre 1,4 e 5,2 $\mathrm{g} \mathrm{kg}^{-1}$, a de Fe entre 36 e $822 \mathrm{mg} \mathrm{kg}^{-1}$, a de Mn entre 26 e $606 \mathrm{mg} \mathrm{kg}^{-1}$, a de Zn entre 5 e $658 \mathrm{mg}$ $\mathrm{kg}^{-1}$, a de $\mathrm{Cu}$ entre 4 e $20 \mathrm{mg} \mathrm{kg}^{-1}$ e a de B entre 25 e $54 \mathrm{mg} \mathrm{kg}^{-1}$.

Confrontando os resultados obtidos com o critério de faixa de suficiência (Basso et al., 1986), com exceção das concentrações de K, Mn e Zn, as concentrações dos demais nutrientes situaram-se dentro da faixa considerada normal, com pequeno 
número de amostras situadas nas faixas abaixo do normal e acima do normal. Considerando as concentrações de nutrientes médias das duas safras, pode-se observar que as concentrações estão dentro da faixa considerada normal para a cultura, segundo o critério de faixas de suficiência, com exceção das concentrações de $\mathrm{K}$ e Zn, cujos valores situaram-se na faixa considerada acima do normal.

As distribuições de freqüência das produções de frutos de macieira de 70 pomares do Rio Grande do Sul e Santa Catarina, considerando os dados das safras 2002 e 2003, são apresentadas na Figuras 3 e os resultados da análise estatística descritiva na Tabela 4. Pode-se observar que a produtividade na safra 2003 foi inferior a da safra 2002. Este fato pode ser considerado normal para a cultura, já que a macieira apresenta alternância de produção, além do fato de que na safra 2003 houve incidência de chuvas no período de polinização das flores.

A produtividade de frutos variou de 11,4 a 104,0 $\mathrm{t} \mathrm{ha}^{-1}$, na safra 2002, e de 12,0 a 75,0 $\mathrm{t} \mathrm{ha}^{-1}$, na safra 2003. Considerando que a produtividade média da cultura da macieira, nas últimas três safras, no Rio Grande do Sul, Santa Catarina e do Paraná foi de 26,9 $\mathrm{t} \mathrm{ha}^{-1}$ (ABPM, 2004), pode-se observar que a média de produção dos pomares utilizados neste trabalho $\left(47,3 \mathrm{t} \mathrm{ha}^{-1}\right)$ foi bem superior a média da região, o que indica que a amostragem proposta para a definição das normas DRIS foi adequada, já que inclui pomares de alta produtividade. 

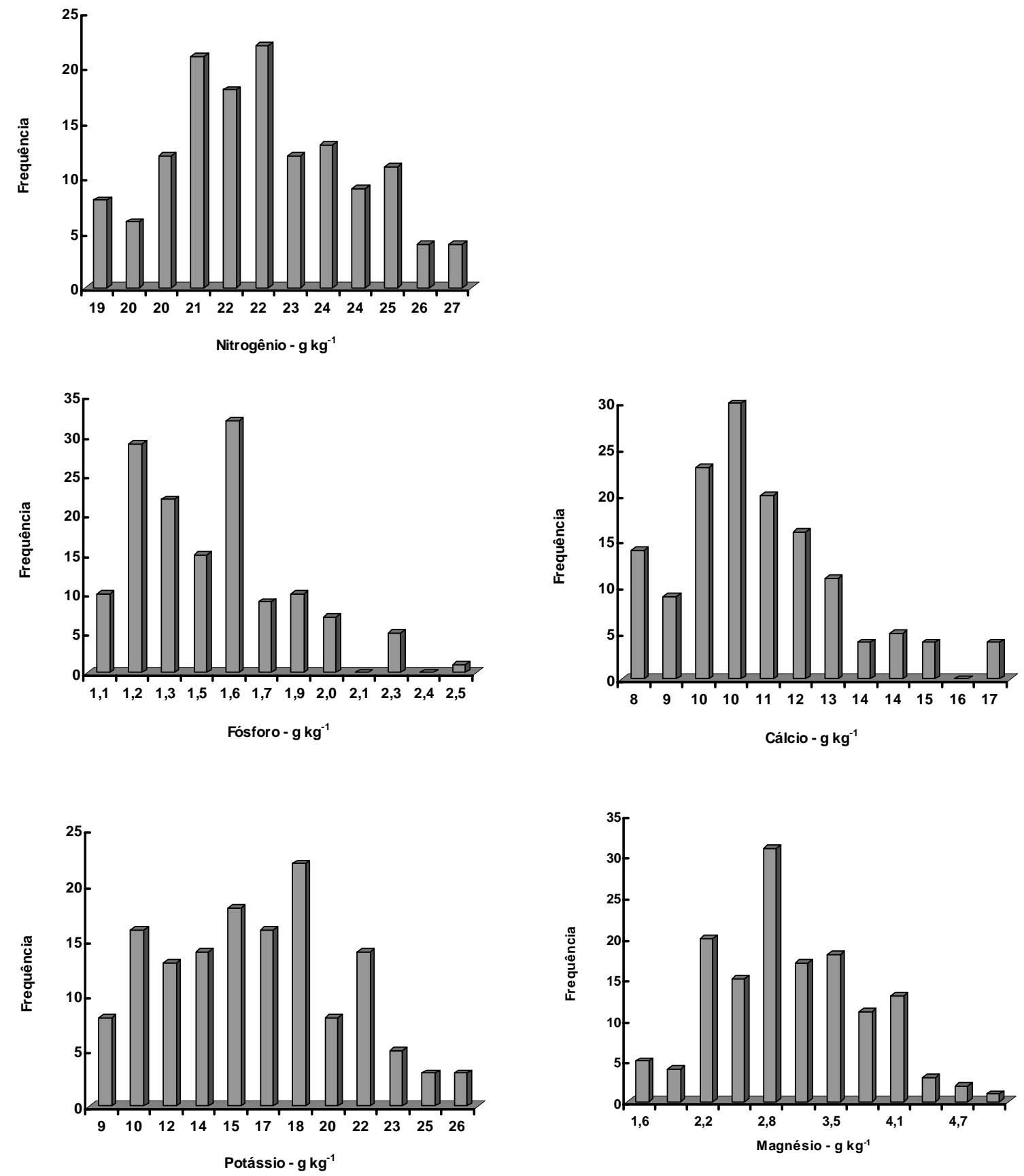

Figura 1 - Distribuição de freqüência das concentrações de nitrogênio, fósforo, potássio, cálcio e magnésio em folhas de macieira de 70 pomares do Rio Grande do Sul e Santa Catarina (Safras 2002 e 2003) 

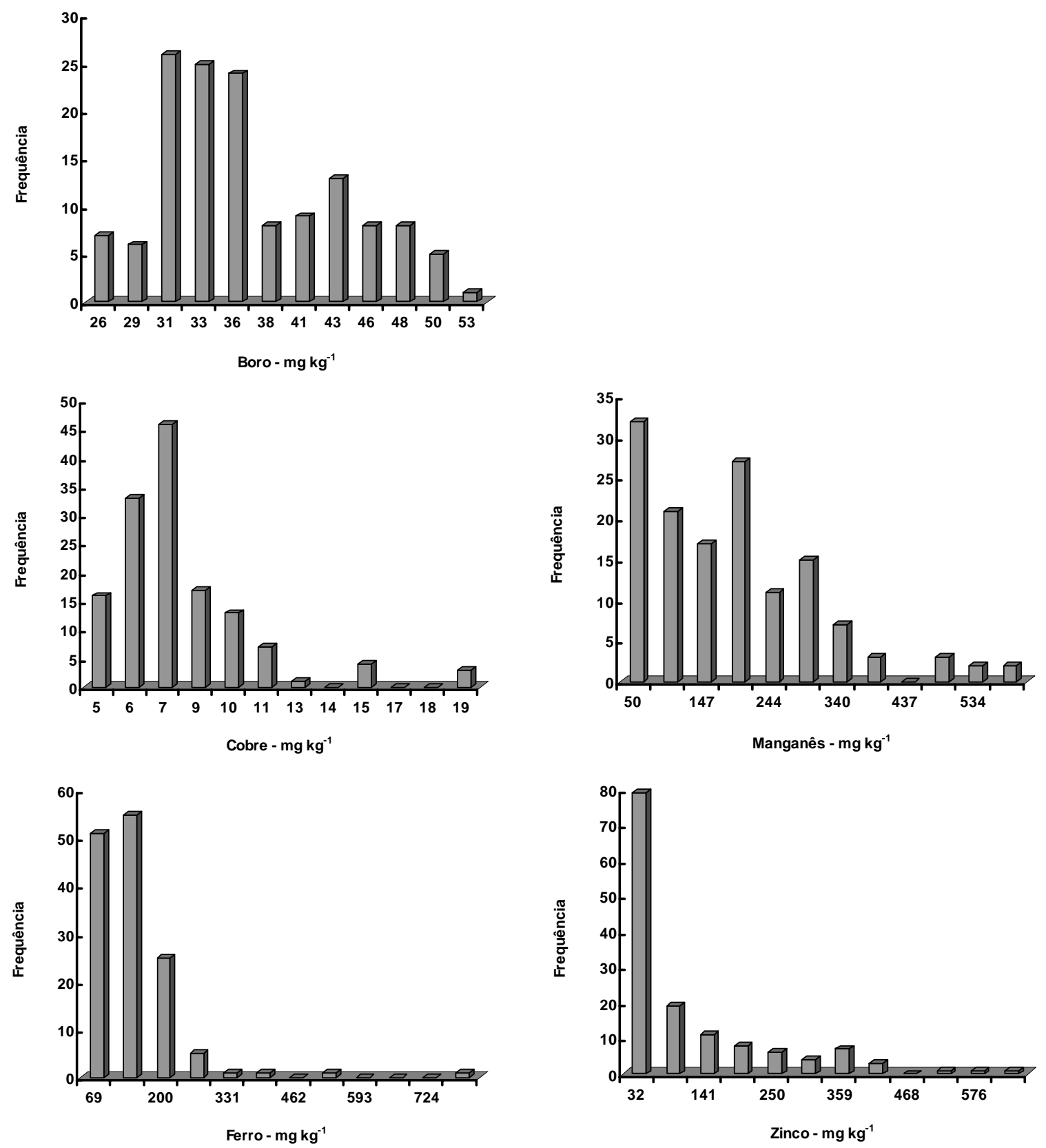

Figura 2 - Distribuição de freqüência das concentrações de boro, cobre, ferro, manganês e zinco em folhas de macieira de 70 pomares do Rio Grande do Sul e Santa Catarina (Safras 2002 e 2003) 
Tabela 3. Estatística descritiva das concentrações de nitrogênio, fósforo, potássio, cálcio, magnésio, boro, cobre, ferro, manganês e zinco em folhas de macieira de 70 pomares do Rio Grande do Sul e Santa Catarina (Safras 2002 e 2003)

\begin{tabular}{|c|c|c|c|c|c|c|c|c|}
\hline Nutriente & Média & Mediana & Moda & $\begin{array}{c}\text { Desvio } \\
\text { padrão }\end{array}$ & $\begin{array}{c}\text { Variância } \\
\text { da amostra }\end{array}$ & $\begin{array}{l}\text { CV } \\
(\%)\end{array}$ & Curtose & Assimetria \\
\hline$\left(\mathrm{g} \mathrm{kg}^{-1}\right)$ & 22,33 & 22,10 & 22,10 & 1,96 & 3,83 & 8,76 & $-0,49$ & 0,25 \\
\hline$\left(\mathrm{g} \mathrm{kg}^{-1}\right)$ & 1,55 & 1,50 & 1,40 & 0,33 & 0,11 & 21,20 & 1,10 & 0,94 \\
\hline$\left(\mathrm{g} \mathrm{kg}^{-1}\right)$ & 16,19 & 16,15 & 18,40 & 4,40 & 19,35 & 27,17 & $-0,58$ & 0,23 \\
\hline Ca $\quad\left(\mathrm{g} \mathrm{kg}^{-1}\right)$ & 11,06 & 10,80 & 11,20 & 1,94 & 3,75 & 17,50 & 0,76 & 0,84 \\
\hline $\operatorname{Mg}\left(g_{k g}^{-1}\right)$ & 3,08 & 3,00 & 3,00 & 0,71 & 0,51 & 23,17 & 0,06 & 0,17 \\
\hline B $\quad\left(\mathrm{mg} \mathrm{kg}^{-1}\right)$ & 36,77 & 35,00 & 33,00 & 6,43 & 41,29 & 17,47 & $-0,52$ & 0,55 \\
\hline Cu (mg kg $\left.{ }^{-1}\right)$ & 8,00 & 8,00 & 6,00 & 2,80 & 7,83 & 34,97 & 4,98 & 1,86 \\
\hline Fe $\left(\mathrm{mg} \mathrm{kg}^{-1}\right)$ & 137,21 & 118,50 & 64,00 & 90,78 & 8241,38 & 66,16 & 25,24 & 4,02 \\
\hline $\operatorname{Mn}\left(\mathrm{mg} \mathrm{kg}^{-1}\right)$ & 181,44 & 170,50 & 188,00 & 124,05 & 15388,23 & 68,37 & 1,53 & 1,17 \\
\hline $\left.\mathrm{Zn} \quad(\mathrm{mg} \mathrm{kg})^{-1}\right)$ & 106,19 & 46,00 & 20,00 & 128,87 & 16606,48 & 121,36 & 3,45 & 1,88 \\
\hline
\end{tabular}



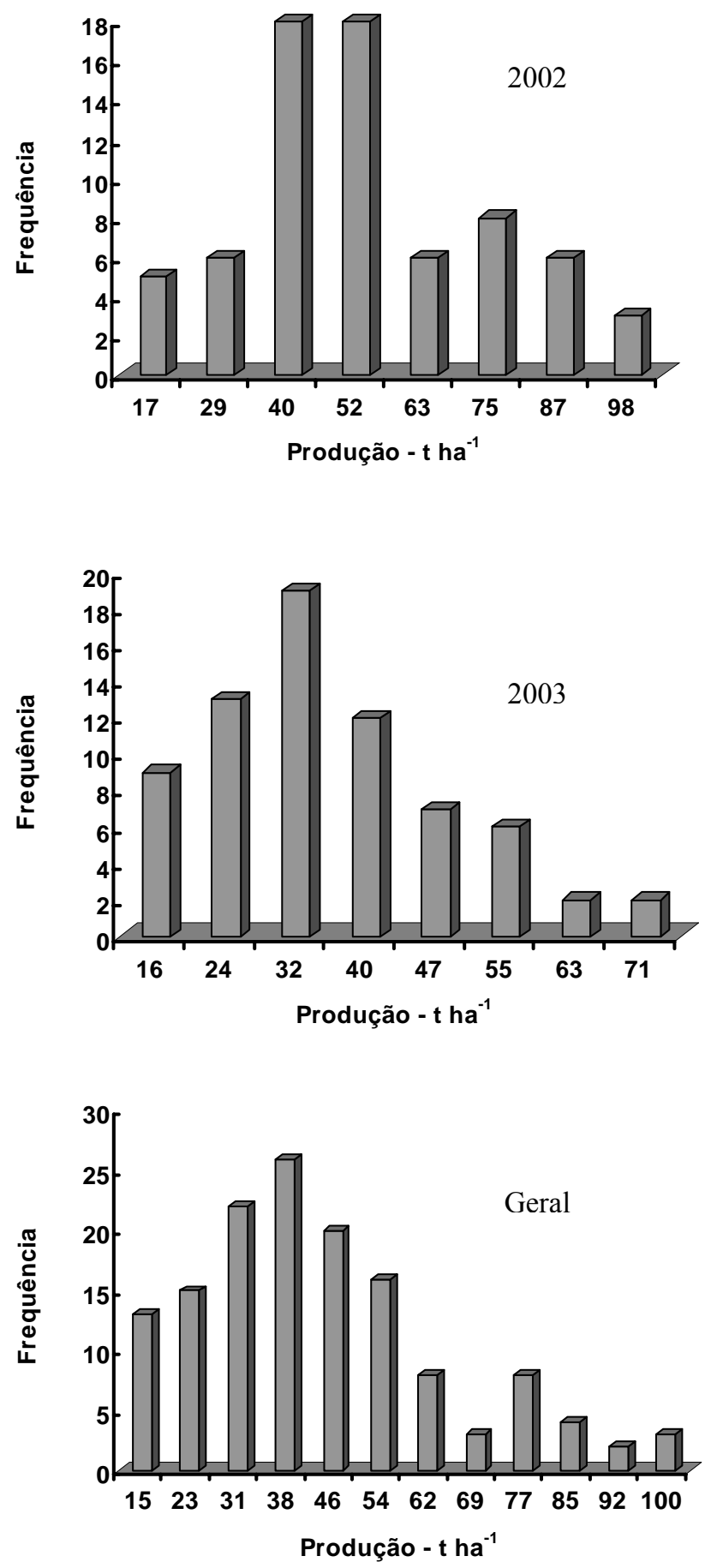

Figura 3 - Distribuição de freqüência da produção de frutos de macieira $\left(\mathrm{t} \mathrm{ha}^{-1}\right)$ nas safras 2002, 2003 e Geral de 70 pomares do Rio Grande do Sul e Santa Catarina 
Tabela 4. Estatística descritiva da produção de frutos de macieira $\left(t \mathrm{tha}^{-1}\right)$ nas safras 2002, 2003 e Geral de 70 pomares do Rio Grande do Sul e Santa Catarina

\begin{tabular}{|c|c|c|c|c|c|c|c|c|}
\hline Nutriente & Média & Mediana & Moda & $\begin{array}{c}\text { Desvio } \\
\text { padrão }\end{array}$ & $\begin{array}{c}\text { Variância } \\
\text { da amostra }\end{array}$ & $\begin{array}{l}\text { CV } \\
(\%)\end{array}$ & Curtose & Assimetria \\
\hline $\left.2002\left(t^{-1}\right)^{-1}\right)$ & 53,02 & 48,00 & 54,00 & 21,45 & 460,29 & 40,47 & $-0,36$ & 0,38 \\
\hline $2003\left(\right.$ t ha $\left.^{-1}\right)$ & 36,15 & 35,00 & 21,10 & 13,74 & 188,90 & 38,02 & 0,04 & 0,60 \\
\hline Geral $\left(t_{\text {ha }}{ }^{-1}\right)$ & 47,30 & 43,20 & 21,10 & 21,76 & 473,64 & 46,02 & $-0,51$ & 0,56 \\
\hline
\end{tabular}

O grupo de pomares avaliados permitiu a definição de três principais cultivares (Gala, Royal Gala e Fuji), três principais porta-enxertos (EM 7, EM 9 e MM 106) e três densidades de plantio (baixa densidade - abaixo de 1200 plantas/ha, média densidade entre 1200 e 1500 plantas/ha e alta densidade - acima de 1500 plantas/ha).

Para avaliar a possível ocorrência do efeito de cultivar, de porta-enxerto, de espaçamento de plantio e de safra nas concentrações de nutrientes nas folhas de macieira, foram primeiramente observados os parâmetros estatísticos (média, desvio padrão e coeficiente de variação) destas variáveis (Apêndices 1 e 2). Então, foram realizadas as comparações das médias das concentrações dos nutrientes através do teste de Tukey a 5\%. Os resultados da análise estatística são apresentados nas Tabelas 5 a 8 .

O efeito de cultivar na concentração de nutrientes nas folhas de macieira foi pouco expressivo, tanto nas duas safras como para a análise conjunta de safras (Tabela 5). Observou-se que, na safra 2002 houve diferença significativa entre cultivares para $\mathrm{N}$, Mn, Zn e B, na safra 2003 houve efeito de cultivar para as concentrações de K, Fe, Mn e $\mathrm{B}$, enquanto que na análise conjunta das safras somente as concentrações de $\mathrm{Mg}$ foram afetadas pelos cultivares. Deve-se considerar que as concentrações de Fe, Mn e Zn apresentaram alto coeficiente de variação devido à contaminação das amostras pela aplicação de produtos fitossanitários ou aplicação foliar de micronutrientes. Estes resultados indicam que o uso dos dados médios das duas safras para a aplicação do método DRIS não esta sujeito ao efeito de cultivar. 
Tabela 5. Concentração média de nitrogênio, fósforo, potássio, cálcio, magnésio, ferro, manganês, zinco, cobre e boro em folhas de macieira em função do tipo de cultivar, nas safras 2002, 2003 e geral

\begin{tabular}{|c|c|c|c|c|c|c|c|c|c|c|}
\hline \multirow{2}{*}{ Cultivar } & \multicolumn{10}{|c|}{ Concentração de nutrientes nas folhas } \\
\hline & $\mathbf{N}$ & $\mathbf{P}$ & $\mathbf{K}$ & Ca & Mg & Fe & Mn & Zn & Cu & B \\
\hline & ------- & -------- & $-\mathrm{g} \mathrm{kg}^{-1}$ & & -- & --------- & ---------- & 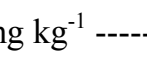 & & \\
\hline & \multicolumn{10}{|c|}{ Safra 2002} \\
\hline Fuji & $23,60 \mathrm{a}^{*}$ & $1,82 \mathrm{a}$ & $13,57 \mathrm{a}$ & $12,20 \mathrm{a}$ & $3,11 \mathrm{a}$ & 205,21 a & $147,06 \mathrm{~b}$ & $54,71 \quad b$ & $9,00 \mathrm{a}$ & 33,18 a \\
\hline Gala & $22,62 \mathrm{ab}$ & $1,68 \mathrm{a}$ & $15,44 \mathrm{a}$ & $12,00 \mathrm{a}$ & $2,77 \mathrm{a}$ & $149,27 \mathrm{a}$ & $100,00 \mathrm{~b}$ & $220,09 \mathrm{a}$ & $8,18 \mathrm{a}$ & $33,36 \mathrm{a}$ \\
\hline Royal Gala & $23,00 \mathrm{ab}$ & $1,61 \mathrm{a}$ & $14,23 \mathrm{a}$ & $11,14 \mathrm{a}$ & $3,13 \mathrm{a}$ & $156,57 \mathrm{a}$ & $285,90 \mathrm{a}$ & $114,95 \mathrm{ab}$ & $8,90 \mathrm{a}$ & $30,67 \mathrm{ab}$ \\
\hline Imperial Gala & $21,27 \quad b$ & $1,55 \mathrm{a}$ & $14,10 \mathrm{a}$ & $10,20 \mathrm{a}$ & $3,02 \mathrm{a}$ & $152,50 \mathrm{a}$ & $206,00 \mathrm{ab}$ & $33,25 \mathrm{~b}$ & $8,00 \mathrm{a}$ & $28,50 \mathrm{~b}$ \\
\hline \multirow[t]{2}{*}{ CV (\%) } & 8,02 & 14,94 & 23,31 & 16,59 & 20,97 & 60,01 & 60,57 & 136,51 & 13,97 & 8,66 \\
\hline & \multicolumn{10}{|c|}{ Safra 2003} \\
\hline Fuji & $22,06 \mathrm{a}$ & $1,43 \mathrm{a}$ & $16,34 \mathrm{~b}$ & $10,91 \mathrm{a}$ & $3,10 \mathrm{a}$ & $100,82 \mathrm{ab}$ & $144,24 \mathrm{~b}$ & $72,59 \mathrm{a}$ & $6,94 \mathrm{a}$ & $41,41 \mathrm{ab}$ \\
\hline Gala & $20,77 \mathrm{a}$ & $1,37 \mathrm{a}$ & $21,46 \mathrm{a}$ & 10,07 a & $2,80 \mathrm{a}$ & $94,36 \mathrm{ab}$ & $138,18 \quad b$ & $161,55 \mathrm{a}$ & $6,27 \mathrm{a}$ & $45,45 \mathrm{a}$ \\
\hline Royal Gala & $21,23 \mathrm{a}$ & $1,27 \mathrm{a}$ & $19,84 \mathrm{ab}$ & $9,76 \mathrm{a}$ & $3,26 \mathrm{a}$ & $82,67 \quad b$ & $225,38 \mathrm{ab}$ & $165,86 \mathrm{a}$ & $8,43 \mathrm{a}$ & $40,24 \mathrm{ab}$ \\
\hline Imperial Gala & $21,05 \mathrm{a}$ & $1,32 \mathrm{a}$ & $16,10 \mathrm{~b}$ & $10,22 \mathrm{a}$ & $3,22 \mathrm{a}$ & $130,75 \mathrm{a}$ & $329,25 \mathrm{a}$ & $77,50 \mathrm{a}$ & $5,75 \mathrm{a}$ & $35,50 \mathrm{~b}$ \\
\hline \multirow[t]{2}{*}{ CV (\%) } & 7,52 & 18,68 & 21,70 & 15,36 & 25,40 & 38,14 & 60,71 & 91,72 & 49,51 & 12,56 \\
\hline & \multicolumn{10}{|c|}{ Geral } \\
\hline Fuji & $22,83 \mathrm{a}$ & $1,63 \mathrm{a}$ & $14,96 \mathrm{a}$ & $11,55 \mathrm{a}$ & $3,10 \mathrm{ab}$ & $153,01 \mathrm{a}$ & $145,65 \mathrm{a}$ & $63,65 \mathrm{a}$ & $7,97 \mathrm{a}$ & $37,29 \mathrm{a}$ \\
\hline Gala & $21,69 \mathrm{a}$ & $1,53 \mathrm{a}$ & $18,45 \mathrm{a}$ & $11,04 \mathrm{a}$ & $2,79 \mathrm{~b}$ & $121,82 \mathrm{a}$ & $119,09 \mathrm{a}$ & $190,82 \mathrm{a}$ & $7,22 \mathrm{a}$ & $39,41 \mathrm{a}$ \\
\hline Royal Gala & $22,12 \mathrm{a}$ & $1,44 \mathrm{a}$ & $17,04 \mathrm{a}$ & $10,45 \mathrm{a}$ & $3,19 \mathrm{a}$ & $119,62 \mathrm{a}$ & $255,64 \mathrm{a}$ & $140,40 \mathrm{a}$ & $8,67 \mathrm{a}$ & $35,45 \mathrm{a}$ \\
\hline Imperial Gala & $21,16 \mathrm{a}$ & $1,44 \mathrm{a}$ & $15,10 \mathrm{a}$ & $10,21 \mathrm{a}$ & $3,12 \mathrm{ab}$ & $141,63 \mathrm{a}$ & 267,63 a & 55,38 a & $6,87 \mathrm{a}$ & $32,00 \mathrm{a}$ \\
\hline CV (\%) & 7,80 & 16,60 & 22,50 & 16,09 & 23,33 & 58,33 & 60,65 & 113,06 & 33,38 & 11,34 \\
\hline
\end{tabular}

Quando foi avaliado o efeito de porta-enxertos na concentração de nutrientes (Tabela 6), pode-se observar que, em função do porta-enxerto utilizado, houve variação nas concentrações de P e Mn na safra 2002, de P, K, Ca e Zn na safra 2003 e de P, K e Zn na análise conjunta das safras. De modo geral, pode-se inferir que a concentração de $\mathrm{P}$ foi maior no porta-enxerto Marubakaido e as concentrações de $\mathrm{K}$ e $\mathrm{Zn}$ foram maiores no porta-enxerto EM-26. Resultados similares também foram obtidos por Tagliavini et al. (1992) e por Poling \& Oberly (1979). Deve-se considerar que o uso do porta-enxerto Marubakaido esta concentrado na região de São Joaquim - SC e que o porta-enxerto 
EM-26 representa uma pequena parcela dos pomares de macieira atualmente implantados. Entre os porta-enxertos mais utilizados (MM-106, EM-7, EM-9 e EM27) não houve diferença significativa para os nutrientes estudados.

A avaliação do efeito de densidade de plantio na concentração de nutrientes nas folhas de macieira (Tabela 7) mostrou que houve efeito significativo da densidade de plantio nas concentrações de $\mathrm{Ca}, \mathrm{Mg}, \mathrm{Mn}$ e B na safra 2002, nas concentrações de Mg, Mn, Zn, Cu e B na safra 2003 e nas concentrações de Mg na análise conjunta das safras. De modo geral, os pomares conduzidos em sistema de alta densidade apresentaram maiores concentrações de $\mathrm{Ca}, \mathrm{Mg}, \mathrm{Mn}$ e $\mathrm{Zn}$ e menores concentrações de B. Este efeito da densidade de plantio na concentração de nutrientes em folhas de macieira também foi observado por Schneider et al. (1978). Considerando que a tendência atual é a utilização de sistemas de condução de média a alta densidade para a cultura da macieira, estes resultados são um indicativo de que novos estudos devem ser realizados para validar estes resultados, principalmente quando da utilização do método DRIS. Estes resultados, também, indicam que as amostras dos pomares de baixa densidade não devem ser empregadas para o estabelecimento das normas DRIS.

O efeito de safra na concentração de nutrientes nas folhas de macieira foi expressivo, onde somente as concentrações de $\mathrm{Mg}$, Fe e Mn não foram afetadas pelas safras (Tabela 8). Este fato pode ser atribuído à alternância de produção que ocorreu nas duas safras avaliadas, fato comum para a cultura da macieira. Estes resultados reforçam a proposta de se utilizar os dados médios das duas safras para o estabelecimento das normas DRIS. 
Tabela 6. Concentração média de nitrogênio, fósforo, potássio, cálcio, magnésio, ferro, manganês, zinco, cobre e boro em folhas de macieira em função do tipo de porta-enxerto, nas safras 2002, 2003 e geral

\begin{tabular}{|c|c|c|c|c|c|c|c|c|c|c|}
\hline \multirow{2}{*}{$\begin{array}{c}\text { Porta- } \\
\text { enxerto }\end{array}$} & \multicolumn{10}{|c|}{ Concentração de nutrientes nas folhas } \\
\hline & $\mathbf{N}$ & $\mathbf{P}$ & $\mathbf{K}$ & Ca & Mg & $\mathbf{F e}$ & Mn & Zn & $\mathrm{Cu}$ & B \\
\hline & \multicolumn{10}{|c|}{ Safra 2002} \\
\hline Marubakaido & $22,32 \mathrm{a}^{*}$ & $2,20 \mathrm{a}$ & $15,18 \mathrm{a}$ & $12,36 \mathrm{a}$ & $3,60 \mathrm{a}$ & 338,67 a & $129,70 \mathrm{~b}$ & $35,30 \mathrm{a}$ & $8,80 \mathrm{a}$ & $33,67 \mathrm{a}$ \\
\hline MM-106 & $22,44 \mathrm{a}$ & $1,68 \mathrm{ab}$ & $14,23 \mathrm{a}$ & $11,60 \mathrm{a}$ & $2,87 \mathrm{a}$ & $176,55 \mathrm{a}$ & $185,70 \mathrm{~b}$ & $108,90 \mathrm{a}$ & $8,54 \mathrm{a}$ & $31,73 \mathrm{a}$ \\
\hline MM-111 & $21,80 \mathrm{a}$ & $1,45 \mathrm{~b}$ & $11,15 \mathrm{a}$ & $10,50 \mathrm{a}$ & $3,25 \mathrm{a}$ & $145,50 \mathrm{a}$ & $135,00 \mathrm{~b}$ & $10,00 \mathrm{a}$ & $8,00 \mathrm{a}$ & $27,50 \mathrm{a}$ \\
\hline EM-7 & $23,25 \mathrm{a}$ & $1,65 \mathrm{ab}$ & $14,32 \mathrm{a}$ & $11,01 \mathrm{a}$ & $2,83 \mathrm{a}$ & $160,34 \mathrm{a}$ & $157,90 \mathrm{ab}$ & 87,30 a & $8,83 \mathrm{a}$ & $32,91 \mathrm{a}$ \\
\hline EM-9 & $23,86 \mathrm{a}$ & $1,74 a b$ & $13,59 \mathrm{a}$ & $13,35 \mathrm{a}$ & $3,53 \mathrm{a}$ & $168,86 \mathrm{a}$ & $247,50 \mathrm{ab}$ & $149,10 \mathrm{a}$ & $9,00 \mathrm{a}$ & $30,93 \mathrm{a}$ \\
\hline EM-26 & $26,10 \mathrm{a}$ & $1,90 \mathrm{ab}$ & $16,50 \mathrm{a}$ & $12,20 \mathrm{a}$ & $2,70 \mathrm{a}$ & $164,00 \mathrm{a}$ & $601,00 \mathrm{a}$ & $233,00 \mathrm{a}$ & $9,00 \mathrm{a}$ & $33,00 \mathrm{a}$ \\
\hline EM-27 & $21,50 \mathrm{a}$ & $1,70 \mathrm{ab}$ & $8,50 \mathrm{a}$ & $14,40 \mathrm{a}$ & $2,80 \mathrm{a}$ & $112,00 \mathrm{a}$ & $245,00 \mathrm{~b}$ & $22,00 \mathrm{a}$ & $8,00 \mathrm{a}$ & $29,00 \mathrm{a}$ \\
\hline CV (\%) & \multicolumn{10}{|c|}{ Safra 2003} \\
\hline Marubakaido & $21,88 \mathrm{a}$ & $1,93 \mathrm{a}$ & $16,43 \mathrm{ab}$ & $13,42 \mathrm{a}$ & $3,55 \mathrm{a}$ & $63,00 \mathrm{a}$ & $154,70 \mathrm{a}$ & $57,50 \mathrm{~b}$ & $5,17 \mathrm{a}$ & $36,17 \mathrm{a}$ \\
\hline MM-106 & 20,86 a & $1,26 \mathrm{~b}$ & $18,84 \mathrm{ab}$ & $10,06 \mathrm{ab}$ & $3,08 \mathrm{a}$ & $82,27 \mathrm{a}$ & $140,80 \mathrm{a}$ & $136,64 \mathrm{ab}$ & $7,09 \mathrm{a}$ & $42,82 \mathrm{a}$ \\
\hline MM-111 & $19,95 \mathrm{a}$ & $1,20 \mathrm{~b}$ & $19,40 \mathrm{ab}$ & $10,50 \mathrm{ab}$ & $3,80 \mathrm{a}$ & $68,50 \mathrm{a}$ & $244,50 \mathrm{a}$ & $37,50 \mathrm{~b}$ & $5,50 \mathrm{a}$ & $41,00 \mathrm{a}$ \\
\hline EM-7 & $21,78 \mathrm{a}$ & $1,35 \mathrm{~b}$ & $18,71 \mathrm{ab}$ & $9,72 \mathrm{~b}$ & $2,77 \mathrm{a}$ & $107,43 \mathrm{a}$ & $199,50 \mathrm{a}$ & $99,00 \mathrm{~b}$ & $6,11 \mathrm{a}$ & $43,09 \mathrm{a}$ \\
\hline EM-9 & $21,69 \mathrm{a}$ & $1,27 \mathrm{~b}$ & $17,30 \mathrm{ab}$ & $10,93 \mathrm{ab}$ & $3,65 \mathrm{a}$ & $99,79 \mathrm{a}$ & $148,50 \mathrm{a}$ & $165,50 \mathrm{ab}$ & $10,93 \mathrm{a}$ & $38,57 \mathrm{a}$ \\
\hline EM-26 & $21,50 \mathrm{a}$ & $1,30 \mathrm{~b}$ & $22,50 \mathrm{a}$ & $11,40 \mathrm{ab}$ & $3,00 \mathrm{a}$ & $74,00 \mathrm{a}$ & $144,00 \mathrm{a}$ & $410,00 \mathrm{a}$ & $11,00 \mathrm{a}$ & $44,00 \mathrm{a}$ \\
\hline EM-27 & $20,50 \mathrm{a}$ & $1,40 \mathrm{ab}$ & $8,60 \mathrm{~b}$ & $10,70 \mathrm{ab}$ & $3,40 \mathrm{a}$ & $63,00 \mathrm{a}$ & $303,00 \mathrm{a}$ & $43,00 \quad b$ & $7,00 \mathrm{a}$ & $33,00 \mathrm{a}$ \\
\hline \multirow[t]{2}{*}{ CV (\%) } & 7,80 & 14,42 & 23,80 & 12,70 & 23,09 & 37,51 & 66,89 & 90,94 & 43,23 & 12,39 \\
\hline & \multicolumn{10}{|c|}{ Geral } \\
\hline Marubakaido & $22,10 \mathrm{a}$ & $2,07 \mathrm{a}$ & $15,81 \mathrm{ab}$ & $12,89 \mathrm{a}$ & $3,57 \mathrm{a}$ & $200,83 \mathrm{a}$ & $142,20 \mathrm{a}$ & 36,42 bc & $7,00 \mathrm{a}$ & $34,92 \mathrm{a}$ \\
\hline MM-106 & $21,65 \mathrm{a}$ & $1,47 \quad b$ & $16,53 \mathrm{ab}$ & $10,83 \mathrm{a}$ & $2,98 \mathrm{a}$ & $129,91 \mathrm{a}$ & $163,30 \mathrm{a}$ & $122,77 \mathrm{bc}$ & $7,82 \mathrm{a}$ & $37,27 \mathrm{a}$ \\
\hline MM-111 & $20,87 \mathrm{a}$ & $1,32 \mathrm{~b}$ & $15,27 \mathrm{ab}$ & $10,50 \mathrm{a}$ & $3,52 \mathrm{a}$ & $107,00 \mathrm{a}$ & $189,80 \mathrm{a}$ & $23,75 \quad \mathrm{c}$ & $6,75 a$ & $34,25 \mathrm{a}$ \\
\hline EM-7 & $22,51 \mathrm{a}$ & $1,50 \mathrm{~b}$ & $16,52 \mathrm{ab}$ & $10,36 \mathrm{a}$ & $2,80 \mathrm{a}$ & $133,89 \mathrm{a}$ & 178,70 a & 93,16 bc & $7,47 a$ & $38,00 \mathrm{a}$ \\
\hline EM-9 & $22,77 \mathrm{a}$ & $1,51 \mathrm{~b}$ & $15,44 \mathrm{ab}$ & $12,14 \mathrm{a}$ & $3,59 \mathrm{a}$ & $134,32 \mathrm{a}$ & $198,00 \mathrm{a}$ & $157,29 \mathrm{~b}$ & $9,96 \mathrm{a}$ & $34,75 \mathrm{a}$ \\
\hline EM-26 & $23,80 \mathrm{a}$ & $1,60 \mathrm{ab}$ & $19,50 \mathrm{a}$ & $11,80 \mathrm{a}$ & $2,85 \mathrm{a}$ & $119,00 \mathrm{a}$ & $372,50 \mathrm{a}$ & $321,50 \mathrm{a}$ & $10,00 \mathrm{a}$ & $38,50 \mathrm{a}$ \\
\hline EM-27 & $21,00 \mathrm{a}$ & $1,55 \mathrm{ab}$ & $8,55 \mathrm{~b}$ & $12,55 \mathrm{a}$ & $3,10 \mathrm{a}$ & $87,50 \mathrm{a}$ & $274,00 \mathrm{a}$ & $32,50 \mathrm{bc}$ & $7,50 \mathrm{a}$ & $31,00 \mathrm{a}$ \\
\hline CV (\%) & 7,95 & 13,93 & 23,77 & 14,34 & 21,10 & 54,79 & 65,59 & 118,73 & 29,82 & 11,38 \\
\hline
\end{tabular}


Tabela 7. Concentração média de nitrogênio, fósforo, potássio, cálcio, magnésio, ferro, manganês, zinco, cobre e boro em folhas de macieira em função da densidade de plantio, nas safras 2002, 2003 e geral

\begin{tabular}{|c|c|c|c|c|c|c|c|c|c|c|}
\hline \multirow{2}{*}{$\begin{array}{l}\text { Densidade } \\
\text { de Plantio }\end{array}$} & \multicolumn{10}{|c|}{ Concentração de nutrientes nas folhas } \\
\hline & $\mathbf{N}$ & $\mathbf{P}$ & $\mathbf{K}$ & $\mathbf{C a}$ & Mg & Fe & Mn & Zn & $\mathrm{Cu}$ & $\mathbf{B}$ \\
\hline & \multicolumn{10}{|c|}{ 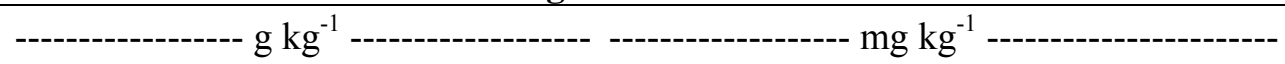 } \\
\hline & \multicolumn{10}{|c|}{ Safra 2002} \\
\hline Baixa & $23,1 \mathrm{a}^{*}$ & $1,77 \mathrm{a}$ & $14,2 \mathrm{a}$ & $11,3 \mathrm{~b}$ & b $2,9 \mathrm{~b}$ & $206,5 \mathrm{a}$ & $133,3 \mathrm{~b}$ & $57,1 \mathrm{a}$ & $8,7 \mathrm{a}$ & $33,1 \mathrm{a}$ \\
\hline Média & $22,8 \mathrm{a}$ & $1,67 \mathrm{a}$ & $14,3 \mathrm{a}$ & $11,2 \mathrm{~b}$ & b $2,9 \mathrm{~b}$ & 140,7 a & $176,6 \mathrm{~b}$ & 116,7 a & $8,4 \mathrm{a}$ & $32,1 \mathrm{ab}$ \\
\hline Alta & $23,5 \mathrm{a}$ & $1,70 \mathrm{a}$ & $13,7 \mathrm{a}$ & $12,8 \mathrm{a}$ & $3,4 \mathrm{a}$ & 178,6 a & 267,6 a & $136,1 \mathrm{a}$ & $9,2 \mathrm{a}$ & $30,9 \mathrm{~b}$ \\
\hline \multirow[t]{2}{*}{ CV (\%) } & 8,30 & 15,85 & 23,55 & 16,27 & 20,05 & 59,30 & 64,63 & 144,76 & 14,02 & 9,37 \\
\hline & \multicolumn{10}{|c|}{ Safra 2003} \\
\hline Baixa & $21,88 \mathrm{a}$ & $1,43 \mathrm{a}$ & $17,36 \mathrm{a}$ & $10,55 \mathrm{a}$ & a $2,91 \quad$ b & $97,4 \mathrm{a}$ & $145,9 \mathrm{~b}$ & $74,8 \mathrm{~b}$ & $5,9 \mathrm{~b}$ & $41,6 \mathrm{ab}$ \\
\hline Média & $20,92 \mathrm{a}$ & $1,35 \mathrm{a}$ & $20,05 \mathrm{a}$ & $9,81 \mathrm{a}$ & a 2,90 b & $91,4 \mathrm{a}$ & $234,9 \mathrm{a}$ & $110,6 \mathrm{ab}$ & $6,1 \mathrm{~b}$ & $43,4 \mathrm{a}$ \\
\hline Alta & $21,73 \mathrm{a}$ & $1,28 \mathrm{a}$ & $17,41 \mathrm{a}$ & $10,76 \mathrm{a}$ & $3,59 \mathrm{a}$ & 99,1 a & $165,5 \mathrm{ab}$ & $177,3 \mathrm{a}$ & $10,2 \mathrm{a}$ & $38,9 \mathrm{~b}$ \\
\hline \multirow[t]{2}{*}{ CV (\%) } & 7,60 & 18,74 & 23,58 & 15,61 & 23,58 & 39,66 & 63,82 & 92,26 & 42,96 & 12,95 \\
\hline & \multicolumn{10}{|c|}{ Geral } \\
\hline Baixa & $22,5 \mathrm{a}$ & $1,60 \mathrm{a}$ & $15,8 \mathrm{a}$ & $11,0 \mathrm{a}$ & $2,9 \quad \mathrm{~b}$ & $152,0 \mathrm{a}$ & $139,6 \mathrm{a}$ & $65,9 \mathrm{a}$ & $7,3 \mathrm{a}$ & $37,3 \mathrm{a}$ \\
\hline Média & $21,9 \mathrm{a}$ & $1,51 \mathrm{a}$ & $17,2 \mathrm{a}$ & $10,5 \mathrm{a}$ & $2,9 \mathrm{~b}$ & $116,0 \mathrm{a}$ & $205,7 \mathrm{a}$ & $113,6 \mathrm{a}$ & $7,3 \mathrm{a}$ & $37,7 \mathrm{a}$ \\
\hline Alta & $22,6 \mathrm{a}$ & $1,49 \mathrm{a}$ & $15,6 \mathrm{a}$ & $11,8 \mathrm{a}$ & $3,5 \mathrm{a}$ & $138,9 \mathrm{a}$ & $216,6 \mathrm{a}$ & $156,7 \mathrm{a}$ & $9,7 \mathrm{a}$ & 34,9 a \\
\hline CV (\%) & 7,99 & 17,14 & 23,76 & 16,02 & 21,92 & 57,97 & 64,25 & 117,55 & 29,48 & 11,82 \\
\hline
\end{tabular}


Tabela 8. Concentração média de nitrogênio, fósforo, potássio, cálcio, magnésio, ferro, manganês, zinco, cobre e boro em folhas de macieira em função da safra

\begin{tabular}{|c|c|c|c|c|c|c|c|c|c|c|}
\hline \multirow{2}{*}{ Safra } & \multicolumn{10}{|c|}{ Concentração de nutrientes nas folhas } \\
\hline & $\mathbf{N}$ & $\mathbf{P}$ & $\mathbf{K}$ & $\mathbf{C a}$ & $\mathrm{Mg}$ & Fe & Mn & Zn & $\mathbf{C u}$ & $\mathbf{B}$ \\
\hline & -------. & ------- & $-\mathrm{g} \mathrm{kg}^{-1}$ & --------- & -------- & -------- & -------- n & $\mathrm{g} \mathrm{kg}^{-1}--$ & 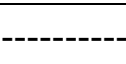 & -------- \\
\hline 2002 & $23,1 \mathrm{a}^{*}$ & $1,72 \mathrm{a}$ & $14,1 \mathrm{~b}$ & $11,7 \mathrm{a}$ & $3,0 \mathrm{a}$ & $178,8 \mathrm{a}$ & $184,7 \mathrm{a}$ & $97,5 \mathrm{a}$ & $8,8 \mathrm{a}$ & $32,2 \mathrm{~b}$ \\
\hline 2003 & $21,5 \mathrm{~b}$ & $1,37 \mathrm{~b}$ & $18,2 \mathrm{a}$ & $10,4 \mathrm{~b}$ & $3,1 \mathrm{a}$ & $96,1 \mathrm{a}$ & $178,2 \mathrm{a}$ & $114,8 \mathrm{a}$ & $7,2 \mathrm{~b}$ & $41,3 \mathrm{a}$ \\
\hline CV (\%) & 7,99 & 17,14 & 23,76 & 16,02 & 21,92 & 57,97 & 64,25 & 117,55 & 29,48 & 11,82 \\
\hline
\end{tabular}

As distribuiçõos de freqüência dos valores de pH em água (1:1) e dos teores de fósforo e potássio no solo (camadas de 0 a 20 e 20 a $40 \mathrm{~cm}$ ) de 70 pomares do Rio Grande do Sul e Santa Catarina, considerando os dados das safras 2002 e 2003, são apresentadas nas Figuras 4 e 5 e os resultados da análise estatística descritiva na Tabela 9. Os dados originais são apresentados nos Apêndices 3 a 6. Observou-se que poucos pomares apresentaram, na camada de 0 a $20 \mathrm{~cm}$, valores de $\mathrm{pH}$ em água (1:1) inferiores a 6,0, valor considerado ideal para a cultura. Já na camada de $20-40 \mathrm{~cm}$ houve maior freqüência de pomares com $\mathrm{pH}$ inferior a 6,0 . Os teores de $\mathrm{P}$ e $\mathrm{K}$ na camada de $0-20$ $\mathrm{cm}$ do solo apresentaram-se dentro da faixa considerada ideal para a cultura. $\mathrm{Na}$ camada de $20-40 \mathrm{~cm}$, os teores destes nutrientes foram menores que na camada superficial, mas mesmo assim dentro de uma faixa considerada adequada. Para os teores de matéria orgânica do solo, os valores observados estão de acordo com o esperado para os tipos de solos onde estão localizados os pomares de macieira, indicando uma alta possibilidade de fornecimento de N para a cultura. Para cálcio e magnésio do solo, observa-se que os teores refletem o efeito da calagem realizada nestes pomares, visando corrigir o $\mathrm{pH}$ do solo. 
Observou-se que os valores de $\mathrm{pH}$ na camada de 0 a $20 \mathrm{~cm}$ de solo, considerando as safras 2002 e 2003, variaram de 4,0 a 7,3, os teores de P entre 0,40 e $159,2 \mathrm{mg} \mathrm{dm}^{-3}$, os teores de $\mathrm{K}$ entre 29,8 e $1478,8 \mathrm{mg} \mathrm{dm}^{-3}$, os teores de matéria orgânica entre 27,2 e $102,4 \mathrm{~g} \mathrm{dm}^{-3}$, os teores de Ca entre 11,3 e $153,7 \mathrm{mmol}_{\mathrm{c}} \mathrm{dm}^{-3}$ e os teores de $\mathrm{Mg}$ entre 6,1 e 506,7 $\mathrm{mmol}_{\mathrm{c}} \mathrm{dm}^{-3}$. Na camada de 20 a $40 \mathrm{~cm}$ de solo, os valores de $\mathrm{pH}$ variaram de 4,2 a 7,8, os teores de $\mathrm{P}$ entre 0,10 e $81,5 \mathrm{mg} \mathrm{dm}^{-3}$, os teores de $\mathrm{K}$ entre 16,3 e 453,6 $\mathrm{mg} \mathrm{dm}^{-3}$, os teores de matéria orgânica entre 20,0 e 83,7 $\mathrm{g} \mathrm{dm}^{-3}$, os teores de Ca entre 10,8 e 177,0 $\mathrm{mmol}_{\mathrm{c}} \mathrm{dm}^{-3}$ e os teores de $\mathrm{Mg}$ entre 5,9 e 620,4 $\mathrm{mmol}_{\mathrm{c}} \mathrm{dm}^{-3}$.

Considerando os resultados médios de cada camada (Tabela 9), observa-se que houve alta variabilidade para as variáveis $\mathrm{P}, \mathrm{K}$ e $\mathrm{Mg}$, nas duas camadas avaliadas, apresentando valores elevados para a variância da amostra e coeficiente de variação. Estes resultados são conseqüência dos diferentes tipos de manejo do solo utilizado para cada pomar. 
0 a $20 \mathrm{~cm}$
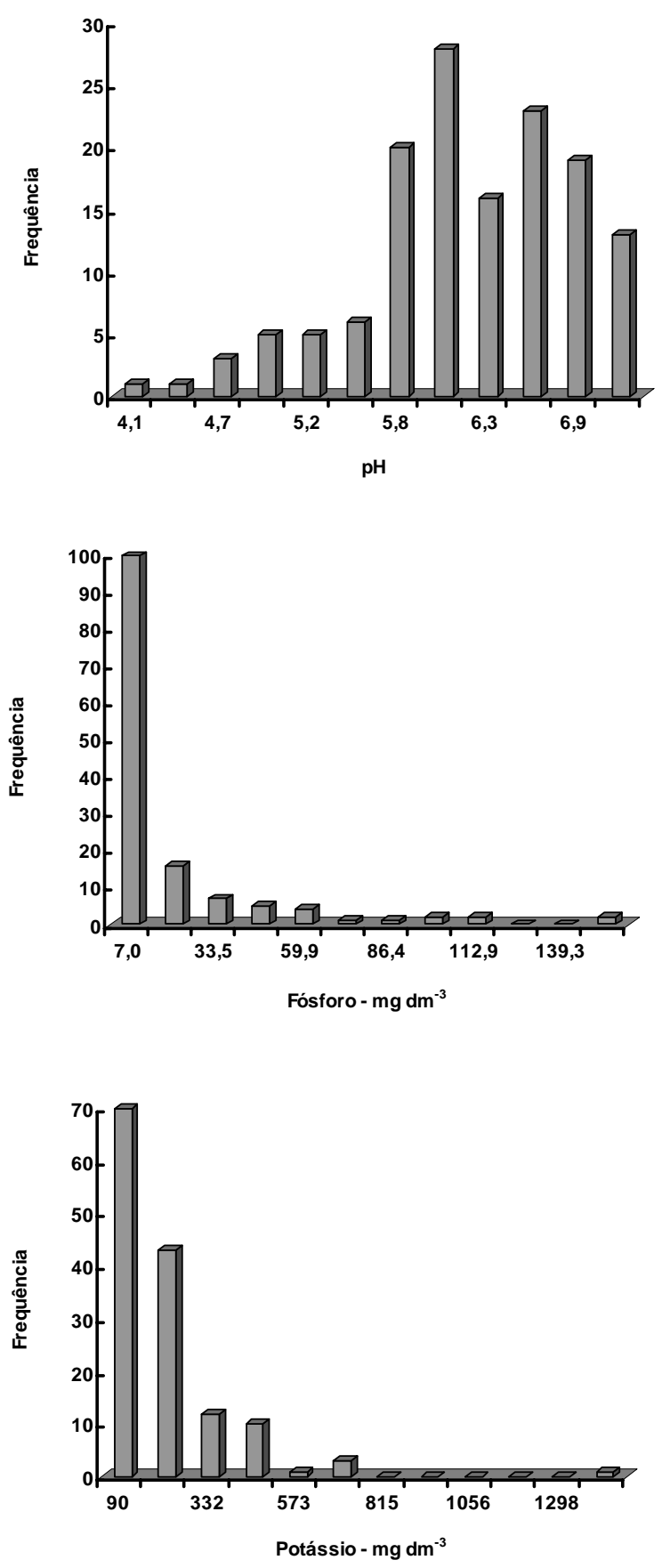

20 a $40 \mathrm{~cm}$
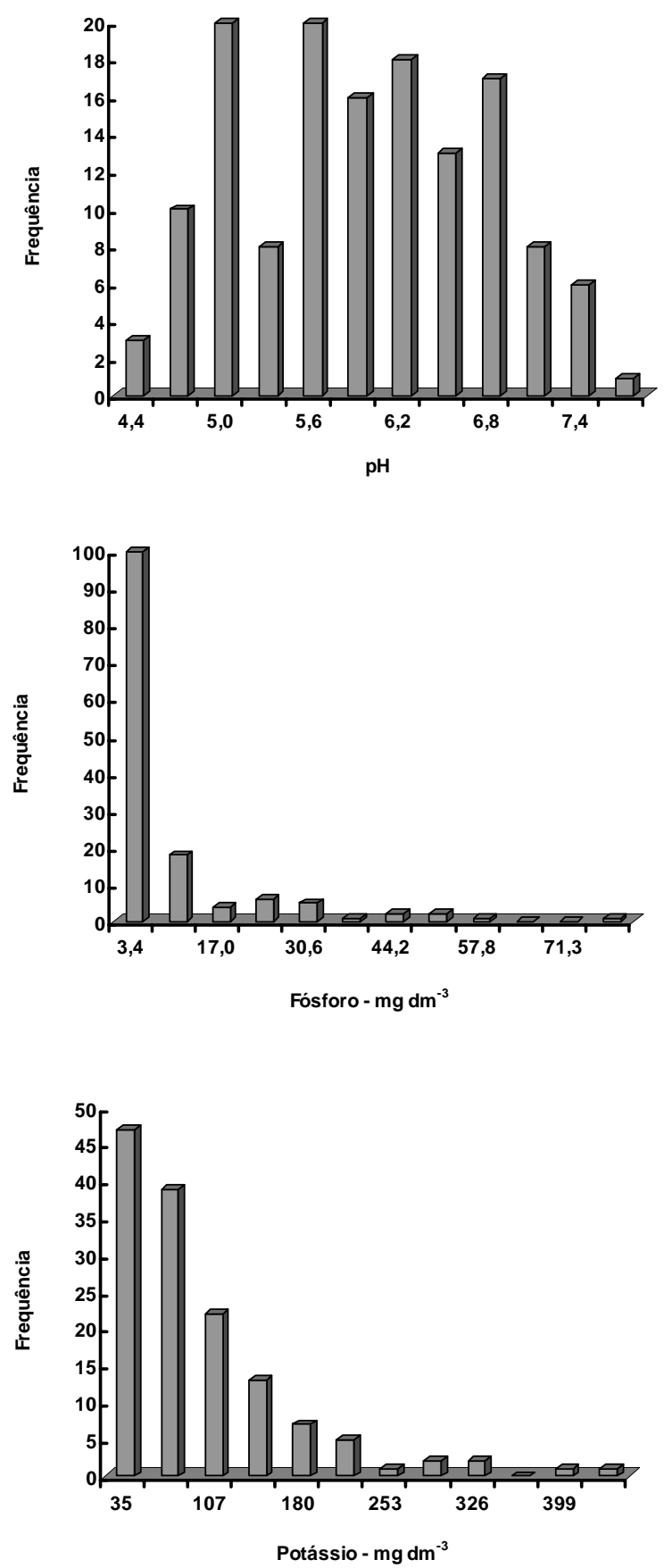

Figura 4 - Distribuição de freqüência dos valores de pH em água (1:1) e dos teores de fósforo e potássio no solo (camadas de 0 a 20 e 20 a $40 \mathrm{~cm}$ ) de 70 pomares de macieira do Rio Grande do Sul e Santa Catarina (Safras 2002 e 2003) 

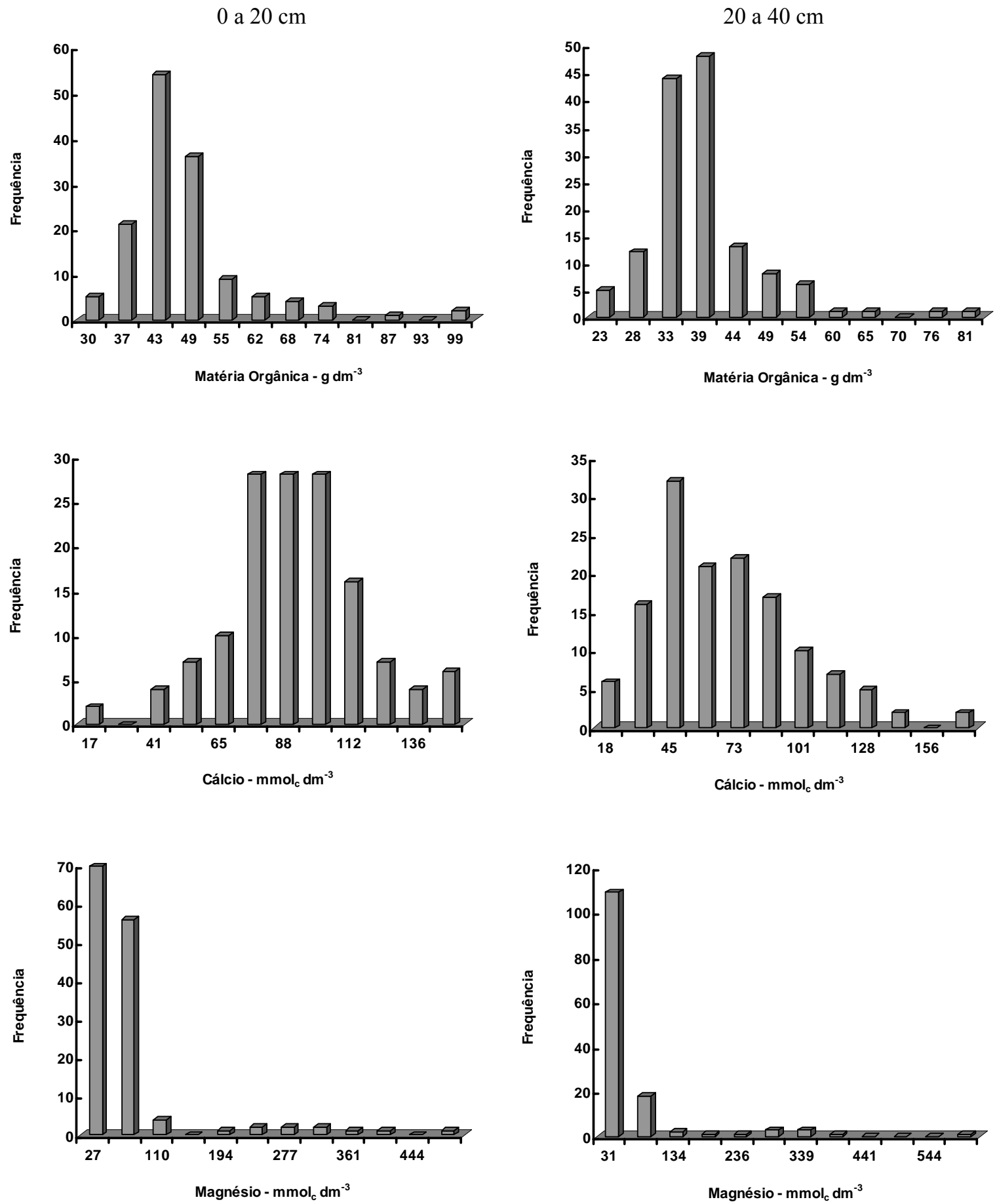

Figura 5 - Distribuição de freqüência dos teores de matéria orgânica, cálcio e magnésio no solo (camadas de 0 a 20 e 20 a $40 \mathrm{~cm}$ ) de 70 pomares de macieira do Rio Grande do Sul e Santa Catarina (Safras 2002 e 2003) 
Tabela 9. Estatística descritiva dos valores de $\mathrm{pH}$ em água (1:1) e dos teores de matéria orgânica, fósforo, potássio cálcio e magnésio no solo (camadas de 0 a 20 e 20 a $40 \mathrm{~cm}$ ) de 70 pomares de macieira do Rio Grande do Sul e Santa Catarina (Safras 2002 e 2003)

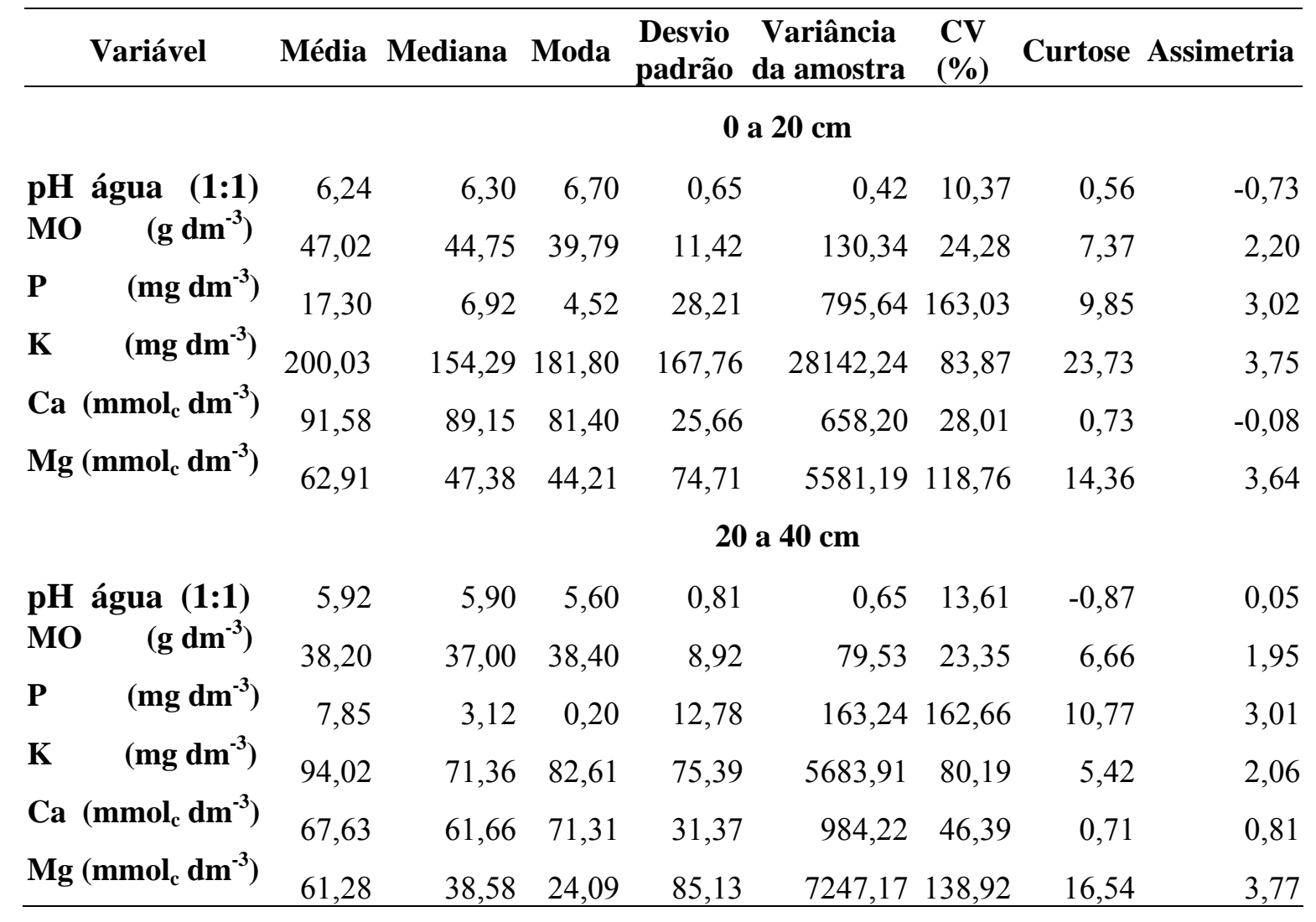

\subsection{Estabelecimento das normas DRIS para a cultura da macieira no Sul do Brasil}

Considerando que: a) a cultura da macieira apresentou alternância de produção nas safras avaliadas; b) as concentrações de Fe, Mn e Zn no tecido foliar apresentaram alta variabilidade, atribuída à contaminação da amostra por produtos fitossanitários ou aplicação foliar de micronutrientes; c) a tendência atual é a utilização de sistemas de condução de média a alta densidade para a cultura da macieira, optou-se por: a) definir como pomares de alta produtividade (população de referência) aqueles que 
apresentaram produção superior a $40 \mathrm{t} \mathrm{ha}^{-1}$ na safra normal e produção superior a 30 t ha ${ }^{-1}$ na safra com alternância; b) utilizar os resultados médios das duas safras estudadas para gerar as normas DRIS; c) não incluir, na definição das normas, os resultados das concentrações de Fe, Mn e Zn, no tecido foliar, maiores que a concentração considerada normal para a cultura (Basso et al., 1986); d) eliminar as amostras provenientes de pomares estabelecidos em sistema de condução de baixa densidade.

O valor médio, o coeficiente de variação e o desvio padrão para as concentrações de nutrientes nas folhas de macieira, nas safras 2002, 2003 e média das safras, para a população de referência são apresentados na Tabela 10. Observou-se que houve variação nas concentrações de nutrientes entre as safras estudadas, o que pode ser atribuído à variação na produtividade e nas condições climáticas que ocorre entre as safras 2002 e 2003. Desconsiderando os nutrientes Fe, Mn e Zn, que apresentaram problemas de contaminação, na safra 2003 as concentrações de N, P, Ca e Cu foram menores que as concentrações observadas em 2002, por outro lado, as concentrações de $\mathrm{K}, \mathrm{Mg}$ e B foram maiores que as concentrações destes nutrientes na safra 2002.

Os coeficientes de variação, obtidos para a concentração de nutrientes nas folhas, não considerando os nutrientes Fe, Mn e Zn, mostraram que, para as duas safras estudadas e para a média das safras, os valores encontrados estão abaixo de $25 \%$, com exceção do B, que apresentou coeficiente de variação de 32\%, 39\% e 35\%, para as safras 2002, 2003 e média das safras, respectivamente. Considerando que quanto menor o coeficiente de variação, menor será a amplitude dos valores dos nutrientes, pode-se inferir que são pequenos os desequilíbrios nutricionais para a população considerada para a definição das normas DRIS.

As concentrações médias dos nutrientes, utilizadas para gerar as normas DRIS para as condições do Sul do Brasil (Tabela 10) foram inferiores às utilizadas por Singh et al. (2000), na Índia, para Mn, Zn e, principalmente para Ca e Fe. Para os demais nutrientes as concentrações foram similares. Para as condições da Nova Zelândia (Goh \& Malakouti, 1992) e Hungria (Szücs et al., 1990; Szücs \& Kállay, 1990), as concentrações de Ca também foram superiores às obtidas neste trabalho. 
Tabela 10. Média, coeficiente de variação e desvio padrão para as concentrações de nutrientes nas folhas de macieira, nas safras 2002, 2003 e média das safras, considerando a população de referência

\begin{tabular}{|c|c|c|c|c|c|c|c|c|c|}
\hline \multirow[b]{2}{*}{ Nutriente } & \multicolumn{3}{|c|}{2002} & \multicolumn{3}{|c|}{2003} & \multicolumn{3}{|c|}{ Média } \\
\hline & Média & CV (\%) & $\begin{array}{l}\text { Desvio } \\
\text { Padrão }\end{array}$ & Média & CV (\%) & $\begin{array}{l}\text { Desvio } \\
\text { Padrão }\end{array}$ & Média & CV (\%) & $\begin{array}{l}\text { Desvio } \\
\text { Padrão }\end{array}$ \\
\hline$\left(\mathrm{g} \mathrm{kg}^{-1}\right)$ & 23,33 & 8,74 & 2,04 & 21,91 & 7,95 & 1,74 & 22,75 & 8,95 & 2,04 \\
\hline$\left(\mathrm{g} \mathrm{kg}^{-1}\right)$ & 1,73 & 11,62 & 0,20 & 1,37 & 18,51 & 0,25 & 1,58 & 17,95 & 0,28 \\
\hline$\left(\mathrm{g} \mathrm{kg}^{-1}\right)$ & 13,55 & 21,87 & 2,96 & 17,18 & 27,06 & 4,65 & 15,05 & 27,48 & 4,13 \\
\hline Ca $\quad\left(\mathrm{g} \mathrm{kg}^{-1}\right)$ & 11,94 & 18,72 & 2,24 & 10,30 & 15,13 & 1,56 & 11,27 & 18,95 & 2,14 \\
\hline $\operatorname{Mg} \quad\left(\mathrm{g} \mathrm{kg}^{-1}\right)$ & 3,09 & 17,93 & 0,55 & 3,26 & 22,90 & 0,75 & 3,16 & 20,32 & 0,64 \\
\hline Fe $\left(\mathrm{mg} \mathrm{kg}^{-1}\right)$ & 137,89 & 23,79 & 32,81 & 97,45 & 36,08 & 35,17 & 119,72 & 32,80 & 39,27 \\
\hline $\operatorname{Mn}\left(\mathrm{mg} \mathrm{kg}^{-1}\right)$ & 124,00 & 41,83 & 51,87 & 119,53 & 35,69 & 42,66 & 122,51 & 39,63 & 48,55 \\
\hline $\mathrm{Zn} \quad\left(\mathrm{mg} \mathrm{kg}{ }^{-1}\right)$ & 26,50 & 85,92 & 22,77 & 48,35 & 51,82 & 25,05 & 35,02 & 73,72 & 25,82 \\
\hline $\mathrm{Cu}\left(\mathrm{mg} \mathrm{kg}^{-1}\right)$ & 8,83 & 13,83 & 1,22 & 7,58 & 56,30 & 4,26 & 8,31 & 35,33 & 2,94 \\
\hline B $\quad\left(\mathrm{mg} \mathrm{kg}^{-1}\right)$ & 31,87 & 9,08 & 2,89 & 39,48 & 13,34 & 5,27 & 35,01 & 15,73 & 5,51 \\
\hline
\end{tabular}

O valor médio das relações entre os nutrientes, dois a dois, o coeficiente de variação, o desvio padrão para as relações (Normas), a variância para as relações entre nutrientes dois a dois, o coeficiente de correlação entre a razão de cada par de nutrientes e a produtividade de frutos de macieira (critério proposto por Nick, (1998)) e a razão entre variâncias das populações de alta e baixa produtividade (critério descrito por Letzsch (1985) e Walworth et al. (1986)), considerando a população de referência, são apresentados na Tabela 11. Os maiores coeficientes de variação observados foram das relações onde participaram os nutrientes $\mathrm{Fe}, \mathrm{Mn}$ e $\mathrm{Zn}$, mesmo com a eliminação dos resultados das concentrações desses nutrientes maiores que a concentração considerada normal para a cultura (Basso et al., 1986).

Os dois critérios para a escolha da ordem da razão dos nutrientes: "valor R" proposto por Nick (1998) e "valor F" descrito por Letzsch (1985) e Walworth et al. (1986) selecionaram razões diferentes, principalmente quando estiveram envolvidos os nutrientes $\mathrm{P}, \mathrm{K}$ e Fe (Tabela 11). 
Tabela 11. Normas DRIS (média, coeficiente de variação e desvio padrão) e variância para as relações entre nutrientes dois a dois, coeficiente de correlação $(\mathrm{R})$ entre a razão de cada par de nutrientes e a produtividade de frutos de macieira (Nick, 1998) e razão entre variâncias das populações de alta e baixa produtividade (Letzsch, 1985 e Walworth et al., 1986), considerando a população de referência

\begin{tabular}{|c|c|c|c|c|c|c|}
\hline Relação & Média & CV (\%) & Desvio Padrão & Variância & $\mathbf{R}$ & $s_{\text {baixa }}^{2} / s_{\text {alta }}^{2}$ \\
\hline $\mathbf{N} / \mathbf{P}$ & 14,691 & 17,261 & 2,536 & 6,430 & $-0,303^{*}$ & 1,6359 \\
\hline N/K & 1,603 & 26,983 & 0,432 & 0,187 & 0,327 & 0,9669 \\
\hline N/Ca & 2,060 & 18,946 & 0,390 & 0,152 & $-0,163$ & 0,5267 \\
\hline N/Mg & 7,614 & 28,736 & 2,188 & 4,787 & 0,192 & 1,3913 \\
\hline N/Fe & 0,219 & 51,427 & 0,113 & 0,009 & $-0,323$ & 0,6829 \\
\hline N/Mn & 0,252 & 70,147 & 0,177 & 0,027 & 0,078 & 2,0697 \\
\hline N/Zn & 1,147 & 82,672 & 0,948 & 0,870 & 0,182 & 0,6529 \\
\hline N/Cu & 3,069 & 28,119 & 0,863 & 0,744 & $-0,175$ & 0,8438 \\
\hline N/B & 0,655 & 17,058 & 0,112 & 0,012 & 0,375 & 1,3086 \\
\hline $\mathbf{P} / \mathbf{N}$ & 0,070 & 17,581 & 0,012 & 0,000 & 0,289 & 1,7760 \\
\hline $\mathbf{P} / \mathbf{K}$ & 0,114 & 34,116 & 0,039 & 0,001 & 0,410 & 1,1276 \\
\hline $\mathbf{P} / \mathbf{C a}$ & 0,142 & 17,065 & 0,024 & 0,001 & 0,123 & 1,5450 \\
\hline P/Mg & 0,526 & 27,117 & 0,143 & 0,020 & 0,377 & 1,0230 \\
\hline $\mathbf{P} / \mathbf{F e}$ & 0,015 & 55,558 & 0,009 & 0,000 & $-0,184$ & 0,9111 \\
\hline $\mathbf{P} / \mathbf{M n}$ & 0,017 & 67,596 & 0,012 & 0,000 & 0,134 & 1,7714 \\
\hline $\mathbf{P} / \mathbf{Z n}$ & 0,086 & 86,655 & 0,074 & 0,006 & 0,214 & 0,5272 \\
\hline $\mathbf{P} / \mathbf{C u}$ & 0,216 & 33,864 & 0,073 & 0,005 & $-0,035$ & 0,8216 \\
\hline $\mathbf{P} / \mathbf{B}$ & 0,046 & 27,271 & 0,013 & 0,000 & 0,401 & 1,4889 \\
\hline $\mathrm{K} / \mathbf{N}$ & 0,671 & 28,037 & 0,188 & 0,035 & $-0,385$ & 1,4176 \\
\hline $\mathbf{K} / \mathbf{P}$ & 10,014 & 39,470 & 3,952 & 15,621 & $-0,404$ & 1,6391 \\
\hline K/Ca & 1,401 & 37,996 & 0,532 & 0,283 & $-0,362$ & 0,9673 \\
\hline K/Mg & 5,204 & 44,002 & 2,290 & 5,244 & $-0,132$ & 2,2889 \\
\hline $\mathrm{K} / \mathrm{Fe}$ & 0,155 & 66,677 & 0,104 & 0,009 & $-0,423$ & 0,8794 \\
\hline K/Mn & 0,162 & 76,126 & 0,124 & 0,015 & $-0,001$ & 3,5336 \\
\hline K/Zn & 0,658 & 74,388 & 0,490 & 0,211 & 0,124 & 1,2933 \\
\hline $\mathrm{K} / \mathrm{Cu}$ & 2,063 & 42,574 & 0,879 & 0,772 & $-0,316$ & 1,5045 \\
\hline K/B & 0,429 & 23,985 & 0,103 & 0,011 & $-0,146$ & 0,7350 \\
\hline $\mathrm{Ca} / \mathrm{N}$ & 0,502 & 18,206 & 0,091 & 0,008 & 0,134 & 0,4963 \\
\hline $\mathbf{C a} / \mathbf{P}$ & 7,252 & 17,181 & 1,246 & 1,552 & $-0,156$ & 1,3712 \\
\hline $\mathrm{Ca} / \mathrm{K}$ & 0,816 & 37,491 & 0,306 & 0,094 & 0,288 & 0,5625 \\
\hline $\mathrm{Ca} / \mathrm{Mg}$ & 3,747 & 27,155 & 1,017 & 1,035 & 0,314 & 1,4519 \\
\hline $\mathrm{Ca} / \mathrm{Fe}$ & 0,111 & 57,355 & 0,064 & 0,003 & $-0,229$ & 0,5780 \\
\hline $\mathrm{Ca} / \mathbf{M n}$ & 0,128 & 70,901 & 0,091 & 0,007 & $\mathbf{0 , 0 8 0}$ & 1,8626 \\
\hline $\mathrm{Ca} / \mathbf{Z n}$ & 0,586 & 84,810 & 0,497 & 0,244 & 0,203 & 0,5381 \\
\hline $\mathrm{Ca} / \mathrm{Cu}$ & 1,537 & 33,339 & 0,512 & 0,263 & $-0,085$ & 0,6123 \\
\hline $\mathbf{C a} / \mathbf{B}$ & 0,330 & 25,989 & 0,086 & 0,007 & 0,345 & 0,7089 \\
\hline
\end{tabular}


Tabela 11. Normas DRIS (média, coeficiente de variação e desvio padrão) e variância para as relações entre nutrientes dois a dois, coeficiente de correlação (R) entre a razão de cada par de nutrientes e a produtividade de frutos de macieira (Nick, 1998) e razão entre variâncias das populações de alta e baixa produtividade (Letzsch, 1985 e Walworth et al., 1986), considerando a população de referência

\begin{tabular}{|c|c|c|c|c|c|c|}
\hline Relação & Média & CV (\%) & Desvio Padrão & Variância & $\mathbf{R}$ & $s_{\text {baixa }}^{2} / s_{\text {alta }}^{2}$ \\
\hline $\mathbf{M g} / \mathbf{N}$ & 0,141 & 25,524 & 0,036 & 0,001 & $-0,188$ & 1,0931 \\
\hline $\mathbf{M g} / \mathbf{P}$ & 2,042 & 26,831 & 0,548 & 0,300 & $-0,377$ & 0,9818 \\
\hline $\mathrm{Mg} / \mathrm{K}$ & 0,230 & 43,795 & 0,101 & 0,010 & 0,056 & 0,7686 \\
\hline $\mathrm{Mg} / \mathrm{Ca}$ & 0,284 & 23,900 & 0,068 & 0,005 & $-0,307$ & 1,2343 \\
\hline $\mathbf{M g} / \mathrm{Fe}$ & 0,031 & 57,206 & 0,018 & 0,000 & $-0,357$ & 1,0552 \\
\hline $\mathrm{Mg} / \mathrm{Mn}$ & 0,034 & 62,906 & 0,021 & 0,000 & $-0,147$ & 1,9789 \\
\hline $\mathbf{M g} / \mathbf{Z n}$ & 0,170 & 86,789 & 0,147 & 0,022 & 0,056 & 0,4862 \\
\hline $\mathrm{Mg} / \mathrm{Cu}$ & 0,439 & 45,020 & 0,198 & 0,039 & $-0,232$ & 0,5440 \\
\hline Mg/B & 0,091 & 27,515 & 0,025 & 0,001 & 0,041 & 1,5337 \\
\hline $\mathrm{Fe} / \mathbf{N}$ & 5,237 & 45,995 & 2,409 & 3,253 & 0,360 & 1,0052 \\
\hline $\mathbf{F e} / \mathbf{P}$ & 75,721 & 46,689 & 35,353 & 722,034 & 0,202 & 1,0579 \\
\hline $\mathrm{Fe} / \mathrm{K}$ & 8,523 & 55,569 & 4,736 & 16,662 & 0,424 & 0,6173 \\
\hline $\mathbf{F e} / \mathrm{Ca}$ & 10,710 & 47,991 & 5,140 & 16,056 & 0,217 & 0,8637 \\
\hline $\mathrm{Fe} / \mathrm{Mg}$ & 39,177 & 52,833 & 20,698 & 300,197 & 0,428 & 1,2505 \\
\hline $\mathrm{Fe} / \mathrm{Mn}$ & 1,159 & 76,562 & 0,887 & 0,916 & 0,368 & 2,4745 \\
\hline $\mathrm{Fe} / \mathrm{Zn}$ & 6,237 & 88,153 & 5,498 & 32,641 & 0,307 & 0,8533 \\
\hline $\mathrm{Fe} / \mathrm{Cu}$ & 15,974 & 48,922 & 7,815 & 38,337 & 0,185 & 1,1918 \\
\hline $\mathbf{F e} / \mathrm{B}$ & 3,482 & 52,544 & 1,829 & 2,329 & 0,407 & 0,6311 \\
\hline $\mathbf{M n} / \mathbf{N}$ & 5,267 & 60,253 & 3,174 & 5,651 & 0,027 & 1,6258 \\
\hline $\mathbf{M n} / \mathbf{P}$ & 74,780 & 60,267 & 45,068 & 1140,711 & $-0,148$ & 1,5744 \\
\hline $\mathbf{M n} / \mathbf{K}$ & 8,818 & 62,311 & 5,495 & 19,300 & 0,213 & 0,8767 \\
\hline Mn/Ca & 10,758 & 62,441 & 6,718 & 29,060 & $-0,027$ & 1,4945 \\
\hline $\mathbf{M n} / \mathbf{M g}$ & 37,512 & 61,485 & 23,064 & 323,859 & 0,122 & 1,0751 \\
\hline $\mathbf{M n} / \mathbf{F e}$ & 1,213 & 64,159 & 0,778 & 0,478 & $-0,282$ & 1,5853 \\
\hline $\mathbf{M n} / \mathbf{Z n}$ & 7,972 & 61,872 & 4,932 & 20,348 & 0,131 & 0,8951 \\
\hline $\mathbf{M n} / \mathbf{C u}$ & 15,424 & 63,616 & 9,812 & 65,943 & $-0,038$ & 1,5641 \\
\hline $\mathbf{M n} / \mathbf{B}$ & 3,538 & 62,338 & 2,205 & 3,113 & $\mathbf{0 , 1 2 5}$ & 0,9330 \\
\hline $\mathrm{Zn} / \mathbf{N}$ & 1,562 & 77,144 & 1,205 & 1,324 & $-0,234$ & 0,6238 \\
\hline $\mathrm{Zn} / \mathbf{P}$ & 23,115 & 83,150 & 19,220 & 359,175 & $-0,233$ & 0,9384 \\
\hline $\mathrm{Zn} / \mathrm{K}$ & 2,305 & 69,738 & 1,607 & 2,107 & $-0,133$ & 0,7955 \\
\hline Zn/Ca & 3,388 & 83,332 & 2,824 & 7,764 & $-0,236$ & 0,6820 \\
\hline $\mathrm{Zn} / \mathbf{M g}$ & 11,465 & 83,806 & 9,609 & 90,298 & $-0,196$ & 0,7725 \\
\hline $\mathrm{Zn} / \mathrm{Fe}$ & 0,338 & 85,554 & 0,289 & 0,088 & $-0,309$ & 0,6117 \\
\hline $\mathbf{Z n} / \mathbf{M n}$ & 0,165 & 59,906 & 0,099 & 0,007 & $-0,084$ & 2,7354 \\
\hline $\mathrm{Zn} / \mathbf{C u}$ & 5,195 & 87,429 & 4,542 & 20,785 & $-0,261$ & 0,5214 \\
\hline $\mathrm{Zn} / \mathbf{B}$ & 0,974 & 75,639 & 0,737 & 0,486 & $-0,169$ & 0,5270 \\
\hline
\end{tabular}


Tabela 11. Normas DRIS (média, coeficiente de variação e desvio padrão) e variância para as relações entre nutrientes dois a dois, coeficiente de correlação $(\mathrm{R})$ entre a razão de cada par de nutrientes e a produtividade de frutos de macieira (Nick, 1998) e razão entre variâncias das populações de alta e baixa produtividade (Letzsch, 1985 e Walworth et al., 1986), considerando a população de referência

\begin{tabular}{lrccrrc}
\hline Relação & Média & $\mathbf{C V}(\mathbf{\%})$ & Desvio Padrão & Variância & $\mathbf{R}$ & $\mathbf{s}^{2}{ }_{\text {baixa }} / \mathbf{s}^{2}{ }_{\text {alta }}$ \\
\hline $\mathbf{C u} / \mathbf{N}$ & 0,356 & 36,002 & 0,128 & 0,016 & $-0,035$ & $\mathbf{0 , 9 3 5 9}$ \\
$\mathbf{C u} / \mathbf{P}$ & 5,297 & 49,297 & 2,612 & 6,820 & $\mathbf{- 0 , 1 7 4}$ & 0,7507 \\
$\mathbf{C u} / \mathbf{K}$ & 0,566 & 38,192 & 0,216 & 0,047 & $\mathbf{0 , 2 7 3}$ & 0,9711 \\
$\mathbf{C u} / \mathbf{C a}$ & 0,731 & 38,891 & 0,284 & 0,081 & $\mathbf{- 0 , 1 1 0}$ & $\mathbf{0 , 7 6 9 2}$ \\
$\mathbf{C u} / \mathbf{M g}$ & 2,726 & 44,088 & 1,202 & 1,444 & 0,083 & $\mathbf{0 , 5 8 9 0}$ \\
$\mathbf{C u} / \mathbf{F e}$ & 0,078 & 72,925 & 0,057 & 0,003 & $\mathbf{- 0 , 2 6 0}$ & 0,9119 \\
$\mathbf{C u} / \mathbf{M n}$ & 0,094 & 73,679 & 0,069 & 0,005 & $-0,041$ & 1,3442 \\
$\mathbf{C u} / \mathbf{Z n}$ & 0,405 & 90,714 & 0,368 & 0,139 & 0,191 & $\mathbf{0 , 6 0 4 1}$ \\
$\mathbf{C u} / \mathbf{B}$ & 0,233 & 35,140 & 0,082 & 0,007 & 0,176 & 1,0612 \\
$\mathbf{B} / \mathbf{N}$ & 1,576 & 19,320 & 0,305 & 0,093 & $\mathbf{- 0 , 3 9 9}$ & $\mathbf{1 , 6 9 8 7}$ \\
$\mathbf{B} / \mathbf{P}$ & 23,382 & 30,053 & 7,027 & 49,377 & $\mathbf{- 0 , 4 4 1}$ & $\mathbf{2 , 0 7 7 2}$ \\
$\mathbf{B} / \mathbf{K}$ & 2,465 & 24,862 & 0,613 & 0,375 & 0,081 & 0,4650 \\
$\mathbf{B} / \mathbf{C a}$ & 3,254 & 27,898 & 0,908 & 0,824 & $\mathbf{- 0 , 3 7 6}$ & $\mathbf{1 , 0 8 2 2}$ \\
$\mathbf{B} / \mathbf{M g}$ & 1,905 & 32,160 & 3,829 & 14,658 & $\mathbf{- 0 , 0 8 1}$ & $\mathbf{3 , 0 5 0 6}$ \\
$\mathbf{B} / \mathbf{F e}$ & 0,356 & 56,917 & 0,203 & 0,031 & $\mathbf{- 0 , 4 3 6}$ & $\mathbf{0 , 8 2 6 0}$ \\
$\mathbf{B} / \mathbf{M n}$ & 0,383 & 69,669 & 0,267 & 0,061 & 0,007 & $\mathbf{3 , 5 7 6 8}$ \\
$\mathbf{B} / \mathbf{Z n}$ & 1,720 & 77,158 & 1,327 & 1,607 & 0,132 & $\mathbf{0 , 6 6 0 6}$ \\
$\mathbf{B} / \mathbf{C u}$ & 4,880 & 38,060 & 1,857 & 3,450 & $\mathbf{- 0 , 3 1 2}$ & $\mathbf{1 , 3 9 5 0}$ \\
\hline
\end{tabular}

${ }^{*}$ Os valores em negrito correspondem as relações entre nutrientes selecionadas.

\subsection{Avaliação dos métodos de cálculo do DRIS}

Tendo-se definido as Normas DRIS, procurou-se estabelecer o procedimento padrão para o cálculo dos Índices DRIS, utilizando os dois critérios para a escolha da ordem da razão dos nutrientes: "valor R" proposto por Nick (1998) e "valor F" descrito por Letzsch (1985) e Walworth et al. (1986), e os três métodos mais comumente utilizados em trabalho científicos sobre DRIS: o proposto por Beaufils (1973), o proposto por Jones (1981) e o proposto por Elwali \& Gascho (1984). A equação original de Beaufils (1973) gera índices DRIS realçando os nutrientes que se apresentam mais deficientes, a equação de Jones (1981) se caracteriza por envolver cálculos mais 
simples, enquanto que a equação de Elwali \& Gascho (1984) consiste em uma modificação do método proposto por Beaufils (1973), em que se utiliza um limite de tolerância para considerar dois nutrientes balanceados.

As relações entre os índices DRIS obtidos pelos métodos Beaufils (1973), Jones (1981) e Elwali \& Gascho (1984) para combinações de critérios de escolha da ordem das razões entre nutrientes ("valor R" e "valor F") e as concentrações de nutrientes nas folhas de macieira são apresentadas nas Figuras 6 a 11. Verificam-se correlações positivas e significativas $(p<0,01)$ entre as concentrações dos nutrientes e os respectivos índices DRIS, com exceção do N. Baixa relação entre o índice DRIS para N e a concentração de $\mathrm{N}$ também tem sido constatada para outras culturas perenes, como cereja e avelã (Righetti et al., 1988), citros (Salvo, 2001) e cafeeiro (Reis Júnior et al., 2002). Estes resultados indicam que para o N, o índice DRIS é fortemente dependente da concentração dos demais nutrientes nas folhas, enquanto que para os demais nutrientes os índices DRIS são dependentes das suas próprias concentrações.

Considerando que a planta apresenta equilíbrio nutricional, para um dado nutriente, quando os valores dos índices, definidos pelo método DRIS, estiverem mais próximos de zero (Walworth \& Summer, 1987), buscou-se estabelecer graficamente a concentração do nutriente na folha equivalente a este ponto de equilíbrio nutricional, utilizando a equação de ajuste dos dados. Observou-se que o ponto de equilíbrio nutricional, definido pelo método DRIS, apresenta coincidência com a concentração considerada normal pelo critério de faixa de suficiência (Basso et al, 1986), com exceção do N, K e Mn, onde o método DRIS indicou concentrações equivalente ao equilíbrio nutricional superiores às concentrações consideradas normais para a cultura (Tabela 12). Por outro lado, o ponto de equilíbrio nutricional obtido pelos métodos DRIS para cada nutriente foi superior ao nível crítico para a cultura (concentração que define o limite inferior da faixa normal (Basso et al., 1986)).

O critério para a escolha da ordem da razão dos nutrientes "valor R", proposto por Nick (1998), apresentou melhores ajustes entre os índices DRIS e as concentrações dos nutrientes para os métodos Beaufils (1973) e Elwali \& Gascho (1984), enquanto que o critério "valor F", descrito por Letzsch (1985) e Walworth et al. (1986), apresentou 
melhor ajuste entre os índices DRIS e as concentrações dos nutrientes para o método Jones (1981). Verifica-se que entre os métodos estudados, o proposto por Jones (1981) foi o mais sensível ao tipo de razão entre nutrientes utilizada, resultado também observado por Bataglia \& Santos (1990).

Comparando as combinações de critérios de escolha das razões entre nutrientes (valor R e F) e de métodos de cálculo dos índices DRIS, observou-se que os melhores ajustes entre os índices DRIS e as concentrações dos nutrientes foram obtidos com o método Jones (1981), utilizando o "valor F" como critério de escolha da ordem das razões, enquanto que os menores ajustes foram obtidos com o método Elwali \& Gascho (1984), utilizando o "valor F" como critério de escolha da ordem das razões.

Baseado nas relações obtidas entre os índices DRIS e as concentrações dos nutrientes como critério de seleção do método DRIS para a cultura da macieira, o método Jones (1981), utilizando o "valor F" como critério de escolha da ordem das razões, seria o melhor modelo. Contudo, a relação entre os índices DRIS e as concentrações de nutrientes nas folhas não é o melhor critério para a seleção do método DRIS, além disto, deve-se considerar que o baixo ajuste obtido pelo método Elwali \& Gascho (1984), provavelmente esteja relacionado ao fato de que o método utiliza um limite de tolerância para considerar dois nutrientes balanceados. Assim, o passo seguinte foi utilizar outro critério para selecionar o melhor método DRIS para a cultura. 

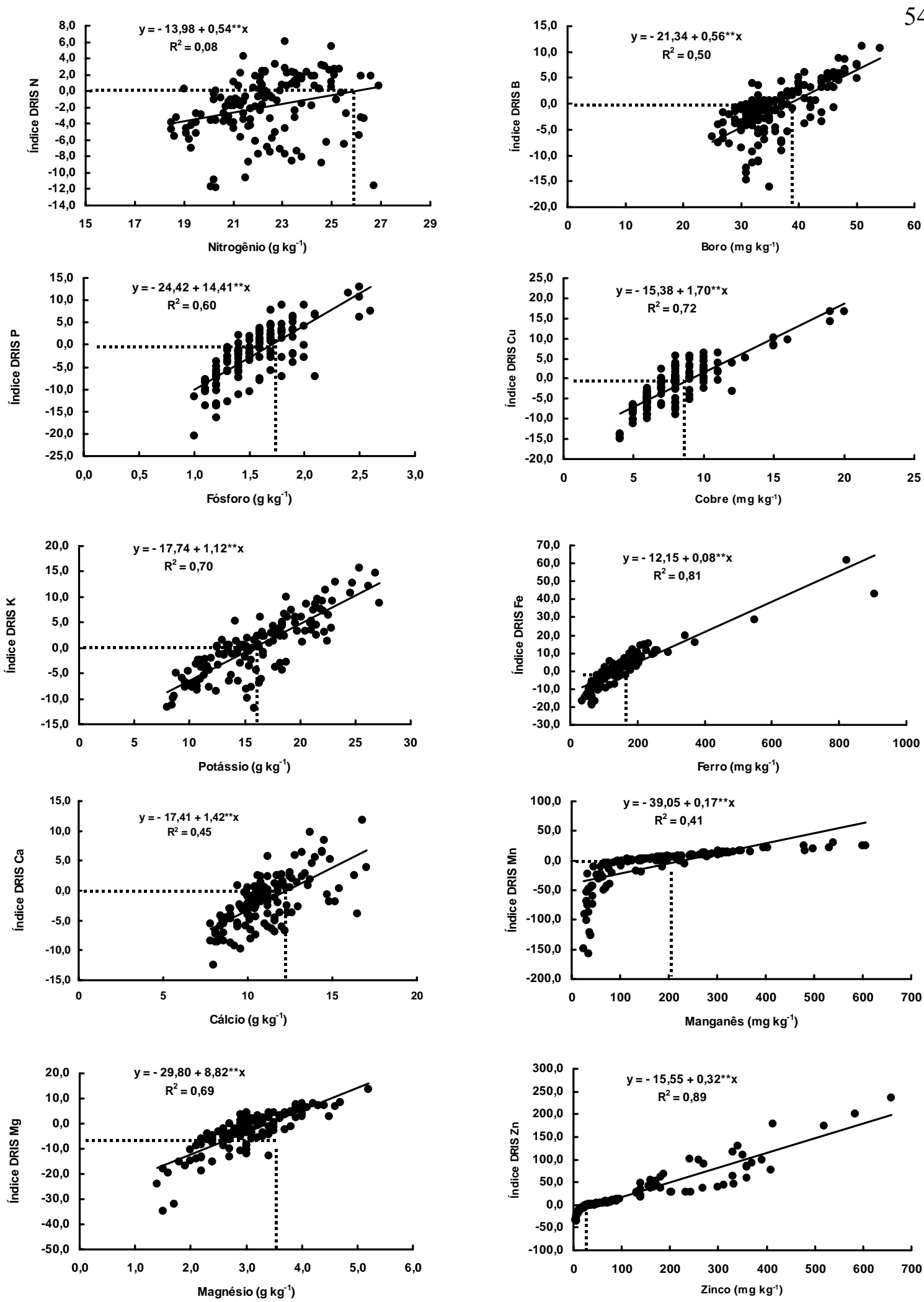

Figura 6 - Relação entre os Índices DRIS obtidos pelo método Beaufils (1973) e a concentração de macronutrientes nas folhas, considerando o "valor R" para a escolha da ordem da razão dos nutrientes, para a população avaliada 

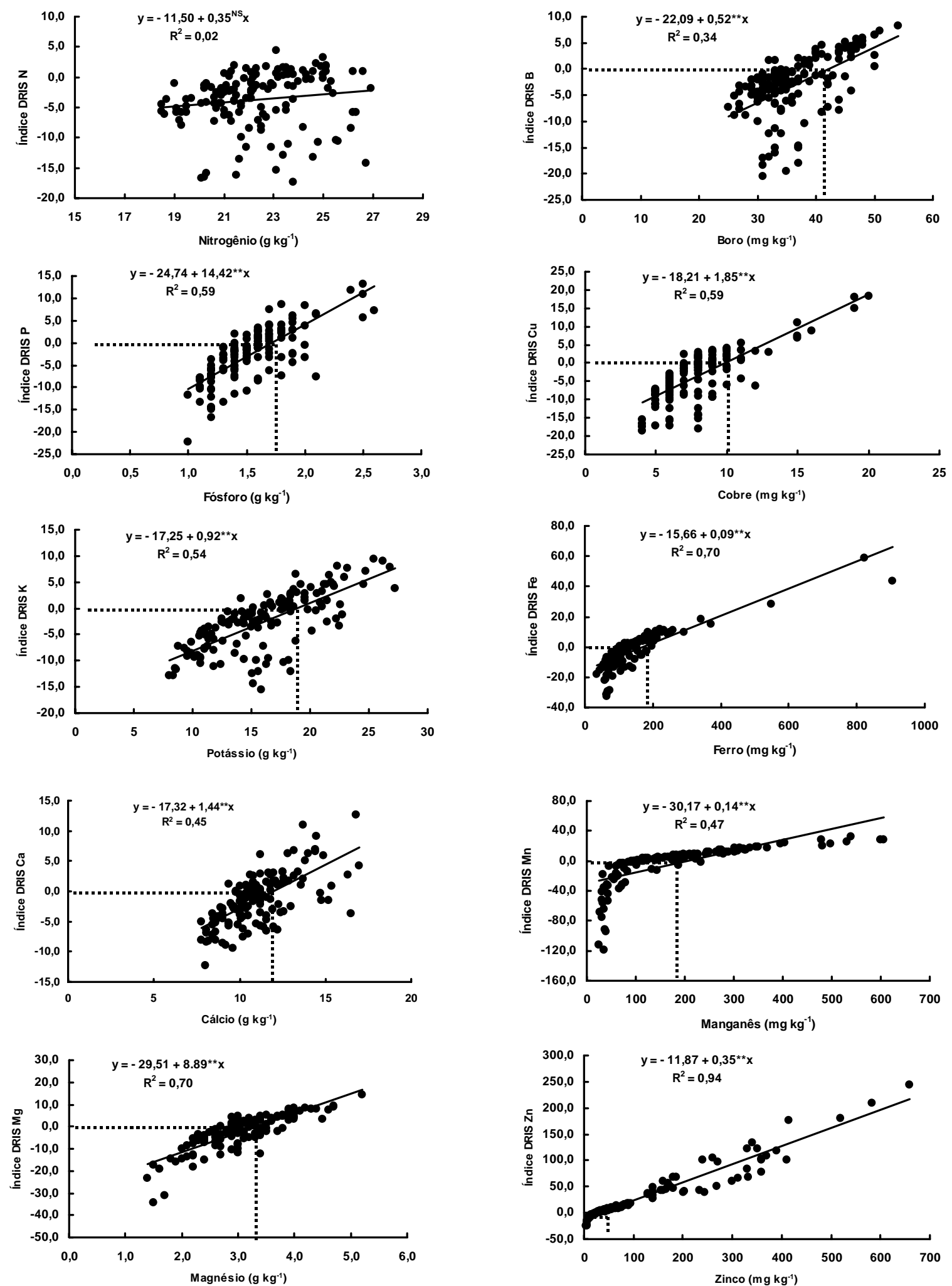

Figura 7 - Relação entre os Índices DRIS obtidos pelo método Beaufils (1973) e a concentração de macronutrientes nas folhas, considerando o "valor F" para a escolha da ordem da razão dos nutrientes, para a população avaliada 

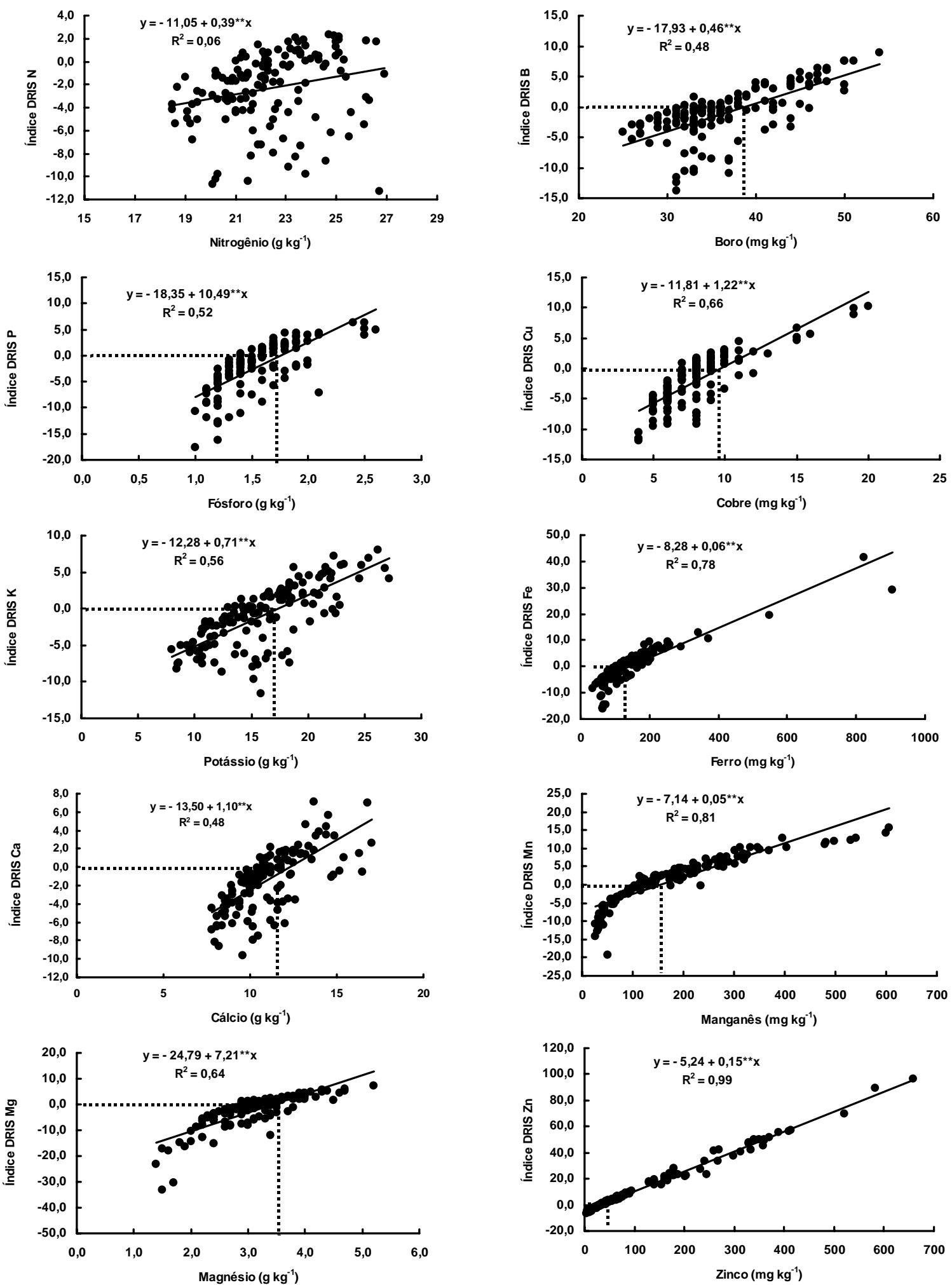

Figura 8 - Relação entre os Índices DRIS obtidos pelo método Jones (1981) e a concentração de macronutrientes nas folhas, considerando o "valor R" para a escolha da ordem da razão dos nutrientes, para a população avaliada 

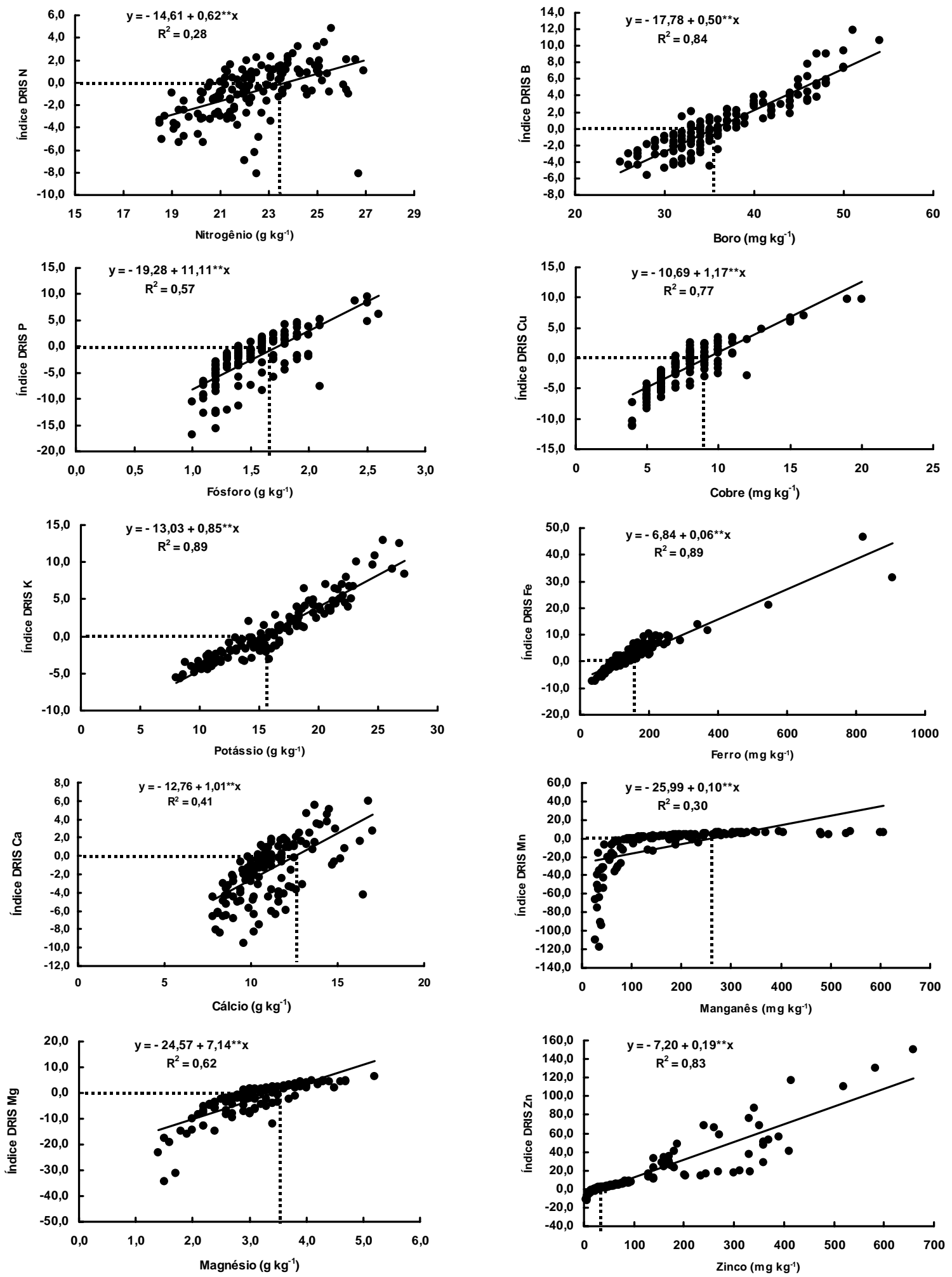

Figura 9 - Relação entre os Índices DRIS obtidos pelo método Jones (1981) e a concentração de macronutrientes nas folhas, considerando o "valor F" para a escolha da ordem da razão dos nutrientes, para a população avaliada 

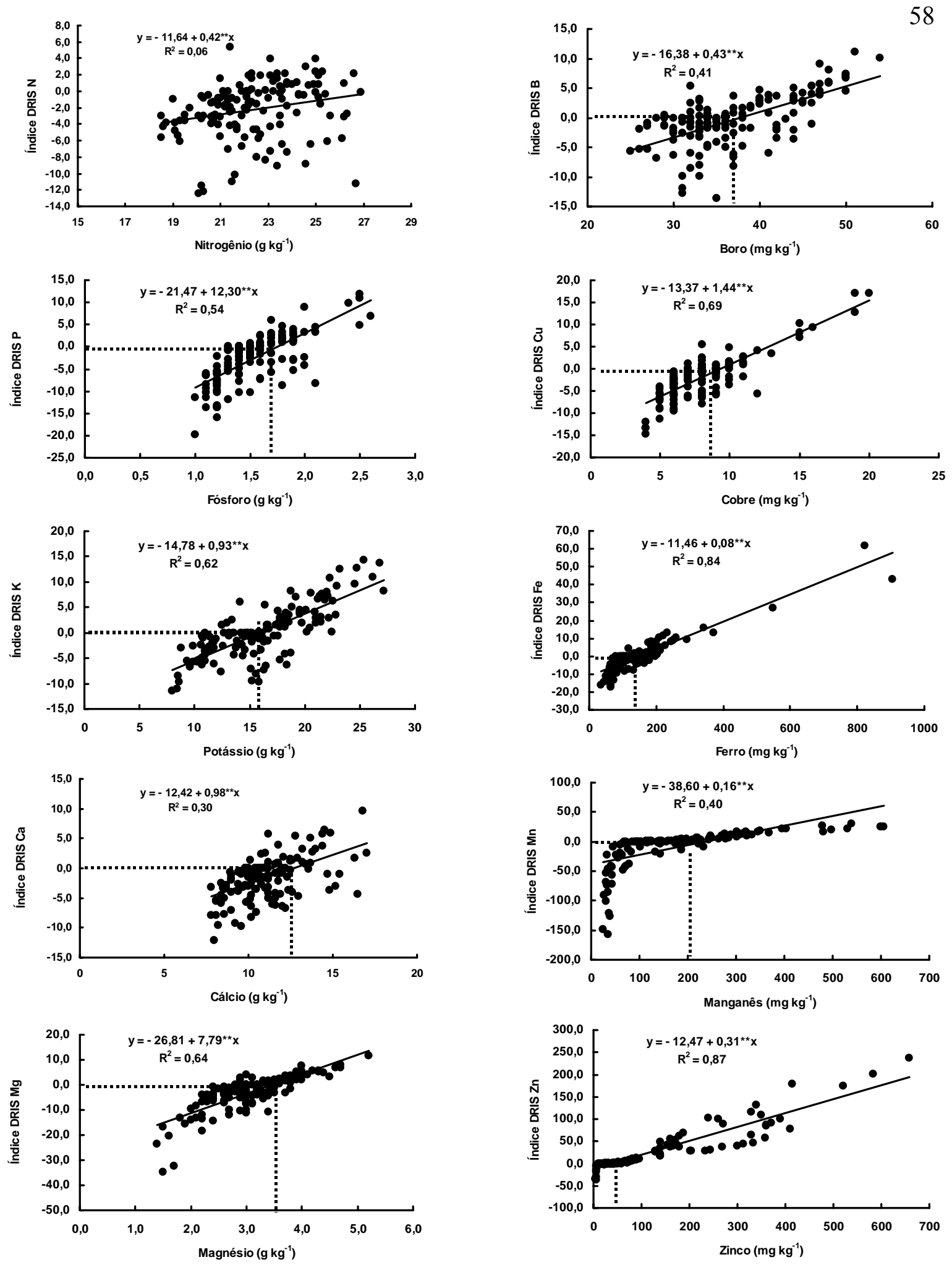

Figura 10 - Relação entre os Índices DRIS obtidos pelo método Elwali \& Gascho (1984) e a concentração de macronutrientes nas folhas, considerando o "valor R" para a escolha da ordem da razão dos nutrientes, para a população avaliada 

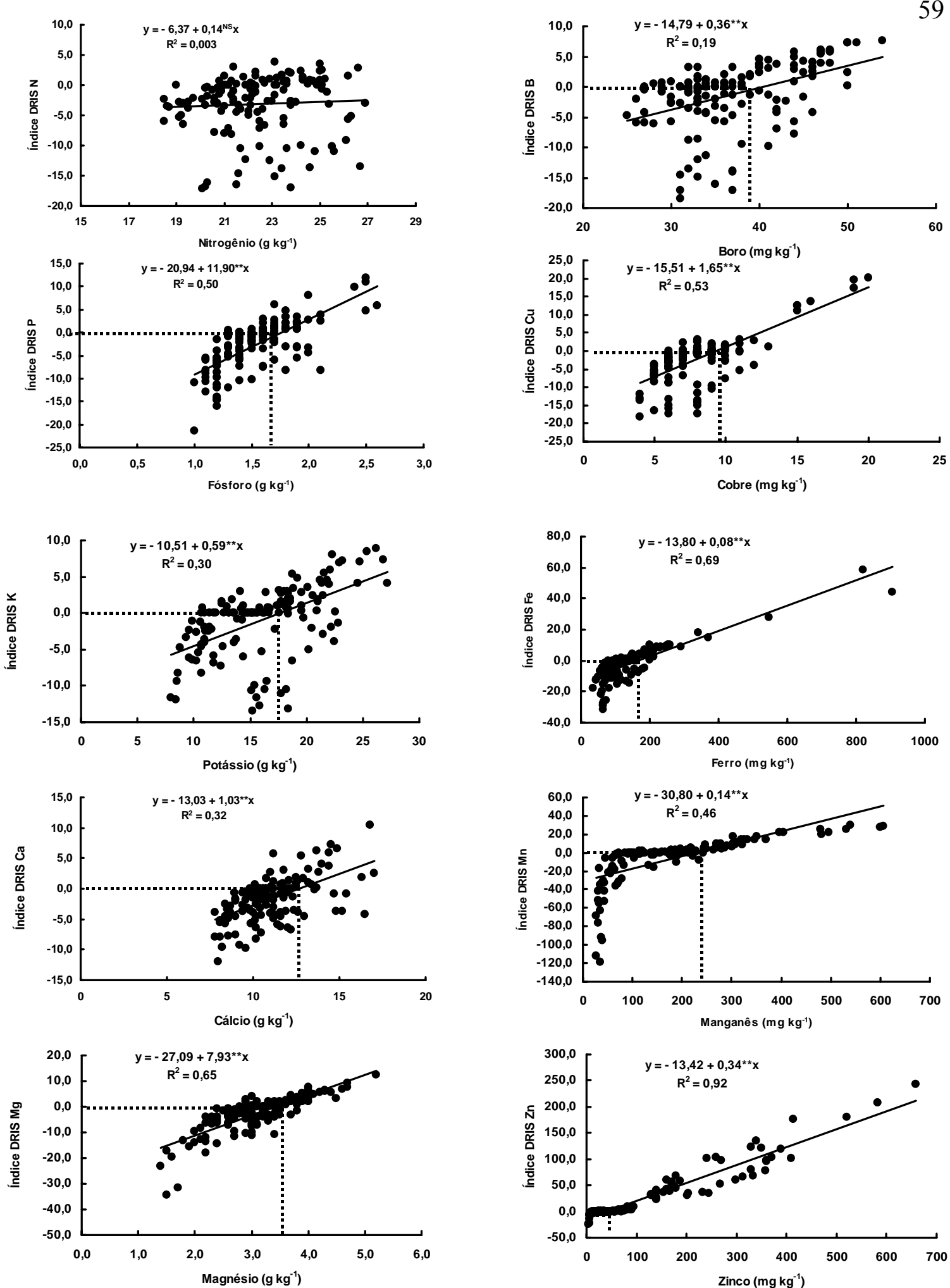

Figura 11 - Relação entre os Índices DRIS obtidos pelo método Elwali \& Gascho (1984) e a concentração de macronutrientes nas folhas, considerando o "valor F" para a escolha da ordem da razão dos nutrientes, para a população avaliada 
Tabela 12. Nível crítico considerando o critério de faixa de suficiência (Basso et al., 1986) e obtido para combinações de métodos de escolha da ordem das razões entre nutrientes (valor R - Nick (1998) e valor F - Letzsch (1985) e Walworth et al. (1986)) e índices DRIS (métodos Beaufils (1973), Jones (1981) e Elwali \& Gascho (1984)) para a população avaliada

\begin{tabular}{|c|c|c|c|c|c|c|c|}
\hline \multirow[t]{2}{*}{ Nutriente } & \multirow{2}{*}{$\begin{array}{c}\text { Critério } \\
\text { de } \\
\text { Faixa } \\
\end{array}$} & \multicolumn{2}{|c|}{ Beaufils (1973) } & \multicolumn{2}{|c|}{ Jones(1981) } & \multicolumn{2}{|c|}{$\begin{array}{c}\text { Elwali \& Gascho } \\
(1984)\end{array}$} \\
\hline & & $\mathbf{R}$ & $\mathbf{F}$ & $\mathbf{R}$ & $\mathbf{F}$ & $\mathbf{R}$ & $\mathbf{F}$ \\
\hline$\left(\mathrm{g} \mathrm{kg}^{-1}\right)$ & 20,0 & 25,9 & 32,9 & 28,3 & 23,6 & 27,7 & 45,5 \\
\hline$P \quad\left(g^{~ k g}\right)$ & 1,5 & 1,7 & 1,7 & 1,7 & 1,7 & 1,7 & 1,7 \\
\hline $\mathrm{K} \quad\left(\mathrm{g} \mathrm{kg}^{-1}\right)$ & 12,0 & 15,8 & 18,7 & 17,3 & 15,3 & 15,9 & 17,8 \\
\hline Ca $\left.\quad\left(g_{k g}\right)^{-1}\right)$ & 11,0 & 12,3 & 12,0 & 12,3 & 12,6 & 12,7 & 12,6 \\
\hline $\operatorname{Mg}\left(\mathrm{g} \mathrm{kg}^{-1}\right)$ & 2,5 & 3,4 & 3,3 & 3,4 & 3,4 & 3,4 & 3,4 \\
\hline Fe $\left(\mathrm{mg} \mathrm{kg}^{-1}\right)$ & 50 & 152 & 174 & 138 & 114 & 143 & 172 \\
\hline $\operatorname{Mn}\left(\mathrm{mg} \mathrm{kg}^{-1}\right)$ & 30 & 230 & 215 & 143 & 260 & 241 & 220 \\
\hline Zn (mg kg $\left.{ }^{-1}\right)$ & 20 & 48 & 34 & 35 & 38 & 40 & 39 \\
\hline $\mathrm{Cu}\left(\mathrm{mg} \mathrm{kg}^{-1}\right)$ & 5 & 9 & 10 & 10 & 9 & 9 & 9 \\
\hline B $\left(\mathrm{mg} \mathrm{kg}^{-1}\right)$ & 41 & 38 & 42 & 39 & 35 & 38 & 41 \\
\hline
\end{tabular}

Entre os critérios para a escolha do melhor procedimento de cálculo dos índices DRIS, o coeficiente de correlação entre o Índice de Balanço Nutricional (IBN) e a produtividade é bastante utilizado (Santos, 1997; Mourão Filho \& Azevedo, 2003). Assim, para avaliar o melhor método, a partir dos índices DRIS foi calculado o Índice de Balanço Nutricional (IBN) para a população de referência e a população de baixa produtividade, uma vez que se espera melhores correlações entre o valor do IBN e a produtividade para altos níveis produtivos do que para a população geral (Beaufils, 1973). Deste modo, é esperada uma correlação negativa, pois quanto maior o valor do IBN, maior é o desequilíbrio nutricional e menor a produtividade.

As relações entre os valores de IBN e a produtividade para a população de referência são apresentadas na Figura 12, enquanto que as relações para a população de baixa produtividade são apresentadas na Figura 13. Pode-se observar que os coeficientes 
de correlação obtidos para a população de referência foram significativos, enquanto que para a população de baixa produtividade não foi observada relação significativa.

Comparando as combinações de critérios de escolha das razões entre nutrientes ("valor R" e "valor F") e de métodos de cálculo dos índices DRIS, observouse que os melhores ajustes entre os valores de IBN e a produtividade para a população de referência foram obtidos pelos métodos Jones (1981), utilizando o "valor F" e Elwali \& Gascho (1984), utilizando o "valor F" e o "valor R". Em estudos de comparação de métodos DRIS, Santos (1997), trabalhando com citros no Estado de São Paulo, verificou superioridade do método Jones (1981) sobre os demais, resultados também observados por Nick (1998) para o cafeeiro e por Mourão Filho et al. (2002) para a laranjeira 'Valência'. Para o critério da escolha da ordem das razões entre os nutrientes, Nick (1998) e Mourão Filho et al. (2002) observaram que o critério do "valor R" foi superior ao "valor F". Para a cultura da macieira não existem estudos sobre a comparação de métodos e de critérios de escolha da razão de nutrientes. Singh et al. (2000) utilizaram, na avaliação do método DRIS em macieiras na Índia, o método proposto por Beaufils (1973) e o critério da maior razão entre variâncias entre a população de baixa e alta produtividade ("valor F").

Pelos resultados obtidos, tornou-se difícil a escolha do melhor procedimento entre os três que apresentaram melhor ajuste entre o IBN e a produtividade, assim, o próximo passo foi avaliar a eficiência destes três métodos, utilizando os resultados dos experimentos de adubação com doses de nitrogênio e potássio, bem como comparar o diagnóstico nutricional obtido por estes métodos com o critério de faixa de suficiência. 

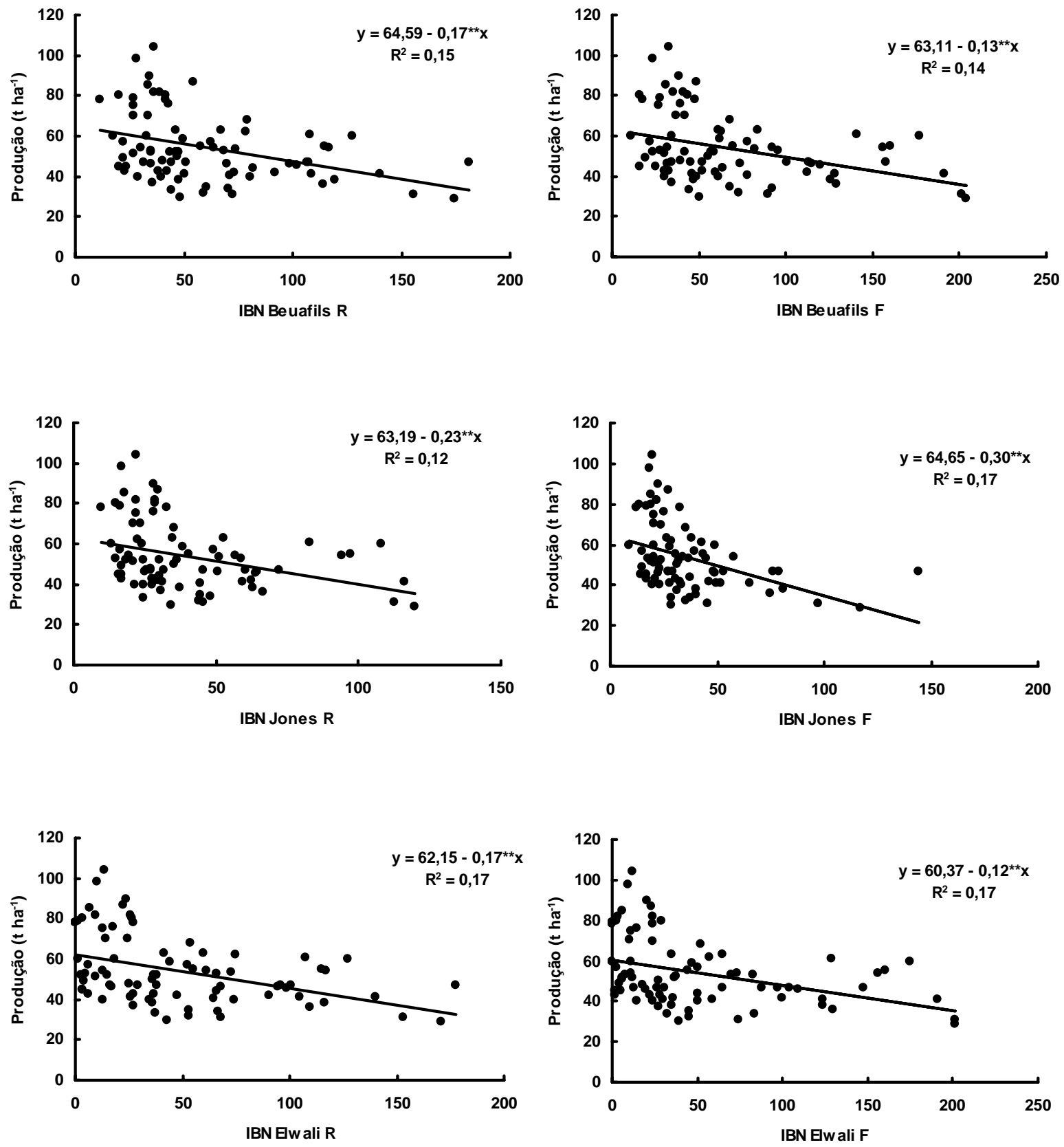

Figura 12 - Relação entre os valores de IBN e a produtividade $\left(\mathrm{t} \mathrm{ha}^{-1}\right)$ para combinações de métodos de escolha da ordem das razões entre nutrientes (valor R - Nick (1998) e valor F - Letzsch (1985) e Walworth et al. (1986)) e índices DRIS (métodos Beaufils (1973), Jones (1981) e Elwali \& Gascho (1984)) para a população de referência 

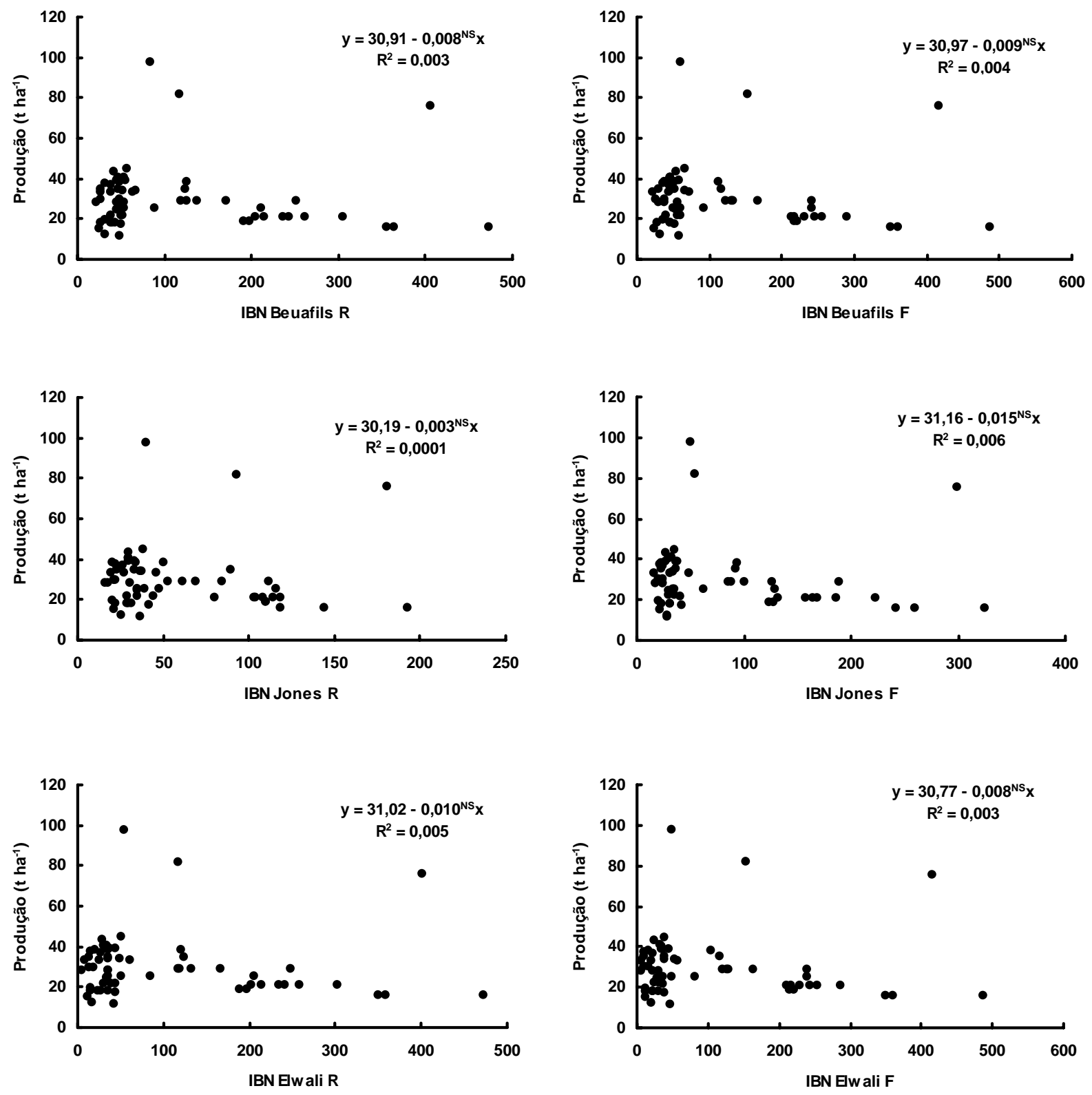

Figura 13 - Relação entre os valores de IBN e a produtividade $\left(\mathrm{t} \mathrm{ha}^{-1}\right)$ para combinações de métodos de escolha da ordem das razões entre nutrientes (valor R - Nick (1998) e valor F - Letzsch (1985) e Walworth et al. (1986)) e índices DRIS (métodos Beaufils (1973), Jones (1981) e Elwali \& Gascho (1984)) para a população de baixa produtividade 


\subsection{Avaliação da eficiência dos métodos de cálculo do DRIS}

Para avaliar a eficiência do método DRIS em realizar o diagnóstico nutricional da cultura, utilizou-se de resultados coletados de dois experimentos de campo de longa duração, conduzidos na Estação Experimental de Vacaria da Embrapa Uva e Vinho.

O primeiro experimento trata de níveis de adubação potássica em pré-plantio e em manutenção, instalado em um Latossolo Bruno alumínico câmbico, com teor inicial de potássio trocável no solo de $1,15 \mathrm{mmol}_{\mathrm{c}} \mathrm{dm}^{-3}$. O segundo experimento trata de fontes e níveis de adubação nitrogenada em manutenção, instalado no mesmo solo do experimento de adubação potássica, com teor inicial de matéria orgânica no solo de $51 \mathrm{~g}$ $\mathrm{dm}^{-3}$. Foram determinados, para as safras de 1995 a 2000, os Índices DRIS para cada nutriente e o IBN para os dois experimentos, considerando os resultados médios de cada tratamento, utilizando os métodos Beaufils (1973), Jones (1981) e Elwali \& Gascho (1984) e as combinações de critérios de escolha das razões entre nutrientes (“valor R" e "valor F").

Para o experimento de adubação potássica, as relações entre as concentrações de $\mathrm{K}$ nas folhas de macieira cv. Gala e os índices DRIS K, em função das doses de adubo potássico, são apresentadas na Figura 14. Verificam-se correlações positivas e significativas $(\mathrm{p}<0,01)$, seguindo o modelo quadrático, entre as concentrações de $\mathrm{K}$ e os índices DRIS K. Observou-se que o ponto de equilíbrio nutricional, definido pelo método DRIS, apresenta coincidência com a concentração de K considerada normal pelo critério de faixa de suficiência (Basso et al, 1986), com exceção do método Beaufils (1973), utilizando o "valor F" como critério de escolha da ordem da razão dos nutrientes, que indicou concentrações equivalente ao equilíbrio nutricional superiores à concentração considerada normal para a cultura.

Na Figura 15 são apresentadas as relações entre a produção relativa de frutos de macieira cv. Gala e os índices DRIS K e entre a produção relativa de frutos e a concentração de $\mathrm{K}$ nas folhas, em função das doses de adubo potássico. Observou-se correlações positivas e significativas $(\mathrm{p}<0,01)$, seguindo o modelo quadrático, entre estas 
variáveis, para todos os métodos e critérios utilizados. Verifica-se que a maior produtividade foi obtida quando as concentrações de $\mathrm{K}$ nas folhas estiveram entre dentro da faixa considerada normal para a cultura e que os desequilíbrios nutricionais indicados pelo índice DRIS estão relacionados a redução de produtividade. Estes resultados indicaram que quanto mais próximo de zero o índice DRIS para $K$, maior foi a produtividade da cultura da macieira. A concentração de $\mathrm{K}$ nas folhas também apresentou correlações positivas e significativas $(p<0,01)$ com a produção relativa, seguindo o modelo quadrático.

A relação entre a produção relativa de frutos de macieira cv. Gala e o Índice de Balanço Nutricional (IBN), em função das doses de adubo potássico, é apresentada na Figura 16. O IBN apresentou comportamento próximo do modelo teórico, com ajuste seguindo o modelo quadrático e relação inversa à produção de frutos. As correlações foram significativas $(\mathrm{p}<0,01)$, o que indica que os métodos DRIS foram eficientes na avaliação do estado nutricional da cultura, com exceção para o método Jones (1981), utilizando o "valor F". As maiores produtividades estiveram relacionadas com os menores valores de IBN. 

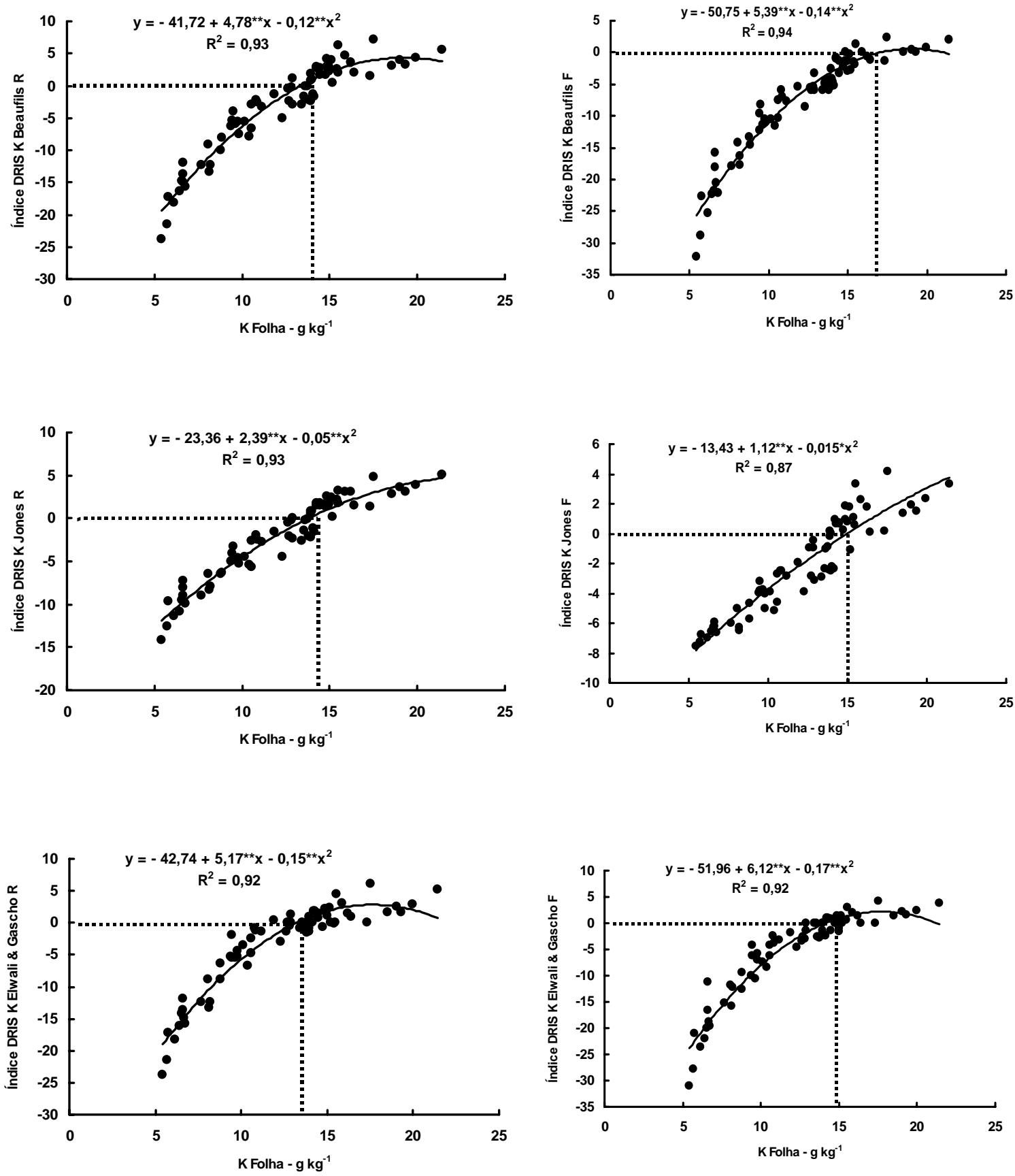

Figura 14 - Relação entre a concentração de K nas folhas de macieira cv. Gala e os índices DRIS K para combinações de métodos de escolha da ordem das razões entre nutrientes (valor R - Nick (1998) e valor F - Letzsch (1985) e Walworth et al. (1986)) e índices DRIS (métodos Beaufils (1973), Jones (1981) e Elwali \& Gascho (1984)), em função de doses de adubo potássico. (Resultados de seis anos) 

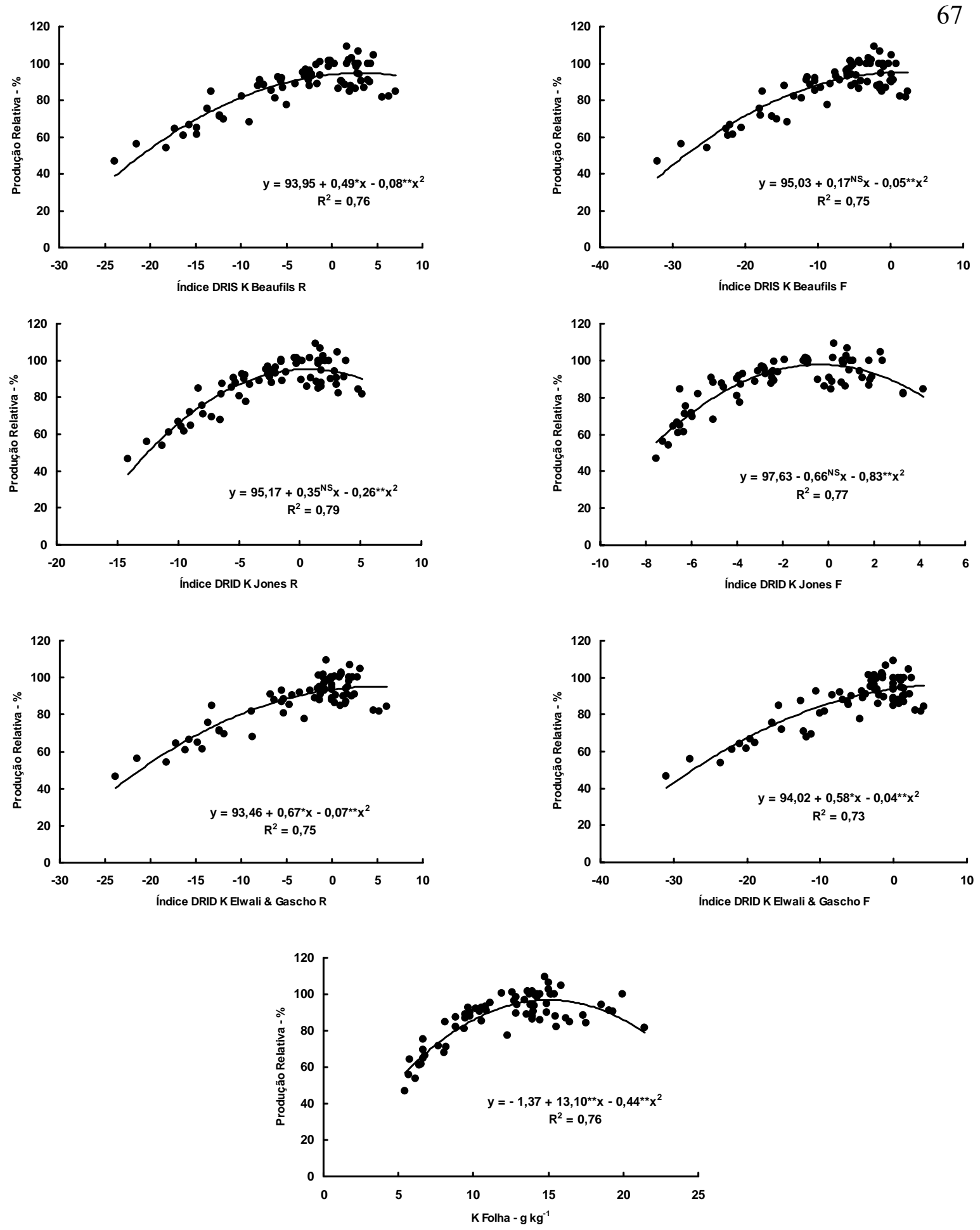

Figura 15 - Relação entre a produção relativa de frutos de macieira cv. Gala e os índices DRIS K para combinações de métodos de escolha da ordem das razões entre nutrientes (valor R - Nick (1998) e valor F - Letzsch (1985) e Walworth et al. (1986)) e índices DRIS (métodos Beaufils (1973), Jones (1981) e Elwali \& Gascho (1984)) e a concentração de K nas folhas (e), em função de doses de adubo potássico. (Resultados de seis anos) 

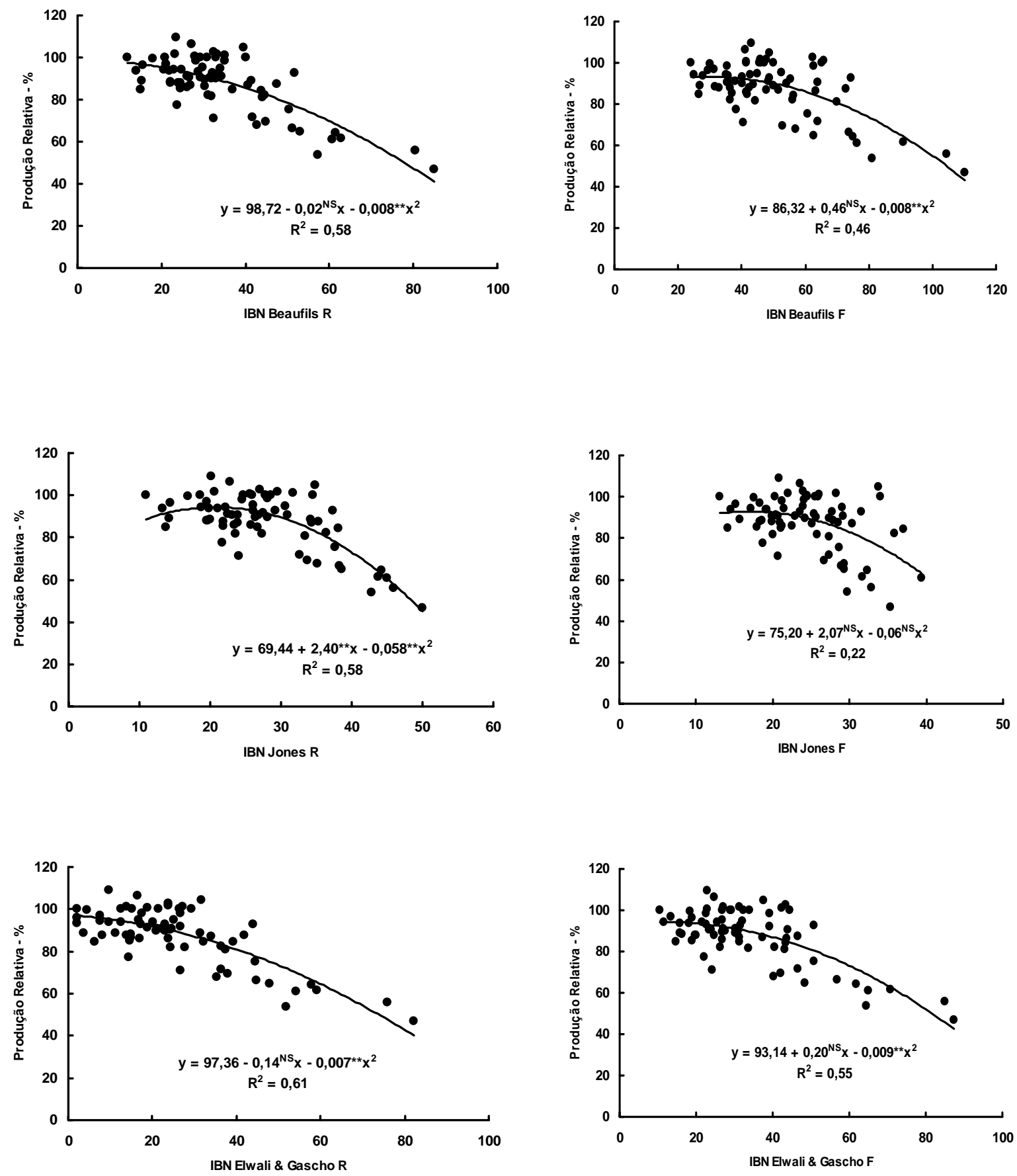

Figura 16 - Relação entre a produção relativa de frutos de macieira cv. Gala e os Índices de Balanço Nutricional (IBN) para combinações de métodos de escolha da ordem das razões entre nutrientes (valor R - Nick (1998) e valor F - Letzsch (1985) e Walworth et al. (1986)) e índices DRIS (métodos Beaufils (1973), Jones (1981) e Elwali \& Gascho (1984)), em função de doses de adubo potássico. (Resultados de seis anos) 
Para a definição do melhor método, optou-se por verificar a percentagem de concordância entre os métodos DRIS e o critério de faixas de suficiência quanto ao diagnóstico nutricional, considerando todos os nutrientes avaliados no experimento de adubação potássica. Para isto, verificou-se o número de amostras com concentrações deficientes (abaixo do normal), normais e em excesso (acima do normal) para o critério de faixas de suficiência e o número de amostras com índices DRIS deficientes (índice DRIS do nutriente menor que zero e índice DRIS, em módulo, superior ao IBNm), normais (índice DRIS, em módulo, menor ou igual ao IBNm) e em excesso (índice DRIS do nutriente maior que zero e índice DRIS, em módulo, superior ao IBNm) para os métodos DRIS. Bataglia et al. (2001) também utilizou a porcentagem correta de diagnose pelo DRIS em relação ao critério de faixa de suficiência, como forma de selecionar a população de referência de cafeeiro.

Verifica-se que para o diagnóstico referente ao $\mathrm{K}$, elemento que apresentou a maior variação entre os resultados obtidos devido às doses do nutriente aplicadas ao solo, a percentagem de concordância no diagnóstico nutricional variou entre $62 \%$ e $78 \%$ entre os modelos avaliados (Tabela 13). Quando foram considerados todos os nutrientes, o maior número de concordância foi observado quando utilizou-se o método Elwali \& Gascho (1984), utilizando o critério "valor F". Além disso, observou-se que os outros métodos apresentaram concordância baixa com critério de faixa de suficiência para $\mathrm{P}$, $\mathrm{Ca}$ e $\mathrm{Zn}$.

Comparando os resultados das Tabelas 14 e 15, verifica-se que, mesmo para o método DRIS que apresentou maior porcentagem de dignóstico semelhante ao critério de faixas de suficiência, houve diferenças no diagnóstico, já que para $\mathrm{P}$ e $\mathrm{Ca}$, o critério de faixas de suficiência identificou maior número de amostras deficientes do que os métodos Beuafils (1973) e Jones (1981), enquanto que para Zn estes métodos identificaram maior número de amostras com excesso do que o critério de faixas de suficiência. 
Tabela 13. Porcentagem de concordância no diagnóstico nutricional da macieira (deficiência, normal e excesso) entre o critério de faixas de suficiência e os métodos DRIS para combinações de critérios de escolha da ordem das razões entre nutrientes (valor R - Nick (1998) e valor F - Letzsch (1985) e Walworth et al. (1986)) e índices DRIS (métodos Beaufils (1973), Jones (1981) e Elwali \& Gascho (1984)), em função de doses de adubo potássico. (Resultados de seis anos)

\begin{tabular}{|c|c|c|c|c|c|c|}
\hline \multirow{2}{*}{ Nutriente } & \multicolumn{2}{|c|}{ Beaufils (1973) } & \multicolumn{2}{|c|}{ Jones(1981) } & \multicolumn{2}{|c|}{ Elwali \& Gascho (1984) } \\
\hline & $\mathbf{R}$ & $\mathbf{F}$ & $\mathbf{R}$ & $\mathbf{F}$ & $\mathbf{R}$ & $\mathbf{F}$ \\
\hline & & & & & & -------- \\
\hline $\mathbf{N}$ & 62,50 & 70,83 & 55,56 & 68,06 & 50,00 & 73,61 \\
\hline $\mathbf{P}$ & 43,06 & 68,06 & 51,39 & 58,33 & 45,83 & 81,94 \\
\hline $\mathbf{K}$ & 77,78 & 65,28 & 75,00 & 62,50 & 73,61 & 70,83 \\
\hline Ca & 43,06 & 59,72 & 47,22 & 50,00 & 37,50 & 70,83 \\
\hline Mg & 54,17 & 80,56 & 58,33 & 68,06 & 63,89 & 63,89 \\
\hline $\mathbf{F e}$ & 76,39 & 86,11 & 81,94 & 97,22 & 97,22 & 95,83 \\
\hline Mn & 100,00 & 100,00 & 100,00 & 100,00 & 100,00 & 100,00 \\
\hline Zn & 19,44 & 0,00 & 8,33 & 8,33 & 38,89 & 94,44 \\
\hline $\mathbf{C u}$ & 77,78 & 81,94 & 83,33 & 54,17 & 91,67 & 93,06 \\
\hline $\mathbf{B}$ & 83,33 & 87,50 & 83,33 & 84,72 & 80,56 & 81,94 \\
\hline Média & 63,75 & 70,00 & 64,44 & 65,14 & 67,92 & 82,64 \\
\hline
\end{tabular}


Tabela 14. Concentração de macro e micronutrientes em folhas de macieira em função da aplicação anual de doses de adubo potássico e o diagnóstico nutricional segundo o critério de faixas de suficiência. (Média de quatro repetições)

\begin{tabular}{|c|c|c|c|c|c|c|c|c|c|c|c|}
\hline \multirow{2}{*}{ Ano } & \multirow{2}{*}{ Trat. } & \multicolumn{10}{|c|}{ Análise Foliar } \\
\hline & & \multirow{2}{*}{\multicolumn{5}{|c|}{$\mathbf{r}-\mathrm{n}^{-1}$}} & $\mathbf{F e}$ & Mn & Zn & $\mathbf{C u}$ & B \\
\hline \multirow{13}{*}{1995} & & & & & & & \multicolumn{5}{|c|}{ - } \\
\hline & 1 & $26,4 \mathbf{E}$ & $1,5 \mathbf{N}$ & $13,4 \mathbf{N}$ & $10,3 \mathbf{D}$ & $2,7 \mathbf{N}$ & $140 \mathbf{N}$ & $328 \mathbf{E}$ & $61 \mathbf{N}$ & $10 \mathbf{N}$ & $38 \mathbf{N}$ \\
\hline & 2 & $24,2 \mathbf{N}$ & $1,6 \mathbf{N}$ & $14,0 \mathbf{N}$ & $9,1 \mathbf{D}$ & $2,7 \mathbf{N}$ & $166 \mathbf{N}$ & $335 \mathbf{E}$ & $59 \mathbf{N}$ & $11 \mathbf{N}$ & $39 \mathbf{N}$ \\
\hline & 3 & $24,3 \mathbf{N}$ & $1,6 \mathbf{N}$ & $17,3 \mathbf{E}$ & $9,1 \mathbf{D}$ & $2,5 \mathbf{N}$ & $150 \mathbf{N}$ & $333 \mathbf{E}$ & $62 \mathbf{N}$ & $10 \mathbf{N}$ & $37 \mathbf{N}$ \\
\hline & 4 & $23,9 \mathbf{N}$ & $1,6 \mathbf{N}$ & $21,4 \mathbf{E}$ & $8,6 \mathbf{D}$ & $2,3 \mathbf{D}$ & $138 \mathbf{N}$ & $424 \mathbf{E}$ & $61 \mathbf{N}$ & $12 \mathbf{N}$ & $37 \mathbf{N}$ \\
\hline & 5 & $23,6 \mathbf{N}$ & $1,5 \mathbf{D}$ & $10,6 \mathbf{D}$ & $9,5 \mathbf{D}$ & $2,8 \mathbf{N}$ & $141 \mathbf{N}$ & $347 \mathbf{E}$ & $62 \mathrm{~N}$ & $10 \mathbf{N}$ & $37 \mathbf{N}$ \\
\hline & 6 & $24,6 \mathbf{N}$ & $1,6 \mathbf{N}$ & $13,9 \mathbf{N}$ & $9,3 \mathbf{D}$ & $2,7 \mathbf{N}$ & $146 \mathbf{N}$ & $351 \mathbf{E}$ & $62 \mathrm{~N}$ & $11 \mathbf{N}$ & $37 \mathbf{N}$ \\
\hline & 7 & $24,4 \mathbf{N}$ & $1,6 \mathbf{N}$ & $18,5 \mathbf{E}$ & $9,2 \mathbf{D}$ & $2,3 \mathbf{D}$ & $124 \mathbf{N}$ & $337 \mathbf{E}$ & $60 N$ & $11 \mathbf{N}$ & $36 \mathbf{N}$ \\
\hline & 8 & $24,5 \mathrm{~N}$ & $1,6 \mathbf{N}$ & $19,0 \mathbf{E}$ & $9,5 \mathbf{D}$ & $2,2 \mathbf{D}$ & $110 \mathbf{N}$ & $444 \mathbf{E}$ & $53 \mathbf{N}$ & $10 \mathbf{N}$ & $34 \mathrm{~N}$ \\
\hline & 9 & $23,4 \mathbf{N}$ & $1,5 \mathbf{N}$ & $12,3 \mathbf{N}$ & $10,5 \mathbf{D}$ & $3,0 \mathbf{N}$ & $157 \mathbf{N}$ & $378 \mathbf{E}$ & $67 \mathbf{N}$ & $11 \mathbf{N}$ & $39 \mathbf{N}$ \\
\hline & 10 & $24,1 \mathbf{N}$ & $1,4 \mathbf{D}$ & $13,8 \mathbf{N}$ & $9,5 \mathbf{D}$ & $2,9 \mathbf{N}$ & $138 \mathbf{N}$ & $411 \mathbf{E}$ & $66 N$ & $11 \mathbf{N}$ & $35 \mathbf{N}$ \\
\hline & 11 & $25,1 \mathbf{E}$ & $1,7 \mathbf{N}$ & $19,3 \mathbf{E}$ & $9,3 \mathbf{D}$ & $2,3 \mathbf{D}$ & $135 \mathbf{N}$ & $387 \mathbf{E}$ & $63 \mathbf{N}$ & $11 \mathbf{N}$ & $37 \mathbf{N}$ \\
\hline & 12 & $24,3 \mathbf{N}$ & $1,5 \mathbf{N}$ & $20,0 \mathbf{E}$ & $9,0 \mathbf{D}$ & $2,2 \mathbf{D}$ & $126 \mathrm{~N}$ & $402 \mathbf{E}$ & $73 \mathbf{N}$ & $11 \mathbf{N}$ & $37 \mathbf{N}$ \\
\hline \multirow{12}{*}{1996} & 1 & $24,4 \mathbf{N}$ & $1,3 \mathbf{D}$ & $8,8 \mathbf{D}$ & $12,2 \mathbf{N}$ & $4,0 \mathbf{N}$ & $126 \mathbf{N}$ & $297 \mathbf{E}$ & $43 \mathbf{N}$ & $7 \mathbf{N}$ & $36 \mathbf{N}$ \\
\hline & 2 & $26,4 \mathbf{E}$ & $1,3 \mathbf{D}$ & $10,4 \mathbf{D}$ & $13,1 \mathbf{N}$ & $4,0 \mathbf{N}$ & $134 \mathbf{N}$ & $362 \mathbf{E}$ & $51 \mathbf{N}$ & $\mathbf{N}$ & $40 \mathrm{~N}$ \\
\hline & 3 & $25,6 \mathbf{E}$ & $1,3 \mathbf{D}$ & $12,9 \mathbf{N}$ & $12,2 \mathbf{N}$ & $3,6 \mathbf{N}$ & $147 \mathbf{N}$ & $314 \mathbf{E}$ & $45 \mathbf{N}$ & $7 \mathbf{N}$ & $38 \mathbf{N}$ \\
\hline & 4 & $26,0 \mathbf{E}$ & $1,4 \mathbf{D}$ & $14,1 \mathbf{N}$ & $11,1 \mathbf{N}$ & $3,2 \mathbf{N}$ & $131 \mathbf{N}$ & $383 \mathbf{E}$ & $47 \mathbf{N}$ & $7 \mathbf{N}$ & $40 \mathbf{N}$ \\
\hline & 5 & $25,8 \mathbf{E}$ & $1,3 \mathbf{D}$ & $8,2 \mathbf{D}$ & $11,8 \mathbf{N}$ & $4,1 \mathbf{N}$ & $131 \mathbf{N}$ & $359 \mathbf{E}$ & $53 \mathrm{~N}$ & $8 \mathbf{N}$ & $39 \mathbf{N}$ \\
\hline & 6 & $26,0 \mathbf{E}$ & $1,3 \mathbf{D}$ & $9,8 \mathbf{D}$ & $11,0 \mathbf{D}$ & $3,7 \mathbf{N}$ & $130 \mathbf{N}$ & $322 \mathbf{E}$ & $44 \mathrm{~N}$ & $7 \mathbf{N}$ & $36 \mathbf{N}$ \\
\hline & 7 & $25,9 \mathbf{E}$ & $1,4 \mathbf{D}$ & $13,6 \mathbf{N}$ & $10,1 \mathbf{D}$ & $2,9 \mathbf{N}$ & $139 \mathbf{N}$ & $347 \mathrm{E}$ & $46 \mathbf{N}$ & $\mathbf{N}$ & $38 \mathbf{N}$ \\
\hline & 8 & $25,2 \mathbf{E}$ & $1,2 \mathbf{D}$ & $16,4 \mathbf{E}$ & $10,5 \mathbf{D}$ & $2,9 \mathbf{N}$ & $123 \mathbf{N}$ & $341 \mathbf{E}$ & $46 \mathbf{N}$ & $7 \mathbf{N}$ & $36 \mathbf{N}$ \\
\hline & 9 & $25,1 \mathbf{E}$ & $1,4 \mathbf{D}$ & $8,2 \mathbf{D}$ & $11,8 \mathbf{N}$ & $4,3 \mathbf{N}$ & $134 \mathbf{N}$ & $333 \mathbf{E}$ & $48 \mathbf{N}$ & $7 \mathbf{N}$ & $34 \mathbf{N}$ \\
\hline & 10 & $24,9 \mathbf{N}$ & $1,3 \mathbf{D}$ & $12,7 \mathbf{N}$ & $11,0 \mathbf{D}$ & $3,2 \mathbf{N}$ & $134 \mathbf{N}$ & $379 \mathbf{E}$ & $48 \mathbf{N}$ & $7 \mathbf{N}$ & $36 \mathbf{N}$ \\
\hline & 11 & $26,5 \mathbf{E}$ & $1,3 \mathbf{D}$ & $14,2 \mathbf{N}$ & $10,9 \mathbf{D}$ & $3,0 \mathbf{N}$ & $155 \mathrm{~N}$ & $396 \mathbf{E}$ & $52 \mathrm{~N}$ & $8 \mathbf{N}$ & $40 \mathbf{N}$ \\
\hline & 12 & $24,8 \mathbf{N}$ & $1,3 \mathbf{D}$ & $15,2 \mathbf{E}$ & $10,7 \mathbf{D}$ & $3,1 \mathbf{N}$ & $138 \mathbf{N}$ & $339 \mathbf{E}$ & $45 \mathbf{N}$ & $7 \mathbf{N}$ & $37 \mathbf{N}$ \\
\hline \multirow{12}{*}{1997} & 1 & & $1,1 \mathbf{D}$ & $6,6 \mathbf{D}$ & $8,2 \mathbf{D}$ & $3,9 \mathbf{N}$ & $102 \mathrm{~N}$ & $253 \mathbf{E}$ & 41 & 4 & $31 \mathbf{N}$ \\
\hline & 2 & $20,9 \mathbf{N}$ & $1,2 \mathbf{D}$ & $10,8 \mathbf{D}$ & $8,2 \mathbf{D}$ & $3,2 \mathbf{N}$ & $110 \mathbf{N}$ & $306 \mathbf{E}$ & $49 \mathbf{N}$ & $4 D$ & $32 \mathbf{N}$ \\
\hline & 3 & $22,1 \mathbf{~ N}$ & $1,2 \mathbf{D}$ & $14,3 \mathbf{N}$ & $8,2 \mathbf{D}$ & $2,8 \mathbf{N}$ & $105 \mathbf{N}$ & $293 \mathbf{E}$ & $49 \mathbf{N}$ & 4D & $32 \mathbf{N}$ \\
\hline & 4 & $21,2 \mathbf{N}$ & $1,2 \mathbf{D}$ & $15,5 \mathbf{E}$ & $7,8 \mathbf{D}$ & $2,4 \mathbf{D}$ & $100 \mathbf{N}$ & $383 \mathbf{E}$ & $56 \mathrm{~N}$ & $3 \mathrm{D}$ & $33 \mathbf{N}$ \\
\hline & 5 & $19,0 \mathbf{D}$ & $1,1 \mathbf{D}$ & $5,8 \mathbf{D}$ & $8,8 \mathbf{D}$ & $4,1 \mathbf{N}$ & $103 \mathbf{N}$ & $306 \mathbf{E}$ & $53 \mathbf{N}$ & $4 D$ & $34 \mathbf{N}$ \\
\hline & 6 & $21,5 \mathbf{N}$ & $1,1 \mathbf{D}$ & $9,5 \mathbf{D}$ & $7,8 \mathbf{D}$ & $3,4 \mathbf{N}$ & $139 \mathbf{N}$ & $329 \mathbf{E}$ & $53 \mathrm{~N}$ & $5 \mathrm{D}$ & $32 \mathbf{N}$ \\
\hline & 7 & $21,4 \mathbf{N}$ & $1,2 \mathbf{D}$ & $12,9 \mathbf{N}$ & $8,6 \mathbf{D}$ & $2,8 \mathbf{N}$ & $107 \mathbf{N}$ & $367 \mathbf{E}$ & $54 \mathbf{N}$ & $4 \mathrm{D}$ & $34 \mathbf{N}$ \\
\hline & 8 & $20,9 \mathbf{N}$ & $1,2 \mathbf{D}$ & $14,9 \mathbf{N}$ & $7,9 \mathbf{D}$ & $2,3 \mathbf{D}$ & $113 \mathbf{N}$ & $326 \mathbf{E}$ & $52 \mathbf{N}$ & 4D & $32 \mathbf{N}$ \\
\hline & 9 & $19,7 \mathbf{D}$ & $1,1 \mathbf{D}$ & $6,6 \mathrm{D}$ & $9,0 \mathbf{D}$ & $4,3 \mathbf{N}$ & $113 \mathbf{N}$ & $291 \mathbf{E}$ & $47 \mathbf{N}$ & $4 \mathrm{D}$ & $33 \mathbf{N}$ \\
\hline & 10 & $20,7 \mathbf{N}$ & $1,2 \mathbf{D}$ & $9,5 \mathbf{D}$ & $9,3 \mathbf{D}$ & $3,3 \mathbf{N}$ & $104 \mathbf{N}$ & $320 \mathbf{E}$ & $49 \mathbf{N}$ & $3 \mathrm{D}$ & $32 \mathbf{N}$ \\
\hline & 11 & $21,6 \mathbf{N}$ & $1,2 \mathbf{D}$ & $14,5 \mathbf{N}$ & $8,2 \mathbf{D}$ & $2,4 \mathrm{D}$ & $103 \mathbf{N}$ & $361 \mathrm{E}$ & $55 \mathrm{~N}$ & $5 \mathrm{D}$ & $33 \mathbf{N}$ \\
\hline & 12 & $20,9 \mathbf{N}$ & $1,2 \mathbf{D}$ & $14,3 \mathbf{N}$ & $7,6 \mathbf{D}$ & $2,5 \mathbf{D}$ & $103 \mathbf{N}$ & $328 \mathbf{E}$ & $56 \mathrm{~N}$ & 4D & $33 \mathbf{N}$ \\
\hline
\end{tabular}


Tabela 14. Concentração de macro e micronutrientes em folhas de macieira em função da aplicação anual de de adubo potássico e o diagnóstico nutricional segundo o critério de faixas de suficiência. (Média de quatro repetições)

\begin{tabular}{|c|c|c|c|c|c|c|c|c|c|c|c|}
\hline \multirow{2}{*}{ Ano } & \multirow{2}{*}{ Trat. } & \multicolumn{10}{|c|}{ Análise Foliar } \\
\hline & & $\mathbf{N}$ & $\mathbf{P}$ & $\mathbf{K}$ & Ca & Mg & $\mathbf{F e}$ & Mn & Zn & $\mathbf{C u}$ & B \\
\hline \multirow{13}{*}{1998} & & \multicolumn{5}{|c|}{ - } & \multicolumn{5}{|c|}{ - } \\
\hline & 1 & $20,4 \mathbf{N}$ & $1,3 \mathbf{D}$ & $8,1 \mathbf{D}$ & $8,5 \mathbf{D}$ & $3,1 \mathbf{N}$ & $115 \mathbf{N}$ & $357 \mathbf{E}$ & $63 \mathrm{~N}$ & $4 \mathrm{D}$ & $36 \mathbf{N}$ \\
\hline & 2 & $22,2 \mathbf{N}$ & $1,2 \mathbf{D}$ & $11,9 \mathbf{D}$ & $9,2 \mathbf{D}$ & $2,7 \mathbf{N}$ & $124 \mathbf{N}$ & $348 \mathbf{E}$ & $57 \mathbf{N}$ & $4 \mathrm{D}$ & $35 \mathbf{N}$ \\
\hline & 3 & $22,7 \mathbf{N}$ & $1,3 \mathbf{D}$ & $15,0 \mathbf{N}$ & $9,5 \mathbf{D}$ & $2,5 \mathbf{D}$ & $126 \mathbf{N}$ & $401 \mathbf{E}$ & $52 \mathbf{N}$ & $4 \mathrm{D}$ & $32 \mathbf{N}$ \\
\hline & 4 & $21,8 \mathbf{N}$ & $1,2 \mathbf{D}$ & $15,9 \mathbf{E}$ & $8,2 \mathbf{D}$ & $1,9 \mathbf{D}$ & $116 \mathbf{N}$ & $401 \mathbf{E}$ & $59 \mathrm{~N}$ & 4D & $35 \mathrm{~N}$ \\
\hline & 5 & $19,8 \mathbf{D}$ & $1,2 \mathbf{D}$ & $6,4 \mathbf{D}$ & $9,0 \mathbf{D}$ & $3,4 \mathbf{N}$ & $200 \mathbf{N}$ & $373 \mathbf{E}$ & $58 \mathbf{N}$ & 4D & $35 \mathbf{N}$ \\
\hline & 6 & $21,2 \mathbf{N}$ & $1,2 \mathbf{D}$ & $10,9 \mathbf{D}$ & $8,2 \mathbf{D}$ & $2,7 \mathbf{N}$ & $129 \mathbf{N}$ & $363 \mathbf{E}$ & $62 \mathbf{N}$ & 4D & $35 \mathrm{~N}$ \\
\hline & 7 & $21,8 \mathbf{N}$ & $1,2 \mathbf{D}$ & $13,9 \mathbf{N}$ & $8,4 \mathbf{D}$ & $2,3 \mathbf{D}$ & $117 \mathbf{N}$ & $398 \mathbf{E}$ & $60 \mathrm{~N}$ & 4D & $36 \mathbf{N}$ \\
\hline & 8 & $21,1 \mathbf{N}$ & $1,2 \mathbf{D}$ & $17,5 \mathbf{E}$ & $7,8 \mathbf{D}$ & $1,9 \mathbf{D}$ & $109 \mathrm{~N}$ & $395 \mathbf{E}$ & $64 \mathbf{N}$ & 4D & $35 \mathbf{N}$ \\
\hline & 9 & $20,8 \mathbf{N}$ & $1,2 \mathbf{D}$ & $6,7 \mathbf{D}$ & $10,0 \mathbf{D}$ & $3,8 \mathbf{N}$ & $117 \mathbf{N}$ & $360 \mathbf{E}$ & $56 \mathrm{~N}$ & 4D & $36 \mathbf{N}$ \\
\hline & 10 & $20,5 \mathbf{N}$ & $1,1 \mathbf{D}$ & $10,6 \mathbf{D}$ & $8,6 \mathbf{D}$ & $2,6 \mathbf{N}$ & $119 \mathbf{N}$ & $374 \mathrm{E}$ & $58 \mathbf{N}$ & 4D & $36 \mathrm{~N}$ \\
\hline & 11 & $22,2 \mathbf{N}$ & $1,3 \mathbf{D}$ & $14,9 \mathbf{N}$ & $8,6 \mathbf{D}$ & $2,1 \mathbf{D}$ & $115 \mathbf{N}$ & $384 \mathbf{E}$ & $58 \mathrm{~N}$ & 4D & $36 \mathrm{~N}$ \\
\hline & 12 & $21,1 \mathbf{N}$ & $1,2 \mathbf{D}$ & $15,1 \mathbf{E}$ & $8,0 \mathbf{D}$ & $2,1 \mathbf{D}$ & $129 \mathrm{~N}$ & $366 \mathbf{E}$ & $57 \mathbf{N}$ & 4D & $35 \mathbf{N}$ \\
\hline \multirow{12}{*}{1999} & 1 & $19,3 \mathbf{D}$ & $1,3 \mathbf{D}$ & 7,7 D & $9,1 \mathbf{D}$ & $4,2 \mathbf{N}$ & $155 \mathbf{N}$ & $385 \mathbf{E}$ & $65 \mathrm{~N}$ & 18 & $30 \mathrm{D}$ \\
\hline & 2 & $20,4 \mathbf{N}$ & $1,2 \mathbf{D}$ & $11,2 \mathbf{D}$ & $8,7 \mathbf{D}$ & $3,5 \mathrm{~N}$ & $131 \mathbf{N}$ & $394 \mathbf{E}$ & $67 \mathrm{~N}$ & $6 \mathbf{N}$ & 29 D \\
\hline & 3 & $19,1 \mathbf{D}$ & $1,2 \mathbf{D}$ & $14,8 \mathbf{N}$ & $8,2 \mathbf{D}$ & $2,9 \mathbf{N}$ & $149 \mathbf{N}$ & $381 \mathbf{E}$ & $60 \mathrm{~N}$ & $7 \mathbf{N}$ & $30 \mathbf{N}$ \\
\hline & 4 & $19,5 \mathbf{D}$ & $1,3 \mathbf{D}$ & $16,2 \mathbf{E}$ & $7,8 \mathbf{D}$ & $2,5 \mathbf{D}$ & $141 \mathbf{N}$ & $428 \mathbf{E}$ & $64 \mathrm{~N}$ & $\mathbf{N}$ & $30 \mathrm{D}$ \\
\hline & 5 & $17,8 \mathbf{D}$ & $1,1 \mathbf{D}$ & $6,2 \mathbf{D}$ & $10,1 \mathbf{D}$ & $4,8 \mathbf{E}$ & $129 \mathbf{N}$ & $416 \mathbf{E}$ & $67 \mathrm{~N}$ & $6 \mathbf{N}$ & $30 \mathrm{D}$ \\
\hline & 6 & $20,3 \mathbf{N}$ & $1,2 \mathbf{D}$ & $10,2 \mathbf{D}$ & $9,1 \mathbf{D}$ & $3,8 \mathbf{N}$ & $141 \mathbf{N}$ & $418 \mathbf{E}$ & $66 \mathbf{N}$ & $7 \mathbf{N}$ & $30 \mathrm{D}$ \\
\hline & 7 & $20,0 \mathbf{N}$ & $1,2 \mathbf{D}$ & $13,6 \mathbf{N}$ & $8,5 \mathbf{D}$ & $3,1 \mathbf{N}$ & $144 \mathbf{N}$ & $416 \mathbf{E}$ & $66 \mathbf{N}$ & $7 \mathbf{N}$ & $31 \mathbf{N}$ \\
\hline & 8 & $19,2 \mathbf{D}$ & $1,3 \mathbf{D}$ & $15,5 \mathbf{E}$ & $8,8 \mathbf{D}$ & $2,9 \mathbf{N}$ & $142 \mathrm{~N}$ & $409 \mathrm{E}$ & $62 \mathbf{N}$ & $7 \mathbf{N}$ & 29 D \\
\hline & 9 & $18,5 \mathbf{D}$ & $1,2 \mathbf{D}$ & $6,8 \mathbf{D}$ & $10,4 \mathbf{D}$ & $4,8 \mathbf{E}$ & $138 \mathbf{N}$ & $413 \mathbf{E}$ & $63 \mathrm{~N}$ & $\mathbf{N}$ & $31 \mathbf{N}$ \\
\hline & 10 & $18,8 \mathbf{D}$ & $1,2 \mathbf{D}$ & $9,8 \mathbf{D}$ & $8,9 \mathbf{D}$ & $3,7 \mathbf{N}$ & $145 \mathrm{~N}$ & $398 \mathbf{E}$ & $60 \mathrm{~N}$ & $6 \mathbf{N}$ & $30 \mathbf{N}$ \\
\hline & 11 & $19,7 \mathbf{D}$ & $1,4 \mathbf{D}$ & $13,8 \mathbf{N}$ & $8,4 \mathbf{D}$ & $2,9 \mathbf{N}$ & $142 \mathbf{N}$ & $425 \mathbf{E}$ & $68 \mathbf{N}$ & $7 \mathbf{N}$ & $30 \mathrm{D}$ \\
\hline & 12 & $19,1 \mathbf{D}$ & $1,2 \mathbf{D}$ & $15,4 \mathbf{E}$ & $7,5 \mathbf{D}$ & $2,6 \mathbf{N}$ & $146 \mathbf{N}$ & $401 \mathbf{E}$ & $69 \mathrm{~N}$ & $6 \mathbf{N}$ & $31 \mathbf{N}$ \\
\hline \multirow{12}{*}{2000} & 1 & $15,3 \mathbf{D}$ & $1,1 \mathbf{D}$ & 6,6 D & $11,6 \mathbf{N}$ & $4,7 \mathbf{E}$ & $88 \mathbf{N}$ & $423 \mathbf{E}$ & $65 \mathrm{~N}$ & & $25 \mathrm{D}$ \\
\hline & 2 & $15,2 \mathbf{D}$ & $1,8 \mathbf{N}$ & $9,7 \mathbf{D}$ & $11,3 \mathbf{N}$ & $3,9 \mathbf{N}$ & $84 \mathbf{N}$ & $448 \mathbf{E}$ & $69 \mathrm{~N}$ & $7 \mathbf{N}$ & $23 \mathbf{D}$ \\
\hline & 3 & $16,5 \mathbf{D}$ & $1,1 \mathbf{D}$ & $12,6 \mathbf{N}$ & $10,9 \mathbf{D}$ & $3,3 \mathbf{N}$ & $89 \mathbf{N}$ & $470 \mathbf{E}$ & $77 \mathbf{N}$ & $7 \mathbf{N}$ & $26 D$ \\
\hline & 4 & $16,4 \mathbf{D}$ & $1,7 \mathbf{N}$ & $15,0 \mathbf{N}$ & $10,4 \mathbf{D}$ & $2,9 \mathbf{N}$ & $91 \mathbf{N}$ & $548 \mathbf{E}$ & $72 \mathbf{N}$ & $7 \mathbf{N}$ & $24 \mathrm{D}$ \\
\hline & 5 & $14,5 \mathbf{D}$ & $1,6 \mathbf{N}$ & 5,4 D & $13,7 \mathbf{N}$ & $5,5 \mathbf{E}$ & $88 \mathbf{N}$ & $449 \mathbf{E}$ & $68 \mathbf{N}$ & $7 \mathbf{N}$ & $25 \mathrm{D}$ \\
\hline & 6 & $15,1 \mathbf{D}$ & $1,5 \mathbf{N}$ & $9,4 \mathbf{D}$ & $11,2 \mathbf{N}$ & $3,8 \mathbf{N}$ & $91 \mathbf{N}$ & $478 \mathbf{E}$ & $71 \mathbf{N}$ & $7 \mathbf{N}$ & $25 \mathrm{D}$ \\
\hline & 7 & $15,8 \mathbf{D}$ & $1,5 \mathbf{D}$ & $12,9 \mathbf{N}$ & $11,2 \mathbf{N}$ & $3,4 \mathbf{N}$ & $85 \mathbf{N}$ & $498 \mathbf{E}$ & $71 \mathbf{N}$ & $7 \mathbf{N}$ & 24 D \\
\hline & 8 & $15,7 \mathbf{D}$ & $1,6 \mathbf{N}$ & $13,9 \mathbf{N}$ & $10,6 \mathbf{D}$ & $3,0 \mathbf{N}$ & $97 \mathbf{N}$ & $523 \mathbf{E}$ & $77 \mathbf{N}$ & $7 \mathbf{N}$ & $25 \mathrm{D}$ \\
\hline & 9 & $14,4 \mathbf{D}$ & $1,4 \mathbf{D}$ & 5,7 D & $13,3 \mathbf{N}$ & $5,7 \mathbf{E}$ & $87 \mathbf{N}$ & $421 \mathbf{E}$ & $61 \mathbf{N}$ & $8 \mathbf{N}$ & $25 \mathrm{D}$ \\
\hline & 10 & $15,1 \mathbf{D}$ & $1,6 \mathbf{N}$ & $8,8 \mathbf{D}$ & $11,1 \mathbf{N}$ & $4,0 \mathbf{N}$ & $90 \mathbf{N}$ & $503 \mathbf{E}$ & $72 \mathbf{N}$ & $7 \mathbf{N}$ & 26D \\
\hline & 11 & $15,5 \mathbf{D}$ & $1,6 \mathbf{N}$ & $14,0 \mathbf{N}$ & $9,9 \mathbf{D}$ & $2,9 \mathbf{N}$ & $87 \mathbf{N}$ & $520 \mathbf{E}$ & $76 \mathbf{N}$ & $7 \mathbf{N}$ & $25 \mathrm{D}$ \\
\hline & 12 & $15,3 \mathbf{D}$ & $1,6 \mathbf{N}$ & $14,5 \mathbf{N}$ & $9,8 \mathbf{D}$ & $2,9 \mathbf{N}$ & $93 \mathbf{N}$ & $510 \mathbf{E}$ & $79 \mathbf{N}$ & $7 \mathbf{N}$ & $24 \mathrm{D}$ \\
\hline
\end{tabular}

$\mathrm{N}=$ normal; $\mathrm{D}=$ deficiente e $\mathrm{E}=$ excesso.

${ }^{(*)} 1-0 \mathrm{~kg} / \mathrm{ha}$ de $\mathrm{K}_{2} \mathrm{O}+0 \mathrm{~kg} / \mathrm{ha} / \mathrm{ano}$ de $\mathrm{K}_{2} \mathrm{O} ; 2-0 \mathrm{~kg} / \mathrm{ha}$ de $\mathrm{K}_{2} \mathrm{O}+50 \mathrm{~kg} / \mathrm{ha} /$ ano de $\mathrm{K}_{2} \mathrm{O} ; 3-0 \mathrm{~kg} / \mathrm{ha}$ de $\mathrm{K}_{2} \mathrm{O}+100$ $\mathrm{kg} / \mathrm{ha} / \mathrm{ano}$ de $\mathrm{K}_{2} \mathrm{O} ; 4-0 \mathrm{~kg} / \mathrm{ha}$ de $\mathrm{K}_{2} \mathrm{O}+150 \mathrm{~kg} / \mathrm{ha} /$ ano de $\mathrm{K}_{2} \mathrm{O} ; 5-50 \mathrm{~kg} / \mathrm{ha} \mathrm{de} \mathrm{K}_{2} \mathrm{O}+0 \mathrm{~kg} / \mathrm{ha} /$ ano de $\mathrm{K}_{2} \mathrm{O} ; 6-50 \mathrm{~kg} / \mathrm{ha}$ de $\mathrm{K}_{2} \mathrm{O}+50 \mathrm{~kg} / \mathrm{ha} / \mathrm{ano}$ de $\mathrm{K}_{2} \mathrm{O} ; 7-50 \mathrm{~kg} / \mathrm{ha}$ de $\mathrm{K}_{2} \mathrm{O}+100 \mathrm{~kg} / \mathrm{ha} /$ ano de $\mathrm{K}_{2} \mathrm{O} ; 8-50 \mathrm{~kg} / \mathrm{ha}$ de $\mathrm{K}_{2} \mathrm{O}+150 \mathrm{~kg} / \mathrm{ha} / \mathrm{ano}$ de $\mathrm{K}_{2} \mathrm{O} ; 9-100 \mathrm{~kg} / \mathrm{ha}$ de $\mathrm{K}_{2} \mathrm{O}+0 \mathrm{~kg} / \mathrm{ha} /$ ano de $\mathrm{K}_{2} \mathrm{O} ; 10-100 \mathrm{~kg} / \mathrm{ha}$ de $\mathrm{K}_{2} \mathrm{O}+50 \mathrm{~kg} / \mathrm{ha} /$ ano de $\mathrm{K}_{2} \mathrm{O} ; 11-100 \mathrm{~kg} / \mathrm{ha} \mathrm{de}$ $\mathrm{K}_{2} \mathrm{O}+100 \mathrm{~kg} / \mathrm{ha} /$ ano de $\mathrm{K}_{2} \mathrm{O} ; 12-100 \mathrm{~kg} / \mathrm{ha}$ de $\mathrm{K}_{2} \mathrm{O}+150 \mathrm{~kg} / \mathrm{ha} /$ ano de $\mathrm{K}_{2} \mathrm{O}$. 
Tabela 15. Índices DRIS pelo método Elwali \& Gascho (1984), utilizando o "Valor F" para a escolha da razão entre nutrientes, em função de doses de adubo potássico, e o diagnóstico nutricional segundo o critério do IBNm. (Média de quatro repetições)

\begin{tabular}{|c|c|c|c|c|c|c|c|c|c|c|c|c|}
\hline \multirow{2}{*}{\multicolumn{2}{|c|}{ Ano Trat ${ }^{*}$}} & \multicolumn{10}{|c|}{ Índice DRIS Elwali \& Gascho (1984) “Valor F” } & \multirow{2}{*}{ IBN } \\
\hline & & $\mathbf{N}$ & $\mathbf{P}$ & $\mathbf{K}$ & Ca & Mg & Fe & Mn & Zn & $\mathbf{C u}$ & B & \\
\hline \multirow{12}{*}{1995} & 1 & $2,09 \mathbf{E}$ & $89 \mathbf{D}$ & $\mathbf{N}$ & $87 \mathbf{D}$ & D & $\mathbf{N}$ & $\mathbf{E}$ & $62 \mathrm{~N}$ & -0 & $0,00 \mathbf{N}$ & \\
\hline & 2 & $99 N$ & 37D & $\mathbf{N}$ & -7 & & & & & & & \\
\hline & 3 & $\mathbf{N}$ & $-1,3$ & $0,00 \mathbf{N}$ & $-6,1$ & $-5,56 \mathbf{D}$ & & & & $0,38 \mathbf{N}$ &, $00 \mathrm{~N}$ & 16,4 \\
\hline & 4 & $-1,33 \mathbf{N}$ & $-1,87 \mathbf{N}$ & $3,74 \mathbf{N}$ & $-9,43 \mathbf{D}$ & $-10,59 D$ & $-1,25 \mathbf{N}$ & $19,34 \mathbf{E}$ & $\mathbf{N}$ & $1,90 \mathbf{N}$ & $5 \mathbf{N}$ & 33,7 \\
\hline & 5 & & & $-6,15 \mathbf{D}$ & & & & & & & & \\
\hline & 6 & $-1,09 \mathbf{N}$ & $-1,59 \mathrm{~N}$ & $0,00 \mathbf{N}$ & $-5,58 \mathbf{D}$ & $-4,01 \mathbf{D}$ & $0,00 \mathbf{N}$ & 12 & $1,22 \mathbf{N}$ & $\mathbf{N}$ & & , \\
\hline & 7 & & & & & & & & & & & 21,7 \\
\hline & 8 & & & $2,20 \mathbf{N}$ & & & & & & & & 27,0 \\
\hline & 9 & $\mathbf{N}$ & $-4,12 \mathbf{D}$ & $-4,59 \mathbf{D}$ & $-3,7$ & $-3,28 \mathbf{D}$ & & & & & & 22,1 \\
\hline & 10 & & $-4,87 \mathbf{D}$ & $-2,58 \mathbf{N}$ & $-5,4$ & -3, & -1 & & & & & \\
\hline & 11 & & -0 & $1,50 \mathrm{~N}$ & $-6,9$ & -9 & -1 , & & & & & 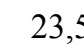 \\
\hline & 12 & & &, $50 \mathrm{~N}$ & $-7,59 \mathrm{D}$ & & $-1,46 \mathbf{N}$ & & & & & \\
\hline \multirow{12}{*}{1996} & 1 & $61 \mathbf{N}$ & $-5,63 \mathrm{D}$ & $-9,44 \mathbf{D}$ & & & & & & & & \\
\hline & 2 & $\mathbf{N}$ & -6 , & $-8,3$ & $\mathbf{N}$ & & -1, & & & & & 9 \\
\hline & 3 & 1 & $-6,29 \mathbf{D}$ & 0,0 & 1,1 & $-0,6$ & & & & & & \\
\hline & 4 & & & $-2,2$ & & & -1, & & & & & \\
\hline & 5 & & & -15 & & & -1 & & & & & 1,2 \\
\hline & 6 & & & & & & & & & & & 9,9 \\
\hline & 7 & $\mathbf{N}$ & -3 & $0,00 \mathbf{N}$ & & -2 & -1 & & & & & \\
\hline & 8 & $\mathbf{N}$ & -5 & 0,0 & -1, & -2 & -1, & & & & & \\
\hline & 9 & & & & & & & & & & & \\
\hline & 10 & $\mathbf{N}$ & -4 & -2 , & -2, & -2 & -1, & & 0, & & & , \\
\hline & 11 & c & & -2 & & & -0 & & & & & 8,5 \\
\hline & 12 & & & $0,00 \mathbf{N}$ & $-2,16 \mathbf{D}$ & & $0,00 \mathbf{N}$ & 10 , & & & & \\
\hline \multirow{12}{*}{1997} & 1 & & & & & & & & & & & \\
\hline & 2 & & -4 & $-2,4$ & -4, & $1,29 \mathbf{N}$ & -1 , & & & & & \\
\hline & 3 & & -2 & N & $-3,43 \mathbf{D}$ & $-0,83 \mathbf{N}$ & -0 & $E$ & $0,00 \mathbf{N}$ & $-9,67 \mathbf{D}$ & -0 & 22,7 \\
\hline & 4 & & $-3,21 \mathbf{N}$ & $3,01 \mathbf{N}$ & $-4,84 \mathbf{D}$ & $-2,65 \mathbf{N}$ & $-1,29 \mathbf{N}$ & $25,97 \mathbf{E}$ & $2,00 \mathbf{N}$ & -21 , & $3 \mathbf{N}$ & 40,5 \\
\hline & 5 & $0,22 \mathbf{N}$ & $-4,06 \mathbf{N}$ & $-20,95 \mathbf{D}$ & $-1,06 \mathbf{N}$ & $11,08 \mathbf{E}$ & $-0,93 \mathbf{N}$ & $18,77 \mathbf{E}$ & $4,35 \mathbf{N}$ & -13 , & $4 N$ & \\
\hline & 6 & & $-7,15 \mathbf{D}$ & $-6,24 \mathbf{D}$ & $-6,79 \mathbf{D}$ & $3,22 \mathbf{N}$ & & & & -7 & & \\
\hline & 7 & & -3 & $-1,32 \mathbf{N}$ & & $-1,2$ & & & & & & \\
\hline & 8 & $1,07 \mathbf{N}$ & $-3,61 \mathbf{D}$ & $1,31 \mathbf{N}$ & $-4,40 \mathbf{D}$ & $-3,76 \mathbf{D}$ & $-0,80 \mathbf{N}$ & $19,27 \mathbf{E}$ & $1,75 \mathrm{~N}$ & $-9,95 \mathbf{D}$ & $-0,87 \mathbf{N}$ & 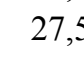 \\
\hline & 9 & $0,41 \mathbf{N}$ & $-3,89 \mathbf{N}$ & $-16,52 \mathrm{D}$ & $-1,57 \mathbf{N}$ & $11,62 \mathbf{E}$ & $-0,65 \mathbf{N}$ & $15,80 \mathbf{E}$ & $2,63 \mathbf{N}$ & $-10,65 \mathbf{D}$ & $2,81 \mathbf{N}$ & 50,8 \\
\hline & 10 & $1,81 \mathbf{N}$ & $-2,96 \mathbf{N}$ & $-4,21 \mathbf{D}$ & $-0,44 \mathbf{N}$ & $1,61 \mathbf{N}$ & $-0,66 \mathbf{N}$ & $21,51 \mathbf{E}$ & $0,00 \mathbf{N}$ & $-17,63 \mathbf{D}$ & $0,98 \mathbf{N}$ & 30,3 \\
\hline & 11 & $0,41 \mathbf{N}$ & $-4,70 \mathbf{D}$ & $0,81 \mathbf{N}$ & $-4,68 \mathbf{D}$ & $-4,09 \mathbf{D}$ & $-2,34 \mathbf{N}$ & $20,70 \mathbf{E}$ & $1,83 \mathbf{N}$ & $-6,48 \mathbf{D}$ & $-1,46 \mathbf{N}$ & 26,8 \\
\hline & 12 & $0,87 \mathbf{N}$ & $-3,41 \mathbf{D}$ & $1,04 \mathbf{N}$ & $-5,62 \mathrm{D}$ & $-3,50 \mathbf{D}$ & $-1,40 \mathbf{N}$ & $19,03 \mathbf{E}$ & $1,95 \mathbf{N}$ & $-8,79 \mathbf{D}$ & $-0,17 \mathbf{N}$ & 26,8 \\
\hline
\end{tabular}


Tabela 15. Índices DRIS pelo método Elwali \& Gascho (1984), utilizando o "Valor F" para a escolha da razão entre nutrientes, em função de doses de adubo potássico, e o diagnóstico nutricional segundo o critério do IBNm. (Média de quatro repetições)

\begin{tabular}{|c|c|c|c|c|c|c|c|c|c|c|c|c|}
\hline \multirow{2}{*}{ Ano } & \multirow{2}{*}{ Trat $^{*}$} & \multicolumn{10}{|c|}{ Índice DRIS Elwali \& Gascho (1984) “Valor F” } & \multirow{2}{*}{ IBN } \\
\hline & & $\mathbf{N}$ & $\mathbf{P}$ & $\mathbf{K}$ & Ca & Mg & Fe & Mn & Zn & $\mathbf{C u}$ & B & \\
\hline \multirow{12}{*}{1998} & 1 & $31 \mathbf{N}$ & $-2,42 \mathbf{N}-$ & & & $1,36 \mathbf{N}$ & & & \multicolumn{2}{|c|}{$4,45 \mathbf{N}-12,49 \mathbf{D}$} & 4 & \\
\hline & 2 & & & & & & & & \multicolumn{2}{|c|}{$0,64 \mathbf{N}-11,63 \mathbf{D}$} & & \\
\hline & 3 & $-0,20 \mathbf{N}$ & ,07D & $-1,0$ & $-2,0$ & & & & \multicolumn{2}{|c|}{$0,00 \mathbf{N}-11,90 \mathbf{D}$} & $-1,66 \mathbf{N}$ & \\
\hline & 4 & $\mathbf{N}$ & $-4,24 \mathbf{D}$ & $2,10 \mathbf{N}$ & $-5,87 \mathbf{D}$ & $-9,6$ & $-0,7$ & & \multicolumn{2}{|c|}{$2,46 \mathbf{N}-10,63 \mathbf{D}$} & & 37,6 \\
\hline & 5 & $\mathbf{N}$ & $-5,79 \mathrm{~N}-2$ & $-22,04 \mathbf{D}$ & $-3,37 \mathbf{N}$ & $3,09 \mathrm{~N}$ & & & \multicolumn{2}{|c|}{$4,82 \mathbf{N}-12,71 \mathbf{D}$} & & 64,9 \\
\hline & 6 & $62 \mathrm{~N}$ & $-5,10 \mathbf{D}$ & $-3,84 \mathbf{D}$ & $-5,40 \mathbf{D}$ & $-2,59 \mathbf{N}$ & & & & $-9,83 \mathbf{D}$ & & 30,1 \\
\hline & 7 & & D & & & & & & \multicolumn{2}{|c|}{$2,23 \mathbf{N}-10,27 \mathbf{D}$} & & 31,4 \\
\hline & 8 & & & & & & & & \multicolumn{2}{|c|}{$2,97 \mathbf{N}-10,45 \mathbf{D}$} & & 43,3 \\
\hline & 9 & & $-3,37 \mathbf{N}-$ & & $-0,6$ & & & & \multicolumn{2}{|c|}{$3,89 \mathbf{N}-12,08 \mathbf{D}$} & & 48,3 \\
\hline & 10 & & & & & $-2,7$ & & & \multicolumn{2}{|c|}{$1,99 \mathbf{N}-10,67 \mathbf{D}$} & & 31,6 \\
\hline & 11 & & -4, & & & -7 & & & \multirow{2}{*}{\multicolumn{2}{|c|}{$\begin{array}{l}2,18 \mathbf{N}-9,32 \mathbf{D} \\
2,22 \mathbf{N}-11,24 \mathbf{D}\end{array}$}} & & 32,1 \\
\hline & 12 & & & & & & & & & & & 33,0 \\
\hline \multirow{12}{*}{1999} & 1 & & & & & & & & \multirow{2}{*}{$\begin{array}{l}4,78 \mathbf{N} \\
1,72 \mathbf{N}\end{array}$} & & & \\
\hline & 2 & & & & & & & & & & & 6,8 \\
\hline & 3 & & $-5,3$ & 0,0 & $-5,0$ & $-2,9$ & & & $1,50 \mathbf{N}$ & & & 22,9 \\
\hline & 4 & & -4 & 1,3 & -7 & -5 & & & $2,43 \mathbf{N}$ & & & 31,3 \\
\hline & 5 & & D - -2 & & & & & & $6,17 \mathbf{N}$ & & & 1,4 \\
\hline & 6 & & & & & & & & $3,95 \mathrm{~N}$ & & & 39,2 \\
\hline & 7 & & & $-2,6$ & & & & & $1,65 \mathbf{N}$ & & & 27,2 \\
\hline & 8 & -3 & $-4,14 \mathbf{D}$ & 0,5 & $-4,2$ & $-3,1$ & $-1,7$ & & $1,35 \mathbf{N}$ & $\mathbf{N}$ & & 24,7 \\
\hline & 9 & & $-7,64 \mathbf{D}-$ & & -1, & & & & $4,51 \mathbf{N}$ & & & 56,7 \\
\hline & 10 & & & & & & & & & & & 31,1 \\
\hline & 11 & & & & & & & & & & & 29,1 \\
\hline & 12 & & & 0,6 & & & & & & & & 280 \\
\hline & 1 & & & & & & & & & & & \\
\hline & 2 & & - & -10 & & & & & & & & 50,7 \\
\hline & 3 & & & & & & & & & & & 42,4 \\
\hline & 4 & & $-1,04 \mathbf{N}$ & $-1,56 \mathbf{N}$ & $-3,79 \mathbf{N}$ & $-5,24 \mathbf{D}$ & & & & $2 \mathbf{N}-$ & & 43,5 \\
\hline & 5 & $26 \mathbf{D}$ & $-0,31 \mathbf{N}-$ & $-30,97 \mathbf{D}$ & $5,54 \mathbf{N}$ & $17,94 \mathbf{E}$ & $-5,5$ & $29,89 \mathbf{E}$ & $5,26 \mathbf{N}$ & $-2,59 \mathbf{N}$ & $-7,00 \mathbf{N}$ & 87,4 \\
\hline & 6 & $20 \mathbf{D}$ & $-2,78 \mathbf{N}-$ & & & & & & & $3 \mathbf{N}$ & & 43,1 \\
\hline & 7 & & & & & -0 & & & & & & 39,2 \\
\hline & 8 & D & $-2,13 \mathbf{N}$ & $-2,07 \mathbf{N}$ & $-3,38 \mathbf{N}$ & $-4,0$ & -4 & & & $5 \mathbf{N}$ & & 43,6 \\
\hline & 9 & $-12,35 \mathbf{D}$ & $-3,50 \mathrm{~N}-2$ & $-27,76 \mathbf{D}$ & $5,10 \mathbf{N}$ & $19,25 \mathbf{E}$ & $-5,4$ & $E$ & $4,37 \mathbf{N}$ & $-0,98 \mathbf{N}$ & $-6,33 \mathbf{N}$ & 85,1 \\
\hline & 10 & $-10,87 \mathbf{D}$ & $-0,46 \mathbf{N}-$ & $-12,62 \mathrm{D}$ & $-0,56 \mathbf{N}$ & $2,49 \mathbf{N}$ & $-4,27 \mathbf{N}$ & $32,97 \mathbf{E}$ & $4,32 \mathbf{N}$ & $-3,19 \mathbf{N}$ & $-7,81 \mathbf{D}$ & 46,6 \\
\hline & 11 & & & & & & & & & & & 44,1 \\
\hline & 12 & D & $-1,4$ & $-1,4$ & 20 & -4 & -4 & $\mathbf{E}$ & 5,6 & -3 , & 5D & 44,4 \\
\hline
\end{tabular}

\footnotetext{
$\mathrm{N}=$ normal; $\mathrm{D}=$ deficiente e $\mathrm{E}=$ excesso.

(*)1- $0 \mathrm{~kg} / \mathrm{ha}$ de $\mathrm{K}_{2} \mathrm{O}+0 \mathrm{~kg} / \mathrm{ha} / \mathrm{ano}$ de $\mathrm{K}_{2} \mathrm{O} ; 2-0 \mathrm{~kg} / \mathrm{ha}$ de $\mathrm{K}_{2} \mathrm{O}+50 \mathrm{~kg} / \mathrm{ha} / \mathrm{ano}$ de $\mathrm{K}_{2} \mathrm{O} ; 3-0 \mathrm{~kg} / \mathrm{ha}$ de $\mathrm{K}_{2} \mathrm{O}+100$ $\mathrm{kg} / \mathrm{ha} / \mathrm{ano}$ de $\mathrm{K}_{2} \mathrm{O} ; 4$ - $0 \mathrm{~kg} / \mathrm{ha}$ de $\mathrm{K}_{2} \mathrm{O}+150 \mathrm{~kg} / \mathrm{ha} / \mathrm{ano}$ de $\mathrm{K}_{2} \mathrm{O} ; 5-50 \mathrm{~kg} / \mathrm{ha}$ de $\mathrm{K}_{2} \mathrm{O}+0 \mathrm{~kg} / \mathrm{ha} /$ ano de $\mathrm{K}_{2} \mathrm{O} ; 6$ 6- $50 \mathrm{~kg} / \mathrm{ha}$ de $\mathrm{K}_{2} \mathrm{O}+50 \mathrm{~kg} / \mathrm{ha} /$ ano de $\mathrm{K}_{2} \mathrm{O} ; 7-50 \mathrm{~kg} / \mathrm{ha}$ de $\mathrm{K}_{2} \mathrm{O}+100 \mathrm{~kg} / \mathrm{ha} / \mathrm{ano}$ de $\mathrm{K}_{2} \mathrm{O} ; 8$ 8- $50 \mathrm{~kg} / \mathrm{ha} \mathrm{de} \mathrm{K}_{2} \mathrm{O}+150 \mathrm{~kg} / \mathrm{ha} / \mathrm{ano}$ de $\mathrm{K}_{2} \mathrm{O} ; 9-100 \mathrm{~kg} / \mathrm{ha}$ de $\mathrm{K}_{2} \mathrm{O}+0 \mathrm{~kg} / \mathrm{ha} / \mathrm{ano}$ de $\mathrm{K}_{2} \mathrm{O} ; \mathbf{1 0}-100 \mathrm{~kg} / \mathrm{ha}$ de $\mathrm{K}_{2} \mathrm{O}+50 \mathrm{~kg} / \mathrm{ha} /$ ano de $\mathrm{K}_{2} \mathrm{O} ; 11-100 \mathrm{~kg} / \mathrm{ha}$ de $\mathrm{K}_{2} \mathrm{O}+100 \mathrm{~kg} / \mathrm{ha} /$ ano de $\mathrm{K}_{2} \mathrm{O} ; \mathbf{1 2}-100 \mathrm{~kg} / \mathrm{ha}$ de $\mathrm{K}_{2} \mathrm{O}+150 \mathrm{~kg} / \mathrm{ha} /$ ano de $\mathrm{K}_{2} \mathrm{O}$.
} 
Para o experimento de adubação nitrogenada, as relações entre as concentrações de $\mathrm{N}$ nas folhas de macieira cv. Fuji e os índices DRIS N, em função das doses e fontes de adubo nitrogenado, são apresentadas na Figura 17. Verificam-se correlações positivas e significativas $(p<0,01)$, seguindo o modelo linear, entre as concentrações de $\mathrm{N}$ e os índices DRIS N. Observou-se que o ponto de equilíbrio nutricional, definido pelo método DRIS, apresenta coincidência com a concentração de $\mathrm{N}$ considerada normal pelo critério de faixas de suficiência (Basso et al, 1986).

Na Figura 18 são apresentadas as relações entre a produção relativa de frutos de macieira cv. Fuji e os índices DRIS $\mathrm{N}$ e entre a produção relativa de frutos e a concentração de $\mathrm{N}$ nas folhas, em função das doses de adubo nitrogenado. Observou-se correlações negativas e significativas $(p<0,01)$, seguindo o modelo linear, entre estas variáveis, para todos os métodos e critérios utilizados. Verifica-se que a maior produtividade foi obtida quando o índice DRIS $\mathrm{N}$ foi próximo a zero. A concentração de $\mathrm{N}$ nas folhas também apresentou correlações positivas e significativas $(\mathrm{p}<0,05)$ com a produção relativa, seguindo o modelo quadrático. Estes resultados indicam que, quanto mais próximo de zero o índice DRIS para $\mathrm{N}$, maior é a produtividade da cultura da macieira.

A relação entre a produção relativa de frutos de macieira cv. Fuji e o Índice de Balanço Nutricional (IBN), em função das doses e fontes de adubo nitrogenado, é apresentada na Figura 19. O IBN apresentou comportamento próximo do modelo teórico, com ajuste seguindo o modelo linear significativo $(\mathrm{p}<0,01)$ e relação inversa à produção de frutos para os métodos Jones (1981), utilizando o "valor R" e o "valor F" e Elwali \& Gascho (1984), utilizando o "valor R". Para o método Elwali \& Gascho (1984), utilizando o "valor F" a relação não foi significativa. As maiores produtividades estiveram relacionadas com os menores valores de IBN. 

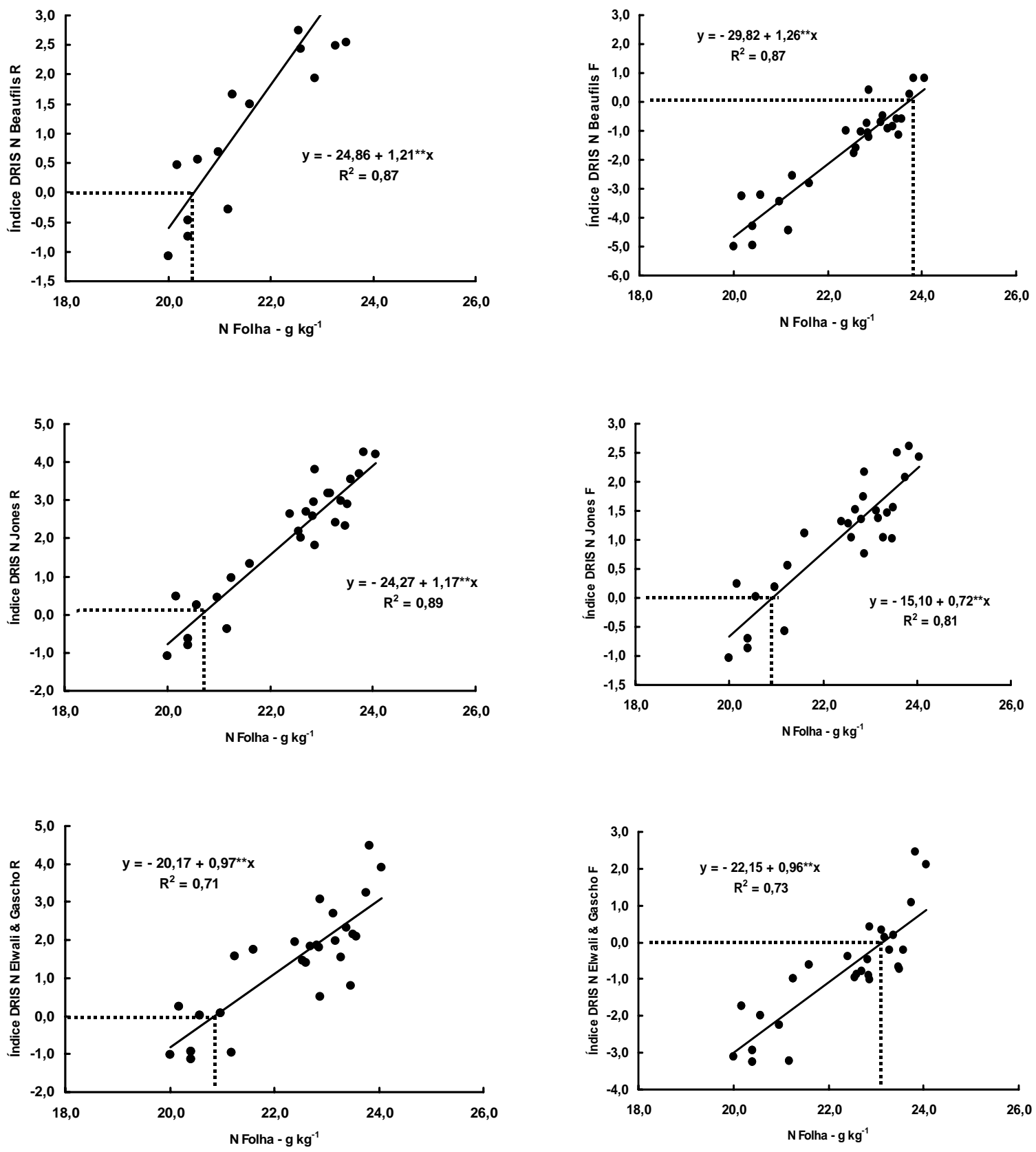

Figura 17 - Relação entre a concentração de $\mathrm{N}$ nas folhas de macieira cv. Fuji e os índices DRIS N para combinações de métodos de escolha da ordem das razões entre nutrientes (valor R - Nick (1998) e valor F - Letzsch (1985) e Walworth et al. (1986)) e índices DRIS (métodos Beaufils (1973), Jones (1981) e Elwali \& Gascho (1984)), em função de doses e fontes de adubo nitrogenado. (Resultados de cinco anos) 

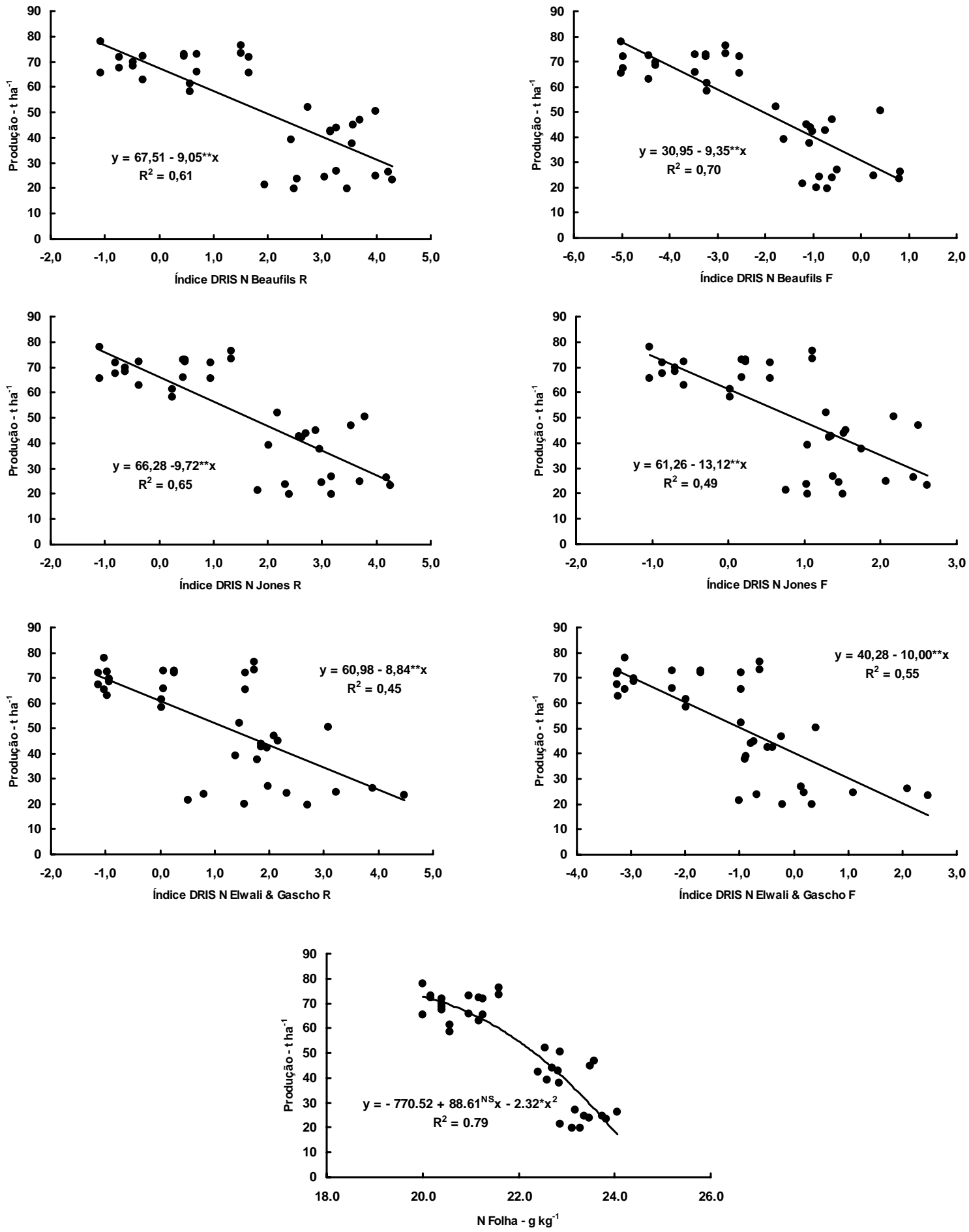

Figura 18 - Relação entre a produção relativa de frutos de macieira cv. Fuji e os índices DRIS N para combinações de métodos de escolha da ordem das razões entre nutrientes (valor R - Nick (1998) e valor F - Letzsch (1985) e Walworth et al. (1986)) e índices DRIS (métodos Beaufils (1973), Jones (1981) e Elwali \& Gascho (1984)) e a concentração de K nas folhas (e), em função de doses e fontes de adubo nitrogenado. (Resultados de cinco anos) 

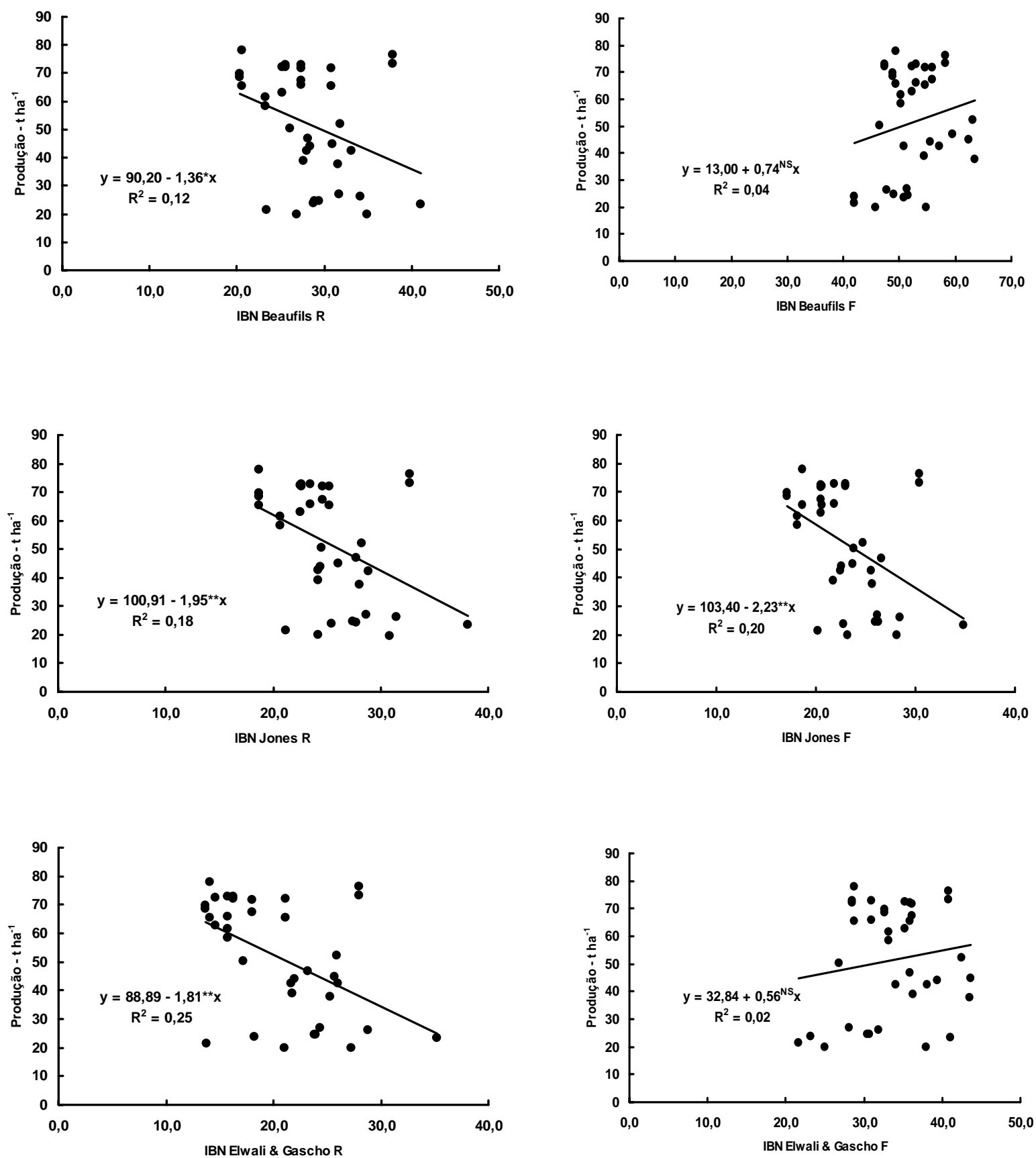

Figura 19 - Relação entre a produção relativa de frutos de macieira cv. Fuji e os Índices de Balanço Nutricional (IBN) para combinações de métodos de escolha da ordem das razões entre nutrientes (valor R - Nick (1998) e valor F - Letzsch (1985) e Walworth et al. (1986)) e índices DRIS (métodos Beaufils (1973), Jones (1981) e Elwali \& Gascho (1984)), em função de doses e fontes de adubo nitrogenado. (Resultados de cinco anos) 
Da mesma forma utilizada para o experimento de adubação potássica, para a definição do melhor método, também foi verificada a percentagem de concordância entre os métodos DRIS e o critério de faixas de suficiência quanto ao diagnóstico nutricional (percentagem de amostras deficientes, normais e em excesso), considerando todos os nutrientes avaliados. Verifica-se que para o diagnóstico referente ao $\mathrm{N}$, a percentagem de concordância no diagnóstico nutricional variou entre $78 \%$ e $100 \%$ entre os modelos avaliados (Tabela 16).

Quando foram considerados todos os nutrientes, o maior número de concordância foi observado quando utilizou-se o método Elwali \& Gascho (1984), utilizando o critério "valor F". Como também verificado nos resultado do experimento de adubação potássica, os outros métodos apresentaram concordância baixa em relação ao critério de faixas de suficiência para P, Ca e Zn.

Comparando os resultados das Tabelas 17 e 18, verifica-se que, mesmo para o método DRIS que apresentou maior porcentagem de dignóstico semelhante ao critério de faixas de suficiência, houve diferenças no diagnóstico, já que para $\mathrm{P}$ e $\mathrm{Ca}$, o critério de faixas de suficiência identificou maior número de amostras deficientes do que o método DRIS, enquanto que para $\mathrm{Zn}$ o método DRIS identificou maior número de amostras com excesso do que o critério de faixas de suficiência.

Os resultado obtidos, tanto para o experimento de adubação potássica como para adubação nitrogenada, indicam que o método de Elwali \& Gascho (1984), utilizando o critério "valor F" é o mais indicado para a cultura da macieira, por ter apresentado valores de IBN que indicaram o estado nutricional das plantas e pela eficiência no diagnóstico nutricional da cultura. 
Tabela 16. Porcentagem de concordância no diagnóstico nutricional da macieira (deficiência, normal e excesso) entre o Critério de Faixa de Suficiência e os métodos DRIS para combinações de critérios de escolha da ordem das razões entre nutrientes (valor R - Nick (1998) e valor F - Letzsch (1985) e Walworth et al. (1986)) e índices DRIS (métodos Beaufils (1973), Jones (1981) e Elwali \& Gascho (1984)), em função de doses e fontes de adubo nitrogenado. (Resultados de cinco anos)

\begin{tabular}{|c|c|c|c|c|c|c|}
\hline \multirow{2}{*}{ Nutriente } & \multicolumn{2}{|c|}{ Beaufils (1973) } & \multicolumn{2}{|c|}{ Jones(1981) } & \multicolumn{2}{|c|}{ Elwali \& Gascho (1984) } \\
\hline & $\mathbf{R}$ & $\mathbf{F}$ & $\mathbf{R}$ & $\mathbf{F}$ & $\mathbf{R}$ & $\mathbf{F}$ \\
\hline & & & & & & ------ \\
\hline $\mathbf{N}$ & 77,78 & 100,00 & 86,11 & 100,00 & 88,89 & 100,00 \\
\hline $\mathbf{P}$ & 22,22 & 22,22 & 22,22 & 22,22 & 22,22 & 58,33 \\
\hline $\mathbf{K}$ & 91,67 & 77,78 & 88,89 & 88,89 & 72,22 & 88,89 \\
\hline Ca & 25,00 & 25,00 & 25,00 & 25,00 & 25,00 & 61,11 \\
\hline Mg & 91,67 & 94,44 & 94,44 & 94,44 & 80,56 & 55,56 \\
\hline $\mathbf{F e}$ & 100,00 & 94,44 & 100,00 & 100,00 & 100,00 & 100,00 \\
\hline Mn & 100,00 & 100,00 & 100,00 & 100,00 & 100,00 & 100,00 \\
\hline Zn & 0,00 & 0,00 & 0,00 & 0,00 & 0,00 & 44,44 \\
\hline $\mathbf{C u}$ & 61,11 & 33,33 & 66,67 & 33,33 & 86,11 & 77,78 \\
\hline B & 83,33 & 100,00 & 86,11 & 88,89 & 80,56 & 83,33 \\
\hline Média & 65,28 & 64,72 & 66,94 & 65,28 & 65,56 & 76,94 \\
\hline
\end{tabular}


Tabela 17. Concentração de macro e micronutrientes em folhas de macieira em função da aplicação anual de doses e fontes de adubo nitrogenado e o diagnóstico nutricional segundo o critério de Faixa de Suficiência. (Média de quatro repetições)

\begin{tabular}{|c|c|c|c|c|c|c|c|c|c|c|c|}
\hline \multirow{2}{*}{ Ano } & \multirow{2}{*}{ Trat. ${ }^{*}$} & \multicolumn{10}{|c|}{ Análise Foliar } \\
\hline & & $\mathbf{N}$ & $\mathbf{P}$ & $\mathbf{K}$ & Ca & Mg & $\mathbf{F e}$ & Mn & Zn & $\mathbf{C u}$ & $\mathbf{B}$ \\
\hline & & \multicolumn{5}{|c|}{ - } & \multicolumn{5}{|c|}{ - } \\
\hline \multirow{9}{*}{1996} & 1 & $23,3 \mathbf{N}$ & $1,5 \mathbf{D}$ & $12,9 \mathbf{N}$ & $10,4 \mathbf{D}$ & $2,5 \mathbf{D}$ & $112 \mathbf{N}$ & $363 \mathbf{E}$ & $70 \mathbf{N}$ & $5 \mathbf{D}$ & $38 \mathbf{N}$ \\
\hline & 2 & $23,2 \mathbf{N}$ & $1,3 \mathbf{D}$ & $12,8 \mathbf{N}$ & $10,3 \mathbf{D}$ & $2,5 \mathbf{N}$ & $112 \mathbf{N}$ & $377 \mathbf{E}$ & $74 \mathbf{N}$ & $4 \mathbf{D}$ & $37 \mathbf{N}$ \\
\hline & 3 & $23,1 \mathbf{N}$ & $1,3 \mathbf{D}$ & $10,7 \mathbf{D}$ & $10,2 \mathbf{D}$ & $2,5 \mathbf{D}$ & $118 \mathbf{N}$ & $431 \mathbf{E}$ & $72 \mathbf{N}$ & $4 \mathrm{D}$ & $38 \mathbf{N}$ \\
\hline & 4 & $23,4 \mathbf{N}$ & $1,3 \mathbf{D}$ & $13,5 \mathbf{N}$ & $10,0 \mathbf{D}$ & $2,4 \mathbf{D}$ & $113 \mathbf{N}$ & & & & $38 \mathbf{N}$ \\
\hline & 5 & $23,8 \mathbf{N}$ & $1,3 \mathbf{D}$ & $11,2 \mathbf{D}$ & & $2,5 \mathbf{D}$ & $110 \mathbf{N}$ & $397 \mathbf{E}$ & & $5 \mathrm{D}$ & $38 \mathbf{N}$ \\
\hline & 6 & $24,1 \mathbf{N}$ & $1,4 \mathbf{D}$ & $14,8 \mathbf{N}$ & $9,5 \mathbf{D}$ & $2,0 \mathbf{D}$ & $114 \mathbf{N}$ & $350 \mathbf{E}$ & $70 \mathbf{N}$ & $5 \mathrm{D}$ & $38 \mathbf{N}$ \\
\hline & 7 & $23,8 \mathbf{N}$ & $1,4 \mathbf{D}$ & $16,6 \mathbf{E}$ & $9,0 \mathbf{D}$ & $1,8 \mathbf{D}$ & $110 \mathbf{N}$ & $365 \mathbf{E}$ & $68 \mathbf{N}$ & $5 \mathrm{D}$ & $40 \mathrm{~N}$ \\
\hline & 8 & $22,9 \mathbf{N}$ & $1,4 \mathbf{D}$ & $12,1 \mathbf{N}$ & $10,7 \mathbf{D}$ & $2,6 \mathbf{N}$ & $112 \mathbf{N}$ & $343 \mathbf{E}$ & $67 N$ & $5 \mathrm{~N}$ & $37 \mathbf{N}$ \\
\hline & 9 & $23,5 \mathbf{N}$ & $1,4 \mathbf{D}$ & $11,5 \mathbf{D}$ & $11,1 \mathbf{N}$ & $2,7 \mathbf{N}$ & $125 \mathbf{N}$ & $337 \mathbf{E}$ & $68 \mathbf{N}$ & $5 \mathrm{D}$ & $37 \mathbf{N}$ \\
\hline \multirow{9}{*}{1997} & 1 & $22,6 \mathbf{N}$ & $1,5 \mathbf{D}$ & $10,2 \mathbf{D}$ & $10,8 \mathbf{D}$ & $2,7 \mathbf{N}$ & $95 \mathbf{N}$ & $430 \mathrm{E}$ & $71 \mathbf{N}$ & $5 \mathrm{~N}$ & $34 \mathbf{N}$ \\
\hline & 2 & $22,6 \mathbf{N}$ & $1,4 \mathbf{D}$ & $9,4 \mathbf{D}$ & $10,4 \mathbf{D}$ & $2,7 \mathbf{N}$ & $97 \mathbf{N}$ & $466 \mathrm{E}$ & & $5 \mathrm{~N}$ & $35 \mathbf{N}$ \\
\hline & 3 & $23,5 \mathbf{N}$ & $1,4 \mathbf{D}$ & $9,3 \mathbf{D}$ & $10,7 \mathbf{D}$ & $2,9 \mathbf{N}$ & $100 \mathbf{N}$ & $509 \mathbf{E}$ & & $5 \mathrm{D}$ & $34 \mathbf{N}$ \\
\hline & 4 & $22,9 \mathbf{N}$ & $1,4 \mathbf{D}$ & $9,6 \mathbf{D}$ & $9,9 \mathbf{D}$ & $2,6 \mathbf{N}$ & $90 \mathbf{N}$ & $482 \mathbf{E}$ & 7 & $5 \mathrm{D}$ & $35 \mathbf{N}$ \\
\hline & 5 & $22,7 \mathbf{N}$ & $1,4 \mathbf{D}$ & $9,2 \mathbf{D}$ & $10,2 \mathbf{D}$ & $2,6 \mathbf{N}$ & $109 \mathbf{N}$ & $459 \mathbf{E}$ & 6 & $5 \mathbf{N}$ & $34 \mathbf{N}$ \\
\hline & 6 & $22,9 \mathbf{N}$ & $1,4 \mathbf{D}$ & $12,1 \mathbf{N}$ & $9,0 \mathbf{D}$ & $2,3 \mathbf{D}$ & $97 \mathbf{N}$ & $369 \mathbf{E}$ & $61 \mathbf{N}$ & $5 \mathrm{D}$ & $34 \mathbf{N}$ \\
\hline & 7 & $23,6 \mathbf{N}$ & $1,4 \mathbf{D}$ & $13,0 \mathbf{N}$ & $9,1 \mathbf{D}$ & $2,1 \mathbf{D}$ & $101 \mathbf{N}$ & $458 \mathbf{E}$ & $\mathbf{N}$ & $6 \mathbf{N}$ & $34 \mathbf{N}$ \\
\hline & 8 & $22,8 \mathbf{N}$ & $1,4 \mathbf{D}$ & $9,5 \mathbf{D}$ & $11,0 \mathbf{D}$ & $2,8 \mathbf{N}$ & $97 \mathbf{N}$ & $419 \mathbf{E}$ & & & $34 \mathbf{N}$ \\
\hline & 9 & $22,4 \mathbf{N}$ & $1,3 \mathbf{D}$ & $9,4 \mathbf{D}$ & $10,9 \mathbf{D}$ & $2,6 \mathbf{N}$ & $97 \mathbf{N}$ & $425 \mathbf{E}$ & $72 \mathbf{N}$ & $5 \mathrm{D}$ & $34 \mathbf{N}$ \\
\hline \multirow{9}{*}{1998} & 1 & $20,4 \mathbf{N}$ & $1,6 \mathbf{N}$ & $10,5 \mathbf{D}$ & $10,1 \mathbf{D}$ & $3,2 \mathbf{N}$ & $120 \mathbf{N}$ & $435 \mathbf{E}$ & $78 \mathbf{N}$ & $6 N$ & 29 D \\
\hline & 2 & $20,0 \mathbf{N}$ & $1,4 \mathbf{D}$ & $11,5 \mathbf{D}$ & $8,7 \mathbf{D}$ & $2,9 \mathbf{N}$ & $127 \mathbf{N}$ & $411 \mathbf{E}$ & & $6 \mathbf{N}$ & $33 \mathbf{N}$ \\
\hline & 3 & $21,3 \mathbf{N}$ & $1,5 \mathbf{D}$ & $9,2 \mathbf{D}$ & $10,0 \mathbf{D}$ & $3,2 \mathbf{N}$ & $118 \mathbf{N}$ & $439 \mathrm{E}$ & & $6 N$ & $24 \mathrm{D}$ \\
\hline & 4 & $21,0 \mathbf{N}$ & $1,6 \mathbf{N}$ & $12,2 \mathbf{N}$ & $8,7 \mathbf{D}$ & $2,8 \mathbf{N}$ & $130 \mathbf{N}$ & $435 \mathbf{E}$ & $73 \mathbf{N}$ & $6 \mathbf{N}$ & $25 \mathrm{D}$ \\
\hline & 5 & $21,2 \mathbf{N}$ & $1,6 \mathbf{N}$ & $11,1 \mathbf{D}$ & $9,6 \mathbf{D}$ & $3,0 \mathbf{N}$ & $129 \mathbf{N}$ & $450 \mathbf{E}$ & $74 \mathrm{~N}$ & $6 \mathbf{N}$ & $30 \mathrm{D}$ \\
\hline & 6 & $20,2 \mathbf{N}$ & $1,5 \mathbf{D}$ & $13,2 \mathbf{N}$ & $7,2 \mathbf{D}$ & $2,3 \mathbf{D}$ & $127 \mathbf{N}$ & $378 \mathbf{E}$ & $68 \mathbf{N}$ & $6 \mathbf{N}$ & $32 \mathbf{N}$ \\
\hline & 7 & $21,6 \mathbf{N}$ & $1,6 \mathbf{N}$ & $15,3 \mathbf{E}$ & $7,8 \mathbf{D}$ & $2,2 \mathbf{D}$ & $128 \mathbf{N}$ & $448 \mathbf{E}$ & $81 \mathbf{N}$ & $6 \mathbf{N}$ & $27 \mathrm{D}$ \\
\hline & 8 & $20,4 \mathbf{N}$ & $1,5 \mathbf{D}$ & $10,2 \mathbf{D}$ & $10,0 \mathbf{D}$ & $3,0 \mathbf{N}$ & $118 \mathbf{N}$ & $403 \mathbf{E}$ & $70 \mathbf{N}$ & $6 \mathbf{N}$ & $30 \mathbf{N}$ \\
\hline & 9 & $20,6 \mathbf{N}$ & $1,4 \mathbf{D}$ & $9,6 \mathbf{D}$ & $9,6 \mathbf{D}$ & $3,0 \mathbf{N}$ & $111 \mathbf{N}$ & $391 \mathbf{E}$ & $70 \mathbf{N}$ & $6 \mathbf{N}$ & $28 \mathbf{D}$ \\
\hline \multirow{9}{*}{1999} & 1 & $20,4 \mathbf{N}$ & $1,6 \mathbf{N}$ & $10,5 \mathbf{D}$ & $10,1 \mathbf{D}$ & $3,2 \mathbf{N}$ & $120 \mathrm{~N}$ & $435 \mathbf{E}$ & $78 \mathbf{N}$ & $6 N$ & 29 D \\
\hline & 2 & $20,0 \mathbf{N}$ & $1,4 \mathbf{D}$ & $11,5 \mathbf{D}$ & $8,7 \mathbf{D}$ & $2,9 \mathbf{N}$ & $127 \mathbf{N}$ & $411 \mathbf{E}$ & $72 \mathbf{N}$ & $6 \mathbf{N}$ & $33 \mathbf{N}$ \\
\hline & 3 & $21,3 \mathbf{N}$ & $1,5 \mathbf{D}$ & $9,2 \mathbf{D}$ & $10,0 \mathbf{D}$ & $3,2 \mathbf{N}$ & $118 \mathbf{N}$ & $439 \mathrm{E}$ & $70 \mathbf{N}$ & $6 N$ & $24 \mathrm{D}$ \\
\hline & 4 & $21,0 \mathbf{N}$ & $1,6 \mathbf{N}$ & $12,2 \mathbf{N}$ & $8,7 \mathbf{D}$ & $2,8 \mathbf{N}$ & $130 \mathbf{N}$ & $435 \mathbf{E}$ & $73 \mathbf{N}$ & $6 N$ & $25 \mathrm{D}$ \\
\hline & 5 & $21,2 \mathbf{N}$ & $1,6 \mathbf{N}$ & $11,1 \mathbf{D}$ & $9,6 \mathbf{D}$ & $3,0 \mathbf{N}$ & $129 \mathrm{~N}$ & $450 \mathbf{E}$ & $74 \mathrm{~N}$ & $6 \mathbf{N}$ & $30 \mathrm{D}$ \\
\hline & 6 & $20,2 \mathbf{N}$ & $1,5 \mathbf{D}$ & $13,2 \mathbf{N}$ & $7,2 \mathbf{D}$ & 2,3 D & $127 \mathbf{N}$ & $378 \mathbf{E}$ & $68 \mathbf{N}$ & $6 N$ & $32 \mathbf{N}$ \\
\hline & 7 & $21,6 \mathbf{N}$ & $1,6 \mathbf{N}$ & $15,3 \mathbf{E}$ & $7,8 \mathbf{D}$ & 2,2 D & $128 \mathbf{N}$ & $448 \mathbf{E}$ & $81 \mathbf{N}$ & $6 \mathbf{N}$ & $27 \mathrm{D}$ \\
\hline & 8 & $20,4 \mathbf{N}$ & $1,5 \mathbf{D}$ & $10,2 \mathbf{D}$ & $10,0 \mathbf{D}$ & $3,0 \mathbf{N}$ & $118 \mathbf{N}$ & $403 \mathbf{E}$ & $70 \mathbf{N}$ & $6 \mathbf{N}$ & $30 \mathbf{N}$ \\
\hline & 9 & $20,6 \mathbf{N}$ & $1,4 \mathbf{D}$ & $9,6 \mathbf{D}$ & $9,6 \mathbf{D}$ & $3,0 \mathbf{N}$ & $111 \mathbf{N}$ & $391 \mathbf{E}$ & $70 \mathrm{~N}$ & $6 \mathbf{N}$ & $28 \mathbf{D}$ \\
\hline
\end{tabular}

$\mathrm{N}=$ normal; $\mathrm{D}=$ deficiente e $\mathrm{E}=$ excesso.

1- Testemunha (sem aplicação de nitrogênio); $2-50 \mathrm{~g} /$ planta/ano de $\mathrm{N}$ na forma de uréia; 3- $100 \mathrm{~g} /$ planta/ano de $\mathrm{N}$ na forma de uréia; 4- $50 \mathrm{~g} / \mathrm{planta} /$ ano de $\mathrm{N}$ na forma de sulfato de amônio; 5- $100 \mathrm{~g} / \mathrm{planta} /$ ano de $\mathrm{N}$ na forma de sulfato de amônio; 6- $50 \mathrm{~g} /$ planta/ano de $\mathrm{N}$ na forma de nitrato de potássio; 7- $100 \mathrm{~g} /$ planta/ano de $\mathrm{N}$ na forma de nitrato de potássio; 8- $50 \mathrm{~g} / \mathrm{planta} /$ ano de $\mathrm{N}$ na forma de nitrato de cálcio; 9- $100 \mathrm{~g} / \mathrm{planta} /$ ano de $\mathrm{N}$ na forma de nitrato de cálcio. 
Tabela 18. Índices DRIS pelo método Elwali \& Gascho (1984), utilizando o "Valor F" para a escolha da razão entre nutrientes, em função de doses e fontes de adubo nitrogenado, e o diagnóstico nutricional segundo o critério do IBN médio. (Média de quatro repetições)

\begin{tabular}{|c|c|c|c|c|c|c|c|c|c|c|c|c|}
\hline \multirow{2}{*}{ Ano } & \multirow{2}{*}{ Trat $^{*}$} & \multicolumn{10}{|c|}{ Índice DRIS Elwali \& Gascho (1984) “Valor F” } & \multirow{2}{*}{ IBN } \\
\hline & & $\mathbf{N}$ & $\mathbf{P}$ & $\mathbf{K}$ & Ca & Mg & Fe & Mn & $\mathrm{Zn}$ & $\mathbf{C u}$ & $\mathbf{B}$ & \\
\hline \multirow{9}{*}{1996} & 1 & $-0,22 \mathbf{N}$ & $-2,15 \mathbf{N}$ & $-1,82 \mathbf{N}$ & $-2,00 \mathbf{N}$ & $-5,42 \mathbf{D}$ & $-1,51 \mathbf{N}$ & $20,57 \mathbf{E}$ & $2,21 \mathbf{N}$ & $-9,53 \mathbf{D}$ & $-0,14 \mathbf{N}$ & 25,0 \\
\hline & 2 & $0,14 \mathbf{N}$ & $-3,59 \mathbf{D}$ & $-1,74 \mathbf{N}$ & $-1,98 \mathbf{N}$ & $-3,39 \mathbf{D}$ & $-1,41 \mathbf{N}$ & $22,65 \mathbf{E}$ & $2,59 \mathbf{N}$ & $-12,66 \mathbf{D}$ & $-0,61 \mathbf{N}$ & 28,1 \\
\hline & 3 & $0,33 \mathbf{N}$ & $-4,26 \mathbf{D}$ & $-8,27 \mathbf{D}$ & $-2,64 \mathbf{N}$ & $-5,07 \mathbf{D}$ & $-1,69 \mathbf{N}$ & $27,14 \mathbf{E}$ & $4,95 \mathbf{E}$ & $-10,59 \mathbf{D}$ & $0,10 \mathbf{N}$ & 37,9 \\
\hline & 4 & $0,20 \mathbf{N}$ & $-4,28 \mathbf{D}$ & $-2,01 \mathbf{N}$ & $-2,83 \mathbf{N}$ & $-6,35 \mathbf{D}$ & $-1,86 \mathbf{N}$ & $24,86 \mathbf{E}$ & $2,62 \mathbf{N}$ & $-9,92 \mathbf{D}$ & $-0,42 \mathbf{N}$ & 30,5 \\
\hline & 5 & $1,09 \mathbf{N}$ & $-4,19 \mathbf{D}$ & $-5,03 \mathbf{D}$ & $-3,69 \mathbf{D}$ & $-5,15 \mathbf{D}$ & $-2,45 \mathbf{N}$ & $24,06 \mathbf{E}$ & $2,26 \mathbf{N}$ & $-6,75 \mathbf{D}$ & $-0,15 \mathbf{N}$ & 30,7 \\
\hline & 6 & $2,10 \mathbf{N}$ & $-2,63 \mathbf{N}$ & $1,42 \mathbf{N}$ & $-3,44 \mathbf{N}$ & $-9,40 \mathbf{D}$ & $-1,29 \mathbf{N}$ & $18,62 \mathbf{E}$ & $2,77 \mathbf{N}$ & $-8,49 \mathbf{D}$ & $0,33 \mathbf{N}$ & 31,9 \\
\hline & 7 & $2,47 \mathbf{N}$ & $-2,66 \mathbf{N}$ & $2,10 \mathbf{N}$ & $-4,43 \mathbf{N}$ & $-13,71 \mathbf{D}$ & $-1,45 \mathbf{N}$ & $18,69 \mathbf{E}$ & $3,00 \mathbf{N}$ & $-7,60 \mathrm{D}$ & $3,60 \mathbf{N}$ & 41,0 \\
\hline & 8 & $-1,01 \mathbf{N}$ & $-2,55 \mathbf{D}$ & $-3,17 \mathbf{D}$ & $-2,20 \mathbf{N}$ & $-3,62 \mathrm{D}$ & $-1,94 \mathbf{N}$ & $18,82 \mathbf{E}$ & $1,42 \mathbf{N}$ & $-5,52 \mathbf{D}$ & $-0,22 \mathbf{N}$ & 21,6 \\
\hline & 9 & $-0,68 \mathbf{N}$ & $-2,40 \mathbf{N}$ & $-3,44 \mathbf{D}$ & $-0,94 \mathbf{N}$ & $-3,53 \mathbf{D}$ & $-0,89 \mathbf{N}$ & $16,44 \mathbf{E}$ & $1,47 \mathbf{N}$ & $-7,91 \mathbf{D}$ & $1,88 \mathbf{N}$ & 23,1 \\
\hline \multirow{9}{*}{1997} & 1 & $-0,88 \mathbf{N}$ & $-3,22 \mathbf{N}$ & $-8,52 \mathbf{D}$ & $-2,63 \mathbf{N}$ & $-4,61 \mathbf{D}$ & $-3,31 \mathbf{N}$ & $26,76 \mathbf{E}$ & $4,76 \mathbf{E}$ & $-7,28 \mathbf{D}$ & $-1,08 \mathbf{N}$ & 36,3 \\
\hline & 2 & $-0,97 \mathbf{N}$ & $-4,86 \mathbf{D}$ & $10,69 \mathbf{D}$ & $-4,20 \mathbf{N}$ & $-5,18 \mathbf{D}$ & $-3,55 \mathbf{N}$ & $30,29 \mathbf{E}$ & $6,10 \mathbf{E}$ & $-6,13 \mathbf{D}$ & $-0,81 \mathbf{N}$ & 42,5 \\
\hline & 3 & $-0,74 \mathbf{N}$ & $-4,04 \mathbf{N}$ & 11,1 & $-3,28 \mathbf{N}$ & $-5,02 \mathbf{D}$ & $-3,80 \mathbf{N}$ & $32,99 \mathbf{E}$ & $5,30 \mathbf{E}$ & $-9,05 \mathbf{D}$ & $-1,22 \mathbf{N}$ & 43,6 \\
\hline & 4 & $-0,90 \mathbf{N}$ & $-3,96 \mathbf{N}$ & $10,34 \mathbf{D}$ & $-4,55 \mathbf{N}$ & $-5,45 \mathbf{D}$ & $-4,06 \mathbf{N}$ & $32,30 \mathbf{E}$ & $5,60 \mathbf{E}$ & $-7,60 \mathbf{D}$ & $-1,04 \mathbf{N}$ & 43,5 \\
\hline & 5 & $-0,78 \mathbf{N}$ & $-4,55 \mathbf{D}$ & $10,21 \mathbf{D}$ & $-4,04 \mathbf{N}$ & $-4,97 \mathbf{D}$ & $-2,98 \mathbf{N}$ & $29,57 \mathbf{E}$ & $4,92 \mathbf{E}$ & $-6,00 \mathbf{D}$ & $-0,96 \mathbf{N}$ & 39,4 \\
\hline & 6 & $0,42 \mathbf{N}$ & $-1,88 \mathbf{N}$ & $-2,65 \mathbf{N}$ & $-4,32 \mathbf{D}$ & $-5,22 \mathbf{D}$ & $-2,60 \mathbf{N}$ & $23,03 \mathbf{E}$ & $1,45 \mathbf{N}$ & $-6,87 \mathbf{D}$ & $-1,36 \mathbf{N}$ & 26,8 \\
\hline & 7 & $-0,23 \mathbf{N}$ & $-4,65 \mathrm{D}$ & $-3,17 \mathbf{N}$ & $-5,62 \mathbf{D}$ & $-8,55 \mathbf{D}$ & $-3,31 \mathbf{N}$ & $29,15 \mathbf{E}$ & $3,38 \mathbf{N}$ & $-4,71 \mathbf{D}$ & $-2,28 \mathbf{N}$ & 35,9 \\
\hline & 8 & $-0,48 \mathbf{N}$ & $-4,09 \mathbf{D}$ & $-9,18 \mathbf{D}$ & $-1,81 \mathbf{N}$ & $-4,15 \mathbf{D}$ & $-3,11 \mathbf{N}$ & $4 E$ & $3,89 \mathbf{E}$ & $-6,52 \mathbf{D}$ & $-0,80 \mathbf{N}$ & 34,0 \\
\hline & 9 & $-0,39 \mathbf{N}$ & $-3,65 \mathbf{N}$ & $-9,72 \mathbf{D}$ & $-2,22 \mathbf{N}$ & $-4,62 \mathbf{D}$ & $-3,14 \mathbf{N}$ & $27,60 \mathbf{E}$ & $5,23 \mathbf{E}$ & $-8,59 \mathbf{D}$ & $-0,50 \mathbf{N}$ & 38,1 \\
\hline \multirow{9}{*}{1998} & 1 & $-3,25 \mathbf{N}$ & $-3,10 \mathbf{N}$ & $-6,72 \mathbf{D}$ & $-4,05 \mathbf{D}$ & $-3,75 \mathbf{N}$ & $-2,46 \mathbf{N}$ & $25,92 \mathbf{E}$ & $5,09 \mathbf{E}$ & $-4,24 \mathbf{D}$ & $-3,43 \mathbf{N}$ & 36,1 \\
\hline & 2 & $-3,11 \mathbf{N}$ & $-3,85 \mathbf{D}$ & $-3,25 \mathbf{D}$ & $-4,55 \mathbf{D}$ & $-3,91 \mathbf{D}$ & $-2,09 \mathbf{N}$ & $23,91 \mathbf{E}$ & $2,39 \mathbf{N}$ & $-2,85 \mathbf{N}$ & $-2,69 \mathbf{N}$ & 28,7 \\
\hline & 3 & $-0,98 \mathbf{N}$ & $-3,97 \mathbf{N}$ & $-9,43 \mathbf{D}$ & $-3,99 \mathbf{D}$ & $-1,08 \mathbf{N}$ & $-2,54 \mathbf{N}$ & $27,52 \mathbf{E}$ & $4,20 \mathbf{E}$ & $-3,26 \mathbf{N}$ & $-6,45 \mathbf{D}$ & 35,9 \\
\hline & 4 & $-2,24 \mathbf{N}$ & $-2,83 \mathbf{N}$ & $-3,24 \mathbf{N}$ & $-5,59 \mathbf{D}$ & $-4,30 \mathbf{D}$ & $-2,20 \mathbf{N}$ & $26,31 \mathbf{E}$ & $2,34 \mathbf{N}$ & $-3,23 \mathbf{N}$ & $-5,01 \mathbf{D}$ & 31,0 \\
\hline & 5 & $-3,24 \mathbf{N}$ & $-2,94 \mathbf{N}$ & $-6,23 \mathbf{D}$ & $-5,00 \mathbf{D}$ & $-4,08 \mathbf{D}$ & $-2,32 \mathbf{N}$ & $26,09 \mathbf{E}$ & $4,55 \mathbf{E}$ & $-3,37 \mathbf{N}$ & $-3,47 \mathbf{N}$ & 35,2 \\
\hline & 6 & $-1,72 \mathbf{N}$ & $-2,01 \mathbf{N}$ & $-2,46 \mathbf{N}$ & $-9,05 \mathbf{D}$ & $-4,88 \mathbf{D}$ & $-1,13 \mathbf{N}$ & $22,96 \mathbf{E}$ & $2,80 \mathbf{N}$ & $-2,69 \mathbf{N}$ & $-1,82 \mathbf{N}$ & 28,5 \\
\hline & 7 & $-0,62 \mathbf{N}$ & $-1,57 \mathbf{N}$ & $-1,12 \mathbf{N}$ & $-9,51 \mathbf{D}$ & $-8,73 \mathbf{D}$ & $-1,10 \mathbf{N}$ & $27,85 \mathbf{E}$ & $6,46 \mathbf{E}$ & $-3,18 \mathbf{N}$ & $-8,48 \mathbf{D}$ & 40,8 \\
\hline & 8 & $-2,95 \mathbf{N}$ & $-3,64 \mathbf{D}$ & $-6,24 \mathbf{D}$ & $-3,66 \mathbf{D}$ & $-3,57 \mathbf{N}$ & $-2,26 \mathbf{N}$ & $23,51 \mathbf{E}$ & $4,55 \mathbf{E}$ & $-2,77 \mathbf{N}$ & $-2,96 \mathbf{N}$ & 32,6 \\
\hline & 9 & $-1,98 \mathbf{N}$ & $-3,61 \mathbf{N}$ & $-7,36 \mathbf{D}$ & $-3,72 \mathbf{D}$ & $-3,44 \mathbf{N}$ & $-2,35 \mathbf{N}$ & $23,64 \mathbf{E}$ & $4,77 \mathbf{E}$ & $-2,81 \mathbf{N}$ & $-3,14 \mathbf{N}$ & 33,2 \\
\hline \multirow{9}{*}{1999} & 1 & $-3,25 \mathbf{N}$ & $-3,10 \mathbf{N}$ & $-6,72 \mathbf{D}$ & $-4,05 \mathbf{D}$ & $-3,75 \mathbf{N}$ & $-2,46 \mathbf{N}$ & $25,92 \mathbf{E}$ & $5,09 \mathbf{E}$ & $-4,24 \mathbf{D}$ & $-3,43 \mathbf{N}$ & 36,1 \\
\hline & 2 & $-3,11 \mathbf{N}$ & $-3,85 \mathbf{D}$ & $-3,25 \mathbf{D}$ & $-4,55 \mathrm{D}$ & $-3,91 \mathbf{D}$ & $-2,09 \mathbf{N}$ & $23,91 \mathbf{E}$ & $2,39 \mathbf{N}$ & $-2,85 \mathbf{N}$ & $-2,69 \mathbf{N}$ & 28,7 \\
\hline & 3 & $-0,98 \mathbf{N}$ & $-3,97 \mathbf{N}$ & $-9,43 \mathbf{D}$ & $-3,99 \mathbf{D}$ & $-1,08 \mathbf{N}$ & $-2,54 \mathbf{N}$ & $27,52 \mathbf{E}$ & $4,20 \mathbf{E}$ & $-3,26 \mathbf{N}$ & $-6,45 \mathbf{D}$ & 35,9 \\
\hline & 4 & $-2,24 \mathbf{N}$ & $-2,83 \mathbf{N}$ & $-3,24 \mathbf{N}$ & $-5,59 \mathbf{D}$ & $-4,30 \mathbf{D}$ & $-2,20 \mathbf{N}$ & $26,31 \mathbf{E}$ & $2,34 \mathbf{N}$ & $-3,23 \mathbf{N}$ & $-5,01 \mathbf{D}$ & 31,0 \\
\hline & 5 & $-3,24 \mathbf{N}$ & $-2,94 \mathbf{N}$ & $-6,23 \mathbf{D}$ & $-5,00 \mathrm{D}$ & $-4,08 \mathbf{D}$ & $-2,32 \mathbf{N}$ & $26,09 \mathbf{E}$ & $4,55 \mathbf{E}$ & $-3,37 \mathbf{N}$ & $-3,47 \mathbf{N}$ & 35,2 \\
\hline & 6 & $-1,72 \mathbf{N}$ & $-2,01 \mathbf{N}$ & $-2,46 \mathbf{N}$ & $-9,05 \mathbf{D}$ & $-4,88 \mathbf{D}$ & $-1,13 \mathbf{N}$ & $22,96 \mathbf{E}$ & $2,80 \mathbf{N}$ & $-2,69 \mathbf{N}$ & $-1,82 \mathbf{N}$ & 28,5 \\
\hline & 7 & $-0,62 \mathbf{N}$ & $-1,57 \mathbf{N}$ & $-1,12 \mathbf{N}$ & $-9,51 \mathbf{D}$ & $-8,73 \mathbf{D}$ & $-1,10 \mathbf{N}$ & $27,85 \mathbf{E}$ & $6,46 \mathbf{E}$ & $-3,18 \mathbf{N}$ & $-8,48 \mathbf{D}$ & 40,8 \\
\hline & 8 & $-2,95 \mathbf{N}$ & $-3,64 \mathbf{D}$ & $-6,24 \mathbf{D}$ & $-3,66 \mathbf{D}$ & $-3,57 \mathbf{N}$ & $-2,26 \mathbf{N}$ & $23,51 \mathbf{E}$ & $4,55 \mathbf{E}$ & $-2,77 \mathbf{N}$ & $-2,96 \mathbf{N}$ & 32,6 \\
\hline & 9 & $-1,98 \mathbf{N}$ & $-3,61 \mathbf{N}$ & $-7,36 \mathbf{D}$ & $-3,72 \mathbf{D}$ & $-3,44 \mathbf{N}$ & $-2,35 \mathbf{N}$ & $23,64 \mathbf{E}$ & $4,77 \mathbf{E}$ & $-2,81 \mathbf{N}$ & $-3,14 \mathbf{N}$ & 33,2 \\
\hline
\end{tabular}

$\mathrm{N}=$ normal; $\mathrm{D}=$ deficiente e $\mathrm{E}=$ excesso.

1- Testemunha (sem aplicação de nitrogênio); 2- $50 \mathrm{~g} /$ planta/ano de $\mathrm{N}$ na forma de uréia; 3- $100 \mathrm{~g} / \mathrm{planta} /$ ano de $\mathrm{N}$ na forma de uréia; 4- $50 \mathrm{~g} / \mathrm{planta} /$ ano de $\mathrm{N}$ na forma de sulfato de amônio; 5- $100 \mathrm{~g} / \mathrm{planta} /$ ano de $\mathrm{N}$ na forma de sulfato de amônio; 6- $50 \mathrm{~g} /$ planta/ano de $\mathrm{N}$ na forma de nitrato de potássio; 7- $100 \mathrm{~g} / \mathrm{planta} /$ ano de $\mathrm{N}$ na forma de nitrato de potássio; 8- 50 g/planta/ano de $\mathrm{N}$ na forma de nitrato de cálcio; 9- $100 \mathrm{~g} / \mathrm{planta} /$ ano de $\mathrm{N}$ na forma de nitrato de cálcio. 


\subsection{Avaliação da época de amostragem de folhas de macieira para o método DRIS}

A distribuição sazonal da concentração de macro e micronutrientes em folhas de macieira cv. Gala, Golden Delicious e Fuji no período de 30 semanas após a plena floração (APF) é apresentada nas Figuras 20 e 21. Observou-se que a concentração de N, $\mathrm{P}, \mathrm{K}, \mathrm{Cu}$ e B nas folhas diminuiu, a concentração de $\mathrm{Ca}$ aumentou e a concentração de $\mathrm{Mg}, \mathrm{Fe}, \mathrm{Mn}$ e $\mathrm{Zn}$ pouco variou ao longo do ciclo vegetativo da cultura. Estes resultados são semelhantes aos de Hilmelrich \& Walker (1982), que ao trabalharem com oito cultivares do grupo 'Delicious' e oito do grupo 'Virginia Gold', observaram que a concentração de $\mathrm{Ca}$ aumentou, a de $\mathrm{K}$ diminuiu e a de $\mathrm{Mg}$ permaneceu constante durante

o ciclo vegetativo. Da mesma forma, Rogers et al. (1953) observaram que a concentração de $\mathrm{N}$ diminui lentamente até 140 dias após a floração, passando para um decréscimo acentuado a partir deste período, o $\mathrm{P}$ decresce ao longo do ciclo, principalmente após 140 dias após a floração, o K diminui de forma gradual e contínua ao longo do ciclo e o $\mathrm{Ca}$ aumenta rapidamente nos primeiros 65 dias após a floração, permanecendo praticamente constante até 155 dias após a floração e aumentando novamente a partir desta data.

A redução na concentração de $\mathrm{N}$ e $\mathrm{P}$ foi maior nas primeiras cinco semanas após a plena floração, evoluindo para uma lenta redução entre a quinta e vigésima semana após a plena floração e apresentando uma queda mais pronunciada da vigésima semana após a plena floração em diante. Este comportamento pode estar relacionado ao efeito diluição, que ocorreu ao longo do ciclo da cultura e a redistribuição destes nutrientes para outros órgãos no final do ciclo vegetativo. A redução na concentração de $\mathrm{K}$ foi praticamente uniforme ao longo do ciclo vegetativo, com exceção da cv. Golden Delicious que apresentou aumento na concentração até a oitava semana após a plena floração e, a partir deste período, apresentou decréscimo contínuo. Além disto, a concentração de $\mathrm{K}$ neste cultivar foi bem superior à obtida para os demais cultivares. Para $\mathrm{Cu}$ e B, observou-se uma maior queda na concentração nas cinco primeiras semanas após a plena floração, evoluindo parra uma redução mais lenta e gradual ao longo do ciclo vegetativo. 
O aumento na concentração de Ca foi maior nas primeiras cinco semanas após a plena floração, evoluindo para um aumento lento a partir deste período. No cv. Golden Delicious a concentração deste nutriente praticamente não apresentou variação ao longo do ciclo e foi menor do que os demais cultivares, o que pode ser explicado pelo antagonismo com o K, que teve maior concentração durante o ciclo neste cultivar.

A variabilidade na concentração de $\mathrm{Fe}, \mathrm{Mn}$ e $\mathrm{Zn}$, ao longo do ciclo vegetativo da cultura, pode ser atribuída a contaminação das amostras por produtos utilizados no controle fitossanitário do pomar. 

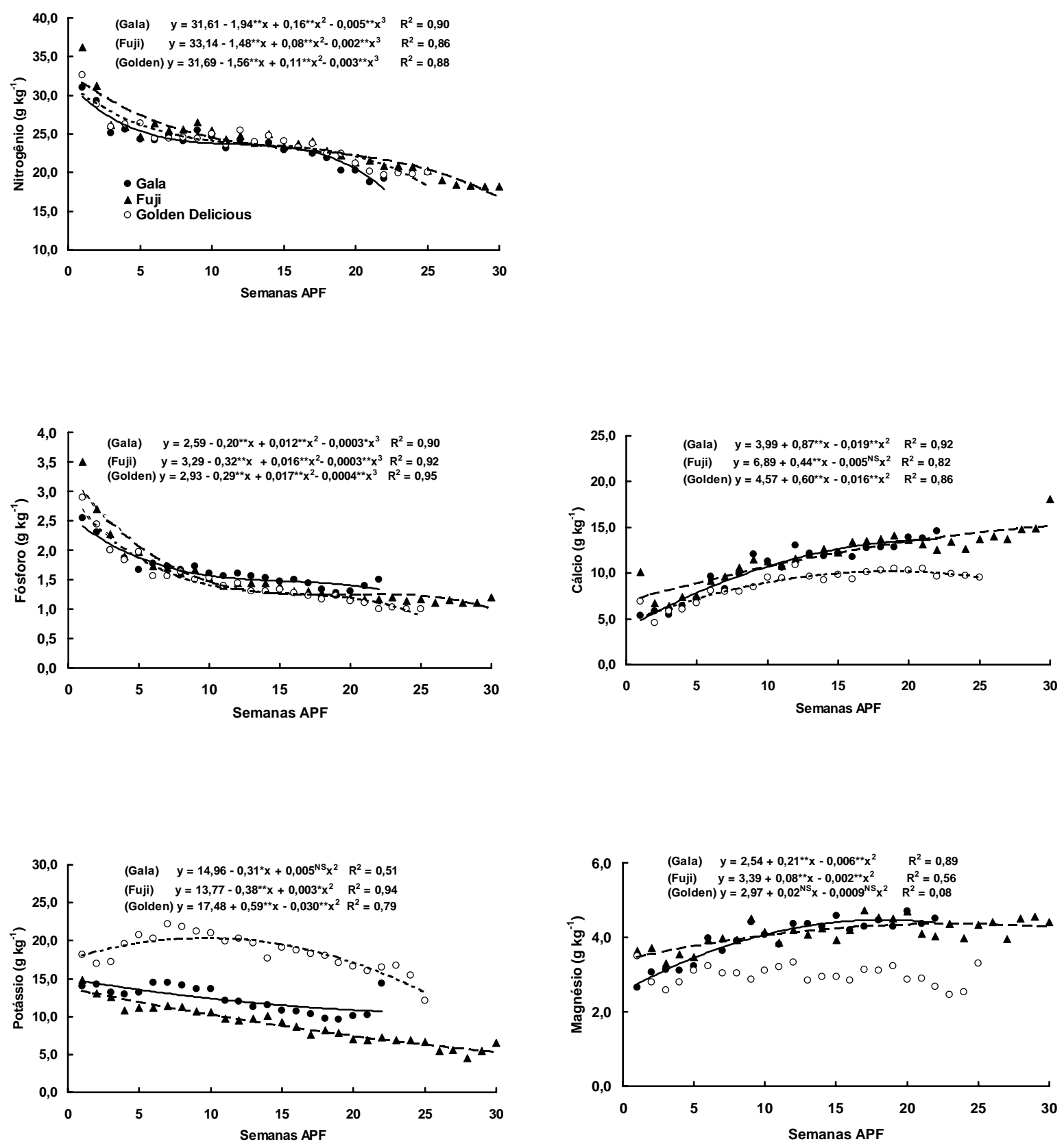

Figura 20 - Distribuição sazonal da concentração de N, P, K, Ca e Mg em folhas de macieira cv. Gala, Golden Delicious e Fuji no período de 1 a 30 semanas após a plena floração (APF). (Média de três anos) 

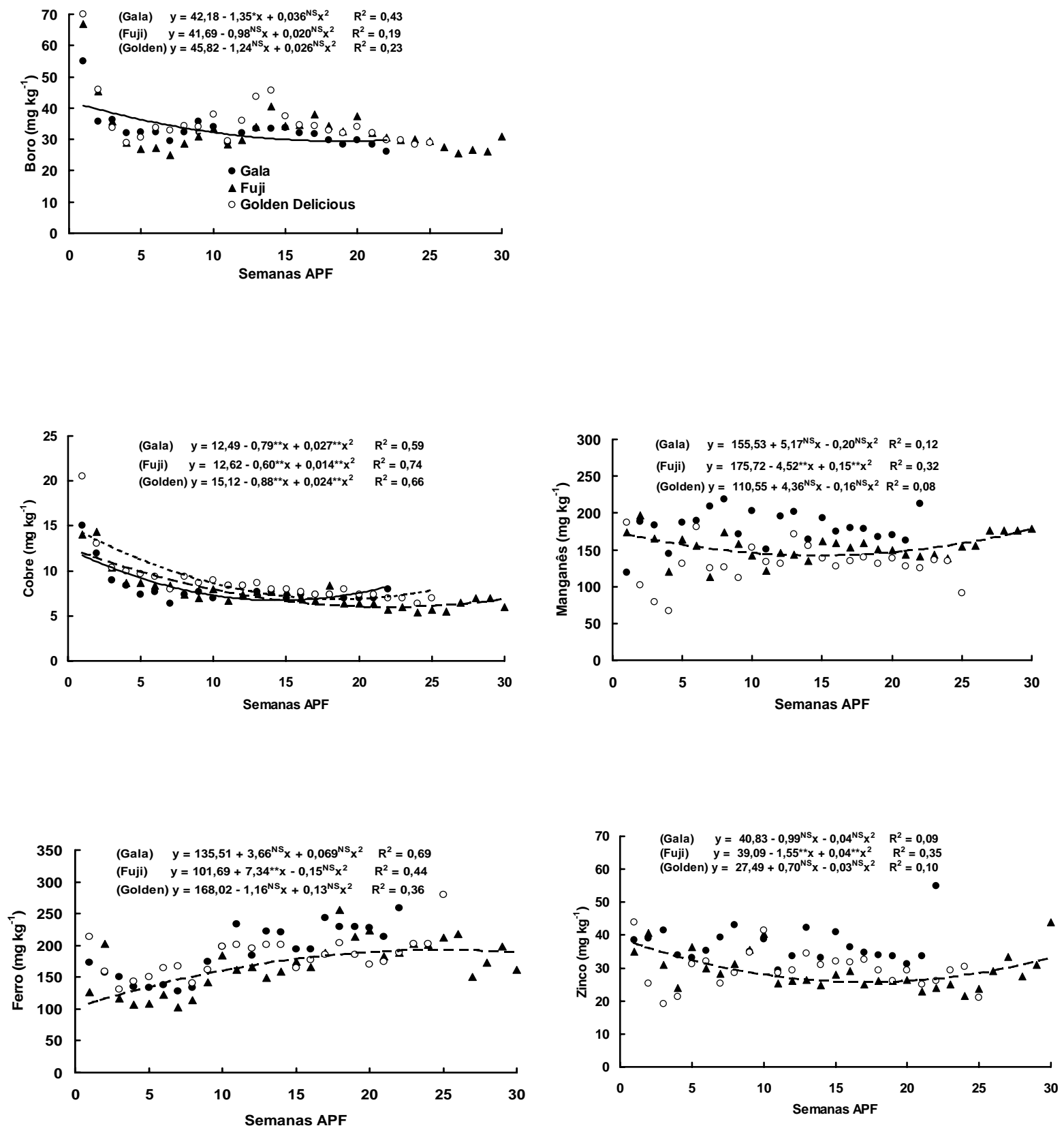

Figura 21 - Distribuição sazonal da concentração de B, Cu, Fe, Mn e Zn em folhas de macieira cv. Gala, Golden Delicious e Fuji no período de 1 a 30 semanas após a plena floração (APF). (Média de três anos) 
Considerando que o método de Elwali \& Gascho (1984), utilizando o "valor F” como critério de escolha da ordem da razão dos nutrientes foi o modelo que apresentou maior eficiência no diagnóstico nutricional da macieira, os resultados das concentrações sazonais de macro e micronutrientes dos cvs. Gala, Golden Delicious e Fuji (média de três anos) foram submetidos ao método selecionado.

A distribuição sazonal dos índices DRIS para macro e micronutrientes em folhas de macieira cv. Gala, Golden Delicious e Fuji no período de 30 semanas após a plena floração (APF), pelo método Elwali \& Gascho (1984) utilizando o "valor F", é apresentada nas Figuras 22 e 23. Observou-se que, os índices DRIS, para N, P, K, Cu e $\mathrm{B}$ diminuíram, o índice DRIS para Ca aumentou e os índices DRIS para $\mathrm{Mg}, \mathrm{Fe}, \mathrm{Mn}$ e $\mathrm{Zn}$ pouco variaram ao longo do ciclo vegetativo da cultura, seguindo o mesmo comportamento da concentração destes nutrientes nas folhas.

$\mathrm{O}$ decréscimo nos índices DRIS para $\mathrm{N}$ e $\mathrm{P}$ foi maior nas primeiras cinco semanas após a plena floração, evoluindo para uma lenta redução entre a quinta e vigésima semana após a plena floração e apresentando uma queda mais pronunciada da vigésima semana após a plena floração em diante. O decréscimo no índice DRIS para K foi pequeno e uniforme ao longo do ciclo vegetativo, com exceção do cv. Golden Delicious que apresentou aumento do índice DRIS K até a quinta semana após a plena floração e, a partir deste período, apresentou decréscimo pequeno e contínuo. Além disto, como também observado para o comportamento da concentração de $\mathrm{K}$ neste cultivar, o índice DRIS K foi bem superior ao obtido para os demais cultivares. Para $\mathrm{Cu}$ e B, observou-se uma maior queda no índice DRIS nas cinco primeiras semanas após a plena floração, evoluindo parra uma redução mais lenta e gradual ao longo do ciclo vegetativo. $\mathrm{O}$ aumento no índice DRIS para $\mathrm{Ca}$ foi maior nas primeiras cinco semanas após a plena floração, evoluindo para um aumento lento a partir deste período. A variabilidade nos índices DRIS para Fe, Mn e $\mathrm{Zn}$, ao longo do ciclo vegetativo da cultura, podem ser atribuída a contaminação das amostras por produtos utilizados no controle fitossanitário do pomar. 

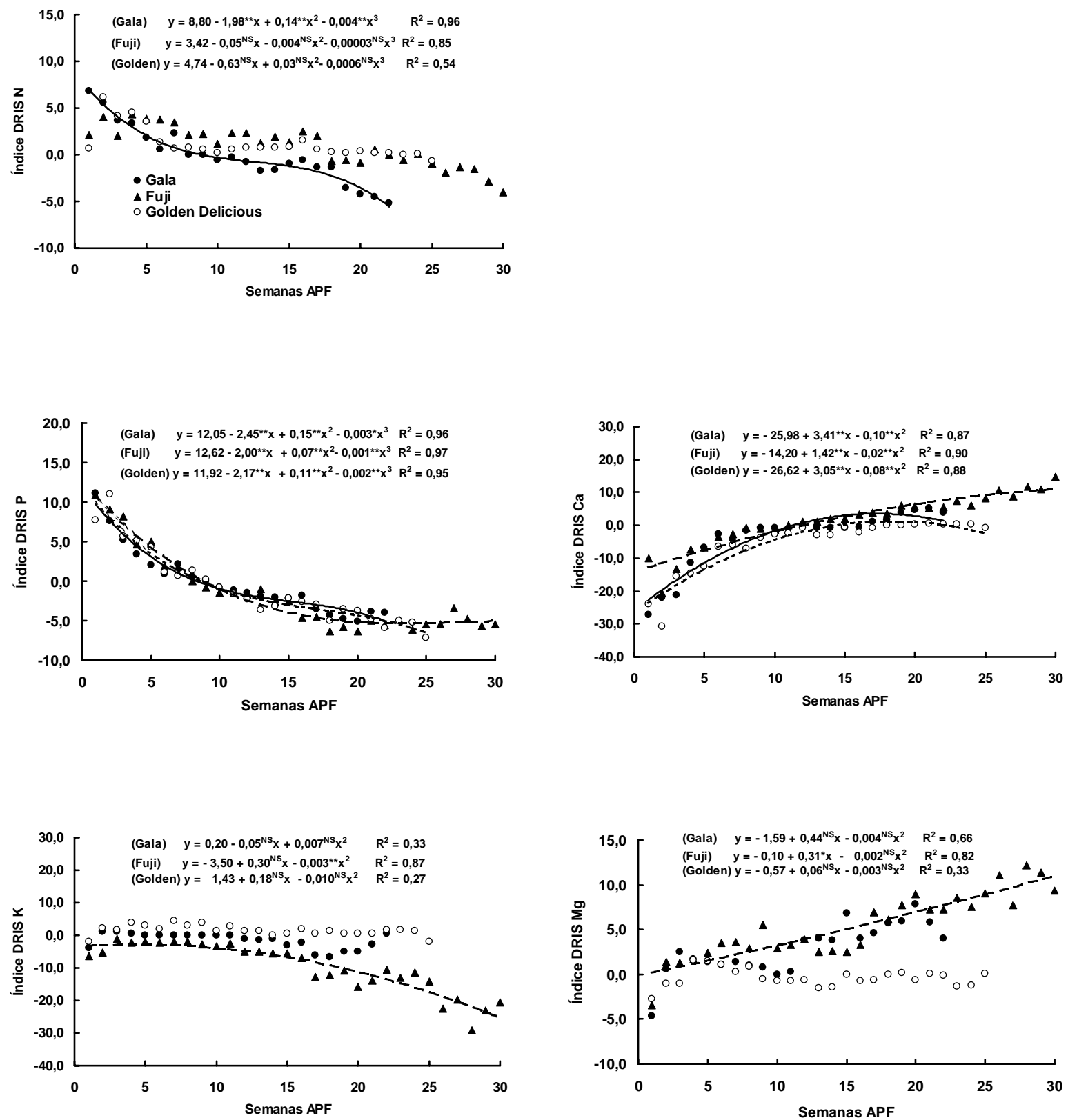

Figura 22 - Distribuição sazonal dos Índices DRIS para N, P, K, Ca e Mg pelo método Elwali \& Gascho (1984) (valor F) em folhas de macieira cv. Gala, Golden Delicious e Fuji no período de 1 a 30 semanas após a plena floração (APF). (Média de três anos) 

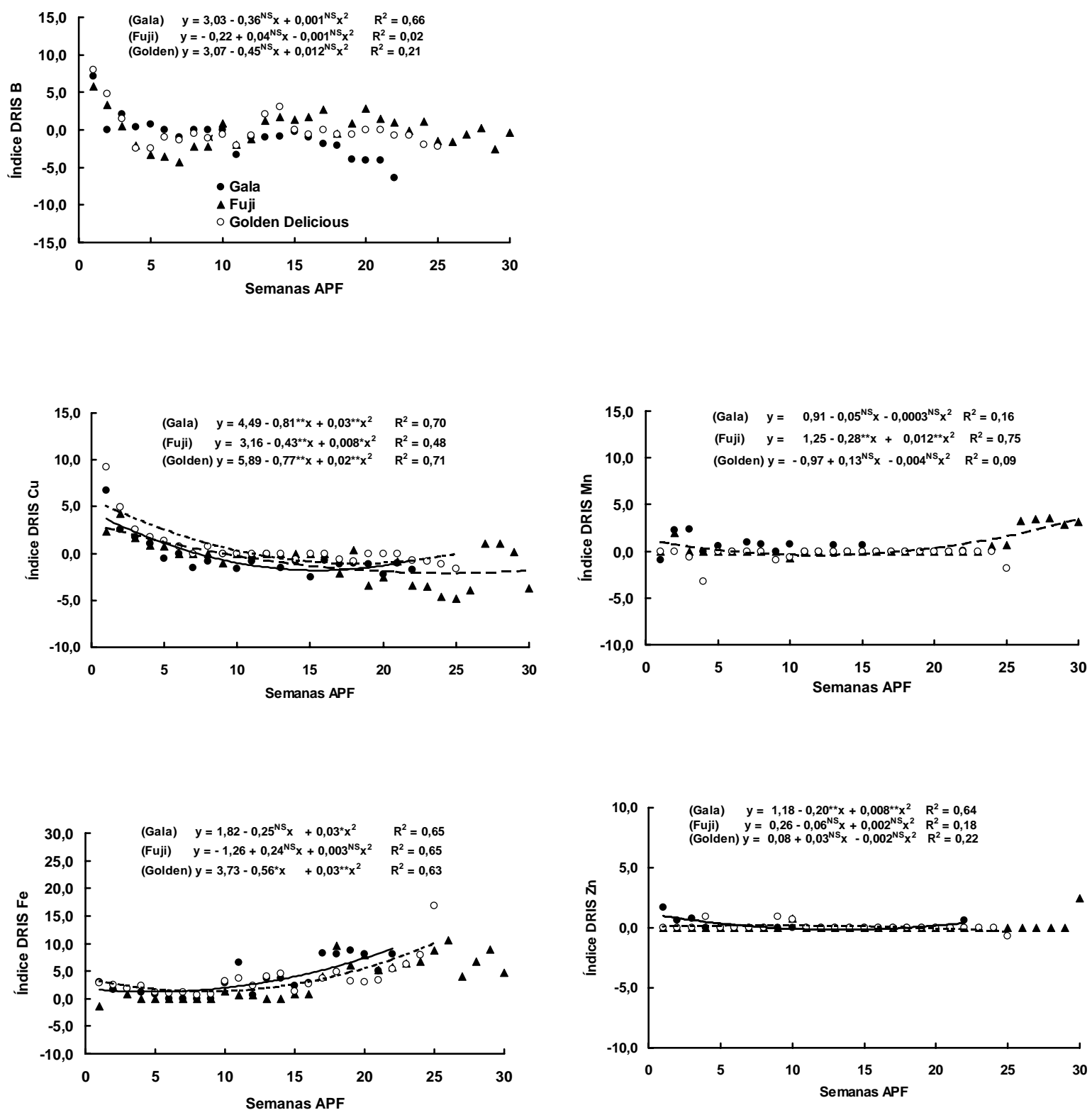

Figura 23 - Distribuição sazonal dos Índices DRIS para $\mathrm{B}, \mathrm{Cu}, \mathrm{Fe}, \mathrm{Mn}$ e $\mathrm{Zn}$ pelo método Elwali \& Gascho (1984) (valor F) em folhas de macieira cv. Gala, Golden Delicious e Fuji no período de 1 a 30 semanas após a plena floração (APF). (Média de três anos) 
A distribuição sazonal dos valores de IBN para o método Elwali \& Gascho (1984), utilizando o "valor F", no período de 30 semanas após a plena floração (APF), mostra que a melhor época de coleta de folhas para o método DRIS esta situada entre a quinta e a décima quinta semana após a plena floração (APF), devido à estabilidade dos valores de IBN neste período (Figura 24).

O método de diagnóstico utilizado atualmente estabelece que a amostragem de folhas deve ser feita entre 15 de janeiro e 15 de fevereiro (aproximadamente entre a décima quarta e décima oitava semana após a plena floração) (Magnani et al., 1997). Este período de amostragem tem a desvantagem de ser muito próximo a colheita, principalmente para o cv. Gala, o que impede a correção de possíveis distúrbios nutricionais na própria safra. A época de amostragem indicada pelos resultados deste estudo permite ao produtor realizar correções dos distúrbios nutricionais que ocorreram na safra, podendo ainda obter resultados positivos de produtividade e qualidade, bem como é mais amplo que o método atualmente utilizado. Goh \& Malakouti (1992) na Nova Zelândia, utilizando uma base de dados constituída por experimento com o cultivar Golden Delicious, verificaram que a melhor época de amostragem para fins de diagnose foliar foi de três a cinco meses após o florescimento. 


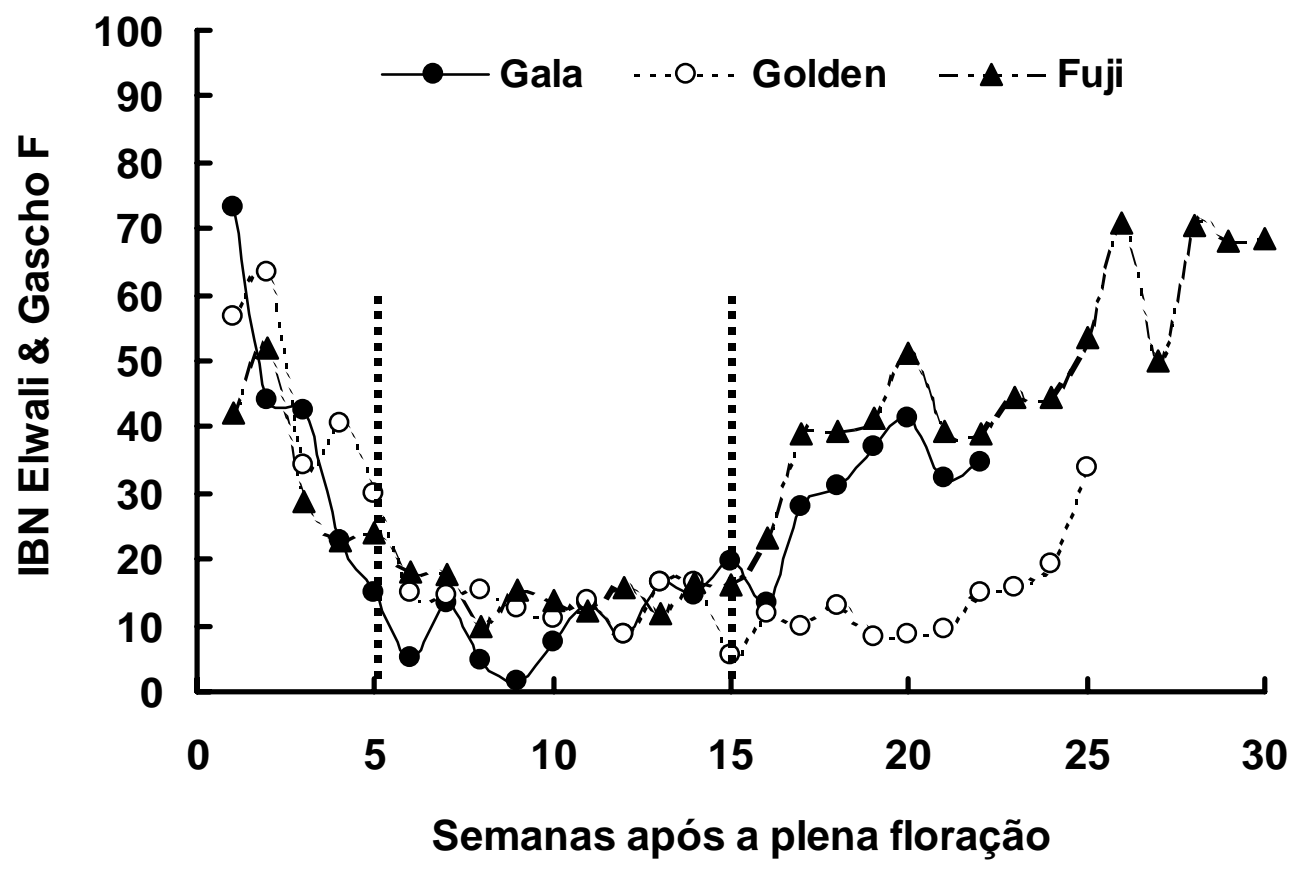

Figura 24 - Distribuição sazonal dos Índices de Balanço Nutricional (IBN) pelo método Elwali \& Gascho (1984) (Valor F) em folhas de macieira cv. Gala, Golden Delicious e Fuji no período de 1 a 30 semanas após a plena floração (APF). (Média de três anos) 


\section{CONCLUSÕES}

Os resultados obtidos neste trabalho possibilitaram as seguintes conclusões:

1. A concentração dos nutrientes apresentou correlação positiva e significativa $(p<0,01)$ com os respectivos índices DRIS, com exceção do N;

2. O critério do “valor F” (Letzsch, 1985 e Walworth et al., 1986) mostrou-se mais eficiente que o “valor R” (Nick, 1998) para a escolha da ordem da razão dos nutrientes para a cultura da macieira;

3. O Índice de Balanço Nutricional (IBN), calculado a partir das normas geradas, apresentou correlação negativa e significativa $(p<0,01)$ com a produtividade para a população de referência, em todas as combinações de métodos testados;

4. O método DRIS descrito por Elwali \& Gascho (1984), utilizando o “valor F”, quando comparado com o critério de faixas de suficiência, apresentou diagnóstico nutricional mais eficiente que os demais métodos de cálculo, verificando-se que o DRIS detecta nutriente deficiente ou em excesso que não são considerados pelo critério de faixas de suficiência, além de estabelecer uma ordem de deficiência e excesso para os nutrientes;

5. O método de cálculo do DRIS, com base no somatório das funções, descrito por Elwali \& Gascho (1984), utilizando o “valor F” é o mais indicado para a cultura da macieira, por apresentar valores de IBN que melhor indicam o estado nutricional das plantas e pela eficiência no diagnóstico nutricional da cultura; 
6. A melhor época de coleta de folhas para o método DRIS esta situada entre a quinta e a décima quinta semana após a plena floração, devido à menor variabilidade dos valores de IBN;

7. As normas DRIS geradas neste trabalho foram adequadas para o diagnóstico nutricional da macieira, para as condições do Sul do Brasil. 


\section{REFERÊNCIAS BIBLIOGRÁFICAS}

ASSOCIAÇÃO BRASILEIRA DOS PRODUTORES DE MAÇÃ. Informações estatísticas. http://www.abpm.org.br. (20 jan. 2004).

ALKOSHAB, O.; RIGHETTI, T.L.; DIXON, A.R. Evaluation of DRIS for judging the nutritional status of hazelnuts. Journal of the American Society for Horticultural Science, v.113, p.643-647, 1988.

ANGELES, D.E.; SUMMER, M.E.; BARBOUR, N.W. Preliminary nitrogen, phosphorus, and potassium DRIS norms for pineapple. HortScience, v.25, p.652655, 1990.

ANGELES, D.E.; SUMMER, M.E.; LAHAV, E. Preliminary DRIS norms for banana. Journal of Plant Nutrition, v.16, p.1059-1070, 1993.

BAILEY, J.S.; BEATTIE, J.A.M.; KILPATRICK, D.J. The diagnosis and recommendation integrated system (DRIS) for diagnosing the nutrient status of grassland swards: I. Model establishment. Plant and Soil, v.197, p.127-135, 1997.

BALDOCK, J.O.; SCHULTE, E.E. Plant analysis with standarized score combines DRIS and suficiency range approaches for corn. Agronomy Journal, v.88, p.448456, 1996.

BASSO, C.; SUZUKI, A. Adubação de fruteiras de clima temperado. In: ENCONTRO NACIONAL SOBRE FRUTICULTURA DE CLIMA TEMPERADO, 3., Fraiburgo, 2000. Anais. Caçador: EPAGRI, 2000. p.134-140.

BASSO, C.; WILMS, F.W.W.; SUZUKI, A . Fertilidade do solo e nutrição de plantas. In: EMPRESA CATARINENSE DE PESQUISA AGROPECUÁRIA. Manual da cultura da macieira. Florianópolis: EMPASC, DID, 1986. p.236-265. 
BATAGLIA, O.C. DRIS - citros - uma alternativa para avaliar a nutrição das plantas. Laranja, v.10, p.565-576, 1989.

BATAGLIA, O.C.; DECHEN, A.R. Critérios alternativos para diagnose foliar. In: SIMPÓSIO AVANÇADO DE QUÍMICA E FERTILIDADE DO SOLO, Piracicaba, 1986. Anais. Campinas: Fundação Cargill, 1986. p.115-136.

BATAGLIA, O.C.; SANTOS, W.R. Efeito do procedimento de cálculo e da população de referência nos índices do sistema integrado de diagnose e recomendação (DRIS). Revista Brasileira de Ciência do Solo, v.14, p.339-344, 1990.

BATAGLIA, O.C.; DECHEN, A.R.; SANTOS, W.R. Princípios da diagnose foliar. In: ALVAREZ, V.H.; FONTES, L.E.F.; FONTES, M.P.F. (Ed.). O solo nos grandes domínios morfoclimáticos do Brasil e o desenvolvimento sustentado. Viçosa: SBCS, UFV, DPS, 1996. p.647-660.

BATAGLIA, O.C.; SANTOS, W.R.; QUAGGIO, J.A. Reference populations for evaluation of the nutritional status of coffee by DRIS. In: HORST, W.J.; BÜRKERT, A.; CLAASSEN, N. et al. (Ed.). Plant nutrition: food security and sustainability of agro-ecosystems. Dordrecht: Kluwer Academic, 2001. p.728-729.

BEAUFILS, E.R. Physiological diagnosis - a guide for improving maize production based on principles developed for rubber trees. Fertilizer Society of South African Journal, v.1, p.1-30, 1971.

BEAUFILS, E.R. Diagnosis and recomendation integrated system (DRIS). A general scheme for experimentation and calibration based on principles developed from research in plant nutrition. Pietermararitzburg: University of Natal, 1973. 132p. (Soil Science Bulletin, 1).

BEVERLY, R.B. A practical guide to the diagnosis and recommendation integrated system (DRIS). Athens: Micro-Macro, 1991. 87p.

BEVERLY, R.B. Prescient diagnostic-analysis shows sufficiency range approach superior to DRIS for citrus. Communications in Soil Science and Plant Analysis, v.23, p.2641-2649, 1992. 
BEVERLY, R.B.; STARK, J.C.; OJALA, J.C. et al. Nutrient diagnosis of Valência oranges by DRIS. Journal of the American Society for Horticultural Science, v.109, p.649-654, 1984.

BEVERLY, R.B.; SUMNER, M.E.; LETZSCH, W.S. et al. Foliar diagnosis of soybean by DRIS. Communications in Soil Science and Plant Analysis, v.17, p.237-256, 1986.

BHARGAVA, B.S.; RAGHUPATHI, H.B. Current status and new norms of nitrogen nutrition for grapevine (Vitis vinifera). Indian Journal of Agricultural Sciences, v.65, p.165-169, 1996.

BONETTI, J.I. S.; CESA, J.D.; PETRI L.J. et al. Cadeias produtivas do Estado de Santa Catarina: maçã. Florianópolis: EPAGRI, 1999. 94p. (EPAGRI. Boletim Técnico, 105).

BORGES JÚNIOR, L. Mercado atual e perspectivas para maçã. In: REUNIÃO SOBRE O SISTEMA DE PRODUÇÃO INTEGRADA DE MACIEIRA NO BRASIL, 1., Bento Gonçalves, 1998. Anais. Bento Gonçalves: Embrapa Uva e Vinho, 1998. p.3-5.

BOWEN, J.E. Comparative DRIS and critical concetration interpretation of papaya tissue analysis data. Tropical Agriculture, v.69, p.63-67, 1992.

CERDA, A.; NIEVES, M.; MARTINEZ, V. An evaluation of mineral analysis of Verna lemons by DRIS. Communications in Soil Science and Plant Analysis, v.26, p.1697-1707, 1995.

CHELVAN, R.C.; SHIKHAMANY, S.D.; CHADHA, K.L. Evaluation of low yielding vines of Thompson seedless for nutrient indices by DRIS analysis. Indian Journal of Horticulture, v.41, p.166-170, 1984.

COMISSÃO DE FERTILIDADE DO SOLO. Recomendações de adubação e de calagem para os Estados do Rio Grande do Sul e de Santa Catarina. 3. ed. Passo Fundo: SBCS, Núcleo Regional Sul, 1995. 224p. 
COSTA, A.N. Uso do sistema integrado de diagnose e recomendação (DRIS), na avaliação do estado nutricional do mamoeiro (Carica papaya L.) no Estado do Espírito Santo. Viçosa, 1995. 95p. Tese (Doutorado) - Universidade Federal de Viçosa.

COSTA, A.N. Sistema integrado de diagnose e recomendação (DRIS). Boletim Informativo da Sociedade Brasileira de Ciência do Solo, v.24, p.13-15, 1999.

COSTA, F. Avaliação do estado nutricional da videira cultivar Itália em três estádios de desenvolvimento, na região de Jundiaí - SP, utilizando o método DRIS. Piracicaba, 1998. 91p. Dissertação (Mestrado) - Escola Superior de Agricultura "Luiz de Queiroz", Universidade de São Paulo.

CRESTE, J.E.; GRASSI FILHO, H. Estabelecimento de curvas de produtividade para três variedades e dois porta-enxertos cítricos na região sudoeste do Estado de São Paulo, com ênfase ao DRIS. In: CONGRESSO BRASILEIRO DE FRUTICULTURA, 15., Poços de Caldas, 1998. Resumos. Poços de Caldas: Sociedade Brasileira de Fruticultura, 1998. v.1, p.299.

CRESTE, J.E.; NAKAGAWA, J. Estabelecimento do método DRIS para a cultura do limoeiro em função da análise foliar; 1: cálculo das normas. Revista Brasileira de Fruticultura, v.19, p.297-305, 1997.

DAVEE D.E.; RIGHETTI, T.L. FALLAHI, E. et al. An evaluation of the DRIS approach for identifying mineral limitations on yield in "Napoleon" sweet chery. Journal of the American Society for Horticultural Science, v.11, p.988-993, 1986.

ELWALI, A.M.O.; GASCHO, G.J. Soil testing, foliar analysis, and DRIS as guide for sugarcane fertilization. Agronomy Journal, v.76, p.466-470, 1984.

ELWALI, A.M.O.; GASCHO, G.J.; SUMNER, M.E. Sufficiency levels and DRIS norms for 11 nutrients in corn. Agronomy Journal, v.77, p.506-508, 1985.

FAUST, M. Physiology of temperate zone fruit trees. New York: John Wiley. 1989. 338p. 
FREIRE, C.J.S. Manual de métodos de análise de tecido vegetal, solo e calcário. Pelotas: EMBRAPA, CPACT, 1998. 208p.

GERGOLETTI, I.F. Avaliação do estado nutricional da videira - cultivar Itália em três estádios de desenvolvimento em São Miguel Arcanjo/SP, utilizando o método DRIS. Piracicaba, 1995. 84p. Dissertação (Mestrado) - Escola Superior de Agricultura "Luiz de Queiroz", Universidade de São Paulo.

GOH, K.M.; MALAKOUTI, M.J. Preliminary nitrogen, phosphorus, potassium, calcium and magnesium DRIS norms and indices for apple orchards in Canterbury, New Zealand. Communications in Soil Science and Plant Analysis, v.23, p.1371-1385, 1992.

GUILHERME, M.A.S. Avaliação do estado nutricional da videira Itália em três estádios de desenvolvimento, na região de Jales/SP, utilizando o método DRIS. Piracicaba, 1995. 81p. Dissertação (Mestrado) - Escola Superior de Agricultura "Luiz de Queiroz", Universidade de São Paulo.

HALLMARK, W.B.; BEVERLY, R.B. Review - An update in the use of the diagnosis and recommendation integrated system. Journal of Fertilizer Issues, v.8, p.74-88, 1991.

HILMELRICH, D.G.; WALKER, C.E. Seasonal trends of calcium, magnesium, and potassium fractions in apple leaf and fruit tissues. Journal of the American Society for Horticultural Science, v.107, p.1078-1080, 1982.

JONES, C.A. Proposed modifications of the diagnosis and recommendation integrated system (DRIS) for interpreting plant analysis. Communications in Soil Science and Plant Analysis, v.12, p.785-794, 1981.

KENWORTHY, A.L. Leaf analysis as an aid in fertilizing orchards. In: WALSH, L.M.; BEATON, J.D. Soil testing and plant analysis. Madison: Soil Science Society of America, 1973. p.381-392. 
LEANDRO, W.M.; OLIVEIRA, S.A.; BRASIL, E.M. et al. Níveis de suficiência no solo para soja (BR-15 e IAC-15) em Goianésia/GO, através do método DRIS. In: SIMPÓSIO SOBRE O CERRADO, 8.; INTERNATIONAL SYMPOSIM ON TROPICAL SAVANNAS, 1., Brasília, 1996. Anais. Planaltina: EMBRAPA, CPAC, 1996. p.337-340.

LEITE, R.A. Avaliação do estado nutricional do cafeeiro Conilon no Estado do Espírito Santo utilizando diferentes métodos de interpretação de análise foliar. Viçosa, 1993. 87p. Dissertação (Mestrado) - Universidade Federal de Viçosa.

LETZSCH, W.S. Computer program for selection of norms for use in the diagnosis and recommendation integrated system (DRIS). Communications in Soil Science and Plant Analysis, v.16, p.339-347, 1985.

LETZSCH, W.S.; SUMMER, M.E. Effect of population size and yield level in selection of diagnosis and recommendation integrated system (DRIS) norms. Communications in Soil Science and Plant Analysis, v.15, p.997-1006, 1984.

MAEDA, S.; STAUT, L.A.; KURTHARA, C.H. et al. Valores de referência do DRIS para a soja em Mato Grosso. Dourados: Embrapa Agropecuária Oeste, 2003. 22p. (Embrapa Agropecuária Oeste. Documentos, 58).

MAGNANI, M.; FREIRE, C.J.S.; CHOER, E. Manual para análise foliar: macieira. 3.ed. Pelotas: EMBRAPA, CPACT, 1997. 7p. (EMBRAPA. CPACT. Documentos, 34).

MALAVOLTA, E.; MALAVOLTA, M.L. Diagnose foliar - princípios e aplicações. In: SIMPÓSIO SOBRE INTERPRETAÇÃO DE ANÁLISE QUÍMICA DE SOLO E PLANTA PARA FINS DE ADUBAÇÃO, Botucatu, 1988. Anais. Botucatu: UNESP, 1988. p.1-86.

MARANGONI, B. Fertilidade do solo e a nutrição de plantas no sistema de produção integrada de frutas (PIF). In: SEMINÁRIO SOBRE PRODUÇÃO INTEGRADA DE FRUTAS DE CLIMA TEMPERADO NO BRASIL, 1., Bento Gonçalves, 1999. Anais. Bento Gonçalves: Embrapa Uva e Vinho, 2000. p.29-33. 
MARSCHNER, H. Mineral nutrition of higher plants. 2. ed. London: Academic Press, 1995. 889p.

MENGEL, K.; KIRKBY, E.A. Principles of plant nutrition. 5. ed. Dordrecht: Kluwer Academic, 2001. 849p.

MONGE, E.; MONTAÑÊS, L.; VAL, J. et al. A comparative study of the DOP and the DRIS methods, for evaluating the nutritional status of peach trees. Acta Horticulturae, n.383, p.191-199, 1995.

MOURÃO FILHO, F.A.A.; AZEVEDO, J.C. DRIS norms for 'Valencia' sweet orange on three rootstocks. Pesquisa Agropecuária Brasileira, v.38, p.85-93, 2003.

MOURÃO FILHO, F.A.A.; AZEVEDO, J.C.; NICK, J.A. Funções e ordem da razão dos nutrientes no estabelecimento de normas DRIS em laranjeiras 'Valência’. Pesquisa Agropecuária Brasileira, v.37, p.185-192, 2002.

NICK, J.A. DRIS para cafeeiros podados. Piracicaba, 1998. 86p. Dissertação (Mestrado) - Escola Superior de Agricultura "Luiz de Queiroz", Universidade de São Paulo.

NOGUEIRA, D.J.P.; MAGNANI, M. Simplificação de cálculo dos índices do balanço nutritivo para fruteiras de clima temperado. In: CONGRESSO BRASILEIRO DE FRUTICULTURA, 6., Recife, 1981. Anais. Recife: SBF, 1981. v.4, p.1332-1338.

PARENT, L.E.; GRANGER, R.L. Derivation of DRIS norms for a high density apple orchard established in the Quebec Appalachian mountains. Journal of the American Society for Horticultural Science, v.114, p.915-919, 1989.

PETRI, J.L.; HOFFMANN, A.; BERNARDI, J. et al. Manejo da planta e do solo na produção integrada de maçã. In: PROTAS, J.F.S.; SANHUEZA, R.M.V. (Ed.). Produção integrada de frutas: o caso da maçã no Brasil. Bento Gonçalves: Embrapa Uva e Vinho, 2003. p.69-76.

POLING, E.B.; OBERLY, G.H. Effect of rootstock on mineral composition of apples leaves. Journal of the American Society for Horticultural Science, v.104, p.799801, 1979. 
RAGHUPATHI, H.B.; BHARGAVA, B.S. Preliminary nutrient norms for 'Alphonso' mango using diagnosis and recommendation integrated system. Indian Journal of Agricultural Sciences, v.69, p.648-650, 1999.

REIS JÚNIOR, R.A.; MONNERAT. P.H. Diagnose nutricional da cana-de-açúcar em Campos dos Goytacazes (RJ). Revista Brasileira de Ciência do Solo, v.26, p.367372, 2002.

REIS JÚNIOR, R.A.; CORRÊA, J.B.; CARVALHO, J.G. et al. Estabelecimento de normas DRIS para o cafeeiro no Sul de Minas Gerais. $1^{\mathrm{a}}$ aproximação. Ciência Agrotécnica, v.26, p.269-282, 2002.

RIGHETTI, T.L.; ALKOSHAB, O.; WILDER, K. Verifying critical values from DRIS norms in sweet cherry and hazelnut. Communications in Soil Science and Plant Analysis, v.19, p.1449-1466, 1988.

RODRIGUEZ, O.; ROJAS, E.; SUMMER, M. Valencia orange DRIS norms for Venezuela. Communications in Soil Science and Plant Analysis, v.28, p.14611468, 1997.

ROGERS, B.L.; BATJER, L.P.; THOMPSON, A.H. Seasonal trend of several nutrient elements in Delicious apple leaves expressed on a per cent and unit area basis. Proceedings of the American Society for Horticultural Science, v.61, p.1-5, 1953.

SALVO, J.G. Uso do DRIS na avaliação do estado nutricional de plantas cítricas afetadas pela clorose variegada dos citros. Piracicaba, 2001. 108p. Dissertação (Mestrado) - Escola Superior de Agricultura "Luiz de Queiroz", Universidade de São Paulo.

SANTOS, W.R. Métodos diagnósticos do equilíbrio nutricional dos macronutrientes em citros. Piracicaba, 1997. 113p. Dissertação (Mestrado) - Escola Superior de Agricultura "Luiz de Queiroz", Universidade de São Paulo. 
SANZ, M.; HERAS, L.; MONTANES, L. Relationships between yield and leaf nutrient contents in peach-trees - early nutritional-status diagnosis. Journal of Plant Nutrition, v.15, p.1457-1466, 1992.

SAS INSTITUTE. SAS User’s guide: statistics. 5 ed. Cary, 1985. 956p.

SCHAFFER, B.; LARSON, K.D.; SNYDER, G.H. et al. Identification of mineral deficiencies associated with mango decline by DRIS. HortScience, v.23, p.617-619, 1988.

SCHALLER, K.; LÖHNERTZ, O.; MICHEL, H. Improvements of the DRIS-Sistem and first experiences in grapevine nutrition with special consideration of the compositional nutrient diagnosis approach. Acta Horticulturae, n.383, p.171-189, 1995.

SCHNEIDER, G.W.; CHAPLIN, C.E.; MARTIN, D.C. Effects of apple rootstock, tree spacing, and cultivar on fruit na tree size, yield, and foliar mineral composition. Journal of the American Society for Horticultural Science, v.103, p.230-232, 1978.

SHARMA, D.D.; CHAUHAN, J.S. Effects of different rootstocks and training systems on the mineral composition of 'Delicious' apple leaves. Journal of Horticultural Science, v.66, p.703-707, 1991.

SILVA, E.B.; NOGUEIRA, F.D.; GUIMARÃES, P.T.G. Uso do DRIS na avaliação do estado nutricional do cafeeiro em resposta à adubação potássica. Revista Brasileira de Ciência do Solo, v.27, p.247-255, 2003.

SINGH, N.P.; AWASTHI, R.P.; SUD, A. Diagnosis and recommendation integrated system (DRIS) norms for apple (Malus x Domestica Borkh. L. CV. Starking Delicious) in Himachal Pradesh. Indian Journal of Horticulture, v.57, p.196-204, 2000.

STRECK, E.V.; KÄMPF, N.; DALMOLIN, R.S.D. et al. Solos do Rio Grande do Sul. Porto Alegre: EMATER/RS; UFRGS, 2002. 107p. 
SUMMER, M.E. Preliminary N, P, K foliar diagnostic norms for wheat. Communications in Soil Science and Plant Analysis, v.8, p.149-167, 1977a.

SUMMER, M.E. Preliminary N, P, and K foliar diagnostic norms for soybeans. Agronomy Journal, v.69, p.226-230, 1977b.

SZÜCS, E.; KÁLLAY, T. Determination of fruiting capacity of apple trees (Malus domestica) by DRIS. In: INTERNATIONAL PLANT NUTRITION COLLOQUIUM, 11., Wageningen, 1989. Annals. Dordrecht: Kluwer Academic, 1990. p.717-721.

SZÜCS, E.; KÁLLAY, T.; SZENCI, G. Determination of DRIS indices for apple (Malus domestica Borkh). Acta Horticulturae, n.274, p. 443-453, 1990.

TAGLIAVINI, M.; SCUDELLARI, D.; MARANGONI, B. et al. Leaf mineral composition of apple tree: Sampling date and effects of cultivar and rootstock. Journal of Plant Nutrition, v.15, p.605-619, 1992.

TEIXEIRA, L.A.J.; SANTOS, W.R.; BATAGLIA, O.C. Diagnose nutricional para nitrogênio e potássio em bananeira por meio do sistema integrado de diagnose e recomendação (DRIS) e para níveis críticos. Revista Brasileira de Fruticultura, v.24, p.530-535, 2002.

TERBLANCHE, J.H.; DU PLESSIS, S.F. Summary of workshop on leaf and soil analysis as a tool determining fertilizer requirements of citrus. Proceedings of the International Society of Citriculture, v.2, p.744-745, 1992.

VELOSO, C.A.C.; GRAÇA, J.J.C.; GAMA, J.R.N.F. Estabelecimento do método DRIS para a cultura de citros na Mesorregião do Nordeste do Estado do Pará. Revista Brasileira de Fruticultura, v.22, p.372-376, 2000.

WADT, P.G.S. Os métodos da chance matemática e do sistema integrado de diagnose e recomendação (DRIS) na avaliação nutricional de plantios de eucalipto. Viçosa, 1996. 123p. Tese (Doutorado) - Universidade Federal de Viçosa. 
WADT, P.G.S.; NOVAIS, R.F.; VENEGAS, V.H.A. et al. Alternativas de aplicação do "DRIS" à cultura de café Conilon (Coffea canephora Pierre). Scientia Agricola, v.56, p.83-92, 1999a.

WADT, P.G.S.; NOVAIS, R.F.; ALVAREZ-V., V.H. et al. Uso de diferentes compartimentos da árvore nos índices DRIS e seus efeitos na avaliação da nutrição nitrogenada em eucaliptos. Revista Árvore, v.23, p.271-277, 1999b.

WALLACE, A. Nitrogen, phosphorus, potassium interaction on Valencia orange yields. Journal of Plant Nutrition, v.13, p.357-365, 1990.

WALWORTH, J.L.; SUMMER, M.E. The diagnosis and recommendation integrated system (DRIS). Advances in Soil Sciences, v.6, p.149-188, 1987.

WALWORTH, J.L.; SUMMER, M.E.; ISAAC, R.A. et al. Use of boundry lines in establishing diagnostic norms. Soil Science Society of America Journal, v.50, p.123-128, 1986.

WOODS, D.B.; VILLIERS, J.M. Diagnosing the nutrient status of 'Valencia' oranges in Southern Africa. In: INTERNATIONAL CITRUS CONGRESS, 7., Acireale, 1992. Proceedings. Acireale: International Society of Citriculture, 1992. p.556-559.

WORTMANN, C.S.; BOSCH, C.H.; MUKANDALA, L. Foliar nutrient analysis in bananas grown in the highlands of East-Africa. Journal of Agronomy and Crop Science, v.172, p.223-226, 1994.

ZAMBELLO JÚNIOR, E. Aplicação do sistema integrado de diagnose e recomendação para diferentes solos e épocas de amostragem foliar em soqueiras de cana-de-açúcar (Saccharum spp). Piracicaba, 1979. 95p. Dissertação (Mestrado) - Escola Superior de Agricultura "Luiz de Queiroz", Universidade de São Paulo. 


\section{APÊNDICES}


APÊNDICE 1. Concentração de macro e micronutrientes em folhas e a produção de frutos em 70 pomares de macieira no Rio Grande do Sul e Santa Catarina. (Safra 2002)

\begin{tabular}{|c|c|c|c|c|c|c|c|c|c|c|c|}
\hline Amostra & $\mathbf{N}$ & $\mathbf{P}$ & $\mathbf{K}$ & Ca & Mg & Fe & Mn & Zn & $\mathbf{C u}$ & B & Produção \\
\hline & \multicolumn{5}{|c|}{----------------- g kg-1 ---------------- } & \multicolumn{5}{|c|}{ 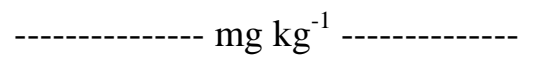 } & $--\mathrm{t} \mathrm{ha}^{-1}--$ \\
\hline 1 & 22,60 & 2,60 & 15,60 & 11,00 & 4,50 & 204 & 199 & 44 & 11 & 33 & 33,0 \\
\hline 2 & 22,40 & 2,50 & 13,80 & 11,60 & 3,80 & 371 & 193 & 43 & 10 & 36 & 35,0 \\
\hline 3 & 22,50 & 2,00 & 12,40 & 13,00 & 3,30 & 822 & 52 & 23 & 10 & 36 & 35,0 \\
\hline 4 & 22,00 & 1,80 & 13,60 & 12,40 & 3,70 & 548 & 176 & 63 & 10 & 34 & 33,0 \\
\hline 5 & 21,30 & 2,50 & 21,60 & 12,50 & 3,40 & 51 & 113 & 29 & 5 & 30 & 39,0 \\
\hline 6 & 23,10 & 1,80 & 14,10 & 13,70 & 2,90 & 36 & 45 & 10 & 7 & 33 & 68,0 \\
\hline 7 & 22,60 & 1,70 & 10,20 & 10,50 & 4,60 & 131 & 264 & 42 & 8 & 26 & 18,1 \\
\hline 8 & 21,00 & 1,50 & 10,70 & 11,20 & 3,40 & 244 & 326 & 56 & 9 & 32 & 11,4 \\
\hline 9 & 21,40 & 1,40 & 10,70 & 11,20 & 4,00 & 252 & 244 & 42 & 10 & 30 & 24,3 \\
\hline 10 & 19,00 & 1,40 & 18,80 & 9,40 & 3,00 & 102 & 120 & 7 & 8 & 27 & 29,9 \\
\hline 11 & 21,50 & 1,70 & 8,50 & 14,40 & 2,80 & 112 & 245 & 22 & 8 & 29 & 81,7 \\
\hline 12 & 24,20 & 1,80 & 9,90 & 13,80 & 3,20 & 84 & 312 & 20 & 7 & 27 & 38,6 \\
\hline 13 & 25,10 & 2,10 & 13,10 & 11,80 & 3,20 & 155 & 156 & 12 & 8 & 32 & 85,0 \\
\hline 14 & 22,30 & 2,10 & 14,60 & 12,00 & 2,60 & 159 & 112 & 6 & 8 & 33 & 98,0 \\
\hline 15 & 22,20 & 1,90 & 15,10 & 13,40 & 3,00 & 134 & 96 & 24 & 9 & 34 & 80,0 \\
\hline 16 & 24,30 & 1,80 & 11,40 & 14,40 & 2,60 & 156 & 221 & 10 & 9 & 32 & 87,0 \\
\hline 17 & 22,80 & 1,90 & 11,30 & 12,20 & 3,20 & 125 & 333 & 14 & 9 & 33 & 80,0 \\
\hline 18 & 24,50 & 2,00 & 11,00 & 13,20 & 2,90 & 211 & 178 & 16 & 10 & 32 & 76,0 \\
\hline 19 & 23,20 & 1,80 & 9,60 & 11,20 & 3,60 & 163 & 140 & 14 & 10 & 34 & 104,0 \\
\hline 20 & 20,90 & 1,80 & 11,00 & 12,90 & 3,90 & 144 & 286 & 31 & 8 & 30 & 90,0 \\
\hline 21 & 21,40 & 1,70 & 8,80 & 11,20 & 3,00 & 118 & 115 & 5 & 8 & 32 & 62,0 \\
\hline 22 & 20,90 & 1,90 & 12,00 & 12,00 & 2,60 & 110 & 184 & 12 & 9 & 32 & 82,0 \\
\hline 23 & 22,10 & 1,70 & 10,70 & 10,40 & 3,40 & 95 & 144 & 13 & 7 & 31 & 79,0 \\
\hline 24 & 18,70 & 1,90 & 11,40 & 11,70 & 3,90 & 96 & 92 & 16 & 7 & 30 & 54,0 \\
\hline 25 & 21,90 & 1,40 & 11,00 & 9,80 & 3,00 & 80 & 114 & 28 & 8 & 31 & 78,0 \\
\hline 26 & 21,30 & 1,30 & 13,00 & 10,60 & 3,00 & 128 & 124 & 9 & 8 & 29 & 53,0 \\
\hline 27 & 22,30 & 1,60 & 9,30 & 10,40 & 3,50 & 163 & 146 & 11 & 8 & 26 & 52,0 \\
\hline 28 & 21,10 & 1,40 & 13,10 & 9,00 & 3,70 & 152 & 176 & 26 & 8 & 31 & 45,0 \\
\hline 29 & 24,60 & 1,80 & 13,40 & 11,80 & 4,20 & 232 & 91 & 6 & 10 & 32 & 40,0 \\
\hline 30 & 21,80 & 1,60 & 9,60 & 9,60 & 3,80 & 185 & 192 & 21 & 8 & 25 & 48,0 \\
\hline 31 & 23,10 & 2,00 & 12,50 & 10,80 & 3,90 & 209 & 64 & 6 & 9 & 32 & 44,0 \\
\hline 32 & 22,30 & 1,70 & 10,60 & 12,80 & 4,00 & 176 & 68 & 7 & 9 & 29 & 42,0 \\
\hline 33 & 22,20 & 1,60 & 11,80 & 11,80 & 4,00 & 195 & 213 & 26 & 9 & 27 & 60,0 \\
\hline 34 & 21,20 & 1,50 & 13,60 & 8,90 & 2,90 & 128 & 196 & 20 & 7 & 27 & 57,0 \\
\hline 35 & 22,70 & 1,60 & 10,80 & 10,00 & 3,20 & 186 & 96 & 8 & 8 & 30 & 38,0 \\
\hline
\end{tabular}


APÊNDICE 1. Concentração de macro e micronutrientes em folhas e a produção de frutos em 70 pomares de macieira no Rio Grande do Sul e Santa Catarina. (Safra 2002)

\begin{tabular}{|c|c|c|c|c|c|c|c|c|c|c|c|}
\hline Amostra & $\mathbf{N}$ & $\mathbf{P}$ & $\mathbf{K}$ & Ca & Mg & Fe & Mn & Zn & $\mathbf{C u}$ & B & Produção \\
\hline & \multicolumn{5}{|c|}{---------------- g kg$^{-1}$--------------- } & \multicolumn{6}{|c|}{ 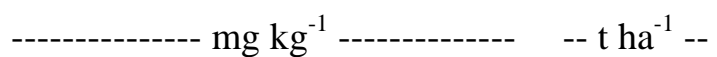 } \\
\hline 36 & 21,00 & 1,40 & 14,40 & 10,40 & 2,80 & 156 & 221 & 42 & 8 & 31 & 43,0 \\
\hline 37 & 22,20 & 1,50 & 12,50 & 10,80 & 2,70 & 222 & 105 & 7 & 8 & 33 & 28,0 \\
\hline 38 & 20,70 & 1,70 & 16,60 & 9,70 & 2,40 & 131 & 194 & 45 & 8 & 29 & 51,0 \\
\hline 39 & 23,20 & 1,60 & 14,20 & 10,00 & 2,60 & 161 & 98 & 12 & 10 & 31 & 52,0 \\
\hline 40 & 20,60 & 1,70 & 18,30 & 8,60 & 2,40 & 260 & 140 & 53 & 10 & 31 & 39,0 \\
\hline 41 & 22,10 & 1,90 & 10,20 & 10,40 & 3,00 & 341 & 116 & 22 & 10 & 31 & 34,0 \\
\hline 42 & 20,30 & 1,60 & 9,90 & 9,80 & 3,40 & 190 & 142 & 9 & 9 & 28 & 47,0 \\
\hline 43 & 22,10 & 1,50 & 8,40 & 12,50 & 3,80 & 228 & 113 & 14 & 11 & 33 & 41,0 \\
\hline 44 & 24,80 & 1,70 & 15,10 & 14,70 & 3,00 & 147 & 188 & 359 & 9 & 32 & 54,0 \\
\hline 45 & 26,30 & 1,90 & 14,40 & 16,30 & 3,40 & 199 & 188 & 202 & 9 & 32 & 63,0 \\
\hline 46 & 26,10 & 1,90 & 16,50 & 12,20 & 2,70 & 164 & 601 & 233 & 9 & 33 & 61,0 \\
\hline 47 & 23,60 & 1,60 & 18,80 & 11,60 & 2,20 & 180 & 531 & 268 & 10 & 31 & 82,0 \\
\hline 48 & 23,40 & 1,50 & 15,60 & 15,40 & 2,90 & 106 & 497 & 312 & 9 & 33 & 60,0 \\
\hline 49 & 26,20 & 1,90 & 16,00 & 17,00 & 3,20 & 132 & 222 & 204 & 8 & 33 & 54,0 \\
\hline 50 & 24,60 & 1,80 & 15,20 & 15,20 & 3,00 & 132 & 606 & 333 & 8 & 31 & 41,0 \\
\hline 51 & 25,50 & 2,00 & 16,30 & 14,80 & 3,00 & 119 & 482 & 299 & 8 & 31 & 55,0 \\
\hline 52 & 26,70 & 2,10 & 15,90 & 16,50 & 3,40 & 906 & 234 & 244 & 12 & 35 & 53,0 \\
\hline 53 & 26,90 & 1,70 & 19,80 & 13,60 & 3,50 & 213 & 43 & 155 & 8 & 34 & 46,8 \\
\hline 54 & 25,60 & 1,20 & 18,20 & 11,20 & 1,50 & 169 & 40 & 583 & 8 & 37 & 75,8 \\
\hline 55 & 25,00 & 1,70 & 16,40 & 13,20 & 2,30 & 186 & 33 & 10 & 8 & 37 & 97,5 \\
\hline 56 & 21,70 & 1,80 & 19,60 & 12,60 & 2,40 & 150 & 32 & 140 & 8 & 37 & 38,1 \\
\hline 57 & 23,80 & 1,60 & 18,40 & 12,00 & 1,70 & 141 & 36 & 658 & 8 & 37 & 15,9 \\
\hline 58 & 23,10 & 1,40 & 17,80 & 12,60 & 2,40 & 184 & 38 & 520 & 8 & 37 & 15,9 \\
\hline 59 & 25,30 & 1,50 & 19,60 & 12,10 & 1,60 & 201 & 31 & 187 & 8 & 40 & 46,9 \\
\hline 60 & 24,20 & 1,40 & 15,40 & 11,20 & 2,60 & 156 & 26 & 414 & 8 & 34 & 15,9 \\
\hline 61 & 25,40 & 1,60 & 11,80 & 13,70 & 2,60 & 253 & 56 & 166 & 9 & 35 & 46,9 \\
\hline 62 & 25,20 & 1,90 & 16,70 & 9,00 & 2,70 & 150 & 302 & 76 & 12 & 33 & 46,9 \\
\hline 63 & 25,00 & 1,50 & 17,60 & 9,40 & 2,70 & 145 & 271 & 58 & 9 & 34 & 37,4 \\
\hline 64 & 23,10 & 1,70 & 16,70 & 12,30 & 3,30 & 291 & 280 & 70 & 11 & 30 & 50,1 \\
\hline 65 & 25,00 & 1,60 & 18,20 & 8,40 & 2,20 & 131 & 174 & 64 & 11 & 38 & 46,8 \\
\hline 66 & 25,10 & 1,90 & 18,40 & 9,00 & 2,40 & 148 & 60 & 24 & 10 & 36 & 43,0 \\
\hline 67 & 22,10 & 1,60 & 16,30 & 9,40 & 2,60 & 114 & 290 & 82 & 9 & 33 & 43,0 \\
\hline 68 & 24,30 & 1,20 & 18,20 & 10,00 & 2,80 & 104 & 270 & 70 & 9 & 35 & 36,8 \\
\hline 69 & 26,20 & 1,60 & 15,40 & 10,00 & 2,60 & 122 & 228 & 66 & 8 & 36 & 70,1 \\
\hline 70 & 26,60 & 1,50 & 15,00 & 9,40 & 2,40 & 206 & 214 & 75 & 10 & 35 & 78,3 \\
\hline
\end{tabular}


APÊNDICE 2. Concentração de macro e micronutrientes em folhas e a produção de frutos em 70 pomares de macieira no Rio Grande do Sul e Santa Catarina. (Safra 2003)

\begin{tabular}{|c|c|c|c|c|c|c|c|c|c|c|c|}
\hline Amostra & $\mathbf{N}$ & $\mathbf{P}$ & $\mathbf{K}$ & Ca & Mg & $\mathbf{F e}$ & Mn & Zn & $\mathbf{C u}$ & B & Produção \\
\hline & & & $\mathrm{g} \mathrm{kg}^{-1}$ & & & & & ng kq & & & -- t ha-1 -- \\
\hline 1 & 20,80 & 1,60 & 18,89 & 10,10 & 3,00 & 60 & 274 & 66 & 4 & 36 & 44,5 \\
\hline 2 & 22,90 & 1,80 & 15,90 & 10,20 & 3,30 & 67 & 250 & 64 & 5 & 35 & 43,2 \\
\hline 3 & 20,20 & 1,60 & 11,00 & 14,50 & 3,90 & 64 & 69 & 15 & 6 & 41 & 40,2 \\
\hline 4 & 22,10 & 1,70 & 8,00 & 16,80 & 5,20 & 62 & 75 & 16 & 6 & 40 & 33,8 \\
\hline 5 & 23,60 & 2,40 & 18,60 & 14,00 & 3,00 & 61 & 73 & 17 & 5 & 37 & 40,6 \\
\hline 6 & 21,70 & 2,50 & 26,20 & 14,90 & 2,90 & 64 & 187 & 47 & 5 & 28 & 40,7 \\
\hline 7 & 20,90 & 1,40 & 17,70 & 9,00 & 3,60 & 66 & 210 & 39 & 8 & 35 & 19,5 \\
\hline 8 & 23,50 & 1,40 & 13,50 & 9,50 & 3,40 & 70 & 184 & 36 & 7 & 34 & 28,3 \\
\hline 9 & 21,40 & 1,40 & 16,20 & 11,20 & 4,00 & 78 & 316 & 58 & 6 & 37 & 28,0 \\
\hline 10 & 21,00 & 1,30 & 22,30 & 7,80 & 2,90 & 45 & 178 & 32 & 7 & 34 & 33,6 \\
\hline 11 & 20,50 & 1,40 & 8,60 & 10,70 & 3,40 & 63 & 303 & 43 & 7 & 33 & 52,2 \\
\hline 12 & 19,50 & 1,20 & 10,40 & 10,90 & 3,60 & 122 & 396 & 44 & 6 & 34 & 58,7 \\
\hline 13 & 19,50 & 1,50 & 21,00 & 10,00 & 2,90 & 120 & 190 & 35 & 8 & 47 & 18,0 \\
\hline 14 & 19,70 & 1,60 & 18,40 & 10,40 & 2,50 & 102 & 140 & 28 & 6 & 44 & 15,0 \\
\hline 15 & 18,60 & 1,40 & 21,80 & 10,70 & 3,00 & 68 & 188 & 34 & 7 & 48 & 22,0 \\
\hline 16 & 19,10 & 1,40 & 14,30 & 11,90 & 2,70 & 103 & 346 & 24 & 6 & 47 & 30,0 \\
\hline 17 & 18,50 & 1,30 & 16,60 & 10,00 & 3,10 & 91 & 167 & 30 & 6 & 45 & 35,0 \\
\hline 18 & 19,30 & 1,40 & 18,60 & 11,60 & 3,00 & 186 & 322 & 49 & 6 & 46 & 25,0 \\
\hline 19 & 20,60 & 1,50 & 17,40 & 10,20 & 3,00 & 192 & 146 & 31 & 5 & 46 & 12,0 \\
\hline 20 & 20,80 & 1,50 & 18,30 & 10,80 & 4,00 & 70 & 276 & 56 & 4 & 47 & 35,0 \\
\hline 21 & 20,30 & 1,70 & 13,90 & 10,80 & 3,20 & 129 & 228 & 26 & 6 & 44 & 75,0 \\
\hline 22 & 19,10 & 1,60 & 16,70 & 11,00 & 3,00 & 99 & 205 & 28 & 6 & 45 & 30,0 \\
\hline 23 & 19,50 & 1,40 & 18,40 & 8,70 & 3,70 & 80 & 188 & 41 & 5 & 41 & 18,0 \\
\hline 24 & 20,10 & 1,60 & 14,80 & 11,20 & 4,70 & 68 & 184 & 41 & 6 & 39 & 70,0 \\
\hline 25 & 20,20 & 1,20 & 19,20 & 8,40 & 3,10 & 56 & 198 & 47 & 5 & 40 & 22,0 \\
\hline 26 & 21,40 & 1,20 & 21,20 & 10,00 & 3,60 & 71 & 219 & 36 & 6 & 42 & 18,0 \\
\hline 27 & 18,50 & 1,20 & 17,60 & 11,00 & 4,00 & 66 & 270 & 39 & 5 & 40 & 25,0 \\
\hline 28 & 19,20 & 1,30 & 15,70 & 10,00 & 4,00 & 186 & 308 & 59 & 6 & 36 & 52,0 \\
\hline 29 & 23,50 & 1,40 & 11,60 & 11,60 & 4,40 & 108 & 149 & 20 & 6 & 39 & 40,0 \\
\hline 30 & 19,30 & 1,20 & 14,40 & 9,80 & 4,00 & 172 & 303 & 77 & 4 & 34 & 57,0 \\
\hline 31 & 22,20 & 1,40 & 11,10 & 10,90 & 4,30 & 154 & 100 & 20 & 5 & 40 & 46,0 \\
\hline 32 & 24,70 & 1,40 & 12,70 & 10,70 & 3,80 & 140 & 86 & 20 & 7 & 35 & 49,0 \\
\hline 33 & 20,70 & 1,30 & 15,20 & 10,80 & 4,00 & 105 & 319 & 68 & 6 & 33 & 63,0 \\
\hline 34 & 21,20 & 1,30 & 16,80 & 8,60 & 2,90 & 108 & 278 & 64 & 6 & 34 & 40,0 \\
\hline 35 & 23,40 & 1,30 & 15,20 & 9,00 & 3,30 & 112 & 160 & 20 & 6 & 38 & 33,0 \\
\hline
\end{tabular}


APÊNDICE 2. Concentração de macro e micronutrientes em folhas e a produção de frutos em 70 pomares de macieira no Rio Grande do Sul e Santa Catarina. (Safra 2003)

\begin{tabular}{|c|c|c|c|c|c|c|c|c|c|c|c|}
\hline Amostra & $\mathbf{N}$ & $\mathbf{P}$ & $\mathbf{K}$ & Ca & Mg & $\mathbf{F e}$ & Mn & $\mathbf{Z n}$ & $\mathbf{C u}$ & B & Produção \\
\hline & & & $\mathrm{g} \mathrm{kg}^{-1}$ & & & & & $\mathrm{ng} \mathrm{kg}$ & & & -- t ha ${ }^{-1}--$ \\
\hline 36 & 21,60 & 1,40 & 14,60 & 10,50 & 3,10 & 204 & 369 & 90 & 6 & 39 & 32,0 \\
\hline 37 & 25,10 & 1,50 & 14,90 & 10,60 & 2,90 & 125 & 137 & 22 & 6 & 44 & 45,0 \\
\hline 38 & 20,70 & 1,30 & 17,80 & 11,00 & 2,90 & 106 & 351 & 88 & 5 & 36 & 55,0 \\
\hline 39 & 24,90 & 1,60 & 16,10 & 10,60 & 3,20 & 115 & 104 & 22 & 6 & 38 & 60,0 \\
\hline 40 & 21,50 & 1,30 & 21,40 & 8,10 & 2,90 & 83 & 60 & 140 & 6 & 38 & 25,0 \\
\hline 41 & 24,00 & 1,50 & 11,80 & 10,60 & 4,10 & 84 & 36 & 160 & 6 & 35 & 29,0 \\
\hline 42 & 23,60 & 1,50 & 12,60 & 11,80 & 4,70 & 87 & 103 & 130 & 4 & 33 & 34,0 \\
\hline 43 & 23,00 & 1,50 & 10,70 & 9,70 & 4,30 & 92 & 78 & 130 & 5 & 35 & 31,0 \\
\hline 44 & 20,20 & 1,20 & 20,20 & 11,90 & 3,50 & 64 & 67 & 390 & 13 & 38 & 26,6 \\
\hline 45 & 23,80 & 1,20 & 17,20 & 12,50 & 3,50 & 58 & 64 & 175 & 15 & 37 & 25,9 \\
\hline 46 & 21,50 & 1,30 & 22,50 & 11,40 & 3,00 & 74 & 144 & 410 & 11 & 44 & 30,8 \\
\hline 47 & 20,30 & 1,00 & 27,20 & 10,20 & 2,70 & 64 & 133 & 330 & 19 & 46 & 32,2 \\
\hline 48 & 20,10 & 1,20 & 22,80 & 11,60 & 3,10 & 64 & 79 & 360 & 15 & 44 & 30,8 \\
\hline 49 & 22,70 & 1,20 & 20,50 & 11,80 & 2,90 & 63 & 84 & 180 & 20 & 42 & 29,4 \\
\hline 50 & 22,90 & 1,20 & 22,20 & 10,50 & 3,10 & 68 & 72 & 360 & 16 & 41 & 28,7 \\
\hline 51 & 21,60 & 1,20 & 21,50 & 9,60 & 3,40 & 65 & 70 & 370 & 15 & 42 & 29,4 \\
\hline 52 & 21,30 & 1,20 & 20,90 & 10,10 & 3,10 & 72 & 62 & 160 & 19 & 42 & 29,4 \\
\hline 53 & 22,10 & 1,10 & 23,20 & 11,20 & 1,50 & 70 & 40 & 180 & 6 & 47 & 28,8 \\
\hline 54 & 22,50 & 1,10 & 24,70 & 8,20 & 1,80 & 90 & 43 & 270 & 6 & 46 & 21,1 \\
\hline 55 & 23,80 & 1,20 & 22,00 & 11,10 & 2,00 & 100 & 42 & 170 & 6 & 46 & 28,8 \\
\hline 56 & 22,50 & 1,40 & 24,60 & 9,90 & 2,00 & 104 & 36 & 330 & 6 & 45 & 21,1 \\
\hline 57 & 21,70 & 1,10 & 26,80 & 10,20 & 1,90 & 112 & 32 & 340 & 6 & 50 & 21,1 \\
\hline 58 & 21,90 & 1,70 & 22,60 & 10,20 & 2,20 & 82 & 44 & 350 & 6 & 50 & 21,1 \\
\hline 59 & 21,20 & 1,10 & 25,40 & 10,30 & 1,40 & 106 & 34 & 260 & 5 & 51 & 28,8 \\
\hline 60 & 20,60 & 1,10 & 20,60 & 10,20 & 2,40 & 93 & 27 & 240 & 7 & 48 & 21,1 \\
\hline 61 & 22,00 & 1,00 & 18,40 & 10,60 & 2,10 & 90 & 58 & 170 & 6 & 54 & 28,8 \\
\hline 62 & 21,90 & 1,20 & 22,10 & 8,10 & 2,40 & 78 & 320 & 95 & 7 & 44 & 53,3 \\
\hline 63 & 23,80 & 1,20 & 22,90 & 7,80 & 2,30 & 73 & 248 & 82 & 6 & 44 & 46,6 \\
\hline 64 & 21,00 & 1,20 & 18,40 & 8,60 & 3,00 & 64 & 405 & 140 & 6 & 41 & 41,7 \\
\hline 65 & 23,40 & 1,10 & 19,60 & 8,10 & 2,40 & 202 & 180 & 37 & 7 & 48 & 38,1 \\
\hline 66 & 23,70 & 1,20 & 20,10 & 8,50 & 2,20 & 136 & 125 & 35 & 7 & 48 & 37,1 \\
\hline 67 & 23,50 & 1,40 & 21,00 & 9,20 & 2,20 & 85 & 540 & 140 & 7 & 42 & 45,6 \\
\hline 68 & 23,50 & 1,40 & 21,50 & 8,00 & 2,10 & 92 & 480 & 140 & 7 & 43 & 46,6 \\
\hline 69 & 20,90 & 1,10 & 17,80 & 8,70 & 2,40 & 146 & 143 & 82 & 6 & 50 & 17,1 \\
\hline 70 & 22,30 & 1,10 & 18,00 & 8,40 & 2,30 & 106 & 179 & 90 & 6 & 50 & 21,6 \\
\hline
\end{tabular}


APÊNDICE 3. Valores de pH em água (1:1) e teores de fósforo (P), potássio (K), matéria orgânica $(\mathrm{MO})$, alumínio $(\mathrm{Al})$, cálcio $(\mathrm{Ca})$ e magnésio $(\mathrm{Mg})$ na camada de 0 a $20 \mathrm{~cm}$ do solo de 70 pomares de macieira no Rio Grande do Sul e Santa Catarina. (Safra 2002)

\begin{tabular}{|c|c|c|c|c|c|c|c|}
\hline Amostra & pH (1:1) & $\mathbf{P}$ & $\mathbf{K}$ & MO & Al & Ca & Mg \\
\hline & & \multicolumn{2}{|c|}{----- mg dm ${ }^{-3}$----- } & $\mathrm{g} \mathrm{dm}^{-3}$ & \multicolumn{3}{|c|}{--------- $\mathrm{mmol}_{\mathrm{c}} \mathrm{dm}^{-3}$} \\
\hline 1 & 5,9 & 49,0 & 327 & 51,9 & 0,2 & 84,4 & 43,4 \\
\hline 2 & 6,1 & 61,2 & 112 & 73,2 & 0,4 & 104,9 & 48,3 \\
\hline 3 & 6,3 & 3,0 & 86 & 70,7 & 0,4 & 101,8 & 59,7 \\
\hline 4 & 5,9 & 2,5 & 121 & 65,6 & 0,3 & 100,1 & 36,0 \\
\hline 5 & 6,4 & 77,7 & 256 & 68,8 & 1,1 & 115,6 & 52,5 \\
\hline 6 & 6,8 & 116,2 & 288 & 67,3 & 0,7 & 127,0 & 50,5 \\
\hline 7 & 5,2 & 3,5 & 48 & 41,7 & 4,6 & 43,1 & 30,9 \\
\hline 8 & 5,7 & 5,3 & 62 & 39,3 & 0,9 & 55,0 & 41,3 \\
\hline 9 & 6,1 & 2,7 & 59 & 38,5 & 0,2 & 69,4 & 47,9 \\
\hline 10 & 5,4 & 2,1 & 1479 & 39,8 & 0,8 & 44,4 & 27,4 \\
\hline 11 & 5,0 & 112,9 & 36 & 41,8 & 5,3 & 67,7 & 9,9 \\
\hline 12 & 4,0 & 4,4 & 44 & 39,8 & 46,1 & 11,3 & 6,1 \\
\hline 13 & 5,8 & 21,1 & 163 & 43,1 & 0,3 & 82,7 & 36,5 \\
\hline 14 & 7,1 & 30,9 & 141 & 43,6 & 0,2 & 109,7 & 51,8 \\
\hline 15 & 6,9 & 21,8 & 171 & 48,3 & 0,3 & 126,4 & 61,4 \\
\hline 16 & 5,7 & 10,3 & 96 & 50,3 & 0,6 & 107,6 & 25,4 \\
\hline 17 & 6,7 & 13,3 & 123 & 40,4 & 0,0 & 129,8 & 58,7 \\
\hline 18 & 7,0 & 18,8 & 83 & 46,7 & 0,0 & 128,1 & 52,8 \\
\hline 19 & 7,2 & 20,9 & 84 & 43,6 & 0,2 & 104,6 & 57,8 \\
\hline 20 & 7,1 & 14,4 & 194 & 42,6 & 0,2 & 93,6 & 56,4 \\
\hline 21 & 5,9 & 13,1 & 71 & 46,2 & 0,2 & 103,2 & 33,7 \\
\hline 22 & 6,2 & 21,6 & 91 & 44,6 & 0,0 & 106,9 & 38,0 \\
\hline 23 & 7,0 & 5,9 & 144 & 42,6 & 0,2 & 80,6 & 57,1 \\
\hline 24 & 6,5 & 11,0 & 187 & 51,2 & 0,1 & 88,8 & 54,1 \\
\hline 25 & 6,3 & 5,9 & 114 & 45,3 & 0,1 & 71,4 & 52,5 \\
\hline 26 & 7,2 & 7,4 & 197 & 38,0 & 0,0 & 78,6 & 60,6 \\
\hline 27 & 7,0 & 8,3 & 297 & 38,9 & 0,2 & 89,2 & 61,3 \\
\hline 28 & 5,7 & 6,5 & 104 & 47,9 & 0,4 & 67,6 & 49,2 \\
\hline 29 & 6,0 & 5,4 & 107 & 50,1 & 0,0 & 67,6 & 51,2 \\
\hline 30 & 6,2 & 8,8 & 206 & 42,7 & 0,0 & 82,0 & 54,4 \\
\hline 31 & 6,7 & 13,3 & 167 & 46,9 & 0,0 & 95,0 & 61,3 \\
\hline 32 & 5,7 & 3,1 & 52 & 28,4 & 0,4 & 47,1 & 35,9 \\
\hline 33 & 6,0 & 9,4 & 200 & 44,0 & 0,2 & 74,1 & 49,2 \\
\hline 34 & 6,9 & 9,2 & 182 & 43,3 & 0,2 & 95,7 & 55,1 \\
\hline 35 & 6,9 & 6,1 & 203 & 41,9 & 0,2 & 56,0 & 56,5 \\
\hline
\end{tabular}


APÊNDICE 3. Valores de pH em água (1:1) e teores de fósforo (P), potássio (K), matéria orgânica $(\mathrm{MO})$, alumínio $(\mathrm{Al})$, cálcio $(\mathrm{Ca})$ e magnésio $(\mathrm{Mg})$ na camada de 0 a $20 \mathrm{~cm}$ do solo de 70 pomares de macieira no Rio Grande do Sul e Santa Catarina. (Safra 2002)

\begin{tabular}{|c|c|c|c|c|c|c|c|}
\hline Amostra & pH (1:1) & $\mathbf{P}$ & $\mathbf{K}$ & MO & Al & Ca & Mg \\
\hline & & \multicolumn{2}{|c|}{------ $\mathrm{mg} \mathrm{dm}{ }^{-3}$------ } & $\mathrm{g} \mathrm{dm}^{-3}$ & \multicolumn{3}{|c|}{------ $\mathrm{mmol}_{\mathrm{c}} \mathrm{dm}^{-3}$} \\
\hline 36 & 6,7 & 7,9 & 135 & 45,2 & 0,2 & 92,2 & 48,9 \\
\hline 37 & 6,1 & 6,8 & 144 & 56,2 & 1,1 & 89,1 & 37,6 \\
\hline 38 & 6,8 & 7,5 & 186 & 46,1 & 0,3 & 102,0 & 54,8 \\
\hline 39 & 6,6 & 7,3 & 127 & 44,7 & 0,0 & 97,7 & 47,6 \\
\hline 40 & 7,1 & 4,5 & 204 & 52,8 & 0,0 & 105,9 & 73,2 \\
\hline 41 & 6,9 & 8,7 & 54 & 50,7 & 0,0 & 105,2 & 60,7 \\
\hline 42 & 6,1 & 6,6 & 74 & 43,4 & 0,1 & 71,4 & 49,9 \\
\hline 43 & 5,9 & 6,8 & 85 & 45,2 & 0,0 & 75,6 & 51,2 \\
\hline 44 & 6,0 & 13,7 & 602 & 50,1 & 0,2 & 104,9 & 55,6 \\
\hline 45 & 5,3 & 4,5 & 398 & 54,7 & 0,5 & 78,6 & 47,8 \\
\hline 46 & 5,6 & 10,2 & 602 & 48,8 & 0,1 & 87,8 & 39,8 \\
\hline 47 & 5,1 & 5,7 & 260 & 51,4 & 1,0 & 70,7 & 39,3 \\
\hline 48 & 5,9 & 8,0 & 481 & 46,9 & 0,1 & 85,5 & 45,9 \\
\hline 49 & 5,9 & 4,7 & 522 & 45,9 & 0,4 & 81,2 & 40,6 \\
\hline 50 & 5,6 & 29,2 & 566 & 42,3 & 0,6 & 104,6 & 42,9 \\
\hline 51 & 6,4 & 11,8 & 460 & 48,7 & 0,0 & 103,6 & 60,3 \\
\hline 52 & 5,6 & 4,5 & 351 & 47,4 & 0,6 & 79,9 & 44,2 \\
\hline 53 & 5,2 & 7,1 & 313 & 42,4 & 5,6 & 71,0 & 10,6 \\
\hline 54 & 5,1 & 8,5 & 218 & 44,7 & 2,0 & 97,3 & 12,9 \\
\hline 55 & 4,7 & 7,5 & 127 & 44,0 & 12,8 & 56,2 & 19,5 \\
\hline 56 & 6,0 & 7,5 & 89 & 45,0 & 0,0 & 107,2 & 24,8 \\
\hline 57 & 5,3 & 5,2 & 138 & 50,9 & 3,1 & 94,1 & 8,3 \\
\hline 58 & 5,6 & 4,5 & 120 & 41,2 & 0,4 & 88,1 & 10,8 \\
\hline 59 & 4,8 & 6,3 & 502 & 37,8 & 15,3 & 43,7 & 8,2 \\
\hline 60 & 6,3 & 6,7 & 104 & 29,4 & 0,1 & 104,6 & 222,2 \\
\hline 61 & 6,4 & 4,5 & 45 & 37,1 & 0,0 & 101,3 & 197,3 \\
\hline 62 & 5,3 & 11,0 & 318 & 41,6 & 2,6 & 82,9 & 96,0 \\
\hline 63 & 6,9 & 17,5 & 164 & 43,5 & 0,0 & 144,1 & 394,7 \\
\hline 64 & 6,4 & 8,6 & 172 & 46,1 & 0,0 & 116,8 & 506,7 \\
\hline 65 & 6,2 & 27,9 & 128 & 42,6 & 0,0 & 137,8 & 320,0 \\
\hline 66 & 6,2 & 49,1 & 132 & 38,9 & 0,0 & 141,1 & 270,2 \\
\hline 67 & 6,4 & 101,5 & 147 & 52,8 & 0,0 & 142,8 & 312,9 \\
\hline 68 & 6,8 & 58,7 & 218 & 50,1 & 0,0 & 153,6 & 357,3 \\
\hline 69 & 6,8 & 32,6 & 119 & 41,6 & 0,0 & 148,7 & 257,8 \\
\hline 70 & 6,2 & 22,5 & 148 & 34,6 & 0,0 & 127,0 & 247,1 \\
\hline
\end{tabular}


APÊNDICE 4. Valores de pH em água (1:1) e teores de fósforo (P), potássio (K), matéria orgânica (MO), alumínio $(\mathrm{Al})$, cálcio $(\mathrm{Ca})$ e magnésio $(\mathrm{Mg})$ na camada de 20 a $40 \mathrm{~cm}$ do solo de 70 pomares de macieira no Rio Grande do Sul e Santa Catarina. (Safra 2002)

\begin{tabular}{|c|c|c|c|c|c|c|c|}
\hline Amostra & pH (1:1) & $\mathbf{P}$ & $\mathbf{K}$ & MO & Al & Ca & Mg \\
\hline & & \multicolumn{2}{|c|}{----- $\mathrm{mg} \mathrm{dm}{ }^{-3}$------ } & $\mathrm{g} \mathrm{dm}^{-3}$ & \multicolumn{3}{|c|}{-------- $\mathrm{mmol}_{\mathrm{c}} \mathrm{dm}^{-3}$-------- } \\
\hline 1 & 5,6 & 11,9 & 70 & 37,3 & 1,3 & 48,9 & 30,9 \\
\hline 2 & 5,6 & 11,5 & 41 & 56,6 & 3,0 & 38,6 & 30,5 \\
\hline 3 & 5,2 & 1,6 & 39 & 37,8 & 10,9 & 36,2 & 26,7 \\
\hline 4 & 4,8 & 1,1 & 23 & 34,6 & 30,1 & 17,1 & 8,6 \\
\hline 5 & 5,6 & 15,4 & 68 & 38,4 & 2,4 & 33,8 & 24,8 \\
\hline 6 & 6,1 & 28,4 & 71 & 34,6 & 1,8 & 37,5 & 21,6 \\
\hline 7 & 4,9 & 1,2 & 23 & 31,0 & 24,9 & 17,8 & 14,7 \\
\hline 8 & 4,7 & 1,1 & 22 & 22,7 & 28,2 & 13,3 & 13,2 \\
\hline 9 & 6,0 & 1,2 & 22 & 24,6 & 0,3 & 40,7 & 36,3 \\
\hline 10 & 4,5 & 1,1 & 454 & 28,2 & 9,7 & 25,3 & 20,8 \\
\hline 11 & 4,9 & 7,3 & 20 & 33,1 & 12,2 & 40,3 & 6,9 \\
\hline 12 & 4,2 & 2,0 & 30 & 35,7 & 40,2 & 12,6 & 7,6 \\
\hline 13 & 6,1 & 12,4 & 115 & 36,8 & 0,3 & 72,8 & 43,1 \\
\hline 14 & 7,0 & 16,7 & 71 & 39,9 & 0,3 & 92,9 & 52,0 \\
\hline 15 & 6,8 & 34,1 & 127 & 41,8 & 0,2 & 119,6 & 64,5 \\
\hline 16 & 5,4 & 21,8 & 46 & 48,9 & 1,0 & 87,8 & 35,3 \\
\hline 17 & 6,7 & 7,1 & 67 & 35,6 & 0,0 & 120,6 & 62,4 \\
\hline 18 & 6,9 & 10,8 & 40 & 41,2 & 0,2 & 97,4 & 58,7 \\
\hline 19 & 6,8 & 5,0 & 34 & 37,9 & 0,0 & 69,0 & 52,5 \\
\hline 20 & 7,0 & 11,5 & 127 & 39,5 & 0,0 & 78,2 & 54,6 \\
\hline 21 & 5,7 & 7,3 & 85 & 48,6 & 0,3 & 82,3 & 38,1 \\
\hline 22 & 6,3 & 22,5 & 42 & 38,4 & 0,1 & 90,5 & 39,8 \\
\hline 23 & 6,8 & 4,8 & 97 & 42,8 & 0,2 & 73,5 & 56,9 \\
\hline 24 & 6,8 & 7,5 & 143 & 43,4 & 0,0 & 80,3 & 59,4 \\
\hline 25 & 6,6 & 0,5 & 61 & 40,4 & 0,2 & 67,0 & 54,3 \\
\hline 26 & 7,0 & 5,2 & 87 & 32,7 & 0,2 & 64,9 & 54,4 \\
\hline 27 & 7,1 & 9,4 & 221 & 34,7 & 0,2 & 84,7 & 60,6 \\
\hline 28 & 5,0 & 2,5 & 39 & 35,2 & 10,4 & 30,4 & 29,3 \\
\hline 29 & 4,9 & 2,3 & 36 & 29,0 & 16,1 & 22,5 & 24,2 \\
\hline 30 & 5,9 & 3,2 & 47 & 32,5 & 0,0 & 49,9 & 47,5 \\
\hline 31 & 5,7 & 3,1 & 40 & 38,5 & 0,7 & 45,1 & 43,6 \\
\hline 32 & 6,4 & 7,4 & 173 & 40,0 & 0,1 & 82,0 & 54,8 \\
\hline 33 & 5,2 & 3,6 & 77 & 35,3 & 4,9 & 42,7 & 35,6 \\
\hline 34 & 6,1 & 2,7 & 57 & 27,3 & 0,2 & 57,4 & 42,7 \\
\hline 35 & 6,2 & 2,5 & 57 & 30,0 & 0,1 & 48,2 & 38,4 \\
\hline
\end{tabular}


APÊNDICE 4. Valores de pH em água (1:1) e teores de fósforo (P), potássio (K), matéria orgânica (MO), alumínio $(\mathrm{Al})$, cálcio $(\mathrm{Ca})$ e magnésio $(\mathrm{Mg})$ na camada de 20 a $40 \mathrm{~cm}$ do solo de 70 pomares de macieira no Rio Grande do Sul e Santa Catarina. (Safra 2002)

\begin{tabular}{|c|c|c|c|c|c|c|c|}
\hline Amostra & pH (1:1) & $\mathbf{P}$ & $\mathbf{K}$ & MO & Al & Ca & Mg \\
\hline & & \multicolumn{2}{|c|}{------ $\mathrm{mg} \mathrm{dm}^{-3}$------ } & $\mathrm{g} \mathrm{dm}^{-3}$ & \multicolumn{3}{|c|}{----- $\mathrm{mmol}_{\mathrm{c}} \mathrm{dm}^{-3}$} \\
\hline 36 & 6,3 & 4,0 & 62 & 36,0 & 0,1 & 63,2 & 40,0 \\
\hline 37 & 5,4 & 3,5 & 44 & 49,6 & 1,3 & 49,3 & 21,1 \\
\hline 38 & 6,2 & 3,1 & 81 & 35,3 & 0,0 & 59,2 & 39,5 \\
\hline 39 & 5,8 & 4,7 & 97 & 38,9 & 0,6 & 57,9 & 34,0 \\
\hline 40 & 5,5 & 2,1 & 93 & 39,2 & 3,3 & 40,1 & 40,6 \\
\hline 41 & 6,3 & 2,6 & 24 & 30,2 & 0,0 & 57,9 & 42,5 \\
\hline 42 & 5,1 & 2,6 & 22 & 31,9 & 9,0 & 28,3 & 24,1 \\
\hline 43 & 5,0 & 2,4 & 25 & 32,5 & 8,9 & 30,6 & 24,1 \\
\hline 44 & 4,9 & 11,1 & 158 & 33,3 & 3,2 & 48,3 & 36,6 \\
\hline 45 & 4,7 & 4,0 & 137 & 40,4 & 4,8 & 46,7 & 37,4 \\
\hline 46 & 4,8 & 11,3 & 180 & 41,0 & 3,4 & 47,4 & 28,1 \\
\hline 47 & 5,0 & 2,8 & 152 & 33,5 & 2,2 & 51,3 & 36,0 \\
\hline 48 & 6,5 & 2,1 & 111 & 35,9 & 0,1 & 74,0 & 58,4 \\
\hline 49 & 4,7 & 2,6 & 83 & 35,4 & 12,7 & 39,8 & 32,1 \\
\hline 50 & 4,9 & 9,4 & 212 & 34,3 & 4,7 & 45,4 & 28,5 \\
\hline 51 & 5,1 & 5,6 & 117 & 37,3 & 1,9 & 49,0 & 40,8 \\
\hline 52 & 4,6 & 2,8 & 99 & 36,9 & 9,4 & 37,8 & 27,1 \\
\hline 53 & 4,9 & 5,4 & 151 & 40,4 & 12,1 & 53,9 & 10,6 \\
\hline 54 & 4,8 & 5,9 & 146 & 44,5 & 7,9 & 71,4 & 18,0 \\
\hline 55 & 4,8 & 4,5 & 91 & 37,8 & 19,1 & 46,4 & 13,7 \\
\hline 56 & 5,0 & 3,1 & 73 & 37,0 & 5,8 & 59,5 & 19,0 \\
\hline 57 & 4,7 & 3,6 & 83 & 42,0 & 22,0 & 49,0 & 5,9 \\
\hline 58 & 5,1 & 4,3 & 83 & 33,8 & 1,6 & 58,2 & 15,6 \\
\hline 59 & 6,6 & 10,6 & 158 & 34,1 & 0,0 & 135,2 & 14,8 \\
\hline 60 & 5,9 & 5,4 & 97 & 37,1 & 0,1 & 103,6 & 188,4 \\
\hline 61 & 6,7 & 43,2 & 194 & 56,3 & 0,0 & 166,1 & 316,4 \\
\hline 62 & 6,3 & 25,4 & 123 & 48,8 & 0,0 & 135,5 & 316,4 \\
\hline 63 & 5,9 & 4,9 & 79 & 36,3 & 0,0 & 96,7 & 359,1 \\
\hline 64 & 6,7 & 6,3 & 87 & 39,8 & 0,0 & 117,1 & 620,4 \\
\hline 65 & 5,3 & 5,8 & 63 & 35,2 & 2,4 & 88,2 & 264,9 \\
\hline 66 & 6,3 & 81,5 & 101 & 37,6 & 0,0 & 128,6 & 371,6 \\
\hline 67 & 5,7 & 13,9 & 65 & 38,1 & 0,2 & 108,2 & 346,7 \\
\hline 68 & 7,4 & 50,0 & 123 & 49,9 & 0,0 & 177,0 & 247,1 \\
\hline 69 & 6,3 & 21,4 & 61 & 36,3 & 0,0 & 126,3 & 268,4 \\
\hline 70 & 5,8 & 5,9 & 55 & 20,0 & 0,0 & 77,0 & 268,4 \\
\hline
\end{tabular}


APÊNDICE 5. Valores de pH em água (1:1) e teores de fósforo (P), potássio (K), matéria orgânica $(\mathrm{MO})$, alumínio $(\mathrm{Al})$, cálcio $(\mathrm{Ca})$ e magnésio $(\mathrm{Mg})$ na camada de 0 a $20 \mathrm{~cm}$ do solo de 70 pomares de macieira no Rio Grande do Sul e Santa Catarina. (Safra 2003)

\begin{tabular}{|c|c|c|c|c|c|c|c|}
\hline Amostra & pH (1:1) & $\mathbf{P}$ & $\mathbf{K}$ & MO & Al & Ca & Mg \\
\hline & & \multicolumn{2}{|c|}{------ $\mathrm{mg} \mathrm{dm}^{-3}$------ } & $\mathrm{g} \mathrm{dm}^{-3}$ & \multicolumn{3}{|c|}{---------- $\mathrm{mmol}_{\mathrm{c}} \mathrm{dm}^{-3}$-------- } \\
\hline 1 & 6,1 & 152,8 & 253 & 64,7 & 0,3 & 89,1 & 45,7 \\
\hline 2 & 7,1 & 159,2 & 292 & 89,9 & 0,3 & 134,5 & 45,7 \\
\hline 3 & 6,2 & 28,6 & 55 & 98,6 & 0,0 & 113,4 & 64,6 \\
\hline 4 & 6,6 & 1,7 & 30 & 102,4 & 0,3 & 114,7 & 74,6 \\
\hline 5 & 6,6 & 42,6 & 148 & 76,0 & 0,2 & 116,0 & 66,0 \\
\hline 6 & 6,2 & 101,6 & 273 & 74,5 & 0,3 & 111,0 & 59,2 \\
\hline 7 & 5,9 & 1,6 & 148 & 46,9 & 0,4 & 61,2 & 46,6 \\
\hline 8 & 6,4 & 2,3 & 41 & 41,8 & 0,0 & 72,3 & 59,2 \\
\hline 9 & 6,1 & 1,2 & 59 & 46,9 & 0,3 & 65,6 & 48,8 \\
\hline 10 & 7,1 & 0,6 & 215 & 45,5 & 0,2 & 75,7 & 57,4 \\
\hline 11 & 4,9 & 35,0 & 42 & 50,3 & 17,8 & 48,4 & 10,8 \\
\hline 12 & 4,4 & 1,4 & 95 & 41,6 & 49,1 & 12,1 & 9,3 \\
\hline 13 & 6,0 & 23,6 & 244 & 42,6 & 0,8 & 85,0 & 31,8 \\
\hline 14 & 6,1 & 13,0 & 66 & 59,6 & 0,0 & 117,7 & 35,7 \\
\hline 15 & 6,4 & 63,7 & 173 & 53,4 & 0,1 & 115,0 & 49,3 \\
\hline 16 & 6,0 & 7,4 & 122 & 54,6 & 0,1 & 101,9 & 40,4 \\
\hline 17 & 5,7 & 28,0 & 59 & 37,3 & 1,1 & 89,8 & 34,1 \\
\hline 18 & 7,3 & 20,2 & 86 & 50,3 & 0,1 & 153,7 & 52,4 \\
\hline 19 & 6,5 & 19,2 & 205 & 63,0 & 0,0 & 102,3 & 40,4 \\
\hline 20 & 6,6 & 10,3 & 143 & 48,3 & 0,0 & 82,4 & 52,9 \\
\hline 21 & 5,8 & 6,9 & 84 & 45,9 & 0,4 & 101,3 & 30,6 \\
\hline 22 & 7,3 & 18,2 & 122 & 47,6 & 0,0 & 110,7 & 43,1 \\
\hline 23 & 7,2 & 2,3 & 138 & 44,5 & 0,0 & 80,7 & 60,4 \\
\hline 24 & 7,2 & 13,4 & 70 & 53,4 & 0,0 & 93,5 & 63,1 \\
\hline 25 & 6,3 & 2,9 & 141 & 58,7 & 0,0 & 70,3 & 52,7 \\
\hline 26 & 6,8 & 2,1 & 292 & 60,4 & 0,0 & 97,5 & 66,5 \\
\hline 27 & 7,0 & 1,2 & 82 & 27,6 & 0,0 & 74,3 & 99,6 \\
\hline 28 & 6,9 & 1,4 & 86 & 27,2 & 0,0 & 83,2 & 106,7 \\
\hline 29 & 6,7 & 1,0 & 71 & 43,4 & 0,0 & 97,2 & 123,7 \\
\hline 30 & 6,5 & 1,4 & 199 & 43,6 & 0,1 & 92,8 & 57,8 \\
\hline 31 & 6,2 & 1,4 & 141 & 43,4 & 0,2 & 81,4 & 47,1 \\
\hline 32 & 5,8 & 6,9 & 197 & 44,8 & 0,2 & 78,5 & 42,2 \\
\hline 33 & 5,8 & 0,6 & 74 & 35,7 & 0,9 & 58,0 & 44,2 \\
\hline 34 & 6,7 & 2,9 & 252 & 39,0 & 0,0 & 86,0 & 44,2 \\
\hline 35 & 6,8 & 1,6 & 143 & 39,3 & 0,0 & 81,4 & 48,2 \\
\hline
\end{tabular}


APÊNDICE 5. Valores de pH em água (1:1) e teores de fósforo (P), potássio (K), matéria orgânica $(\mathrm{MO})$, alumínio $(\mathrm{Al})$, cálcio $(\mathrm{Ca})$ e magnésio $(\mathrm{Mg})$ na camada de 0 a $20 \mathrm{~cm}$ do solo de 70 pomares de macieira no Rio Grande do Sul e Santa Catarina. (Safra 2003)

\begin{tabular}{|c|c|c|c|c|c|c|c|}
\hline Amostra & pH (1:1) & $\mathbf{P}$ & $\mathbf{K}$ & MO & Al & Ca & Mg \\
\hline & & \multicolumn{2}{|c|}{------ $\mathrm{mg} \mathrm{dm}{ }^{-3}$------ } & $\mathrm{g} \mathrm{dm}^{-3}$ & \multicolumn{3}{|c|}{------ $\mathrm{mmol}_{\mathrm{c}} \mathrm{dm}^{-3}$} \\
\hline 36 & 7,0 & 2,4 & 252 & 37,8 & 0,2 & 83,4 & 41,9 \\
\hline 37 & 6,7 & 1,8 & 130 & 47,5 & 0,1 & 87,3 & 35,8 \\
\hline 38 & 6,5 & 4,7 & 201 & 44,6 & 0,1 & 86,6 & 41,8 \\
\hline 39 & 6,7 & 4,5 & 125 & 40,7 & 0,0 & 87,9 & 48,5 \\
\hline 40 & 6,7 & 0,4 & 227 & 43,0 & 0,0 & 82,4 & 61,0 \\
\hline 41 & 6,7 & 1,8 & 102 & 39,0 & 0,4 & 88,2 & 61,0 \\
\hline 42 & 6,3 & 2,0 & 161 & 48,3 & 0,1 & 71,6 & 55,4 \\
\hline 43 & 6,2 & 0,6 & 114 & 39,9 & 0,2 & 65,8 & 44,7 \\
\hline 44 & 6,1 & 1,2 & 371 & 52,3 & 0,2 & 74,9 & 42,6 \\
\hline 45 & 6,7 & 1,6 & 405 & 54,3 & 0,2 & 101,6 & 55,8 \\
\hline 46 & 4,8 & 3,5 & 432 & 47,7 & 7,3 & 40,4 & 12,3 \\
\hline 47 & 5,6 & 1,0 & 211 & 51,0 & 0,8 & 64,5 & 39,7 \\
\hline 48 & 6,4 & 0,6 & 508 & 44,8 & 0,6 & 81,4 & 49,8 \\
\hline 49 & 4,9 & 1,0 & 323 & 37,6 & 5,7 & 62,2 & 26,3 \\
\hline 50 & 6,0 & 0,8 & 487 & 52,9 & 0,3 & 78,1 & 44,2 \\
\hline 51 & 6,6 & 5,2 & 488 & 39,5 & 0,3 & 84,6 & 41,4 \\
\hline 52 & 7,1 & 5,8 & 494 & 47,8 & 0,5 & 101,9 & 52,1 \\
\hline 53 & 5,8 & 3,0 & 88 & 48,4 & 0,7 & 89,5 & 17,2 \\
\hline 54 & 6,2 & 2,8 & 267 & 40,2 & 0,7 & 104,2 & 19,1 \\
\hline 55 & 6,1 & 1,0 & 251 & 40,6 & 0,5 & 81,7 & 27,0 \\
\hline 56 & 5,9 & 3,0 & 161 & 45,7 & 0,8 & 84,6 & 19,1 \\
\hline 57 & 5,7 & 0,6 & 188 & 42,2 & 1,6 & 79,4 & 14,2 \\
\hline 58 & 6,5 & 1,6 & 123 & 35,6 & 0,9 & 96,0 & 8,7 \\
\hline 59 & 6,4 & 8,0 & 301 & 39,1 & 1,0 & 94,7 & 17,2 \\
\hline 60 & 6,9 & 2,8 & 81 & 36,2 & 0,7 & 127,9 & 16,8 \\
\hline 61 & 6,2 & 0,4 & 107 & 27,9 & 0,6 & 79,8 & 15,5 \\
\hline 62 & 6,4 & 60,6 & 196 & 49,1 & 0,4 & 56,0 & 35,3 \\
\hline 63 & 6,6 & 17,6 & 222 & 41,4 & 0,5 & 112,0 & 37,1 \\
\hline 64 & 6,3 & 2,0 & 186 & 35,8 & 0,4 & 93,8 & 35,1 \\
\hline 65 & 6,1 & 12,8 & 137 & 41,0 & 0,5 & 109,7 & 28,6 \\
\hline 66 & 5,9 & 21,8 & 196 & 34,4 & 1,0 & 100,9 & 24,3 \\
\hline 67 & 6,8 & 44,0 & 250 & 43,5 & 0,1 & 120,8 & 34,0 \\
\hline 68 & 7,3 & 49,8 & 269 & 46,8 & 0,7 & 134,1 & 32,7 \\
\hline 69 & 6,7 & 18,6 & 182 & 40,0 & 0,5 & 117,5 & 40,4 \\
\hline 70 & 6,7 & 91,8 & 182 & 50,3 & 0,3 & 141,9 & 32,4 \\
\hline
\end{tabular}


APÊNDICE 6. Valores de pH em água (1:1) e teores de fósforo (P), potássio (K), matéria orgânica $(\mathrm{MO})$, alumínio $(\mathrm{Al})$, cálcio $(\mathrm{Ca})$ e magnésio $(\mathrm{Mg})$ na camada de 20 a $40 \mathrm{~cm}$ do solo de 70 pomares de macieira no Rio Grande do Sul e Santa Catarina. (Safra 2003)

\begin{tabular}{|c|c|c|c|c|c|c|c|}
\hline Amostra & pH (1:1) & $\mathbf{P}$ & $\mathbf{K}$ & MO & Al & Ca & Mg \\
\hline & & \multicolumn{2}{|c|}{------ mg dm ${ }^{-3}$------ } & $\mathrm{g} \mathrm{dm}^{-3}$ & \multicolumn{3}{|c|}{------- $\mathrm{mmol}_{\mathrm{c}} \mathrm{dm}^{-3}$} \\
\hline 1 & 6,2 & 41,8 & 190 & 54,6 & 0,0 & 71,6 & 46,1 \\
\hline 2 & 6,7 & 30,5 & 230 & 83,7 & 0,0 & 91,5 & 52,7 \\
\hline 3 & 5,5 & 6,4 & 28 & 75,8 & 7,6 & 64,6 & 49,3 \\
\hline 4 & 5,3 & 0,4 & 19 & 41,5 & 3,0 & 59,9 & 45,9 \\
\hline 5 & 5,8 & 23,7 & 67 & 65,7 & 2,7 & 71,3 & 61,3 \\
\hline 6 & 5,8 & 59,3 & 228 & 60,8 & 0,9 & 81,4 & 55,8 \\
\hline 7 & 5,0 & 0,4 & 37 & 31,3 & 16,8 & 27,9 & 28,3 \\
\hline 8 & 5,1 & 0,2 & 25 & 26,9 & 10,1 & 30,6 & 27,4 \\
\hline 9 & 5,7 & 0,6 & 49 & 38,5 & 0,8 & 51,8 & 41,8 \\
\hline 10 & 5,7 & 0,2 & 286 & 37,3 & 1,6 & 42,7 & 32,5 \\
\hline 11 & 5,1 & 3,9 & 28 & 39,2 & 15,0 & 47,1 & 9,9 \\
\hline 12 & 4,3 & 0,6 & 79 & 39,0 & 46,9 & 10,8 & 8,4 \\
\hline 13 & 6,5 & 2,7 & 64 & 37,0 & 0,0 & 77,4 & 44,1 \\
\hline 14 & 6,2 & 8,4 & 28 & 54,1 & 0,0 & 93,2 & 61,3 \\
\hline 15 & 7,0 & 27,2 & 61 & 47,9 & 0,1 & 95,9 & 65,3 \\
\hline 16 & 6,1 & 32,1 & 47 & 49,1 & 0,0 & 91,5 & 52,6 \\
\hline 17 & 7,3 & 6,2 & 16 & 34,4 & 0,0 & 124,5 & 75,3 \\
\hline 18 & 7,5 & 22,0 & 32 & 42,6 & 0,0 & 139,9 & 58,7 \\
\hline 19 & 6,9 & 9,5 & 49 & 56,8 & 0,1 & 128,5 & 62,8 \\
\hline 20 & 7,1 & 3,7 & 59 & 40,4 & 0,0 & 71,3 & 59,9 \\
\hline 21 & 6,2 & 5,1 & 31 & 56,0 & 0,0 & 72,7 & 43,2 \\
\hline 22 & 6,7 & 53,8 & 24 & 38,4 & 0,0 & 96,4 & 44,1 \\
\hline 23 & 7,8 & 0,4 & 41 & 33,4 & 0,0 & 69,6 & 60,3 \\
\hline 24 & 6,8 & 1,9 & 36 & 47,1 & 0,0 & 71,3 & 66,4 \\
\hline 25 & 7,3 & 3,1 & 64 & 43,3 & 0,0 & 82,7 & 66,4 \\
\hline 26 & 7,5 & 0,7 & 53 & 36,9 & 0,0 & 101,6 & 147,6 \\
\hline 27 & 7,3 & 0,3 & 23 & 28,9 & 0,0 & 60,7 & 97,8 \\
\hline 28 & 6,8 & 0,3 & 27 & 24,5 & 0,0 & 61,5 & 108,8 \\
\hline 29 & 5,6 & 0,7 & 27 & 39,1 & 4,3 & 50,1 & 84,6 \\
\hline 30 & 5,7 & 0,2 & 46 & 33,7 & 1,6 & 43,0 & 45,7 \\
\hline 31 & 5,3 & 0,4 & 31 & 37,2 & 5,6 & 39,1 & 35,8 \\
\hline 32 & 5,8 & 0,6 & 54 & 32,4 & 0,9 & 57,0 & 36,5 \\
\hline 33 & 6,1 & 1,8 & 189 & 41,7 & 0,1 & 75,2 & 49,3 \\
\hline 34 & 6,9 & 1,0 & 84 & 36,6 & 0,0 & 78,1 & 51,7 \\
\hline 35 & 6,6 & 0,2 & 57 & 28,1 & 0,4 & 54,4 & 39,5 \\
\hline
\end{tabular}


APÊNDICE 6. Valores de pH em água (1:1) e teores de fósforo (P), potássio (K), matéria orgânica $(\mathrm{MO})$, alumínio $(\mathrm{Al})$, cálcio $(\mathrm{Ca})$ e magnésio $(\mathrm{Mg})$ na camada de 20 a $40 \mathrm{~cm}$ do solo de 70 pomares de macieira no Rio Grande do Sul e Santa Catarina. (Safra 2003)

\begin{tabular}{|c|c|c|c|c|c|c|c|}
\hline Amostra & pH (1:1) & $\mathbf{P}$ & $\mathbf{K}$ & MO & Al & Ca & Mg \\
\hline & & \multicolumn{2}{|c|}{------ $\mathrm{mg} \mathrm{dm}{ }^{-3}$------ } & $\mathrm{g} \mathrm{dm}^{-3}$ & \multicolumn{3}{|c|}{------ $\mathrm{mmol}_{\mathrm{c}} \mathrm{dm}^{-3}$} \\
\hline 36 & 7,1 & 0,8 & 112 & 33,7 & 0,3 & 79,8 & 41,5 \\
\hline 37 & 6,6 & 0,6 & 57 & 37,0 & 0,2 & 66,4 & 34,2 \\
\hline 38 & 5,6 & 0,2 & 74 & 34,3 & 3,8 & 41,4 & 29,1 \\
\hline 39 & 5,5 & 0,4 & 52 & 33,3 & 4,5 & 39,1 & 29,1 \\
\hline 40 & 5,9 & 0,2 & 92 & 34,5 & 0,6 & 48,8 & 48,1 \\
\hline 41 & 6,8 & 0,4 & 28 & 31,2 & 0,0 & 62,2 & 54,1 \\
\hline 42 & 5,5 & 0,4 & 45 & 30,2 & 1,8 & 38,4 & 36,7 \\
\hline 43 & 5,9 & 0,2 & 41 & 31,0 & 0,4 & 44,6 & 37,0 \\
\hline 44 & 5,6 & 0,6 & 323 & 43,8 & 1,1 & 53,7 & 43,3 \\
\hline 45 & 6,2 & 0,2 & 242 & 38,6 & 0,3 & 69,0 & 56,1 \\
\hline 46 & 4,7 & 0,8 & 284 & 42,6 & 15,2 & 29,6 & 12,0 \\
\hline 47 & 4,9 & 0,2 & 113 & 40,1 & 7,9 & 34,2 & 29,0 \\
\hline 48 & 5,5 & 0,0 & 135 & 32,6 & 1,7 & 39,7 & 36,1 \\
\hline 49 & 4,9 & 0,2 & 111 & 40,3 & 7,1 & 37,4 & 26,7 \\
\hline 50 & 5,6 & 0,2 & 224 & 34,4 & 1,4 & 51,4 & 38,8 \\
\hline 51 & 6,4 & 0,4 & 403 & 31,1 & 0,3 & 59,3 & 42,7 \\
\hline 52 & 6,3 & 0,4 & 309 & 25,0 & 0,6 & 52,1 & 41,8 \\
\hline 53 & 5,0 & 1,0 & 131 & 41,8 & 21,0 & 37,8 & 10,1 \\
\hline 54 & 5,9 & 1,4 & 166 & 38,9 & 0,9 & 80,7 & 18,4 \\
\hline 55 & 5,4 & 0,8 & 77 & 35,8 & 4,5 & 58,6 & 22,6 \\
\hline 56 & 5,8 & 1,0 & 49 & 41,4 & 0,8 & 85,0 & 17,1 \\
\hline 57 & 5,0 & 0,2 & 71 & 39,5 & 23,2 & 37,4 & 9,8 \\
\hline 58 & 6,4 & 1,0 & 83 & 34,2 & 0,3 & 78,1 & 16,0 \\
\hline 59 & 6,4 & 3,0 & 164 & 37,9 & 0,7 & 97,7 & 19,7 \\
\hline 60 & 6,8 & 2,2 & 51 & 33,7 & 0,7 & 110,4 & 26,5 \\
\hline 61 & 5,8 & 0,4 & 47 & 27,1 & 1,1 & 69,0 & 18,1 \\
\hline 62 & 5,8 & 29,4 & 96 & 36,8 & 0,7 & 96,0 & 31,8 \\
\hline 63 & 5,6 & 0,6 & 72 & 30,4 & 2,2 & 61,2 & 25,0 \\
\hline 64 & 6,4 & 0,6 & 142 & 32,3 & 0,9 & 87,3 & 26,4 \\
\hline 65 & 5,7 & 0,8 & 102 & 32,7 & 1,4 & 61,9 & 30,2 \\
\hline 66 & 5,9 & 4,0 & 96 & 27,5 & 0,9 & 92,8 & 26,4 \\
\hline 67 & 6,9 & 4,8 & 91 & 37,5 & 0,8 & 121,1 & 21,1 \\
\hline 68 & 7,0 & 3,2 & 112 & 32,5 & 0,5 & 97,7 & 35,3 \\
\hline 69 & 6,6 & 7,0 & 105 & 33,3 & 0,3 & 108,7 & 35,9 \\
\hline 70 & 6,4 & 16,2 & 152 & 35,6 & 0,5 & 107,4 & 34,4 \\
\hline
\end{tabular}


APÊNDICE 7. Produção de frutos $\left(\mathrm{t} \mathrm{ha}^{-1}\right)$ e índices DRIS obtidos pelo método Beaufils (1973) utilizando o critério de escolha da razão entre nutrientes "Valor R" em 70 pomares de macieira no Rio Grande do Sul e Santa Catarina. (Safra 2002)

\begin{tabular}{|c|c|c|c|c|c|c|c|c|c|c|c|c|}
\hline \multirow{2}{*}{ Amostra } & \multirow{2}{*}{$\begin{array}{c}\text { Produção } \\
\text { t ha }^{-1}\end{array}$} & \multicolumn{10}{|c|}{ Índices DRIS } & \multirow{2}{*}{ IBN } \\
\hline & & $\mathbf{N}$ & $\mathbf{P}$ & $\mathbf{K}$ & Ca & Mg & $\mathbf{F e}$ & Mn & Zn & $\mathrm{Cu}$ & B & \\
\hline 1 & 33,0 & $-5,80$ & 7,64 & $-2,33$ & $-5,64$ & 2,94 & 4,25 & 2,29 & 0,54 & 1,88 & $-5,76$ & 39,07 \\
\hline 2 & 35,0 & $-6,82$ & 6,10 & $-5,29$ & $-5,05$ & $-1,24$ & 15,67 & 1,52 & $-0,18$ & $-0,15$ & $-4,57$ & 46,58 \\
\hline 3 & 35,0 & $-7,52$ & $-0,19$ & $-8,50$ & $-2,67$ & $-5,29$ & 61,67 & $-24,46$ & $-8,06$ & 0,36 & $-5,33$ & 124,07 \\
\hline 4 & 33,0 & $-7,74$ & $-2,90$ & $-6,52$ & $-3,66$ & $-2,51$ & 28,35 & $-1,01$ & 3,69 & $-0,81$ & $-6,89$ & 64,08 \\
\hline 5 & 39,0 & $-1,79$ & 12,98 & 9,51 & 2,42 & 2,39 & $-13,15$ & $-0,45$ & $-0,39$ & $-7,84$ & $-3,69$ & 54,60 \\
\hline 6 & 68,0 & 6,07 & 8,90 & 5,29 & 9,72 & 3,73 & $-16,57$ & $-10,23$ & $-12,74$ & 2,33 & 3,49 & 79,08 \\
\hline 7 & 18,1 & $-0,88$ & 0,80 & $-7,39$ & $-2,74$ & 6,98 & 0,43 & 9,49 & 1,42 & $-0,58$ & $-7,54$ & 38,25 \\
\hline 8 & 11,4 & $-4,53$ & $-3,59$ & $-8,38$ & $-2,48$ & $-1,11$ & 8,97 & 12,39 & 3,21 & $-0,15$ & $-4,33$ & 49,15 \\
\hline 9 & 24,3 & $-3,50$ & $-4,60$ & $-7,60$ & $-1,91$ & 2,94 & 10,00 & 7,14 & 0,79 & 2,06 & $-5,32$ & 45,85 \\
\hline 10 & 29,9 & 0,25 & 2,13 & 10,00 & 0,84 & 3,53 & 1,88 & 1,97 & $-22,86$ & 4,00 & $-1,74$ & 49,20 \\
\hline 11 & 81,7 & $-0,74$ & 2,21 & $-9,89$ & 6,53 & $-1,92$ & $-0,20$ & 9,90 & $-3,57$ & 0,71 & $-3,03$ & 38,70 \\
\hline 12 & 38,6 & 1,83 & 2,88 & $-7,11$ & 4,63 & 0,12 & $-4,82$ & 15,08 & $-4,86$ & $-2,07$ & $-5,69$ & 49,10 \\
\hline 13 & 85,0 & 1,99 & 6,53 & $-1,42$ & 0,73 & 0,32 & 4,27 & 2,52 & $-13,43$ & 0,53 & $-2,04$ & 33,77 \\
\hline 14 & 98,0 & $-0,78$ & 6,89 & 0,49 & 1,42 & $-3,33$ & 4,58 & $-0,73$ & $-7,94$ & 0,58 & $-1,18$ & 27,92 \\
\hline 15 & 80,0 & $-1,67$ & 3,35 & 0,35 & 2,95 & $-1,23$ & 1,65 & $-3,05$ & $-2,66$ & 1,62 & $-1,30$ & 19,82 \\
\hline 16 & 87,0 & 1,82 & 3,33 & $-3,95$ & 6,34 & $-3,80$ & 4,93 & 7,80 & $-17,70$ & 2,85 & $-1,61$ & 54,13 \\
\hline 17 & 80,0 & $-1,19$ & 3,33 & $-5,41$ & 0,68 & $-0,84$ & 0,23 & 14,95 & $-11,19$ & 1,48 & $-2,04$ & 41,34 \\
\hline 18 & 76,0 & 0,25 & 4,25 & $-6,09$ & 2,30 & $-2,84$ & 8,08 & 3,40 & $-9,43$ & 3,16 & $-3,09$ & 42,89 \\
\hline 19 & 104,0 & & 3,45 & $-7,66$ & 0,16 & 2,99 & 5,04 & 1,46 & $-10,31$ & 4,34 & $-0,08$ & 36,09 \\
\hline 20 & 90,0 & $-3,88$ & 1,36 & $-6,23$ & 1,42 & 2,52 & 1,35 & 10,46 & $-1,37$ & $-1,02$ & $-4,61$ & 34,21 \\
\hline 21 & 62,0 & 4,24 & 7,75 & $-4,93$ & 5,72 & 4,48 & 5,32 & 2,26 & $-34,48$ & 5,70 & 3,94 & 78,83 \\
\hline 22 & 82,0 & $-1,09$ & 5,91 & $-1,97$ & 2,72 & $-2,52$ & 0,52 & 5,58 & $-11,96$ & 3,38 & $-0,56$ & 36,23 \\
\hline 23 & 79,0 & & 4,15 & $-3,11$ & 0,51 & 3,70 & $-0,70$ & 3,01 & $-9,28$ & 0,19 & $-0,20$ & 26,57 \\
\hline 24 & 54,0 & $-3,19$ & 6,45 & $-2,18$ & 2,61 & 6,16 & $-0,73$ & $-1,64$ & $-6,28$ & 0,01 & $-1,21$ & 30,46 \\
\hline 25 & 78,0 & 1,85 & 0,31 & $-2,50$ & $-0,30$ & 1,51 & $-2,62$ & 0,14 & 0,11 & 1,73 & $-0,22$ & 11,29 \\
\hline 26 & 53,0 & 2,24 & $-0,53$ & 1,42 & 2,51 & 2,43 & 4,09 & 1,83 & $-16,39$ & 3,09 & $-0,69$ & 35,21 \\
\hline 27 & 52,0 & 2,45 & 2,97 & $-5,97$ & 0,76 & 4,54 & 6,85 & 3,08 & $-13,14$ & 2,47 & $-4,01$ & 46,26 \\
\hline 28 & 45,0 & $-0,92$ & $-1,54$ & $-1,22$ & $-3,99$ & 3,68 & 3,54 & 4,06 & $-2,00$ & 0,44 & $-2,05$ & 23,45 \\
\hline 29 & 40,0 & 3,18 & 4,59 & 0,47 & 2,46 & 7,94 & 15,27 & $-3,02$ & $-36,46$ & 6,48 & $-0,93$ & 80,80 \\
\hline 30 & 48,0 & 0,34 & 1,47 & $-6,71$ & $-2,73$ & 4,70 & 7,08 & 5,63 & $-4,26$ & 0,94 & $-6,46$ & 40,32 \\
\hline 31 & 44,0 & 2,79 & 8,81 & 0,21 & 1,29 & 7,46 & 14,25 & $-7,22$ & $-33,80$ & 5,66 & 0,54 & 82,03 \\
\hline 32 & 42,0 & 2,27 & 4,54 & $-3,13$ & 5,96 & 8,07 & 10,05 & $-5,59$ & $-26,25$ & 5,59 & $-1,50$ & 72,93 \\
\hline 33 & 60,0 & $-1,64$ & $-0,75$ & $-4,40$ & $-0,03$ & 3,63 & 6,18 & 5,62 & $-2,98$ & 1,16 & $-6,80$ & 33,19 \\
\hline 34 & 57,0 & 0,64 & 1,09 & 0,51 & $-3,03$ & 0,15 & 2,18 & 6,63 & $-3,95$ & $-0,57$ & $-3,64$ & 22,39 \\
\hline 35 & 38,0 & 3,33 & 3,63 & $-2,36$ & 0,53 & 3,37 & 10,59 & $-1,14$ & $-20,80$ & 3,16 & $-0,29$ & 49,19 \\
\hline
\end{tabular}


APÊNDICE 7. Produção de frutos $\left(\mathrm{t} \mathrm{ha}^{-1}\right)$ e índices DRIS obtidos pelo método Beaufils (1973) utilizando o critério de escolha da razão entre nutrientes "Valor R” em 70 pomares de macieira no Rio Grande do Sul e Santa Catarina. (Safra 2002)

\begin{tabular}{|c|c|c|c|c|c|c|c|c|c|c|c|c|}
\hline \multirow{2}{*}{ Amostra } & \multirow{2}{*}{$\frac{\text { Produção }}{\text { t ha }^{-1}}$} & \multicolumn{10}{|c|}{ Índices DRIS } & \multirow{2}{*}{ IBN } \\
\hline & & $\mathbf{N}$ & $\mathbf{P}$ & $\mathbf{K}$ & $\mathrm{Ca}$ & Mg & $\mathrm{Fe}$ & Mn & Zn & $\mathrm{Cu}$ & $\mathbf{B}$ & \\
\hline 36 & 43,0 & $-1,76$ & $-2,38$ & $-0,41$ & $-1,51$ & $-2,32$ & 3,18 & 6,70 & 1,53 & $-0,28$ & $-2,76$ & 22,83 \\
\hline 37 & 28,0 & 2,49 & 2,00 & 0,32 & 2,33 & $-0,16$ & 14,89 & $-0,41$ & $-26,10$ & 3,09 & 1,55 & 53,33 \\
\hline 38 & 51,0 & $-1,87$ & 2,38 & 2,21 & $-2,73$ & $-4,82$ & 1,27 & 4,92 & 2,46 & 0,09 & $-3,91$ & 26,64 \\
\hline 39 & 52,0 & 2,16 & 2,38 & 1,26 & $-0,68$ & $-1,83$ & 6,15 & $-1,57$ & $-12,08$ & 5,40 & $-1,17$ & 34,67 \\
\hline 40 & 39,0 & $-3,74$ & 1,42 & 2,78 & $-7,04$ & $-6,45$ & 11,45 & $-0,87$ & 4,10 & 2,62 & $-4,28$ & 44,74 \\
\hline 41 & 34,0 & $-2,21$ & 3,50 & $-7,78$ & $-3,10$ & $-2,19$ & 19,65 & $-1,98$ & $-5,28$ & 3,18 & $-3,81$ & 52,67 \\
\hline 42 & 47,0 & $-0,01$ & 3,41 & $-4,64$ & $-0,40$ & 4,24 & 10,19 & 2,83 & $-18,24$ & 4,79 & $-2,17$ & 50,92 \\
\hline 43 & 41,0 & $-0,54$ & $-0,69$ & $-11,22$ & 2,97 & 4,23 & 11,43 & $-0,95$ & $-11,01$ & 6,42 & $-0,64$ & 50,10 \\
\hline 44 & 54,0 & $-6,22$ & $-5,88$ & $-8,11$ & $-0,60$ & $-8,69$ & $-2,99$ & $-10,19$ & 58,35 & $-4,25$ & $-11,42$ & 116,70 \\
\hline 45 & 63,0 & $-3,37$ & $-2,23$ & $-6,62$ & 2,49 & $-4,46$ & 2,69 & $-4,51$ & 28,25 & $-2,98$ & $-9,25$ & 66,86 \\
\hline 46 & 61,0 & $-5,40$ & $-4,01$ & $-6,18$ & $-6,74$ & $-13,23$ & $-2,11$ & 25,32 & 28,54 & $-5,17$ & $-11,03$ & 107,72 \\
\hline 47 & 82,0 & $-7,40$ & $-7,61$ & $-2,81$ & $-6,86$ & $-18,77$ & 0,21 & 22,24 & 36,02 & $-2,52$ & $-12,49$ & 116,93 \\
\hline 48 & 60,0 & $-8,57$ & $-10,48$ & $-7,77$ & 0,33 & $-10,99$ & $-9,69$ & 19,37 & 44,08 & $-5,14$ & $-11,15$ & 127,58 \\
\hline 49 & 54,0 & $-3,28$ & $-2,04$ & $-4,29$ & 3,82 & $-5,52$ & $-2,91$ & $-0,91$ & 28,20 & $-4,86$ & $-8,21$ & 64,04 \\
\hline 50 & 41,0 & $-8,75$ & $-7,06$ & $-9,86$ & $-1,81$ & $-12,05$ & $-7,08$ & 25,19 & 45,04 & $-8,85$ & $-14,78$ & 140,46 \\
\hline 51 & 55,0 & $-6,56$ & $-2,96$ & $-6,86$ & $-1,81$ & $-10,49$ & $-7,67$ & 17,10 & 40,27 & $-7,64$ & $-13,38$ & 114,73 \\
\hline 52 & 53,0 & $-11,59$ & $-7,14$ & $-11,86$ & $-3,88$ & $-12,97$ & 42,98 & $-5,45$ & 29,23 & $-3,22$ & $-16,11$ & 144,42 \\
\hline 53 & 46,8 & 0,66 & $-2,11$ & 3,32 & 0,78 & $-1,05$ & 7,57 & $-43,31$ & 41,27 & $-2,34$ & $-4,79$ & 107,22 \\
\hline 54 & 75,8 & $-2,77$ & $-16,30$ & $-2,98$ & $-6,04$ & $-34,80$ & 1,87 & $-126,73$ & 200,90 & $-5,98$ & $-7,18$ & 405,55 \\
\hline 55 & 97,5 & 5,52 & 4,34 & 6,08 & 6,49 & $-4,14$ & 11,86 & $-22,01$ & $-15,83$ & 3,44 & 4,25 & 83,95 \\
\hline 56 & 38,1 & $-2,13$ & 2,55 & 5,95 & 1,97 & $-6,50$ & 4,14 & $-53,95$ & 47,31 & 0,18 & 0,48 & 125,16 \\
\hline 57 & 15,9 & $-8,04$ & $-8,10$ & $-4,44$ & $-6,15$ & $-31,94$ & $-3,74$ & $-157,88$ & 236,63 & $-7,30$ & $-9,05$ & 473,27 \\
\hline 58 & 15,9 & $-7,73$ & $-11,31$ & $-3,83$ & $-3,69$ & $-15,37$ & 3,06 & $-122,03$ & 174,53 & $-6,15$ & $-7,48$ & 355,17 \\
\hline 59 & 46,9 & 2,65 & $-2,00$ & 5,91 & 1,47 & $-19,78$ & 10,22 & $-68,85$ & 68,23 & $-0,07$ & 2,23 & 181,40 \\
\hline 60 & 15,9 & $-1,80$ & $-7,43$ & $-3,53$ & $-3,85$ & $-8,94$ & 2,87 & $-148,25$ & 179,19 & $-2,60$ & $-5,65$ & 364,12 \\
\hline 61 & 46,9 & $-0,26$ & $-2,79$ & $-7,80$ & 1,83 & $-7,13$ & 11,30 & $-32,03$ & 40,19 & 0,00 & $-3,32$ & 106,65 \\
\hline 62 & 46,9 & $-1,03$ & 1,63 & $-0,82$ & $-8,83$ & $-6,42$ & 0,67 & 9,77 & 6,21 & 3,88 & $-5,05$ & 44,32 \\
\hline 63 & 37,4 & 0,54 & $-2,62$ & 1,35 & $-5,57$ & $-4,66$ & 1,11 & 8,98 & 3,70 & 0,09 & $-2,91$ & 31,52 \\
\hline 64 & 50,1 & $-4,63$ & $-2,82$ & $-1,51$ & $-2,46$ & $-3,57$ & 10,35 & 7,05 & 4,63 & 1,51 & $-8,56$ & 47,09 \\
\hline 65 & 46,8 & 1,14 & 0,08 & 2,26 & $-7,59$ & $-8,22$ & 0,60 & 2,04 & 5,90 & 3,86 & $-0,08$ & 31,78 \\
\hline 66 & 43,0 & 2,68 & 5,07 & 4,61 & $-4,76$ & $-4,66$ & 3,98 & $-10,16$ & $-1,59$ & 4,27 & 0,55 & 42,34 \\
\hline 67 & 43,0 & $-2,34$ & $-0,85$ & 0,06 & $-5,43$ & $-5,39$ & $-2,01$ & 10,54 & 8,39 & 0,29 & $-3,27$ & 38,56 \\
\hline 68 & 36,8 & 0,57 & $-7,47$ & 2,47 & $-3,41$ & $-3,47$ & $-2,86$ & 9,55 & 6,32 & 0,29 & $-2,00$ & 38,40 \\
\hline 69 & 70,1 & 1,88 & $-0,88$ & $-0,65$ & $-3,83$ & $-4,93$ & $-0,69$ & 6,02 & 5,68 & $-1,25$ & $-1,34$ & 27,18 \\
\hline 70 & 78,3 & 1,85 & $-2,86$ & $-1,78$ & $-5,99$ & $-7,62$ & 6,10 & 4,20 & 7,15 & 1,62 & $-2,67$ & 41,83 \\
\hline
\end{tabular}


APÊNDICE 8. Produção de frutos $\left(\mathrm{t} \mathrm{ha}^{-1}\right)$ e índices DRIS obtidos pelo método Beaufils (1973) utilizando o critério de escolha da razão entre nutrientes "Valor R" em 70 pomares de macieira no Rio Grande do Sul e Santa Catarina. (Safra 2003)

\begin{tabular}{|c|c|c|c|c|c|c|c|c|c|c|c|c|}
\hline \multirow{2}{*}{ Amostra } & \multirow{2}{*}{$\begin{array}{c}\text { Produção } \\
\text { t ha }^{-1}\end{array}$} & \multicolumn{10}{|c|}{ Índices DRIS } & \multirow{2}{*}{ IBN } \\
\hline & & $\mathbf{N}$ & $\mathbf{P}$ & $\mathbf{K}$ & $\mathbf{C a}$ & Mg & $\mathbf{F e}$ & Mn & Zn & $\mathbf{C u}$ & B & \\
\hline 1 & 44,5 & $-1,29$ & 1,23 & 6,07 & $-1,73$ & $-0,43$ & $-11,17$ & 13,14 & 7,28 & $-13,61$ & 0,52 & 56,45 \\
\hline 2 & 43,2 & 0,03 & 3,01 & 1,48 & $-2,63$ & 0,63 & $-9,11$ & 9,67 & 6,29 & $-8,58$ & $-0,80$ & 42,25 \\
\hline 3 & 40,2 & $-1,06$ & 2,62 & $-2,92$ & 8,36 & 6,86 & $-5,94$ & $-4,78$ & $-6,81$ & $-2,30$ & 5,96 & 47,60 \\
\hline 4 & 33,8 & 0,24 & 2,92 & $-11,63$ & 11,76 & 13,69 & $-7,75$ & $-4,31$ & $-6,80$ & $-3,22$ & 5,11 & 67,45 \\
\hline 5 & 40,6 & 1,35 & 11,64 & 6,65 & 5,55 & 0,11 & $-8,43$ & $-5,14$ & $-6,08$ & $-7,32$ & 1,67 & 53,94 \\
\hline 6 & 40,7 & $-3,53$ & 10,63 & 12,20 & 5,17 & $-2,97$ & $-10,90$ & 4,51 & 2,90 & $-10,29$ & $-7,72$ & 70,82 \\
\hline 7 & 19,5 & $-1,41$ & $-1,64$ & 3,78 & $-4,25$ & 3,26 & $-8,00$ & 7,10 & 1,40 & $-0,02$ & $-0,21$ & 31,06 \\
\hline 8 & 28,3 & 2,15 & $-1,13$ & $-0,33$ & $-2,44$ & 2,55 & $-6,08$ & 5,41 & 1,14 & $-1,24$ & $-0,02$ & 22,50 \\
\hline 9 & 28,0 & $-2,82$ & $-4,04$ & 0,82 & $-1,37$ & 3,51 & $-7,36$ & 13,69 & 4,22 & $-6,02$ & $-0,63$ & 44,47 \\
\hline 10 & 33,6 & 1,11 & $-1,19$ & 11,37 & $-5,58$ & 1,32 & $-14,35$ & 6,82 & 0,68 & $-0,86$ & 0,69 & 43,97 \\
\hline 11 & 52,2 & $-0,81$ & $-1,22$ & $-9,56$ & 0,10 & 2,70 & $-8,87$ & 16,07 & 2,71 & $-1,31$ & 0,19 & 43,52 \\
\hline 12 & 58,7 & $-3,79$ & $-6,85$ & $-6,87$ & $-0,74$ & 2,06 & $-0,55$ & 20,89 & 1,92 & $-5,25$ & $-0,82$ & 49,75 \\
\hline 13 & 18,0 & $-5,23$ & $-1,65$ & 5,20 & $-3,12$ & $-2,24$ & $-0,42$ & 4,16 & $-0,16$ & $-0,96$ & 4,43 & 27,57 \\
\hline 14 & 15,0 & $-2,92$ & 1,49 & 4,57 & $-0,59$ & $-3,27$ & $-0,98$ & 1,62 & $-0,97$ & $-3,80$ & 4,85 & 25,07 \\
\hline 15 & 22,0 & $-5,49$ & $-2,24$ & 7,58 & $-0,76$ & $-0,60$ & $-7,59$ & 5,33 & 0,12 & $-2,40$ & 6,05 & 38,15 \\
\hline 16 & 30,0 & $-5,17$ & $-3,16$ & $-0,98$ & 1,09 & $-3,81$ & $-2,35$ & 17,02 & $-3,27$ & $-5,30$ & 5,93 & 48,08 \\
\hline 17 & 35,0 & $-3,90$ & $-2,63$ & 3,05 & $-0,97$ & 0,85 & $-2,29$ & 4,03 & $-0,40$ & $-3,56$ & 5,82 & 27,51 \\
\hline 18 & 25,0 & $-7,00$ & $-5,12$ & 2,24 & $-1,25$ & $-3,41$ & 4,30 & 12,41 & 1,77 & $-7,13$ & 3,20 & 47,82 \\
\hline 19 & 12,0 & $-2,77$ & $-1,08$ & 2,87 & $-1,98$ & $-1,07$ & 6,57 & 1,33 & $-0,75$ & $-8,15$ & 5,03 & 31,59 \\
\hline 20 & 35,0 & $-3,09$ & $-1,76$ & 4,16 & $-1,47$ & 4,39 & $-8,96$ & 11,92 & 4,42 & $-14,96$ & 5,36 & 60,51 \\
\hline 21 & 75,0 & $-3,55$ & 1,35 & $-1,28$ & $-1,30$ & $-0,27$ & 0,79 & 7,41 & $-2,42$ & $-4,76$ & 4,04 & 27,15 \\
\hline 22 & 30,0 & $-4,62$ & 0,60 & 2,23 & $-0,29$ & $-0,89$ & $-2,04$ & 6,25 & $-1,52$ & $-4,47$ & 4,75 & 27,66 \\
\hline 23 & 18,0 & $-2,76$ & $-1,30$ & 5,12 & $-4,56$ & 4,20 & $-4,66$ & 5,55 & 2,07 & $-7,23$ & 3,57 & 41,01 \\
\hline 24 & 70,0 & $-3,57$ & 0,31 & 0,22 & $-0,50$ & 8,25 & $-7,96$ & 4,53 & 1,81 & $-4,61$ & 1,52 & 33,30 \\
\hline 25 & 22,0 & $-0,34$ & $-3,76$ & 7,36 & $-4,15$ & 1,98 & $-10,16$ & 7,72 & 4,00 & $-6,72$ & 4,07 & 50,26 \\
\hline 26 & 18,0 & $-1,30$ & $-6,11$ & 7,36 & $-2,16$ & 2,96 & $-7,20$ & 7,83 & 0,52 & $-4,95$ & 3,04 & 43,43 \\
\hline 27 & 25,0 & $-4,67$ & $-5,88$ & 4,36 & 0,43 & 5,66 & $-8,66$ & 12,55 & 1,35 & $-8,04$ & 2,90 & 54,51 \\
\hline 28 & 52,0 & $-5,88$ & $-6,07$ & $-0,15$ & $-4,07$ & 3,19 & 4,77 & 11,90 & 3,98 & $-6,33$ & $-1,33$ & 47,69 \\
\hline 29 & 40,0 & 1,23 & $-2,18$ & $-3,51$ & 1,17 & 7,16 & $-0,42$ & 2,39 & $-4,52$ & $-3,76$ & 2,44 & 28,78 \\
\hline 30 & 57,0 & $-4,16$ & $-7,11$ & $-0,52$ & $-3,24$ & 4,63 & 4,71 & 13,26 & 8,46 & $-14,64$ & $-1,38$ & 62,11 \\
\hline 31 & 46,0 & 0,70 & $-1,41$ & $-3,74$ & 0,62 & 7,38 & 4,69 & $-1,64$ & $-4,13$ & $-6,39$ & 3,93 & 34,62 \\
\hline 32 & 49,0 & 2,99 & $-1,53$ & $-1,31$ & $-0,08$ & 4,38 & 3,20 & $-3,41$ & $-3,94$ & $-0,93$ & 0,63 & 22,39 \\
\hline 33 & 63,0 & $-3,38$ & $-5,69$ & $-0,39$ & $-1,94$ & 3,56 & $-2,97$ & 13,50 & 6,04 & $-5,91$ & $-2,81$ & 46,19 \\
\hline 34 & 40,0 & $-1,19$ & $-3,92$ & 2,35 & $-5,54$ & $-1,63$ & $-1,65$ & 11,64 & 5,92 & $-4,88$ & $-1,10$ & 39,82 \\
\hline 35 & 33,0 & 2,36 & $-2,52$ & 1,90 & $-3,12$ & 2,21 & 0,47 & 3,67 & $-4,11$ & $-3,26$ & 2,40 & 26,02 \\
\hline
\end{tabular}


APÊNDICE 8. Produção de frutos $\left(\mathrm{t} \mathrm{ha}^{-1}\right)$ e índices DRIS obtidos pelo método Beaufils (1973) utilizando o critério de escolha da razão entre nutrientes "Valor R" em 70 pomares de macieira no Rio Grande do Sul e Santa Catarina. (Safra 2003)

\begin{tabular}{|c|c|c|c|c|c|c|c|c|c|c|c|c|}
\hline \multirow{2}{*}{ Amostra } & \multirow{2}{*}{$\frac{\text { Produção }}{\text { t ha }^{-1}}$} & \multicolumn{10}{|c|}{ Índices DRIS } & \multirow{2}{*}{ IBN } \\
\hline & & $\mathbf{N}$ & $\mathbf{P}$ & $\mathbf{K}$ & Ca & Mg & $\mathbf{F e}$ & Mn & Zn & $\mathbf{C u}$ & B & \\
\hline 36 & 32,0 & $-4,27$ & $-5,79$ & $-2,93$ & $-4,33$ & $-3,55$ & 5,47 & 15,15 & 8,92 & $-7,75$ & $-0,93$ & 59,08 \\
\hline 37 & 45,0 & 2,48 & $-0,62$ & 0,57 & $-0,75$ & $-1,03$ & 1,27 & 1,27 & $-3,52$ & $-4,02$ & 4,34 & 19,87 \\
\hline 38 & 55,0 & $-3,48$ & $-5,95$ & 2,52 & $-1,40$ & $-3,24$ & $-3,15$ & 16,33 & 9,86 & $-10,22$ & $-1,27$ & 57,42 \\
\hline 39 & 60,0 & 2,56 & 0,92 & 2,30 & $-0,56$ & 0,93 & 0,53 & $-1,52$ & $-3,09$ & $-3,70$ & 1,62 & 17,73 \\
\hline 40 & 25,0 & $-0,66$ & $-3,58$ & 8,51 & $-6,72$ & $-0,89$ & $-4,93$ & $-23,13$ & 34,87 & $-4,80$ & 1,34 & 89,43 \\
\hline 41 & 29,0 & 2,28 & $-0,86$ & $-4,35$ & $-1,24$ & 6,38 & $-4,63$ & $-47,78$ & 54,26 & $-4,27$ & 0,20 & 126,27 \\
\hline 42 & 34,0 & 0,76 & $-1,73$ & $-3,47$ & 0,76 & 8,44 & $-4,85$ & $-8,93$ & 25,35 & $-13,97$ & $-2,37$ & 70,61 \\
\hline 43 & 31,0 & 0,76 & $-0,79$ & $-6,54$ & $-3,18$ & 7,00 & $-3,47$ & $-14,47$ & 28,64 & $-7,77$ & $-0,19$ & 72,80 \\
\hline 44 & 25,0 & $-10,87$ & $-13,62$ & 1,04 & $-3,66$ & $-2,74$ & $-18,63$ & $-50,39$ & 99,17 & 5,12 & $-5,41$ & 210,65 \\
\hline 45 & 41,0 & $-1,50$ & $-9,12$ & 0,90 & 0,55 & 0,45 & $-14,29$ & $-27,24$ & 42,11 & 10,25 & $-2,12$ & 108,53 \\
\hline 46 & 31,0 & $-10,57$ & $-12,78$ & 1,36 & $-6,43$ & $-8,25$ & $-16,55$ & $-19,28$ & 76,41 & $-0,50$ & $-3,40$ & 155,55 \\
\hline 47 & 29,0 & $-11,77$ & $-20,54$ & 8,78 & $-8,08$ & $-9,86$ & $-18,77$ & $-17,41$ & 64,32 & 14,11 & $-0,78$ & 174,42 \\
\hline 48 & 19,0 & $-11,72$ & $-13,73$ & 3,82 & $-4,57$ & $-6,01$ & $-18,43$ & $-39,23$ & 83,53 & 8,05 & $-1,72$ & 190,81 \\
\hline 49 & 36,0 & $-5,04$ & $-10,34$ & 3,22 & $-2,02$ & $-5,07$ & $-13,66$ & $-20,30$ & 37,35 & 16,58 & $-0,72$ & 114,32 \\
\hline 50 & 19,0 & $-7,16$ & $-13,75$ & 3,08 & $-7,48$ & $-6,09$ & $-16,78$ & $-44,00$ & 86,34 & 9,69 & $-3,85$ & 198,23 \\
\hline 51 & 21,0 & $-8,72$ & $-13,34$ & 2,55 & $-9,81$ & $-3,40$ & $-18,00$ & $-46,26$ & 91,27 & 8,47 & $-2,75$ & 204,58 \\
\hline 52 & 38,0 & $-5,68$ & $-8,98$ & 4,84 & $-4,90$ & $-2,59$ & $-9,70$ & $-27,72$ & 37,56 & 16,62 & 0,56 & 119,15 \\
\hline 53 & 28,8 & 1,09 & $-8,35$ & 12,97 & 2,31 & $-17,93$ & $-8,03$ & $-46,73$ & 60,93 & $-4,94$ & 8,68 & 171,97 \\
\hline 54 & 21,1 & $-0,60$ & $-10,63$ & 12,72 & $-8,60$ & $-15,05$ & $-5,93$ & $-59,58$ & 89,00 & $-7,16$ & 5,83 & 215,11 \\
\hline 55 & 28,8 & & $-7,18$ & 9,18 & 0,19 & $-10,38$ & $-2,45$ & $-43,24$ & 52,17 & $-5,70$ & 5,96 & 137,89 \\
\hline 56 & 21,1 & $-3,42$ & $-6,03$ & 10,68 & $-5,84$ & $-14,85$ & $-4,76$ & $-86,84$ & 116,82 & $-8,90$ & 3,12 & 261,26 \\
\hline 57 & 21,1 & $-4,16$ & $-13,70$ & 14,78 & $-4,43$ & $-16,61$ & $-3,08$ & $-101,83$ & 130,74 & $-9,06$ & 7,33 & 305,72 \\
\hline 58 & 21,1 & $-6,11$ & $-1,52$ & 6,34 & $-6,53$ & $-13,36$ & $-10,67$ & $-73,14$ & 110,08 & $-9,92$ & 4,83 & 242,50 \\
\hline 59 & 28,8 & $-1,67$ & $-10,34$ & 15,69 & $-1,07$ & $-23,88$ & $-1,89$ & $-75,79$ & 99,01 & $-11,11$ & 11,07 & 251,53 \\
\hline 60 & 21,1 & $-2,74$ & $-9,86$ & 8,69 & $-1,99$ & $-6,30$ & $-3,83$ & $-91,35$ & 101,21 & $-2,40$ & 8,57 & 236,95 \\
\hline 61 & 28,8 & $-0,72$ & $-11,74$ & 4,36 & $-0,44$ & $-8,77$ & $-4,15$ & $-28,55$ & 44,94 & $-5,60$ & 10,67 & 119,94 \\
\hline 62 & 53,3 & $-1,89$ & $-7,56$ & 7,16 & $-8,66$ & $-6,90$ & $-7,89$ & 14,81 & 11,66 & $-3,96$ & 3,23 & 73,72 \\
\hline 63 & 46,6 & 1,74 & $-6,41$ & 9,09 & $-8,45$ & $-6,52$ & $-7,80$ & 9,89 & 10,13 & $-5,77$ & 4,11 & 69,91 \\
\hline 64 & 41,7 & $-3,87$ & $-8,86$ & 2,64 & $-8,49$ & $-3,08$ & $-13,83$ & 21,65 & 20,61 & $-7,73$ & 0,95 & 91,68 \\
\hline 65 & 38,1 & 0,91 & $-8,48$ & 4,87 & $-7,22$ & $-5,46$ & 7,58 & 4,12 & 0,45 & $-2,74$ & 5,98 & 47,81 \\
\hline 66 & 37,1 & 1,88 & $-4,99$ & 5,99 & $-4,88$ & $-5,93$ & 2,38 & $-0,17$ & 0,96 & $-1,84$ & 6,60 & 35,61 \\
\hline 67 & 45,6 & $-3,28$ & $-7,32$ & 3,45 & $-9,31$ & $-13,55$ & $-10,16$ & 29,53 & 18,02 & $-6,77$ & $-0,62$ & 102,01 \\
\hline 68 & 46,6 & $-2,42$ & $-6,30$ & 4,50 & $-12,52$ & $-13,91$ & $-7,96$ & 25,60 & 18,52 & $-6,15$ & 0,65 & 98,53 \\
\hline 69 & 17,1 & $-1,74$ & $-7,74$ & 3,23 & $-4,82$ & $-4,94$ & 2,85 & $-0,77$ & 11,17 & $-4,86$ & 7,63 & 49,75 \\
\hline 70 & 21,6 & 0,02 & $-7,92$ & 3,48 & $-5,83$ & $-5,98$ & $-1,53$ & 2,86 & 12,39 & $-5,05$ & 7,57 & 52,63 \\
\hline
\end{tabular}


APÊNDICE 9. Produção de frutos $\left(\mathrm{t} \mathrm{ha}^{-1}\right)$ e índices DRIS obtidos pelo método Beaufils (1973) utilizando o critério de escolha da razão entre nutrientes "Valor F" em 70 pomares de macieira no Rio Grande do Sul e Santa Catarina. (Safra 2002)

\begin{tabular}{|c|c|c|c|c|c|c|c|c|c|c|c|c|}
\hline \multirow{2}{*}{ Amostra } & \multirow{2}{*}{$\begin{array}{c}\text { Produção } \\
\text { t ha }^{-1}\end{array}$} & \multicolumn{10}{|c|}{ Índices DRIS } & \multirow{2}{*}{ IBN } \\
\hline & & $\mathbf{N}$ & $\mathbf{P}$ & $\mathbf{K}$ & Ca & Mg & $\mathbf{F e}$ & Mn & Zn & $\mathrm{Cu}$ & B & \\
\hline 1 & 33,0 & $-5,98$ & 7,05 & $-1,51$ & $-6,79$ & 1,90 & 4,65 & 1,62 & 2,89 & 1,69 & $-5,03$ & 39,12 \\
\hline 2 & 35,0 & $-7,03$ & 5,55 & $-4,56$ & $-6,02$ & $-2,36$ & 16,08 & ,68 & 3,11 & $-0,44$ & 3,57 & 49,41 \\
\hline 3 & 35,0 & $-7,77$ & $-0,23$ & $-7,78$ & $-3,08$ & $-6,23$ & 64,12 & $-28,42$ & 0,62 & $-0,55$ & $-3,95$ & 122,76 \\
\hline 4 & 33,0 & $-7,95$ & $-3,73$ & $-5,80$ & $-4,86$ & $-3,93$ & 28,71 & $-2,06$ & 8,44 & $-1,12$ & $-5,73$ & 72,33 \\
\hline 5 & 39,0 & $-2,45$ & 11,55 & 10,79 & 1,62 & 0,70 & $-11,09$ & $-1,34$ & 0,31 & $-8,50$ & $-2,70$ & 51,04 \\
\hline 6 & 68,0 & 5,30 & 6,98 & 6,00 & 8,66 & 1,45 & $-14,56$ & $-11,90$ & $-10,14$ & 1,51 & 4,96 & 71,45 \\
\hline 7 & 18,1 & $-0,92$ & 0,18 & $-6,59$ & $-3,65$ & 5,92 & 1,13 & 8,58 & 3,99 & $-1,11$ & $-6,93$ & 39,01 \\
\hline 8 & 11,4 & $-4,71$ & $-4,43$ & $-7,64$ & $-3,50$ & $-2,29$ & 9,30 & 11,35 & 7,26 & $-0,70$ & $-3,41$ & 54,56 \\
\hline 9 & 24,3 & $-3,64$ & $-5,29$ & $-6,83$ & $-2,86$ & 1,90 & 10,27 & 6,29 & 4,04 & 1,73 & $-4,45$ & 47,29 \\
\hline 10 & 29,9 & $-0,07$ & 0,38 & 11,34 & $-1,30$ & 1,12 & 2,36 & 1,35 & $-19,61$ & 3,75 & $-1,11$ & 42,39 \\
\hline 11 & 81,7 & $-0,87$ & 1,57 & $-9,14$ & 5,79 & $-3,01$ & 0,52 & 8,87 & $-1,11$ & 0,15 & $-2,26$ & 33,30 \\
\hline 12 & 38,6 & 1,65 & 2,04 & $-6,37$ & 3,83 & $-1,00$ & $-3,35$ & 13,73 & $-2,57$ & $-2,82$ & $-5,03$ & 42,39 \\
\hline 13 & 85,0 & 1,92 & 5,00 & $-0,72$ & $-0,67$ & $-1,31$ & 4,70 & 1,91 & $-8,87$ & 0,13 & $-1,27$ & 26,51 \\
\hline 14 & 98,0 & $-0,90$ & 5,82 & 1,27 & 0,40 & $-4,80$ & 5,09 & $-1,52$ & $-4,77$ & 0,24 & $-0,29$ & 25,11 \\
\hline 15 & 80,0 & $-1,88$ & 2,72 & 1,10 & 2,27 & $-2,47$ & 2,20 & $-3,85$ & $-0,67$ & 1,21 & $-0,47$ & 18,84 \\
\hline 16 & 87,0 & 1,76 & 1,82 & $-3,26$ & 4,62 & $-5,50$ & 5,40 & 6,93 & $-12,08$ & 2,38 & $-0,75$ & 44,51 \\
\hline 17 & 80,0 & $-1,33$ & 2,23 & $-4,68$ & $-0,40$ & $-2,05$ & 1,07 & 13,64 & $-7,58$ & 0,88 & $-1,25$ & 35,11 \\
\hline 18 & 76,0 & 0,18 & 3,19 & $-5,38$ & 1,17 & $-4,18$ & 8,48 & 2,65 & $-5,03$ & 2,83 & $-2,25$ & 35,33 \\
\hline 19 & 104,0 & 0,47 & 2,32 & $-6,89$ & $-1,16$ & 1,33 & 5,50 & 0,82 & $-5,93$ & 4,13 & 0,74 & 29,28 \\
\hline 20 & 90,0 & $-4,05$ & 0,86 & $-5,47$ & 0,78 & 1,57 & 1,96 & 9,53 & 0,77 & $-1,63$ & $-3,84$ & 30,47 \\
\hline 21 & 62,0 & 4,09 & 4,77 & $-4,18$ & 2,76 & 1,37 & 5,81 & 1,66 & $-24,55$ & 5,37 & 4,75 & 59,32 \\
\hline 22 & 82,0 & $-1,24$ & 4,47 & $-1,28$ & 1,42 & $-3,98$ & 1,19 & 4,70 & $-8,36$ & 3,00 & 0,30 & 29,94 \\
\hline 23 & 79,0 & 1,58 & 2,90 & $-2,37$ & $-0,68$ & 1,98 & 0,08 & 2,36 & $-6,04$ & $-0,24$ & 0,59 & 18,81 \\
\hline 24 & 54,0 & $-3,41$ & 5,39 & $-1,42$ & 1,60 & 4,55 & 0,05 & $-2,52$ & $-3,37$ & $-0,35$ & $-0,44$ & 23,09 \\
\hline 25 & 78,0 & 1,64 & $-0,44$ & $-1,78$ & $-1,21$ & 0,24 & $-1,86$ & $-0,52$ & 1,81 & 1,47 & 0,66 & 11,63 \\
\hline 26 & 53,0 & 2,11 & $-1,78$ & 2,13 & 0,83 & 0,53 & 4,52 & 1,19 & $-11,96$ & 2,78 & 0,11 & 27,94 \\
\hline 27 & 52,0 & 2,41 & 1,73 & $-5,21$ & $-0,65$ & 2,70 & 7,25 & 2,44 & $-7,80$ & 2,14 & $-3,29$ & 35,62 \\
\hline 28 & 45,0 & $-1,03$ & $-2,10$ & $-0,45$ & $-4,97$ & 2,61 & 3,95 & 3,35 & 0,15 & 0,13 & $-1,20$ & 19,94 \\
\hline 29 & 40,0 & 3,07 & 2,11 & 1,21 & $-0,20$ & 4,65 & 15,89 & $-4,04$ & $-24,48$ & 6,08 & $-0,12$ & 61,84 \\
\hline 30 & 48,0 & 0,32 & 0,88 & $-5,94$ & $-3,58$ & 3,50 & 7,41 & 4,93 & $-1,19$ & 0,57 & $-5,75$ & 34,06 \\
\hline 31 & 44,0 & 2,67 & 6,28 & 0,95 & $-1,04$ & 4,48 & 15,04 & $-8,69$ & $-22,48$ & 5,07 & 1,36 & 68,06 \\
\hline 32 & 42,0 & 2,14 & 2,65 & $-2,36$ & 3,78 & 5,38 & 10,72 & $-6,91$ & $-16,99$ & 4,98 & $-0,75$ & 56,65 \\
\hline 33 & 60,0 & $-1,74$ & $-1,26$ & $-3,64$ & $-0,80$ & 2,56 & 6,51 & 4,92 & $-0,36$ & 0,75 & $-6,07$ & 28,60 \\
\hline 34 & 57,0 & 0,58 & 0,48 & 1,32 & $-3,88$ & $-0,84$ & 2,68 & 5,78 & $-1,96$ & $-1,03$ & $-2,92$ & 21,48 \\
\hline 35 & 38,0 & 3,25 & 1,93 & $-1,64$ & $-1,32$ & 1,18 & 11,13 & $-1,94$ & $-13,43$ & 2,86 & 0,54 & 39,21 \\
\hline
\end{tabular}


APÊNDICE 9. Produção de frutos $\left(\mathrm{t} \mathrm{ha}^{-1}\right)$ e índices DRIS obtidos pelo método Beaufils (1973) utilizando o critério de escolha da razão entre nutrientes "Valor F" em 70 pomares de macieira no Rio Grande do Sul e Santa Catarina. (Safra 2002)

\begin{tabular}{|c|c|c|c|c|c|c|c|c|c|c|c|c|}
\hline \multirow{2}{*}{ Amostra } & \multirow{2}{*}{$\frac{\text { Produção }}{\text { t ha }^{-1}}$} & \multicolumn{10}{|c|}{ Índices DRIS } & \multirow{2}{*}{ IBN } \\
\hline & & $\mathbf{N}$ & $\mathbf{P}$ & K & Ca & Mg & $\mathbf{F e}$ & Mn & Zn & $\mathbf{C u}$ & B & \\
\hline 36 & 43,0 & $-1,93$ & $-3,15$ & 0,38 & $-2,43$ & $-3,54$ & 3,63 & 5,79 & 4,22 & $-0,74$ & $-1,91$ & 27,72 \\
\hline 37 & 28,0 & 2,37 & 0,16 & 1,02 & 0,23 & $-2,42$ & 15,42 & $-1,20$ & $-17,33$ & 2,77 & 2,52 & 45,44 \\
\hline 38 & 51,0 & $-2,03$ & 1,64 & 3,34 & $-3,88$ & $-6,46$ & 1,78 & 4,01 & 5,11 & $-0,30$ & $-3,13$ & 31,67 \\
\hline 39 & 52,0 & 2,13 & 1,24 & 2,06 & $-2,15$ & $-3,45$ & 6,67 & $-2,19$ & $-8,34$ & 5,13 & $-0,32$ & 33,69 \\
\hline 40 & 39,0 & $-3,93$ & 0,56 & 4,14 & $-8,97$ & $-8,41$ & 11,89 & $-1,79$ & 7,80 & 2,58 & $-3,30$ & 53,37 \\
\hline 41 & 34,0 & $-2,34$ & 2,85 & $-7,05$ & $-4,09$ & $-3,36$ & 20,20 & $-2,93$ & $-0,86$ & 2,98 & $-2,83$ & 49,48 \\
\hline 42 & 47,0 & $-0,13$ & 1,90 & $-3,89$ & $-2,06$ & 2,14 & 10,60 & 2,12 & $-11,34$ & 4,58 & $-1,35$ & 40,11 \\
\hline 43 & 41,0 & $-0,70$ & $-1,60$ & $-10,41$ & 1,57 & 2,51 & 11,94 & $-1,67$ & $-5,49$ & 6,11 & 0,23 & 42,23 \\
\hline 44 & 54,0 & $-6,32$ & $-11,45$ & $-7,37$ & $-5,06$ & $-15,38$ & $-2,54$ & $-10,91$ & 77,29 & $-4,67$ & $-10,66$ & 151,64 \\
\hline 45 & 63,0 & $-3,47$ & $-5,06$ & $-5,91$ & 0,18 & $-8,10$ & 3,08 & $-5,15$ & 38,87 & $-3,41$ & $-8,48$ & 81,70 \\
\hline 46 & 61,0 & $-5,41$ & $-6,98$ & $-5,33$ & $-9,94$ & $-17,56$ & $-1,12$ & 23,11 & 41,35 & $-6,16$ & $-10,23$ & 127,17 \\
\hline 47 & 82,0 & $-7,47$ & $-11,72$ & $-1,57$ & $-10,89$ & $-25,15$ & 0,99 & 19,94 & 52,41 & $-3,25$ & $-11,63$ & 145,01 \\
\hline 48 & 60,0 & $-8,76$ & $-15,70$ & $-6,99$ & $-3,10$ & $-16,58$ & $-8,38$ & 17,22 & 59,32 & $-6,01$ & $-10,36$ & 152,41 \\
\hline 49 & 54,0 & $-3,38$ & $-4,91$ & $-3,54$ & 1,67 & $-9,39$ & $-2,32$ & $-1,69$ & 37,50 & $-5,41$ & $-7,49$ & 77,29 \\
\hline 50 & 41,0 & $-8,84$ & $-11,64$ & $-9,11$ & $-5,46$ & $-17,59$ & $-5,85$ & 23,07 & 61,63 & $-10,00$ & $-14,06$ & 167,24 \\
\hline 51 & 55,0 & $-6,65$ & $-6,80$ & $-6,06$ & $-5,27$ & $-15,70$ & $-6,46$ & 15,33 & 53,88 & $-8,59$ & $-12,70$ & 137,44 \\
\hline 52 & 53,0 & $-11,75$ & $-9,97$ & $-11,14$ & $-6,62$ & $-17,16$ & 43,12 & $-6,75$ & 43,12 & $-3,60$ & $-14,75$ & 167,97 \\
\hline 53 & 46,8 & 0,52 & $-4,05$ & 4,26 & $-0,81$ & $-3,58$ & 8,66 & $-45,69$ & 49,05 & $-3,28$ & $-4,05$ & 123,95 \\
\hline 54 & 75,8 & $-2,56$ & $-28,90$ & $-1,58$ & $-14,82$ & $-56,69$ & 2,86 & $-128,22$ & 246,21 & $-6,99$ & $-5,62$ & 494,44 \\
\hline 55 & 97,5 & 5,48 & 3,63 & 6,97 & 5,86 & $-6,04$ & 13,12 & $-24,64$ & $-10,87$ & 2,18 & 5,34 & 84,13 \\
\hline 56 & 38,1 & $-2,44$ & 1,28 & 7,16 & 0,79 & $-10,34$ & 5,27 & $-56,49$ & 54,75 & $-1,12$ & 1,53 & 141,17 \\
\hline 57 & 15,9 & $-8,03$ & $-18,35$ & $-3,13$ & $-15,19$ & $-53,31$ & $-2,75$ & $-159,75$ & 279,22 & $-8,44$ & $-7,75$ & 555,93 \\
\hline 58 & 15,9 & $-7,91$ & $-20,71$ & $-2,81$ & $-10,43$ & $-27,22$ & 4,16 & $-124,10$ & 206,60 & $-7,23$ & $-6,33$ & 417,50 \\
\hline 59 & 46,9 & 2,71 & $-4,70$ & 7,34 & $-0,35$ & $-27,91$ & 11,61 & $-71,31$ & 81,42 & $-1,45$ & 3,82 & 212,63 \\
\hline 60 & 15,9 & $-1,85$ & $-14,47$ & $-2,72$ & $-9,62$ & $-17,30$ & 4,20 & $-150,99$ & 205,19 & $-4,18$ & $-4,71$ & 415,23 \\
\hline 61 & 46,9 & $-0,31$ & $-5,28$ & $-7,10$ & 0,03 & $-11,18$ & 12,26 & $-33,71$ & 51,65 & $-0,78$ & $-2,32$ & 124,61 \\
\hline 62 & 46,9 & $-0,97$ & 0,60 & 0,19 & $-11,07$ & $-8,31$ & 1,30 & 8,37 & 10,66 & 3,81 & $-4,21$ & 49,48 \\
\hline 63 & 37,4 & 0,54 & $-3,60$ & 2,42 & $-7,20$ & $-6,31$ & 1,70 & 7,76 & 7,16 & $-0,29$ & $-2,02$ & 39,00 \\
\hline 64 & 50,1 & $-4,80$ & $-3,81$ & $-0,66$ & $-3,72$ & $-5,02$ & 10,59 & 6,09 & 8,74 & 1,16 & $-7,73$ & 52,34 \\
\hline 65 & 46,8 & 1,23 & $-1,07$ & 3,54 & $-9,99$ & $-10,78$ & 1,10 & 1,07 & 9,93 & 3,89 & 1,14 & 43,75 \\
\hline 66 & 43,0 & 2,71 & 4,71 & 5,83 & $-6,05$ & $-6,24$ & 4,70 & $-11,12$ & 0,19 & 3,71 & 1,57 & 46,84 \\
\hline 67 & 43,0 & $-2,45$ & $-2,17$ & 1,08 & $-7,38$ & $-7,45$ & $-1,22$ & 9,11 & 13,09 & $-0,12$ & $-2,38$ & 46,46 \\
\hline 68 & 36,8 & 0,43 & $-9,02$ & 3,55 & $-5,11$ & $-5,29$ & $-2,05$ & 8,15 & 10,26 & $-0,13$ & $-0,99$ & 44,98 \\
\hline 69 & 70,1 & 1,92 & $-2,00$ & 0,19 & $-5,38$ & $-6,90$ & $-0,05$ & 4,97 & 9,53 & $-1,72$ & $-0,36$ & 33,03 \\
\hline 70 & 78,3 & 1,99 & $-4,17$ & $-0,89$ & $-8,00$ & $-9,97$ & 6,45 & 3,21 & 12,36 & 1,43 & $-1,59$ & 50,07 \\
\hline
\end{tabular}


APÊNDICE 10. Produção de frutos $\left(\mathrm{t} \mathrm{ha}^{-1}\right)$ e índices DRIS obtidos pelo método Beaufils (1973) utilizando o critério de escolha da razão entre nutrientes "Valor F" em 70 pomares de macieira no Rio Grande do Sul e Santa Catarina. (Safra 2003)

\begin{tabular}{|c|c|c|c|c|c|c|c|c|c|c|c|c|}
\hline \multirow{2}{*}{ Amostra } & \multirow{2}{*}{$\begin{array}{c}\text { Produção } \\
\text { t ha }^{-1}\end{array}$} & \multicolumn{10}{|c|}{ Índices DRIS } & \multirow{2}{*}{ IBN } \\
\hline & & $\mathbf{N}$ & $\mathbf{P}$ & $\mathbf{K}$ & Ca & Mg & $\mathbf{F e}$ & Mn & Zn & $\mathbf{C u}$ & B & \\
\hline 1 & 44,5 & $-1,86$ & $-0,16$ & 7,23 & $-3,13$ & $-2,30$ & $-9,43$ & 11,88 & 9,56 & $-15,14$ & 2,17 & 62,87 \\
\hline 2 & 43,2 & $-0,34$ & 1,74 & 2,31 & $-3,97$ & $-1,03$ & $-7,49$ & 8,52 & 8,72 & $-9,66$ & 0,50 & 44,27 \\
\hline 3 & 40,2 & $-1,58$ & 1,50 & $-2,15$ & 7,43 & 4,96 & $-4,97$ & $-6,06$ & $-4,06$ & $-2,96$ & 7,57 & 43,24 \\
\hline 4 & 33,8 & $-0,27$ & 1,77 & $-10,72$ & 10,78 & 11,27 & $-6,38$ & $-5,77$ & $-3,33$ & $-3,87$ & 6,54 & 60,69 \\
\hline 5 & 40,6 & 0,83 & 10,17 & 7,58 & 4,82 & $-1,63$ & $-7,12$ & $-6,49$ & $-4,37$ & $-8,02$ & 3,08 & 54,11 \\
\hline 6 & 40,7 & $-4,16$ & 9,43 & 13,90 & 4,51 & $-4,94$ & $-9,13$ & 3,67 & 3,85 & $-11,13$ & $-7,07$ & 71,79 \\
\hline 7 & 19,5 & $-1,85$ & $-2,62$ & 4,83 & $-5,61$ & 1,89 & $-6,62$ & 5,85 & 2,96 & $-0,40$ & 0,96 & 33,60 \\
\hline 8 & 28,3 & 1,87 & $-2,04$ & 0,41 & $-3,47$ & 1,23 & $-4,86$ & 4,38 & 2,86 & $-1,75$ & 1,09 & 23,97 \\
\hline 9 & 28,0 & $-3,21$ & $-5,21$ & 1,63 & $-2,41$ & 2,11 & $-5,91$ & 12,33 & 6,63 & $-7,04$ & 0,66 & 47,14 \\
\hline 10 & 33,6 & 0,42 & $-2,31$ & 13,07 & $-7,27$ & $-0,42$ & $-12,51$ & 5,39 & 1,43 & $-1,26$ & 2,15 & 46,23 \\
\hline 11 & 52,2 & $-1,17$ & $-2,19$ & $-8,77$ & $-0,69$ & 1,31 & $-7,08$ & 14,36 & 5,14 & $-2,05$ & 1,30 & 44,07 \\
\hline 12 & 58,7 & $-4,03$ & $-7,67$ & $-6,11$ & $-1,42$ & 1,14 & 0,39 & 19,48 & 4,88 & $-6,40$ & 0,29 & 51,81 \\
\hline 13 & 18,0 & $-5,89$ & $-2,47$ & 6,55 & $-4,37$ & $-3,72$ & 0,06 & 3,29 & 1,53 & $-1,50$ & 6,27 & 35,65 \\
\hline 14 & 15,0 & $-3,44$ & 0,73 & 5,74 & $-1,53$ & $-4,91$ & $-0,55$ & 0,97 & 0,43 & $-4,54$ & 6,77 & 29,59 \\
\hline 15 & 22,0 & $-6,37$ & $-3,29$ & 8,96 & $-1,85$ & $-2,26$ & $-6,70$ & 4,26 & 1,24 & $-3,13$ & 8,38 & 46,44 \\
\hline 16 & 30,0 & $-5,71$ & $-3,77$ & $-0,19$ & 0,52 & $-4,86$ & $-1,53$ & 15,58 & $-1,64$ & $-6,54$ & 8,07 & 48,40 \\
\hline 17 & 35,0 & $-4,49$ & $-3,51$ & 4,02 & $-1,95$ & $-0,46$ & $-1,76$ & 3,24 & 1,12 & $-4,36$ & 7,91 & 32,84 \\
\hline 18 & 25,0 & $-7,62$ & $-6,09$ & 3,29 & $-2,17$ & $-4,81$ & 4,84 & 11,43 & 4,61 & $-8,30$ & 5,07 & 58,23 \\
\hline 19 & 12,0 & $-3,26$ & $-1,83$ & 3,86 & $-2,99$ & $-2,42$ & 7,04 & 0,75 & 1,40 & $-9,16$ & 7,02 & 39,72 \\
\hline 20 & 35,0 & $-3,75$ & $-3,06$ & 5,09 & $-2,67$ & 2,85 & $-7,55$ & 10,93 & 6,41 & $-16,76$ & 7,79 & 66,87 \\
\hline 21 & 75,0 & $-3,94$ & 0,71 & $-0,55$ & $-2,05$ & $-1,34$ & 1,36 & 6,62 & $-0,56$ & $-5,69$ & 5,64 & 28,46 \\
\hline 22 & 30,0 & $-5,18$ & $-0,14$ & 3,16 & $-1,10$ & $-2,13$ & $-1,43$ & 5,40 & $-0,09$ & $-5,37$ & 6,64 & 30,63 \\
\hline 23 & 18,0 & $-3,29$ & $-2,32$ & 6,23 & $-5,99$ & 2,87 & $-3,75$ & 4,72 & 3,92 & $-8,23$ & 5,42 & 46,74 \\
\hline 24 & 70,0 & $-4,06$ & $-0,70$ & 1,02 & $-1,40$ & 6,65 & $-6,53$ & 3,68 & 3,32 & $-5,38$ & 2,98 & 35,74 \\
\hline 25 & 22,0 & $-0,98$ & $-5,16$ & 8,64 & $-5,79$ & 0,23 & $-8,81$ & 6,51 & 5,89 & $-7,72$ & 6,20 & 55,93 \\
\hline 26 & 18,0 & $-1,90$ & $-7,17$ & 8,60 & $-3,31$ & 1,56 & $-6,09$ & 6,70 & 1,90 & $-5,82$ & 4,86 & 47,90 \\
\hline 27 & 25,0 & $-5,33$ & $-6,94$ & 5,31 & $-0,40$ & 4,30 & $-7,21$ & 11,29 & 2,87 & $-9,27$ & 4,79 & 57,72 \\
\hline 28 & 52,0 & $-6,25$ & $-7,21$ & 0,73 & $-5,30$ & 2,07 & 5,26 & 11,03 & 7,56 & $-7,31$ & $-0,09$ & 52,79 \\
\hline 29 & 40,0 & 1,01 & $-2,92$ & $-2,73$ & 0,24 & 5,51 & 0,23 & 1,83 & $-2,16$ & $-4,45$ & 3,65 & 24,74 \\
\hline 30 & 57,0 & $-4,46$ & $-8,73$ & 0,30 & $-4,72$ & 3,28 & 5,22 & 12,66 & 13,38 & $-16,22$ & 0,05 & 69,01 \\
\hline 31 & 46,0 & 0,46 & $-2,17$ & $-2,96$ & $-0,29$ & 6,00 & 5,23 & $-2,38$ & $-1,30$ & $-7,17$ & 5,33 & 33,29 \\
\hline 32 & 49,0 & 2,90 & $-2,21$ & $-0,58$ & $-0,96$ & 3,15 & 3,76 & $-4,30$ & $-1,52$ & $-1,34$ & 1,55 & 22,27 \\
\hline 33 & 63,0 & $-3,62$ & $-7,00$ & 0,42 & $-3,14$ & 2,21 & $-1,96$ & 12,32 & 9,56 & $-6,87$ & $-1,86$ & 48,96 \\
\hline 34 & 40,0 & $-1,39$ & $-5,21$ & 3,42 & $-7,24$ & $-3,16$ & $-0,87$ & 10,41 & 9,71 & $-5,74$ & 0,03 & 47,18 \\
\hline 35 & 33,0 & 2,23 & $-3,22$ & 2,71 & $-4,17$ & 1,00 & 0,99 & 2,98 & $-2,42$ & $-3,93$ & 3,73 & 27,40 \\
\hline
\end{tabular}


APÊNDICE 10. Produção de frutos $\left(\mathrm{t} \mathrm{ha}^{-1}\right)$ e índices DRIS obtidos pelo método Beaufils (1973) utilizando o critério de escolha da razão entre nutrientes "Valor F" em 70 pomares de macieira no Rio Grande do Sul e Santa Catarina. (Safra 2003)

\begin{tabular}{|c|c|c|c|c|c|c|c|c|c|c|c|c|}
\hline \multirow{2}{*}{ Amostra } & \multirow{2}{*}{$\frac{\text { Produção }}{\text { t ha }^{-1}}$} & \multicolumn{10}{|c|}{ Índices DRIS } & \multirow{2}{*}{ IBN } \\
\hline & & $\mathbf{N}$ & $\mathbf{P}$ & $\mathbf{K}$ & Ca & Mg & $\mathbf{F e}$ & Mn & Zn & $\mathbf{C u}$ & $\mathbf{B}$ & \\
\hline 36 & 32,0 & $-4,54$ & $-7,38$ & $-2,18$ & $-5,92$ & $-5,28$ & 5,99 & 14,07 & 14,74 & $-8,91$ & 0,46 & 69,46 \\
\hline 37 & 45,0 & 2,34 & $-1,38$ & 1,32 & $-1,70$ & $-2,38$ & 1,69 & 0,71 & $-1,72$ & $-4,75$ & 5,95 & 23,96 \\
\hline 38 & 55,0 & $-3,82$ & $-7,67$ & 3,55 & $-2,88$ & $-5,15$ & $-2,22$ & 15,04 & 14,54 & $-11,59$ & 0,05 & 66,51 \\
\hline 39 & 60,0 & 2,43 & 0,21 & 3,09 & $-1,52$ & $-0,31$ & 1,04 & $-2,11$ & $-1,44$ & $-4,27$ & 2,76 & 19,17 \\
\hline 40 & 25,0 & $-1,07$ & $-6,54$ & 10,04 & $-10,66$ & $-4,15$ & $-4,32$ & $-24,07$ & 41,97 & $-5,40$ & 2,86 & 111,09 \\
\hline 41 & 29,0 & 2,05 & $-3,32$ & $-3,60$ & $-3,63$ & 4,22 & $-3,54$ & $-50,02$ & 62,41 & $-5,24$ & 1,26 & 139,29 \\
\hline 42 & 34,0 & 0,52 & $-4,20$ & $-2,70$ & $-1,38$ & 6,26 & $-3,93$ & $-9,53$ & 31,41 & $-14,90$ & $-1,21$ & 76,06 \\
\hline 43 & 31,0 & 0,58 & $-3,17$ & $-5,76$ & $-5,89$ & 4,82 & $-2,67$ & $-15,43$ & 36,03 & $-8,39$ & 0,97 & 83,72 \\
\hline 44 & 25,0 & $-11,51$ & $-22,46$ & 2,16 & $-9,89$ & $-9,19$ & $-17,84$ & $-50,83$ & 113,33 & 4,41 & $-4,06$ & 245,69 \\
\hline 45 & 41,0 & $-2,02$ & $-13,29$ & 1,69 & $-2,24$ & $-2,90$ & $-13,29$ & $-27,55$ & 48,26 & 9,39 & $-0,83$ & 121,47 \\
\hline 46 & 31,0 & $-11,24$ & $-21,39$ & 2,70 & $-13,51$ & $-16,21$ & $-15,82$ & $-20,16$ & 92,91 & $-0,68$ & $-1,74$ & 196,37 \\
\hline 47 & 29,0 & $-12,68$ & $-29,67$ & 10,70 & $-15,35$ & $-17,40$ & $-18,13$ & $-18,02$ & 78,55 & 14,16 & 1,40 & 216,06 \\
\hline 48 & 19,0 & $-12,52$ & $-22,06$ & 5,20 & $-10,84$ & $-12,99$ & $-17,80$ & $-39,44$ & 96,72 & 7,49 & 0,10 & 225,15 \\
\hline 49 & 36,0 & $-5,65$ & $-14,73$ & 4,38 & $-5,63$ & $-9,38$ & $-12,95$ & $-20,20$ & 44,29 & 16,01 & 0,93 & 134,17 \\
\hline 50 & 19,0 & $-7,74$ & $-21,98$ & 4,42 & $-14,60$ & $-12,93$ & $-16,10$ & $-44,07$ & 100,93 & 9,10 & $-2,34$ & 234,20 \\
\hline 51 & 21,0 & $-9,35$ & $-21,81$ & 3,86 & $-17,85$ & $-9,80$ & $-17,28$ & $-46,40$ & 106,00 & 7,94 & $-1,10$ & 241,39 \\
\hline 52 & 38,0 & $-6,28$ & $-12,79$ & 6,11 & $-8,88$ & $-6,09$ & $-9,09$ & $-27,53$ & 44,54 & 15,79 & 2,18 & 139,28 \\
\hline 53 & 28,8 & 0,64 & $-12,89$ & 14,91 & $-0,18$ & $-26,78$ & $-7,58$ & $-47,98$ & 71,51 & $-6,01$ & 11,66 & 200,14 \\
\hline 54 & 21,1 & $-0,93$ & $-17,28$ & 14,86 & $-15,25$ & $-24,65$ & $-5,40$ & $-60,65$ & 106,45 & $-8,11$ & 8,46 & 262,04 \\
\hline 55 & 28,8 & & $-10,99$ & 10,70 & $-2,39$ & $-16,44$ & $-1,83$ & $-44,70$ & 62,03 & $-6,71$ & 8,23 & 165,14 \\
\hline 56 & 21,1 & $-3,80$ & $-11,98$ & 12,57 & $-11,88$ & $-24,85$ & $-4,04$ & $-88,58$ & 135,33 & $-10,01$ & $5,24:$ & 308,27 \\
\hline 57 & 21,1 & $-4,70$ & $-21,87$ & 16,91 & $-10,34$ & $-27,61$ & $-2,30$ & $-103,65$ & 151,90 & $-10,36$ & 10,07 & 359,71 \\
\hline 58 & 21,1 & $-6,69$ & $-6,81$ & 7,92 & $-12,85$ & $-22,90$ & $-10,09$ & $-74,67$ & 126,18 & $-10,94$ & 7,35 & 286,38 \\
\hline 59 & 28,8 & $-2,11$ & $-16,67$ & 18,02 & $-5,33$ & $-36,40$ & $-1,22$ & $-77,52$ & 117,50 & $-12,39$ & 14,50 & 301,66 \\
\hline 60 & 21,1 & $-3,32$ & $-15,50$ & 10,06 & $-5,85$ & $-12,24$ & $-3,09$ & $-93,34$ & 114,84 & $-3,95$ & 10,99 & 273,18 \\
\hline 61 & 28,8 & $-1,21$ & $-16,80$ & 5,57 & $-3,49$ & $-14,57$ & $-3,82$ & $-29,46$ & 55,59 & $-6,51$ & 13,88 & 150,90 \\
\hline 62 & 53,3 & $-2,34$ & $-9,78$ & 8,83 & $-11,54$ & $-9,75$ & $-6,83$ & 12,87 & 16,78 & $-4,77$ & 5,39 & 88,87 \\
\hline 63 & 46,6 & 1,39 & $-8,46$ & 10,86 & $-11,28$ & $-9,44$ & $-6,83$ & 8,36 & 14,50 & $-6,69$ & 6,40 & 84,20 \\
\hline 64 & 41,7 & $-4,40$ & $-12,00$ & 3,81 & $-11,73$ & $-5,97$ & $-11,98$ & 19,29 & 27,04 & $-8,97$ & 2,95 & 108,15 \\
\hline 65 & 38,1 & 0,69 & $-9,66$ & 6,24 & $-9,01$ & $-7,37$ & 7,98 & 3,20 & 3,34 & $-3,35$ & 8,25 & 59,09 \\
\hline 66 & 37,1 & 1,69 & $-6,12$ & 7,42 & $-6,56$ & $-8,17$ & 2,79 & $-0,91$ & 3,25 & $-2,38$ & 8,87 & 48,16 \\
\hline 67 & 45,6 & $-3,56$ & $-9,83$ & 4,95 & $-12,22$ & $-17,17$ & $-8,52$ & 26,52 & 25,45 & $-8,03$ & 1,21 & 117,46 \\
\hline 68 & 46,6 & $-2,62$ & $-8,85$ & 6,18 & $-16,19$ & $-17,86$ & $-6,61$ & 22,87 & 26,70 & $-7,25$ & 2,62 & 117,75 \\
\hline 69 & 17,1 & $-2,18$ & $-10,10$ & 4,45 & $-7,24$ & $-7,83$ & 3,25 & $-1,49$ & 16,90 & $-5,68$ & 10,20 & 69,31 \\
\hline 70 & 21,6 & $-0,29$ & $-10,45$ & 4,73 & $-8,52$ & $-9,13$ & $-1,11$ & 1,91 & 18,35 & $-5,94$ & 10,28 & 70,70 \\
\hline
\end{tabular}


APÊNDICE 11. Produção de frutos $\left(\mathrm{t} \mathrm{ha}^{-1}\right)$ e índices DRIS obtidos pelo método Jones (1981) utilizando o critério de escolha da razão entre nutrientes "Valor R” em 70 pomares de macieira no Rio Grande do Sul e Santa Catarina. (Safra 2002)

\begin{tabular}{|c|c|c|c|c|c|c|c|c|c|c|c|c|}
\hline \multirow{2}{*}{ Amostra } & \multirow{2}{*}{$\begin{array}{c}\text { Produção } \\
\text { t ha' }^{-1}\end{array}$} & \multicolumn{10}{|c|}{ Índices DRIS } & \multirow{2}{*}{ IBN } \\
\hline & & $\mathbf{N}$ & $\mathbf{P}$ & $\mathbf{K}$ & Ca & Mg & $\mathrm{Fe}$ & Mn & $\mathbf{Z n}$ & $\mathrm{Cu}$ & B & \\
\hline 1 & 33,0 & $-4,21$ & 4,88 & $-2,13$ & $-3,39$ & 1,78 & 2,99 & 2,04 & 0,42 & 1,46 & $-3,84$ & 27,15 \\
\hline 2 & 35,0 & $-5,67$ & 3,86 & $-5,05$ & $-2,35$ & $-1,25$ & 10,57 & 1,27 & 0,28 & 0,62 & $-2,28$ & 33,20 \\
\hline 3 & 35,0 & $-7,94$ & $-1,08$ & $-8,62$ & 1,46 & $-5,44$ & 41,42 & $-19,22$ & $-1,92$ & 1,91 & $-0,57$ & 89,57 \\
\hline 4 & 33,0 & $-7,24$ & $-2,92$ & $-6,28$ & $-0,79$ & $-2,70$ & 19,28 & $-0,31$ & 3,21 & 0,75 & $-3,00$ & 46,48 \\
\hline 5 & 39,0 & $-1,42$ & 6,27 & 5,58 & 1,85 & 1,34 & $-6,12$ & $-0,20$ & $-0,15$ & $-4,61$ & $-2,53$ & 30,08 \\
\hline 6 & 68,0 & 1,70 & 4,25 & 1,27 & 7,06 & 1,03 & $-8,51$ & $-5,95$ & $-3,22$ & 0,81 & 1,57 & 35,38 \\
\hline 7 & 18,1 & $-1,00$ & 1,12 & $-5,94$ & $-1,39$ & 4,35 & 0,60 & 6,95 & 1,38 & $-0,70$ & $-5,39$ & 28,81 \\
\hline 8 & 11,4 & $-4,42$ & $-2,08$ & $-7,57$ & $-0,65$ & $-0,34$ & 6,83 & 8,30 & 3,16 & 0,07 & $-3,30$ & 36,72 \\
\hline 9 & 24,3 & $-3,19$ & $-3,61$ & $-6,59$ & $-0,51$ & 2,03 & 7,36 & 5,10 & 0,99 & 1,90 & $-3,49$ & 34,77 \\
\hline 10 & 29,9 & $-1,40$ & 0,44 & 5,60 & $-0,90$ & 1,19 & 0,15 & 1,79 & $-5,33$ & 1,32 & $-2,87$ & 21,00 \\
\hline 11 & 81,7 & $-1,05$ & 2,19 & $-7,52$ & 4,39 & $-1,22$ & 0,19 & 7,20 & $-2,10$ & 0,47 & $-2,57$ & 28,89 \\
\hline 12 & 38,6 & 0,61 & 2,60 & $-5,62$ & 3,41 & 0,50 & $-2,32$ & 10,12 & $-2,93$ & $-1,98$ & $-4,40$ & 34,47 \\
\hline 13 & 85,0 & 0,75 & 3,93 & $-1,93$ & $-0,11$ & $-0,37$ & 2,17 & 2,15 & $-4,31$ & $-0,28$ & $-2,00$ & 18,00 \\
\hline 14 & 98,0 & $-0,85$ & 4,40 & $-0,01$ & 0,91 & $-2,87$ & 3,05 & $-0,75$ & $-3,06$ & 0,19 & $-1,00$ & 17,09 \\
\hline 15 & 80,0 & $-1,42$ & 2,58 & 0,16 & 2,28 & $-1,11$ & 1,31 & $-2,12$ & $-1,67$ & 1,07 & $-1,08$ & 14,81 \\
\hline 16 & 87,0 & 0,16 & 1,64 & $-3,97$ & 3,54 & $-3,31$ & 2,55 & 5,99 & $-5,52$ & 0,89 & $-1,97$ & 29,55 \\
\hline 17 & 80,0 & $-1,83$ & 2,83 & $-5,03$ & 0,67 & $-0,16$ & 0,34 & 10,29 & $-5,09$ & 0,32 & $-2,34$ & 28,92 \\
\hline 18 & 76,0 & $-0,51$ & 2,82 & $-5,35$ & 1,36 & $-2,48$ & 5,27 & 2,69 & $-3,55$ & 1,95 & $-2,20$ & 28,19 \\
\hline 19 & 104,0 & $-0,33$ & 2,36 & $-6,07$ & $-0,53$ & 1,41 & 3,22 & 1,26 & $-3,61$ & 2,86 & $-0,57$ & 22,22 \\
\hline 20 & 90,0 & $-3,34$ & 1,67 & $-5,24$ & 1,34 & 2,06 & 1,33 & 7,69 & $-0,93$ & $-0,97$ & $-3,61$ & 28,19 \\
\hline 21 & 62,0 & 0,37 & 3,33 & $-5,01$ & 1,27 & 0,72 & 1,45 & 2,19 & $-6,26$ & 1,67 & 0,28 & 22,55 \\
\hline 22 & 82,0 & $-1,43$ & 3,72 & $-2,34$ & 1,54 & $-1,97$ & $-0,01$ & 4,22 & $-4,39$ & 1,65 & $-0,99$ & 22,27 \\
\hline 23 & 79,0 & 0,79 & 2,81 & $-2,72$ & $-0,08$ & 2,19 & $-0,75$ & 2,48 & $-3,66$ & $-0,41$ & $-0,65$ & 16,55 \\
\hline 24 & 54,0 & $-2,27$ & 4,36 & $-1,77$ & 1,57 & 3,84 & $-0,58$ & $-1,41$ & $-2,64$ & $-0,22$ & $-0,89$ & 19,55 \\
\hline 25 & 78,0 & 1,48 & 0,24 & $-2,08$ & $-0,29$ & 1,16 & $-2,02$ & 0,37 & $-0,19$ & 1,55 & $-0,21$ & 9,59 \\
\hline 26 & 53,0 & 0,76 & $-1,49$ & 0,11 & 1,00 & 0,97 & 1,96 & 1,51 & $-4,65$ & 1,24 & $-1,40$ & 15,09 \\
\hline 27 & 52,0 & 0,76 & 1,65 & $-5,00$ & $-0,14$ & 2,19 & 3,85 & 2,67 & $-4,24$ & 1,20 & $-2,94$ & 24,65 \\
\hline 28 & 45,0 & $-0,78$ & $-1,17$ & $-1,07$ & $-2,67$ & 2,74 & 2,55 & 2,89 & $-1,29$ & 0,36 & $-1,56$ & 17,09 \\
\hline 29 & 40,0 & $-0,25$ & 0,89 & $-1,94$ & $-0,26$ & 2,81 & 6,61 & $-2,46$ & $-5,46$ & 2,02 & $-1,97$ & 24,66 \\
\hline 30 & 48,0 & $-0,25$ & 1,19 & $-5,53$ & $-1,58$ & 2,78 & 4,59 & 4,41 & $-2,17$ & 0,69 & $-4,15$ & 27,34 \\
\hline 31 & 44,0 & $-0,47$ & 3,99 & $-2,16$ & $-0,76$ & 2,82 & 6,62 & $-5,51$ & $-4,94$ & 1,59 & $-1,19$ & 30,05 \\
\hline 32 & 42,0 & $-0,30$ & 1,68 & $-3,47$ & 2,36 & 3,62 & 5,10 & $-4,46$ & $-4,63$ & 2,00 & $-1,89$ & 29,51 \\
\hline 33 & 60,0 & $-1,67$ & $-0,51$ & $-3,74$ & 0,29 & 2,41 & 4,25 & 4,36 & $-1,66$ & 0,82 & $-4,54$ & 24,25 \\
\hline 34 & 57,0 & 0,33 & 1,07 & 0,32 & $-2,03$ & 0,36 & 1,47 & 4,61 & $-2,35$ & $-0,69$ & $-3,10$ & 16,33 \\
\hline 35 & 38,0 & 1,04 & 1,48 & $-2,95$ & $-0,70$ & 1,06 & 5,53 & $-1,01$ & $-4,67$ & 1,22 & $-1,01$ & 20,66 \\
\hline
\end{tabular}


APÊNDICE 11. Produção de frutos $\left(\mathrm{t} \mathrm{ha}^{-1}\right)$ e índices DRIS obtidos pelo método Jones (1981) utilizando o critério de escolha da razão entre nutrientes "Valor R” em 70 pomares de macieira no Rio Grande do Sul e Santa Catarina. (Safra 2002)

\begin{tabular}{|c|c|c|c|c|c|c|c|c|c|c|c|c|}
\hline \multirow{2}{*}{ Amostra } & \multirow{2}{*}{$\frac{\text { Produção }}{\text { t ha }^{-1}}$} & \multicolumn{10}{|c|}{ Índices DRIS } & \multirow{2}{*}{ IBN } \\
\hline & & $\mathbf{N}$ & $\bar{P}$ & $\mathbf{K}$ & $\mathbf{C a}$ & Mg & Fe & Mn & Zn & $\mathbf{C u}$ & B & \\
\hline 36 & 43,0 & $-1,73$ & $-1,54$ & $-0,46$ & $-0,60$ & $-1,44$ & 2,62 & 4,45 & 1,34 & $-0,26$ & $-2,39$ & 16,83 \\
\hline 37 & 28,0 & 0,10 & $-0,23$ & $-1,49$ & 0,52 & $-1,85$ & 7,56 & $-0,40$ & $-5,18$ & 0,91 & 0,04 & 18,28 \\
\hline 38 & 51,0 & $-1,74$ & 1,93 & 2,12 & $-1,82$ & $-3,48$ & 1,07 & 3,38 & 2,02 & $-0,07$ & $-3,42$ & 21,04 \\
\hline 39 & 52,0 & 1,14 & 1,14 & 0,28 & $-1,15$ & $-2,00$ & 3,79 & $-1,26$ & $-3,70$ & 2,99 & $-1,22$ & 18,67 \\
\hline 40 & 39,0 & $-3,33$ & 0,61 & 2,67 & $-4,78$ & $-5,36$ & 8,24 & $-0,21$ & 2,85 & 2,09 & $-2,77$ & 32,91 \\
\hline 41 & 34,0 & $-2,29$ & 2,32 & $-6,95$ & $-1,41$ & $-2,25$ & 13,06 & $-1,79$ & $-1,95$ & 2,85 & $-1,59$ & 36,47 \\
\hline 42 & 47,0 & $-1,22$ & 1,57 & $-4,57$ & $-0,98$ & 1,68 & 5,45 & 2,41 & $-4,88$ & 2,48 & $-1,95$ & 27,19 \\
\hline 43 & 41,0 & $-1,28$ & $-1,29$ & $-8,28$ & 1,52 & 2,00 & 7,76 & $-0,82$ & $-3,37$ & 4,36 & $-0,62$ & 31,30 \\
\hline 44 & 54,0 & $-6,20$ & $-5,71$ & $-7,96$ & $-1,11$ & $-8,12$ & $-3,18$ & 1,95 & 45,27 & $-4,32$ & $-10,61$ & 94,42 \\
\hline 45 & 63,0 & $-3,42$ & $-2,30$ & $-6,20$ & 1,48 & $-4,23$ & 1,81 & 1,55 & 21,62 & $-2,69$ & $-7,63$ & 52,92 \\
\hline 46 & 61,0 & $-5,51$ & $-1,73$ & $-6,18$ & $-3,49$ & $-8,05$ & $-0,80$ & 14,29 & 27,07 & $-5,28$ & $-10,32$ & 82,73 \\
\hline 47 & 82,0 & $-7,37$ & $-4,85$ & $-2,97$ & $-3,86$ & $-12,61$ & 0,61 & 12,24 & 33,71 & $-3,33$ & $-11,56$ & 93,10 \\
\hline 48 & 60,0 & $-8,30$ & $-7,44$ & $-7,74$ & 1,08 & $-7,59$ & $-6,87$ & 11,95 & 40,86 & $-5,26$ & $-10,69$ & 107,78 \\
\hline 49 & 54,0 & $-3,15$ & $-2,02$ & $-4,09$ & 2,61 & $-4,85$ & $-2,77$ & 3,15 & 22,76 & $-4,38$ & $-7,27$ & 57,04 \\
\hline 50 & 41,0 & $-8,68$ & $-4,30$ & $-9,71$ & $-0,48$ & $-7,81$ & $-4,64$ & 15,67 & 42,40 & $-8,60$ & $-13,85$ & 116,15 \\
\hline 51 & 55,0 & $-6,59$ & $-1,90$ & $-6,86$ & $-0,89$ & $-7,28$ & $-5,47$ & 11,63 & 37,10 & $-7,37$ & $-12,38$ & 97,46 \\
\hline 52 & 53,0 & $-11,26$ & $-7,23$ & $-11,62$ & $-0,48$ & $-12,08$ & 29,30 & $-0,17$ & 22,87 & $-0,84$ & $-8,49$ & 104,34 \\
\hline 53 & 46,8 & $-1,06$ & $-2,04$ & 0,74 & 0,81 & $-1,11$ & 6,29 & $-10,94$ & 15,02 & $-2,68$ & $-5,03$ & 45,73 \\
\hline 54 & 75,8 & $-4,46$ & $-16,33$ & $-5,81$ & $-5,82$ & $-33,38$ & 1,25 & $-8,42$ & 89,33 & $-7,78$ & $-8,57$ & 181,15 \\
\hline 55 & 97,5 & 1,71 & 2,42 & 1,81 & 4,60 & $-4,29$ & 8,36 & $-12,34$ & $-3,58$ & 0,42 & 0,90 & 40,41 \\
\hline 56 & 38,1 & $-3,72$ & 2,01 & 2,20 & 1,85 & $-5,94$ & 3,88 & $-12,18$ & 15,08 & $-1,47$ & $-1,71$ & 50,05 \\
\hline 57 & 15,9 & $-9,80$ & $-8,95$ & $-7,36$ & $-6,13$ & $-30,36$ & $-3,93$ & $-9,62$ & 96,25 & $-9,21$ & $-10,90$ & 192,50 \\
\hline 58 & 15,9 & $-9,21$ & $-11,15$ & $-6,47$ & $-3,60$ & $-15,15$ & 2,31 & $-10,42$ & 69,89 & $-7,26$ & $-8,93$ & 144,38 \\
\hline 59 & 46,9 & 0,13 & $-2,68$ & 1,83 & 1,77 & $-18,10$ & 9,23 & $-12,82$ & 23,11 & $-2,21$ & $-0,26$ & 72,14 \\
\hline 60 & 15,9 & $-4,91$ & $-7,37$ & $-6,93$ & $-3,71$ & $-8,82$ & 2,37 & $-14,34$ & 57,13 & $-5,17$ & $-8,24$ & 119,00 \\
\hline 61 & 46,9 & $-1,33$ & $-2,91$ & $-7,46$ & 1,77 & $-6,84$ & 9,49 & $-8,03$ & 18,92 & $-0,50$ & $-3,12$ & 60,37 \\
\hline 62 & 46,9 & $-0,83$ & 1,38 & $-0,82$ & $-6,15$ & $-3,96$ & 0,64 & 5,60 & 5,66 & 2,69 & $-4,21$ & 31,95 \\
\hline 63 & 37,4 & 0,50 & $-1,50$ & 1,17 & $-3,92$ & $-3,10$ & 1,07 & 5,15 & 3,36 & $-0,07$ & $-2,66$ & 22,50 \\
\hline 64 & 50,1 & $-4,41$ & $-2,08$ & $-1,53$ & $-0,93$ & $-2,55$ & 7,42 & 4,90 & 4,15 & 1,11 & $-6,09$ & 35,17 \\
\hline 65 & 46,8 & 1,29 & $-0,21$ & 2,11 & $-6,34$ & $-6,29$ & 0,44 & 1,50 & 4,58 & 2,84 & 0,08 & 25,69 \\
\hline 66 & 43,0 & 1,90 & 3,59 & 3,23 & $-3,91$ & $-3,75$ & 3,21 & $-5,37$ & $-1,48$ & 2,48 & 0,09 & 29,01 \\
\hline 67 & 43,0 & $-2,25$ & $-0,03$ & $-0,03$ & $-3,72$ & $-3,42$ & $-1,15$ & 6,15 & 7,64 & $-0,06$ & $-3,13$ & 27,59 \\
\hline 68 & 36,8 & 0,52 & $-5,33$ & 1,73 & $-2,23$ & $-2,07$ & $-1,69$ & 5,15 & 5,72 & 0,14 & $-1,93$ & 26,52 \\
\hline 69 & 70,1 & 1,79 & $-0,44$ & $-0,67$ & $-2,87$ & $-3,67$ & $-0,39$ & 3,92 & 4,89 & $-1,29$ & $-1,28$ & 21,19 \\
\hline 70 & 78,3 & 1,74 & $-2,40$ & $-1,76$ & $-4,35$ & $-5,97$ & 4,68 & 2,85 & 5,94 & 1,25 & $-1,98$ & 32,93 \\
\hline
\end{tabular}


APÊNDICE 12. Produção de frutos $\left(\mathrm{t} \mathrm{ha}^{-1}\right)$ e índices DRIS obtidos pelo método Jones (1981) utilizando o critério de escolha da razão entre nutrientes "Valor R” em 70 pomares de macieira no Rio Grande do Sul e Santa Catarina. (Safra 2003)

\begin{tabular}{|c|c|c|c|c|c|c|c|c|c|c|c|c|}
\hline \multirow{2}{*}{ Amostra } & \multirow{2}{*}{$\begin{array}{c}\text { Produção } \\
\text { t ha }^{-1}\end{array}$} & \multicolumn{10}{|c|}{ Índices DRIS } & \multirow{2}{*}{ IBN } \\
\hline & & $\mathbf{N}$ & $\mathbf{P}$ & $\mathbf{K}$ & Ca & Mg & $\mathbf{F e}$ & Mn & Zn & $\mathbf{C u}$ & B & \\
\hline 1 & 44,5 & $-1,68$ & 0,83 & 3,11 & $-1,10$ & 0,17 & $-5,81$ & 7,73 & 6,79 & $-10,55$ & 0,52 & 38,29 \\
\hline 2 & 43,2 & $-0,33$ & 2,05 & 0,33 & $-1,68$ & 0,81 & $-5,06$ & 6,07 & 5,71 & $-7,17$ & $-0,73$ & 29,93 \\
\hline 3 & 40,2 & $-1,24$ & 1,22 & $-1,85$ & 5,62 & 4,23 & $-4,04$ & $-3,39$ & $-2,60$ & $-2,00$ & 4,04 & 30,22 \\
\hline 4 & 33,8 & $-0,27$ & 1,33 & $-5,59$ & 7,00 & 7,32 & $-4,68$ & $-3,31$ & $-2,36$ & $-2,46$ & 3,04 & 37,35 \\
\hline 5 & 40,6 & 0,60 & 6,22 & 3,18 & 3,81 & $-0,23$ & $-4,56$ & $-3,33$ & $-2,38$ & $-4,49$ & 1,19 & 29,99 \\
\hline 6 & 40,7 & $-2,73$ & 5,03 & 8,08 & 3,42 & $-2,21$ & $-5,41$ & 3,28 & 2,45 & $-5,95$ & $-5,97$ & 44,52 \\
\hline 7 & 19,5 & $-1,56$ & $-1,04$ & 2,68 & $-3,01$ & 2,39 & $-4,49$ & 3,93 & 1,21 & 0,04 & $-0,15$ & 20,49 \\
\hline 8 & 28,3 & 1,69 & $-0,86$ & $-0,52$ & $-1,70$ & 2,03 & $-3,72$ & 3,35 & 0,91 & $-1,21$ & 0,02 & 15,99 \\
\hline 9 & 28,0 & $-2,71$ & $-2,47$ & 0,07 & $-0,12$ & 3,18 & $-3,96$ & 7,98 & 4,03 & $-5,46$ & $-0,53$ & 30,51 \\
\hline 10 & 33,6 & 0,05 & $-0,78$ & 7,21 & $-4,43$ & 0,47 & $-6,77$ & 3,10 & 0,73 & $-0,27$ & 0,68 & 24,49 \\
\hline 11 & 52,2 & $-1,47$ & $-0,07$ & $-7,46$ & 0,93 & 2,23 & $-4,61$ & 9,39 & 2,68 & $-1,27$ & $-0,35$ & 30,46 \\
\hline 12 & 58,7 & $-3,58$ & $-3,87$ & $-5,86$ & 0,92 & 2,84 & 0,69 & 12,83 & 1,92 & $-4,92$ & $-0,97$ & 38,39 \\
\hline 13 & 18,0 & $-5,05$ & $-0,91$ & 4,27 & $-2,51$ & $-1,71$ & $-0,11$ & 2,62 & $-0,16$ & $-0,79$ & 4,36 & 22,50 \\
\hline 14 & 15,0 & $-2,79$ & 1,15 & 3,52 & $-0,57$ & $-2,79$ & $-0,71$ & 1,25 & $-0,77$ & $-2,94$ & 4,66 & 21,16 \\
\hline 15 & 22,0 & $-5,42$ & $-1,45$ & 5,15 & $-0,46$ & $-0,58$ & $-4,58$ & 3,02 & 0,18 & $-1,83$ & 5,96 & 28,62 \\
\hline 16 & 30,0 & $-4,98$ & $-1,38$ & $-1,01$ & 1,76 & $-1,75$ & $-0,90$ & 10,09 & $-2,34$ & $-4,78$ & 5,30 & 34,29 \\
\hline 17 & 35,0 & $-3,75$ & $-1,96$ & 2,23 & $-0,70$ & 0,86 & $-1,62$ & 2,71 & $-0,34$ & $-3,06$ & 5,64 & 22,87 \\
\hline 18 & 25,0 & $-6,78$ & $-3,23$ & 1,42 & $-0,09$ & $-1,90$ & 3,53 & 7,69 & 1,73 & $-5,65$ & 3,29 & 35,31 \\
\hline 19 & 12,0 & $-2,73$ & $-1,09$ & 1,91 & $-1,54$ & $-0,93$ & 4,59 & 1,11 & $-0,52$ & $-5,78$ & 4,97 & 25,17 \\
\hline 20 & 35,0 & $-3,02$ & $-1,39$ & 1,71 & $-1,00$ & 3,68 & $-4,91$ & 7,37 & 4,14 & $-11,92$ & 5,34 & 44,49 \\
\hline 21 & 75,0 & $-3,34$ & 1,31 & $-1,19$ & $-0,76$ & 0,19 & 0,68 & 5,20 & $-1,64$ & $-4,06$ & 3,60 & 21,96 \\
\hline 22 & 30,0 & $-4,32$ & 0,66 & 1,61 & $-0,10$ & $-0,41$ & $-1,34$ & 4,18 & $-1,08$ & $-3,74$ & 4,53 & 21,97 \\
\hline 23 & 18,0 & $-2,55$ & $-0,88$ & 3,40 & $-3,42$ & 3,28 & $-2,85$ & 3,68 & 1,71 & $-5,94$ & 3,58 & 31,29 \\
\hline 24 & 70,0 & $-2,96$ & $-0,03$ & $-0,08$ & 0,03 & 5,35 & $-4,59$ & 3,16 & 1,49 & $-4,07$ & 1,69 & 23,45 \\
\hline 25 & 22,0 & $-0,83$ & $-2,65$ & 4,37 & $-3,14$ & 1,49 & $-5,56$ & 4,22 & 3,53 & $-5,51$ & 4,07 & 35,36 \\
\hline 26 & 18,0 & $-1,45$ & $-4,26$ & 4,61 & $-1,30$ & 2,51 & $-3,96$ & 4,33 & 0,54 & $-4,04$ & 3,03 & 30,02 \\
\hline 27 & 25,0 & $-4,21$ & $-4,02$ & 2,36 & 1,07 & 4,51 & $-4,46$ & 7,24 & 1,34 & $-6,76$ & 2,94 & 38,91 \\
\hline 28 & 52,0 & $-5,41$ & $-4,16$ & $-0,51$ & $-1,86$ & 2,99 & 3,58 & 7,81 & 3,76 & $-5,30$ & $-0,90$ & 36,28 \\
\hline 29 & 40,0 & 1,00 & $-2,17$ & $-2,37$ & 0,82 & 5,05 & $-0,35$ & 1,90 & $-2,31$ & $-3,48$ & 1,91 & 21,36 \\
\hline 30 & 57,0 & $-3,71$ & $-5,25$ & $-1,40$ & $-1,55$ & 4,25 & 3,06 & 9,27 & 7,89 & $-11,65$ & $-0,91$ & 48,94 \\
\hline 31 & 46,0 & 0,58 & $-1,77$ & $-2,52$ & 0,29 & 5,42 & 3,23 & $-1,22$ & $-2,01$ & $-5,11$ & 3,11 & 25,25 \\
\hline 32 & 49,0 & 2,35 & $-1,72$ & $-1,07$ & $-0,16$ & 3,38 & 2,36 & $-2,47$ & $-2,07$ & $-0,99$ & 0,37 & 16,95 \\
\hline 33 & 63,0 & $-3,05$ & $-3,69$ & $-0,71$ & $-0,50$ & 3,38 & $-1,54$ & 8,41 & 5,71 & $-5,42$ & $-2,58$ & 35,01 \\
\hline 34 & 40,0 & $-1,19$ & $-2,24$ & 1,63 & $-3,71$ & $-0,48$ & $-0,82$ & 6,78 & 5,50 & $-4,37$ & $-1,09$ & 27,81 \\
\hline 35 & 33,0 & 2,07 & $-2,13$ & 1,24 & $-2,55$ & 1,84 & 0,22 & 2,50 & $-2,30$ & $-2,97$ & 2,07 & 19,89 \\
\hline
\end{tabular}


APÊNDICE 12. Produção de frutos ( $\mathrm{t} \mathrm{ha}^{-1}$ ) e índices DRIS obtidos pelo método Jones (1981) utilizando o critério de escolha da razão entre nutrientes "Valor R” em 70 pomares de macieira no Rio Grande do Sul e Santa Catarina. (Safra 2003)

\begin{tabular}{|c|c|c|c|c|c|c|c|c|c|c|c|c|}
\hline \multirow{2}{*}{ Amostra } & \multirow{2}{*}{$\frac{\text { Produção }}{\text { t ha }^{-1}}$} & \multicolumn{10}{|c|}{ Índices DRIS } & \multirow{2}{*}{ IBN } \\
\hline & & $\mathbf{N}$ & $\mathbf{P}$ & K & $\mathbf{C a}$ & Mg & $\mathbf{F e}$ & Mn & $\mathrm{Zn}$ & $\mathbf{C u}$ & B & \\
\hline 36 & 32,0 & $-4,26$ & $-3,68$ & $-3,11$ & $-2,01$ & $-1,72$ & 4,15 & 9,45 & 8,41 & $-6,58$ & $-0,64$ & 44,00 \\
\hline 37 & 45,0 & 2,19 & $-0,74$ & 0,31 & $-0,87$ & $-1,00$ & 0,78 & 0,96 & $-1,99$ & $-3,45$ & 3,80 & 16,08 \\
\hline 38 & 55,0 & $-3,44$ & $-3,56$ & 1,19 & $-0,22$ & $-1,33$ & $-1,69$ & 9,65 & 9,31 & $-8,64$ & $-1,27$ & 40,29 \\
\hline 39 & 60,0 & 2,21 & 0,56 & 1,56 & $-0,79$ & 0,71 & 0,26 & $-0,94$ & $-1,84$ & $-3,04$ & 1,30 & 13,20 \\
\hline 40 & 25,0 & $-1,23$ & $-3,05$ & 4,84 & $-6,47$ & $-1,17$ & $-3,96$ & $-3,99$ & 18,50 & $-4,09$ & 0,61 & 47,91 \\
\hline 41 & 29,0 & 0,22 & $-1,09$ & $-4,82$ & $-1,16$ & 4,87 & $-3,77$ & $-9,37$ & 21,49 & $-4,86$ & $-1,50$ & 53,15 \\
\hline 42 & 34,0 & 0,79 & $-2,42$ & $-3,34$ & $-0,06$ & 6,07 & $-4,05$ & $-0,81$ & 17,28 & $-11,57$ & $-1,89$ & 48,27 \\
\hline 43 & 31,0 & 0,45 & $-1,17$ & $-5,37$ & $-2,90$ & 4,86 & $-2,99$ & $-2,75$ & 17,44 & $-7,09$ & $-0,48$ & 45,50 \\
\hline 44 & 25,0 & $-10,29$ & $-13,06$ & $-1,85$ & $-3,77$ & $-3,35$ & $-16,31$ & $-3,92$ & 55,69 & 2,47 & $-5,61$ & 116,32 \\
\hline 45 & 41,0 & $-1,90$ & $-8,97$ & $-1,29$ & 0,51 & $-0,03$ & $-11,35$ & $-4,22$ & 22,63 & 6,67 & $-2,05$ & 59,62 \\
\hline 46 & 31,0 & $-10,41$ & $-11,80$ & $-0,64$ & $-6,34$ & $-8,07$ & $-14,48$ & 0,21 & 56,05 & $-1,13$ & $-3,39$ & 112,52 \\
\hline 47 & 29,0 & $-9,82$ & $-17,71$ & 4,06 & $-7,94$ & $-8,31$ & $-15,58$ & $-0,26$ & 46,81 & 8,94 & $-0,19$ & 119,62 \\
\hline 48 & 19,0 & $-10,65$ & $-12,86$ & 0,41 & $-4,67$ & $-5,87$ & $-15,97$ & $-2,94$ & 49,88 & 4,58 & $-1,92$ & 109,74 \\
\hline 49 & 36,0 & $-3,68$ & $-9,74$ & 0,63 & $-2,04$ & $-3,90$ & $-11,27$ & $-2,63$ & 22,46 & 10,29 & $-0,12$ & 66,76 \\
\hline 50 & 19,0 & $-6,75$ & $-12,90$ & $-0,17$ & $-7,47$ & $-5,69$ & $-14,63$ & $-3,45$ & 49,25 & 5,69 & $-3,86$ & 109,88 \\
\hline 51 & 21,0 & $-8,22$ & $-12,61$ & $-0,64$ & $-9,66$ & $-3,73$ & $-15,59$ & $-3,55$ & 51,95 & 5,04 & $-3,00$ & 113,98 \\
\hline 52 & 38,0 & $-4,24$ & $-8,25$ & 1,80 & $-4,87$ & $-1,74$ & $-8,12$ & $-4,28$ & 19,27 & 9,86 & 0,56 & 62,97 \\
\hline 53 & 28,8 & $-0,50$ & $-7,41$ & 6,12 & 2,13 & $-17,21$ & $-6,41$ & $-5,99$ & 27,73 & $-4,74$ & 6,29 & 84,51 \\
\hline 54 & 21,1 & $-1,83$ & $-9,17$ & 5,95 & $-8,58$ & $-14,78$ & $-5,05$ & $-5,65$ & 41,96 & $-6,61$ & 3,77 & 103,37 \\
\hline 55 & 28,8 & 0,03 & $-6,35$ & 4,14 & 0,03 & $-10,21$ & $-1,99$ & $-6,75$ & 22,49 & $-5,21$ & 3,82 & 61,02 \\
\hline 56 & 21,1 & $-5,04$ & $-5,55$ & 4,05 & $-5,90$ & $-14,49$ & $-4,27$ & $-8,20$ & 47,32 & $-8,40$ & 0,48 & 103,71 \\
\hline 57 & 21,1 & $-6,01$ & $-11,89$ & 5,55 & $-4,50$ & $-16,44$ & $-2,64$ & $-9,06$ & 49,90 & $-8,57$ & 3,66 & 118,23 \\
\hline 58 & 21,1 & $-7,22$ & $-2,35$ & 1,57 & $-6,51$ & $-12,87$ & $-9,43$ & $-6,59$ & 50,01 & $-9,17$ & 2,56 & 108,27 \\
\hline 59 & 28,8 & $-3,28$ & $-9,21$ & 6,94 & $-1,36$ & $-23,16$ & $-1,53$ & $-7,87$ & 41,33 & $-9,48$ & 7,60 & 111,74 \\
\hline 60 & 21,1 & $-5,03$ & $-8,86$ & 2,11 & $-2,01$ & $-6,25$ & $-3,34$ & $-10,68$ & 33,87 & $-4,00$ & 4,18 & 80,32 \\
\hline 61 & 28,8 & $-1,32$ & $-10,79$ & 1,52 & $-0,57$ & $-8,73$ & $-3,74$ & $-4,05$ & 23,93 & $-5,18$ & 8,93 & 68,74 \\
\hline 62 & 53,3 & $-2,08$ & $-4,50$ & 4,74 & $-6,37$ & $-4,64$ & $-4,54$ & 6,78 & 10,82 & $-3,43$ & 3,23 & 51,13 \\
\hline 63 & 46,6 & 1,36 & $-4,09$ & 5,91 & $-6,82$ & $-4,98$ & $-4,61$ & 4,82 & 9,06 & $-4,76$ & 4,11 & 50,51 \\
\hline 64 & 41,7 & $-4,24$ & $-5,41$ & 0,67 & $-5,41$ & $-1,36$ & $-7,74$ & 10,30 & 19,44 & $-7,19$ & 0,95 & 62,69 \\
\hline 65 & 38,1 & 0,91 & $-6,75$ & 3,60 & $-5,41$ & $-4,68$ & 5,68 & 2,01 & 0,47 & $-1,88$ & 6,05 & 37,44 \\
\hline 66 & 37,1 & 1,87 & $-4,06$ & 4,58 & $-4,36$ & $-5,44$ & 1,98 & 0,01 & 0,42 & $-1,40$ & 6,40 & 30,53 \\
\hline 67 & 45,6 & $-3,46$ & $-3,36$ & 1,85 & $-5,28$ & $-7,91$ & $-5,07$ & 12,82 & 17,42 & $-6,39$ & $-0,62$ & 64,16 \\
\hline 68 & 46,6 & $-2,54$ & $-3,03$ & 2,90 & $-8,18$ & $-8,65$ & $-4,13$ & 11,04 & 17,71 & $-5,77$ & 0,65 & 64,60 \\
\hline 69 & 17,1 & $-1,74$ & $-6,61$ & 2,19 & $-4,14$ & $-4,54$ & 2,18 & 0,90 & 8,35 & $-4,05$ & 7,48 & 42,18 \\
\hline 70 & 21,6 & 0,00 & $-6,40$ & 2,24 & $-5,04$ & $-5,16$ & $-1,26$ & 2,51 & 10,09 & $-4,48$ & 7,49 & 44,67 \\
\hline
\end{tabular}


APÊNDICE 13. Produção de frutos $\left(\mathrm{t} \mathrm{ha}^{-1}\right)$ e índices DRIS obtidos pelo método Jones (1981) utilizando o critério de escolha da razão entre nutrientes "Valor F” em 70 pomares de macieira no Rio Grande do Sul e Santa Catarina. (Safra 2002)

\begin{tabular}{|c|c|c|c|c|c|c|c|c|c|c|c|c|}
\hline \multirow{2}{*}{ Amostra } & \multirow{2}{*}{$\begin{array}{c}\text { Produção } \\
\text { t ha-1 }\end{array}$} & \multicolumn{10}{|c|}{ Índices DRIS } & \multirow{2}{*}{ IBN } \\
\hline & & $\mathbf{N}$ & $\mathbf{P}$ & $\mathbf{K}$ & Ca & Mg & Fe & Mn & Zn & $\mathrm{Cu}$ & B & \\
\hline 1 & 33,0 & $-4,24$ & 5,11 & $-1,62$ & $-4,59$ & 2,23 & 3,30 & 1,85 & 1,81 & 1,50 & $-4,98$ & 31,25 \\
\hline 2 & 35,0 & $-4,07$ & 4,51 & $-4,56$ & $-3,22$ & $-0,58$ & 8,11 & 1,53 & 1,97 & 0,58 & $-3,59$ & 32,72 \\
\hline 3 & 35,0 & $-1,96$ & 2,47 & $-8,42$ & 0,66 & $-1,12$ & 17,69 & $-5,68$ & $-0,43$ & 2,24 & $-5,01$ & 45,69 \\
\hline 4 & 33,0 & $-3,93$ & $-0,24$ & $-5,80$ & $-1,12$ & $-0,42$ & 12,10 & 0,89 & 4,74 & 0,72 & $-5,73$ & 35,69 \\
\hline 5 & 39,0 & $-0,90$ & 8,20 & 5,14 & 2,26 & 1,35 & $-8,48$ & $-0,54$ & 0,13 & $-5,22$ & $-2,75$ & 34,96 \\
\hline 6 & 68,0 & 2,85 & 5,32 & 1,80 & 6,87 & 1,02 & $-11,15$ & $-4,57$ & $-4,16$ & 0,53 & 1,02 & 39,29 \\
\hline 7 & 18,1 & $-0,84$ & 0,43 & $-6,59$ & $-2,98$ & 6,05 & 0,93 & 7,63 & 2,93 & $-0,02$ & $-6,93$ & 35,33 \\
\hline 8 & 11,4 & $-3,64$ & $-2,64$ & $-7,64$ & $-1,92$ & $-0,91$ & 5,62 & 10,24 & 4,64 & 0,81 & $-3,41$ & 41,48 \\
\hline 9 & 24,3 & $-2,46$ & $-3,62$ & $-6,83$ & $-1,52$ & 2,55 & 6,29 & 5,95 & 2,69 & 2,24 & $-4,45$ & 38,61 \\
\hline 10 & 29,9 & $-1,27$ & 0,64 & 5,17 & $-0,79$ & 1,34 & 0,62 & 1,39 & $-6,50$ & 1,22 & $-1,98$ & 20,92 \\
\hline 11 & 81,7 & $-0,92$ & 1,37 & $-9,14$ & 5,42 & $-2,39$ & 0,30 & 7,98 & $-0,72$ & 0,75 & $-2,32$ & 31,30 \\
\hline 12 & 38,6 & 1,36 & 1,84 & $-6,40$ & 3,72 & $-0,83$ & $-3,39$ & 11,95 & $-1,92$ & $-1,14$ & $-5,12$ & 37,66 \\
\hline 13 & 85,0 & 0,96 & 4,31 & $-1,49$ & $-0,35$ & $-0,94$ & 2,58 & 1,69 & $-4,31$ & $-0,39$ & $-2,05$ & 19,06 \\
\hline 14 & 98,0 & $-0,89$ & 4,46 & 0,62 & 0,47 & $-3,34$ & 2,92 & $-1,03$ & $-2,34$ & $-0,09$ & $-0,75$ & 16,92 \\
\hline 15 & 80,0 & $-1,70$ & 2,20 & 0,77 & 1,94 & $-1,94$ & 1,49 & $-2,39$ & $-0,55$ & 0,83 & $-0,63$ & 14,44 \\
\hline 16 & 87,0 & 0,23 & 1,58 & $-4,11$ & 4,11 & $-3,95$ & 2,63 & 6,39 & $-5,95$ & 1,01 & $-1,92$ & 31,88 \\
\hline 17 & 80,0 & $-1,81$ & 1,93 & $-5,03$ & $-0,36$ & $-1,87$ & 0,18 & 12,36 & $-4,60$ & 1,08 & $-1,83$ & 31,05 \\
\hline 18 & 76,0 & 0,10 & 2,98 & $-5,57$ & 1,33 & $-2,84$ & 4,94 & 2,60 & $-2,71$ & 1,99 & $-2,63$ & 27,68 \\
\hline 19 & 104,0 & 0,11 & 2,27 & $-7,08$ & $-0,76$ & 1,47 & 3,43 & 0,89 & $-2,98$ & 2,71 & 0,11 & 21,80 \\
\hline 20 & 90,0 & $-3,66$ & 0,74 & $-5,47$ & 0,88 & 1,64 & 1,52 & 8,32 & 0,60 & $-0,36$ & $-3,84$ & 27,05 \\
\hline 21 & 62,0 & 0,69 & 4,57 & $-6,09$ & 2,79 & 1,48 & 1,87 & 1,68 & $-9,79$ & 1,43 & 1,35 & 31,73 \\
\hline 22 & 82,0 & $-1,66$ & 3,74 & $-1,91$ & 1,30 & $-3,10$ & 0,25 & 4,39 & $-4,20$ & 1,68 & $-0,52$ & 22,74 \\
\hline 23 & 79,0 & 0,86 & 2,66 & $-2,73$ & $-0,58$ & 1,98 & $-0,42$ & 2,04 & $-3,23$ & $-0,52$ & $-0,05$ & 15,08 \\
\hline 24 & 54,0 & $-3,10$ & 4,36 & $-1,66$ & 1,57 & 4,32 & $-0,32$ & $-1,72$ & $-2,05$ & $-0,59$ & $-0,81$ & 20,49 \\
\hline 25 & 78,0 & 1,58 & $-0,25$ & $-1,82$ & $-0,94$ & 0,40 & $-1,71$ & $-0,05$ & 0,93 & 1,33 & 0,53 & 9,55 \\
\hline 26 & 53,0 & 0,75 & $-1,60$ & 0,73 & 0,91 & 0,61 & 2,22 & 1,15 & $-4,90$ & 1,10 & $-1,02$ & 15,00 \\
\hline 27 & 52,0 & 1,53 & 1,85 & $-5,61$ & $-0,31$ & 2,81 & 4,23 & 2,33 & $-4,06$ & 1,24 & $-3,88$ & 27,86 \\
\hline 28 & 45,0 & $-0,91$ & $-1,76$ & $-0,53$ & $-4,12$ & 2,68 & 2,71 & 3,01 & 0,01 & 0,36 & $-1,26$ & 17,36 \\
\hline 29 & 40,0 & 0,21 & 2,33 & $-1,63$ & 0,35 & 4,59 & 5,51 & $-1,81$ & $-8,78$ & 2,00 & $-2,82$ & 30,03 \\
\hline 30 & 48,0 & 0,51 & 1,05 & $-5,94$ & $-2,79$ & 3,65 & 4,93 & 4,46 & $-0,73$ & 0,99 & $-5,77$ & 30,82 \\
\hline 31 & 44,0 & $-0,13$ & 5,17 & $-1,86$ & $-0,53$ & 4,00 & 5,11 & $-3,63$ & $-8,13$ & 1,61 & $-1,64$ & 31,82 \\
\hline 32 & 42,0 & $-0,11$ & 2,37 & $-3,96$ & 3,39 & 4,79 & 4,39 & $-3,29$ & $-6,92$ & 2,06 & $-2,73$ & 34,01 \\
\hline 33 & 60,0 & $-1,29$ & $-0,84$ & $-3,65$ & $-0,41$ & 2,72 & 4,44 & 4,45 & $-0,19$ & 1,16 & $-6,06$ & 25,21 \\
\hline 34 & 57,0 & 0,37 & 0,38 & 0,92 & $-3,33$ & $-0,72$ & 1,82 & 5,05 & $-1,18$ & $-0,40$ & $-2,88$ & 17,05 \\
\hline 35 & 38,0 & 1,54 & 2,10 & $-2,83$ & $-0,71$ & 1,45 & 4,93 & $-0,99$ & $-5,48$ & 1,01 & $-0,99$ & 22,03 \\
\hline
\end{tabular}


APÊNDICE 13. Produção de frutos ( $\mathrm{t} \mathrm{ha}^{-1}$ ) e índices DRIS obtidos pelo método Jones (1981) utilizando o critério de escolha da razão entre nutrientes "Valor F” em 70 pomares de macieira no Rio Grande do Sul e Santa Catarina. (Safra 2002)

\begin{tabular}{|c|c|c|c|c|c|c|c|c|c|c|c|c|}
\hline \multirow{2}{*}{ Amostra } & \multirow{2}{*}{$\frac{\text { Produção }}{\text { t ha }^{-1}}$} & \multicolumn{10}{|c|}{ Índices DRIS } & \multirow{2}{*}{ IBN } \\
\hline & & $\mathbf{N}$ & $\mathbf{P}$ & K & $\mathbf{C a}$ & Mg & $\mathbf{F e}$ & Mn & $\mathrm{Zn}$ & $\mathbf{C u}$ & B & \\
\hline 36 & 43,0 & $-1,65$ & $-2,24$ & 0,21 & $-1,68$ & $-2,56$ & 2,48 & 5,29 & 2,31 & 0,01 & $-1,87$ & 20,30 \\
\hline 37 & 28,0 & 0,63 & 0,77 & $-0,95$ & 0,82 & $-1,30$ & 5,72 & $-0,26$ & $-6,37$ & 0,65 & 0,27 & 17,74 \\
\hline 38 & 51,0 & $-1,72$ & 1,49 & 2,34 & $-2,69$ & $-4,32$ & 1,24 & 3,93 & 2,60 & 0,09 & $-2,88$ & 23,31 \\
\hline 39 & 52,0 & 1,18 & 1,16 & 0,92 & $-1,47$ & $-2,38$ & 3,43 & $-1,48$ & $-3,20$ & 2,90 & $-1,07$ & 19,20 \\
\hline 40 & 39,0 & $-2,29$ & 1,16 & 2,46 & $-4,70$ & $-4,22$ & 5,76 & 0,25 & 3,29 & 1,84 & $-3,10$ & 29,07 \\
\hline 41 & 34,0 & $-0,45$ & 3,25 & $-7,06$ & $-1,85$ & $-1,30$ & 9,37 & $-0,96$ & $-0,40$ & 2,76 & $-2,92$ & 30,31 \\
\hline 42 & 47,0 & $-0,71$ & 2,07 & $-4,67$ & $-1,27$ & 2,44 & 5,20 & 2,25 & $-5,27$ & 2,46 & $-2,42$ & 28,76 \\
\hline 43 & 41,0 & $-0,35$ & $-0,90$ & $-10,51$ & 2,10 & 2,86 & 6,46 & $-0,75$ & $-2,62$ & 4,37 & $-0,37$ & 31,27 \\
\hline 44 & 54,0 & $-6,30$ & $-1,25$ & $-7,45$ & 2,48 & $-3,24$ & $-2,87$ & 1,83 & 34,71 & $-4,37$ & $-10,60$ & 75,10 \\
\hline 45 & 63,0 & $-3,23$ & $-0,37$ & $-5,93$ & 3,40 & $-2,32$ & 1,91 & 1,21 & 19,15 & $-2,83$ & $-8,46$ & 48,80 \\
\hline 46 & 61,0 & $-5,52$ & $-1,86$ & $-5,62$ & $-4,04$ & $-8,18$ & $-1,89$ & 21,32 & 20,64 & $-2,93$ & $-10,16$ & 82,15 \\
\hline 47 & 82,0 & $-7,36$ & $-3,81$ & $-3,05$ & $-3,51$ & $-10,01$ & $-0,76$ & 19,91 & 23,21 & $-1,57$ & $-11,39$ & 84,57 \\
\hline 48 & 60,0 & $-8,75$ & $-5,63$ & $-7,24$ & 2,75 & $-5,71$ & $-8,31$ & 17,96 & 29,58 & $-3,66$ & $-10,33$ & 99,92 \\
\hline 49 & 54,0 & $-3,41$ & $-0,47$ & $-3,68$ & 4,49 & $-3,17$ & $-2,42$ & 3,03 & 18,61 & $-4,52$ & $-7,42$ & 51,23 \\
\hline 50 & 41,0 & $-8,85$ & $-3,01$ & $-9,24$ & 1,09 & $-6,40$ & $-6,01$ & 21,84 & 32,75 & $-6,03$ & $-13,97$ & 109,18 \\
\hline 51 & 55,0 & $-6,65$ & $-0,32$ & $-6,37$ & 0,70 & $-5,62$ & $-6,48$ & 15,68 & 28,20 & $-5,61$ & $-12,55$ & 88,17 \\
\hline 52 & 53,0 & $-5,84$ & $-0,45$ & $-11,17$ & 1,33 & $-3,92$ & 16,91 & 2,03 & 20,94 & $-0,63$ & $-14,72$ & 77,95 \\
\hline 53 & 46,8 & $-0,74$ & $-1,09$ & 1,16 & 0,83 & $-0,87$ & 3,08 & $-6,27$ & 12,47 & $-2,60$ & $-4,93$ & 34,04 \\
\hline 54 & 75,8 & $-5,99$ & $-3,78$ & $-6,29$ & 0,83 & $-7,22$ & $-3,01$ & $-5,97$ & 51,58 & $-7,52$ & $-8,94$ & 101,11 \\
\hline 55 & 97,5 & 1,47 & 1,38 & 2,29 & 2,93 & $-3,88$ & 4,05 & $-6,66$ & $-3,81$ & 0,90 & 1,30 & 28,68 \\
\hline 56 & 38,1 & $-3,75$ & 1,43 & 2,26 & 1,04 & $-4,11$ & 0,97 & $-7,09$ & 11,52 & $-0,90$ & $-0,99$ & 34,06 \\
\hline 57 & 15,9 & $-10,73$ & 0,24 & $-7,59$ & 0,90 & $-6,65$ & $-6,61$ & $-6,50$ & 58,95 & $-8,81$ & $-10,69$ & 117,68 \\
\hline 58 & 15,9 & $-9,22$ & $-2,28$ & $-6,07$ & 1,60 & $-3,96$ & $-1,52$ & $-6,45$ & 47,31 & $-6,98$ & $-8,41$ & 93,81 \\
\hline 59 & 46,9 & $-0,94$ & $-1,14$ & 1,30 & 0,74 & $-7,16$ & 2,61 & $-7,09$ & 15,05 & $-1,56$ & $-0,61$ & 38,20 \\
\hline 60 & 15,9 & $-5,00$ & $-1,63$ & $-6,30$ & 0,12 & $-2,61$ & $-1,75$ & $-7,79$ & 40,26 & $-4,11$ & $-7,62$ & 77,20 \\
\hline 61 & 46,9 & $-0,73$ & $-0,81$ & $-7,52$ & 2,37 & $-3,57$ & 5,25 & $-5,19$ & 17,07 & $-0,46$ & $-3,12$ & 46,09 \\
\hline 62 & 46,9 & $-1,13$ & 0,80 & $-0,39$ & $-6,64$ & $-4,96$ & 0,61 & 8,35 & 5,16 & 2,78 & $-4,21$ & 35,03 \\
\hline 63 & 37,4 & 0,23 & $-2,40$ & 1,54 & $-4,89$ & $-4,22$ & 0,99 & 7,24 & 3,40 & 0,27 & $-2,01$ & 27,20 \\
\hline 64 & 50,1 & $-3,36$ & $-1,73$ & $-1,02$ & $-1,66$ & $-2,59$ & 6,04 & 6,11 & 4,85 & 1,64 & $-7,49$ & 36,50 \\
\hline 65 & 46,8 & 0,44 & $-0,49$ & 2,13 & $-5,59$ & $-5,75$ & 0,48 & 2,28 & 3,86 & 2,33 & 0,36 & 23,72 \\
\hline 66 & 43,0 & 1,38 & 2,80 & 3,36 & $-3,93$ & $-3,85$ & 2,34 & $-4,73$ & $-0,40$ & 2,46 & 0,54 & 25,79 \\
\hline 67 & 43,0 & $-2,43$ & $-0,74$ & 0,44 & $-4,58$ & $-4,51$ & $-1,32$ & 8,88 & 6,38 & 0,40 & $-2,40$ & 32,10 \\
\hline 68 & 36,8 & 0,33 & $-6,23$ & 2,11 & $-3,08$ & $-3,22$ & $-1,91$ & 7,90 & 4,61 & 0,48 & $-1,18$ & 31,03 \\
\hline 69 & 70,1 & 1,42 & $-1,01$ & $-0,08$ & $-3,52$ & $-4,40$ & $-0,27$ & 5,01 & 4,66 & $-1,03$ & $-0,57$ & 21,95 \\
\hline 70 & 78,3 & 1,46 & $-2,20$ & $-1,23$ & $-4,48$ & $-5,37$ & 3,70 & 4,08 & 5,56 & 1,18 & $-1,89$ & 31,14 \\
\hline
\end{tabular}


APÊNDICE 14. Produção de frutos $\left(\mathrm{t} \mathrm{ha}^{-1}\right)$ e índices DRIS obtidos pelo método Jones (1981) utilizando o critério de escolha da razão entre nutrientes "Valor F” em 70 pomares de macieira no Rio Grande do Sul e Santa Catarina. (Safra 2003)

\begin{tabular}{|c|c|c|c|c|c|c|c|c|c|c|c|c|}
\hline \multirow{2}{*}{ Amostra } & \multirow{2}{*}{$\begin{array}{c}\text { Produção } \\
\text { t ha }^{-1}\end{array}$} & \multicolumn{10}{|c|}{ Índices DRIS } & \multirow{2}{*}{ IBN } \\
\hline & & $\mathbf{N}$ & $\mathbf{P}$ & $\mathbf{K}$ & $\mathrm{Ca}$ & Mg & $\mathbf{F e}$ & Mn & Zn & $\mathrm{Cu}$ & $\mathbf{B}$ & \\
\hline 1 & 44,5 & $-1,42$ & 0,29 & 3,32 & $-1,41$ & $-0,80$ & $-7,67$ & 8,99 & 5,35 & $-8,27$ & 0,45 & 37,98 \\
\hline 2 & 43,2 & $-0,27$ & 1,78 & 0,98 & $-2,39$ & 0,01 & $-6,50$ & 6,97 & 04 & ,92 & $-0,42$ & 30,29 \\
\hline 3 & 40,2 & $-1,84$ & 1,00 & $-2,71$ & 6,70 & 4,37 & $-4,10$ & $-3,08$ & $-2,33$ & $-2,70$ & 4,55 & 33,38 \\
\hline 4 & 33,8 & $-0,79$ & 1,22 & $-10,75$ & 9,95 & 10,29 & $-5,60$ & $-2,67$ & $-2,20$ & $-3,53$ & 4,09 & 51,07 \\
\hline 5 & 40,6 & 0,71 & 6,93 & 3,68 & 4,21 & $-0,85$ & $-5,41$ & $-3,06$ & $-2,21$ & $-5,40$ & 1,01 & 33,47 \\
\hline 6 & 40,7 & $-2,23$ & 6,61 & 6,01 & 4,71 & $-2,36$ & $-7,05$ & 2,97 & 2,32 & $-6,35$ & $-5,66$ & 46,26 \\
\hline 7 & 19,5 & $-1,63$ & $-1,88$ & 3,02 & $-4,29$ & 2,16 & $-5,38$ & 5,42 & 1,44 & 0,17 & 0,39 & 25,77 \\
\hline 8 & 28,3 & 1,74 & $-1,59$ & 0,05 & $-2,80$ & 1,45 & $-4,24$ & 4,00 & 1,56 & $-1,06$ & 0,61 & 19,10 \\
\hline 9 & 28,0 & $-3,06$ & $-3,90$ & 0,67 & $-1,50$ & 2,66 & $-5,23$ & 10,20 & 3,88 & $-4,07$ & $-0,08$ & 35,24 \\
\hline 10 & 33,6 & 0,80 & $-1,19$ & 6,03 & $-4,74$ & 0,33 & $-8,78$ & 5,00 & 0,54 & $-0,19$ & 1,10 & 28,70 \\
\hline 11 & 52,2 & $-1,15$ & $-1,53$ & $-8,81$ & $-0,21$ & 1,70 & $-6,61$ & 12,70 & 3,60 & $-0,32$ & 0,80 & 37,42 \\
\hline 12 & 58,7 & $-3,87$ & $-6,41$ & $-6,11$ & $-0,90$ & 1,49 & $-0,08$ & 16,27 & 3,11 & $-2,83$ & $-0,12$ & 41,19 \\
\hline 13 & 18,0 & $-4,25$ & $-1,54$ & 4,07 & $-3,02$ & $-2,56$ & 0,12 & 2,99 & 0,63 & $-0,67$ & 4,06 & 23,92 \\
\hline 14 & 15,0 & $-2,45$ & 0,62 & 3,70 & $-0,98$ & $-3,41$ & $-0,27$ & 0,82 & 0,15 & $-2,76$ & 4,41 & 19,56 \\
\hline 15 & 22,0 & $-4,41$ & $-1,96$ & 4,81 & $-0,85$ & $-1,27$ & $-4,54$ & 3,77 & 0,56 & $-1,49$ & 4,76 & 28,41 \\
\hline 16 & 30,0 & $-4,80$ & $-3,30$ & $-0,67$ & 0,55 & $-4,04$ & $-1,42$ & 12,94 & $-1,24$ & $-2,92$ & 4,85 & 36,73 \\
\hline 17 & 35,0 & $-3,40$ & $-2,52$ & 2,64 & $-1,26$ & $-0,05$ & $-1,21$ & 2,69 & 0,52 & $-2,62$ & 5,02 & 21,93 \\
\hline 18 & 25,0 & $-5,89$ & $-4,18$ & 1,74 & $-1,09$ & $-3,21$ & 2,41 & 9,12 & 2,44 & $-4,00$ & 2,88 & 36,96 \\
\hline 19 & 12,0 & $-1,98$ & $-1,10$ & 2,36 & $-1,76$ & $-1,38$ & 3,57 & 0,52 & 0,69 & $-5,13$ & 4,34 & 22,84 \\
\hline 20 & & $-2,91$ & $-2,23$ & 2,17 & $-1,36$ & & $-6,03$ & 7,79 & 3,82 & $-9,10$ & 3,75 & 42,53 \\
\hline 21 & 75,0 & $-3,25$ & 0,41 & $-0,76$ & $-1,67$ & $-1,09$ & 0,82 & 5,27 & $-0,39$ & $-3,22$ & 3,97 & 20,86 \\
\hline 22 & 30,0 & $-4,07$ & $-0,16$ & 2,08 & $-0,74$ & $-1,65$ & $-1,09$ & 4,31 & $-0,08$ & $-3,08$ & 4,33 & 21,58 \\
\hline 23 & 18,0 & $-2,55$ & $-1,56$ & 3,60 & $-4,27$ & 3,16 & $-2,87$ & 3,75 & 2,02 & $-4,92$ & 3,21 & 31,91 \\
\hline 24 & 70,0 & $-3,69$ & $-0,50$ & 0,30 & $-0,97$ & 6,75 & $-5,52$ & 3,17 & 2,04 & $-3,77$ & 1,75 & 28,48 \\
\hline 25 & 22,0 & $-0,43$ & $-3,17$ & 4,37 & $-3,61$ & 1,08 & $-6,46$ & 5,53 & 2,78 & $-4,40$ & 3,31 & 35,14 \\
\hline 26 & 18,0 & $-1,20$ & $-5,22$ & 4,64 & $-2,22$ & 1,89 & $-4,45$ & 5,54 & 0,83 & $-3,26$ & 2,85 & 32,10 \\
\hline 27 & 25,0 & $-4,48$ & $-5,45$ & 2,75 & 0,13 & 4,46 & $-5,76$ & 8,93 & 1,60 & $-5,22$ & 2,45 & 41,23 \\
\hline 28 & 52,0 & $-5,34$ & $-4,97$ & 0,01 & $-3,57$ & 2,75 & 2,83 & 9,03 & 4,31 & $-3,89$ & $-0,68$ & 37,38 \\
\hline 29 & 40,0 & 0,75 & $-2,79$ & $-2,84$ & 0,27 & 5,50 & $-0,03$ & 1,31 & $-1,30$ & $-3,49$ & 2,68 & 20,95 \\
\hline 30 & 57,0 & $-3,84$ & $-5,75$ & $-0,86$ & $-2,46$ & 4,34 & 2,43 & 9,35 & 7,72 & $-9,02$ & $-1,14$ & 46,91 \\
\hline 31 & 46,0 & 0,46 & $-1,94$ & $-3,13$ & $-0,08$ & 5,75 & 3,03 & $-1,54$ & $-0,83$ & $-5,22$ & 3,68 & 25,66 \\
\hline 32 & 49,0 & 2,35 & $-2,03$ & $-0,81$ & $-0,88$ & 2,89 & 2,35 & $-2,54$ & $-0,93$ & $-1,31$ & 1,02 & 17,10 \\
\hline 33 & 63,0 & $-3,54$ & $-5,08$ & $-0,14$ & $-1,88$ & 2,99 & $-2,01$ & 10,31 & 5,51 & $-4,04$ & $-2,05$ & 37,54 \\
\hline 34 & 40,0 & $-1,37$ & $-3,33$ & 2,01 & $-4,87$ & $-1,74$ & $-1,00$ & 8,94 & 4,83 & $-3,18$ & $-0,33$ & 31,62 \\
\hline 35 & 33,0 & 1,77 & $-2,81$ & 1,86 & $-3,43$ & 1,02 & 0,56 & 2,33 & $-1,24$ & $-2,70$ & 2,59 & 20,31 \\
\hline
\end{tabular}


APÊNDICE 14. Produção de frutos $\left(\mathrm{t} \mathrm{ha}^{-1}\right)$ e índices DRIS obtidos pelo método Jones (1981) utilizando o critério de escolha da razão entre nutrientes "Valor F” em 70 pomares de macieira no Rio Grande do Sul e Santa Catarina. (Safra 2003)

\begin{tabular}{|c|c|c|c|c|c|c|c|c|c|c|c|c|}
\hline \multirow{2}{*}{ Amostra } & \multirow{2}{*}{$\frac{\text { Produção }}{\text { t ha }^{-1}}$} & \multicolumn{10}{|c|}{ Índices DRIS } & \multirow{2}{*}{ IBN } \\
\hline & & $\mathbf{N}$ & $\mathbf{P}$ & $\mathbf{K}$ & $\mathbf{C a}$ & Mg & Fe & Mn & Zn & $\mathbf{C u}$ & B & \\
\hline 36 & 32,0 & $-3,87$ & $-4,29$ & $-2,47$ & $-3,24$ & $-2,76$ & 2,99 & 11,67 & 7,91 & $-4,60$ & $-0,29$ & 44,08 \\
\hline 37 & 45,0 & 1,99 & $-1,19$ & 0,83 & $-1,31$ & $-1,88$ & 1,12 & 0,40 & $-0,84$ & $-3,30$ & 4,18 & 17,05 \\
\hline 38 & 55,0 & $-3,51$ & $-4,79$ & 1,61 & $-0,94$ & $-2,80$ & $-2,29$ & 12,09 & 7,56 & $-6,37$ & $-0,70$ & 42,66 \\
\hline 39 & 60,0 & 2,02 & 0,07 & 2,23 & $-1,26$ & $-0,24$ & 0,67 & $-1,51$ & $-0,78$ & $-3,25$ & 2,00 & 14,03 \\
\hline 40 & 25,0 & $-1,18$ & $-1,39$ & 4,24 & $-3,90$ & $-0,08$ & $-3,63$ & $-4,04$ & 11,83 & $-4,22$ & 1,03 & 35,52 \\
\hline 41 & 29,0 & 0,21 & $-0,28$ & $-4,89$ & $-0,66$ & 4,78 & $-4,43$ & $-6,03$ & 17,68 & $-4,89$ & $-0,90$ & 44,74 \\
\hline 42 & 34,0 & 0,47 & $-1,30$ & $-3,35$ & 1,46 & 7,78 & $-4,00$ & $-1,58$ & 15,09 & $-12,06$ & $-2,18$ & 49,28 \\
\hline 43 & 31,0 & 0,28 & $-0,10$ & $-5,89$ & $-2,03$ & 6,35 & $-2,80$ & $-2,87$ & 15,46 & $-7,35$ & 0,06 & 43,20 \\
\hline 44 & 25,0 & $-10,21$ & $-5,19$ & $-1,68$ & 1,13 & 1,33 & $-16,10$ & $-4,49$ & 32,01 & 2,87 & $-5,57$ & 80,56 \\
\hline 45 & 41,0 & $-1,64$ & $-6,06$ & $-0,63$ & 1,75 & 1,17 & $-11,54$ & $-4,93$ & 13,98 & 7,53 & $-2,42$ & 51,65 \\
\hline 46 & 31,0 & $-9,96$ & $-4,36$ & $-0,82$ & $-0,75$ & $-2,01$ & $-14,13$ & 0,31 & 31,37 & $-1,44$ & $-3,36$ & 68,51 \\
\hline 47 & 29,0 & $-8,50$ & $-9,48$ & 2,25 & $-1,35$ & $-2,47$ & $-15,10$ & $-0,07$ & 21,94 & 8,32 & $-1,96$ & 71,43 \\
\hline 48 & 19,0 & $-10,00$ & $-5,46$ & 0,08 & 0,38 & $-0,78$ & $-15,42$ & $-3,82$ & 26,73 & 4,73 & $-2,56$ & 69,97 \\
\hline 49 & 36,0 & $-3,36$ & $-6,58$ & 0,87 & 0,37 & $-1,87$ & $-10,88$ & $-3,89$ & 12,65 & 10,88 & $-1,12$ & 52,46 \\
\hline 50 & 19,0 & $-6,40$ & $-5,64$ & $-0,31$ & $-1,53$ & $-0,80$ & $-14,25$ & $-4,50$ & 26,29 & 5,97 & $-4,14$ & 69,84 \\
\hline 51 & 21,0 & $-7,84$ & $-5,07$ & $-0,74$ & $-2,79$ & 0,91 & $-15,25$ & $-4,47$ & 27,89 & 5,06 & $-3,47$ & 73,49 \\
\hline 52 & 38,0 & $-3,91$ & $-5,62$ & 1,80 & $-1,93$ & $-0,58$ & $-7,66$ & $-5,68$ & 11,28 & 10,54 & $-0,26$ & 49,26 \\
\hline 53 & 28,8 & $-0,89$ & $-3,82$ & 4,32 & 2,44 & $-6,63$ & $-6,13$ & $-5,33$ & 14,40 & $-4,61$ & 3,54 & 52,10 \\
\hline 54 & 21,1 & $-2,09$ & $-3,25$ & 3,73 & $-2,48$ & $-5,08$ & $-5,30$ & $-5,17$ & 21,71 & $-6,36$ & 1,79 & 56,96 \\
\hline 55 & 28,8 & $-0,28$ & $-3,57$ & 3,57 & 0,96 & $-4,92$ & $-2,53$ & $-5,48$ & 13,60 & $-5,14$ & 2,84 & 42,87 \\
\hline 56 & 21,1 & $-4,96$ & $-0,90$ & 2,51 & $-1,12$ & $-4,92$ & $-5,23$ & $-6,04$ & 26,92 & $-8,11$ & $-0,16$ & 60,87 \\
\hline 57 & 21,1 & $-5,41$ & $-4,19$ & 3,28 & 0,11 & $-5,07$ & $-4,42$ & $-6,37$ & 26,70 & $-8,01$ & 1,39 & 64,95 \\
\hline 58 & 21,1 & $-6,76$ & 1,50 & 0,87 & $-1,29$ & $-4,36$ & $-9,25$ & $-5,41$ & 29,07 & $-8,91$ & 1,04 & 68,46 \\
\hline 59 & 28,8 & $-3,36$ & $-3,44$ & 3,99 & 1,18 & $-7,03$ & $-3,27$ & $-5,75$ & 21,66 & $-8,95$ & 3,34 & 61,99 \\
\hline 60 & 21,1 & $-4,51$ & $-4,19$ & 1,88 & 0,09 & $-2,66$ & $-4,51$ & $-7,21$ & 20,04 & $-3,12$ & 2,79 & 51,01 \\
\hline 61 & 28,8 & $-1,07$ & $-6,00$ & 1,48 & 1,20 & $-4,10$ & $-3,38$ & $-4,10$ & 14,47 & $-4,94$ & 5,60 & 46,35 \\
\hline 62 & 53,3 & $-1,96$ & $-5,12$ & 3,87 & $-6,17$ & $-5,06$ & $-5,38$ & 11,86 & 6,61 & $-2,20$ & 2,41 & 50,64 \\
\hline 63 & 46,6 & 1,07 & $-4,31$ & 4,79 & $-5,79$ & $-4,71$ & $-5,05$ & 7,86 & 5,52 & $-3,57$ & 3,02 & 45,69 \\
\hline 64 & 41,7 & $-4,03$ & $-5,91$ & 0,88 & $-5,84$ & $-1,89$ & $-10,28$ & 17,15 & 12,15 & $-4,70$ & 0,50 & 63,33 \\
\hline 65 & 38,1 & 0,97 & $-5,84$ & 3,41 & $-5,07$ & $-4,11$ & 3,65 & 3,00 & 1,11 & $-1,56$ & 4,56 & 33,28 \\
\hline 66 & 37,1 & 1,50 & $-3,76$ & 4,26 & $-3,82$ & $-4,63$ & 1,65 & $-0,03$ & 0,99 & $-1,37$ & 5,13 & 27,14 \\
\hline 67 & 45,6 & $-3,74$ & $-5,07$ & 1,40 & $-6,64$ & $-9,22$ & $-7,55$ & 23,15 & 10,62 & $-3,47$ & $-0,68$ & 71,55 \\
\hline 68 & 46,6 & $-3,10$ & $-4,22$ & 2,01 & $-8,40$ & $-9,04$ & $-5,90$ & 20,29 & 10,52 & $-3,32$ & 0,16 & 66,97 \\
\hline 69 & 17,1 & $-1,25$ & $-4,90$ & 2,26 & $-3,15$ & $-3,50$ & 1,54 & 0,97 & 6,39 & $-3,53$ & 5,46 & 32,95 \\
\hline 70 & 21,6 & $-0,06$ & $-5,20$ & 2,25 & $-3,88$ & $-4,21$ & $-1,06$ & 3,36 & 7,00 & $-3,68$ & 5,31 & 36,01 \\
\hline
\end{tabular}


APÊNDICE 15. Produção de frutos ( $\mathrm{t} \mathrm{ha}^{-1}$ ) e índices DRIS obtidos pelo método Elwali \& Gascho (1984) utilizando o critério de escolha da razão entre nutrientes "Valor R” em 70 pomares de macieira no Rio Grande do Sul e Santa Catarina. (Safra 2002)

\begin{tabular}{|c|c|c|c|c|c|c|c|c|c|c|c|c|}
\hline \multirow{2}{*}{ Amostra } & \multirow{2}{*}{$\begin{array}{c}\text { Produção } \\
\text { t ha }^{-1}\end{array}$} & \multicolumn{10}{|c|}{ Índices DRIS } & \multirow{2}{*}{ IBN } \\
\hline & & $\mathbf{N}$ & $\mathbf{P}$ & $\mathbf{K}$ & $\mathbf{C a}$ & $\mathrm{Mg}$ & $\mathbf{F e}$ & Mn & $\mathbf{Z n}$ & $\mathbf{C u}$ & B & \\
\hline 1 & 33,0 & $-5,72$ & 6,87 & $-0,76$ & $-3,41$ & 3,22 & 0,83 & 1,14 & 0,00 & 0,90 & $-3,08$ & 25,92 \\
\hline 2 & 35,0 & $-4,67$ & 4,90 & $-2,99$ & $-4,17$ & $-1,79$ & 13,04 & $-0,83$ & 0,00 & 0,00 & $-3,50$ & 35,89 \\
\hline 3 & 35,0 & $-8,03$ & $-2,41$ & $-7,69$ & $-4,69$ & $-5,53$ & 61,67 & $-22,10$ & $-4,43$ & $-1,77$ & $-5,03$ & 123,35 \\
\hline 4 & 33,0 & $-5,65$ & $-2,91$ & $-4,29$ & $-3,63$ & $-3,32$ & 27,15 & $-3,78$ & 3,83 & $-2,48$ & $-4,92$ & 61,96 \\
\hline 5 & 39,0 & $-1,14$ & 11,95 & 7,59 & 1,13 & 1,51 & $-11,36$ & 0,00 & 0,00 & $-7,11$ & $-2,57$ & 44,35 \\
\hline 6 & 68,0 & 3,90 & 4,68 & 5,99 & 5,13 & 2,76 & $-16,44$ & $-8,41$ & $-1,86$ & 1,05 & 3,19 & 53,41 \\
\hline 7 & 18,1 & $-0,28$ & 1,02 & $-5,57$ & $-1,34$ & 6,69 & 0,00 & 5,27 & 0,59 & $-0,99$ & $-5,39$ & 27,14 \\
\hline 8 & 11,4 & $-3,15$ & $-3,49$ & $-5,28$ & $-3,21$ & $-2,86$ & 8,16 & 12,49 & 0,96 & $-0,52$ & $-3,10$ & 43,23 \\
\hline 9 & 24,3 & $-4,14$ & $-2,45$ & $-5,05$ & $-1,37$ & 3,11 & 8,61 & 3,44 & 0,00 & 1,68 & $-3,82$ & 33,67 \\
\hline 10 & 29,9 & $-0,94$ & $-0,88$ & 8,13 & $-0,61$ & 0,00 & 0,00 & 0,93 & $-5,18$ & 0,00 & $-1,46$ & 18,13 \\
\hline 11 & 81,7 & $-0,88$ & 0,67 & $-8,45$ & 5,73 & $-2,48$ & 0,00 & 6,58 & 0,00 & 0,06 & $-1,23$ & 26,07 \\
\hline 12 & 38,6 & 1,09 & 1,96 & $-5,73$ & 2,63 & $-1,91$ & $-2,53$ & 12,24 & $-0,77$ & $-1,65$ & $-5,32$ & 35,82 \\
\hline 13 & 85,0 & $-0,78$ & 3,31 & $-0,67$ & $-0,93$ & 0,00 & 0,00 & 0,00 & 0,00 & 0,00 & $-0,94$ & 6,63 \\
\hline 14 & 98,0 & $-1,30$ & 4,41 & 0,00 & $-0,86$ & $-2,08$ & 0,68 & 0,00 & 0,00 & 0,00 & $-0,85$ & 10,18 \\
\hline 15 & 80,0 & $-1,63$ & 0,88 & 0,00 & 0,76 & 0,00 & 0,00 & 0,00 & 0,00 & 0,00 & 0,00 & 3,27 \\
\hline 16 & 87,0 & $-0,51$ & 1,53 & $-3,53$ & 3,77 & $-4,19$ & 0,64 & 5,42 & $-1,47$ & 0,00 & $-1,66$ & 22,72 \\
\hline 17 & 80,0 & $-2,35$ & 1,54 & $-2,77$ & 0,00 & $-2,10$ & $-1,56$ & 11,64 & $-1,65$ & $-1,22$ & $-1,55$ & 26,37 \\
\hline 18 & 76,0 & $-0,49$ & 3,35 & $-5,55$ & 0,97 & $-1,92$ & 2,93 & 0,69 & 0,00 & 0,83 & $-0,81$ & 17,53 \\
\hline 19 & 104,0 & 1,17 & 1,06 & $-6,72$ & 0,00 & 1,17 & 0,91 & 0,00 & 0,00 & 1,17 & 1,23 & 13,43 \\
\hline 20 & 90,0 & $-4,05$ & 1,62 & $-4,32$ & 1,76 & 2,83 & 0,00 & 5,63 & 0,00 & $-1,15$ & $-2,31$ & 23,66 \\
\hline 21 & 62,0 & 5,35 & 5,87 & $-3,09$ & 5,67 & 4,02 & 4,37 & 1,56 & $-34,48$ & 5,38 & 5,35 & 75,13 \\
\hline 22 & 82,0 & $-1,72$ & 2,84 & $-1,24$ & 0,00 & $-1,06$ & 0,00 & 1,92 & $-0,74$ & 0,00 & 0,00 & 9,52 \\
\hline 23 & 79,0 & 0,00 & 0,64 & $-0,64$ & 0,00 & 0,00 & 0,00 & 0,00 & 0,00 & 0,00 & 0,00 & 1,29 \\
\hline 24 & 54,0 & $-3,80$ & 3,26 & $-0,76$ & 0,89 & 2,14 & 0,00 & 0,00 & 0,00 & 0,00 & $-1,75$ & 12,60 \\
\hline 25 & 78,0 & 0,00 & 0,00 & 0,00 & 0,00 & 0,00 & 0,00 & 0,00 & 0,00 & 0,00 & 0,00 & 0,00 \\
\hline 26 & 53,0 & 0,00 & 0,00 & 1,92 & 0,00 & 0,00 & 0,00 & 0,57 & $-2,49$ & 0,00 & 0,00 & 4,98 \\
\hline 27 & 52,0 & 2,14 & 0,83 & $-5,48$ & 0,00 & 2,18 & 0,98 & 0,64 & 0,00 & 0,70 & $-1,99$ & 14,94 \\
\hline 28 & 45,0 & 0,00 & $-0,60$ & 0,00 & $-1,12$ & 1,72 & 0,00 & 0,00 & 0,00 & 0,00 & 0,00 & 3,44 \\
\hline 29 & 40,0 & 3,03 & 3,27 & 2,45 & 3,92 & 5,73 & 13,07 & $-0,68$ & $-36,46$ & 4,77 & 0,89 & 74,27 \\
\hline 30 & 48,0 & 0,75 & 1,01 & $-5,92$ & $-1,00$ & 3,66 & 3,95 & 2,60 & 0,00 & 0,64 & $-5,69$ & 25,23 \\
\hline 31 & 44,0 & 1,91 & 8,89 & 1,57 & 2,43 & 5,19 & 10,52 & $-3,61$ & $-29,34$ & 0,00 & 2,42 & 65,89 \\
\hline 32 & 42,0 & 1,57 & 0,67 & $-2,34$ & 5,42 & 7,54 & 7,57 & $-2,16$ & $-19,39$ & 0,68 & 0,44 & 47,78 \\
\hline 33 & 60,0 & $-1,44$ & $-0,71$ & $-1,73$ & 0,81 & 2,05 & 3,75 & 2,60 & 0,00 & 0,00 & $-5,32$ & 18,41 \\
\hline 34 & 57,0 & $-0,66$ & 0,71 & 0,00 & $-0,71$ & 0,00 & 0,00 & 2,22 & 0,00 & $-0,71$ & $-0,86$ & 5,85 \\
\hline 35 & 38,0 & 1,87 & $-0,62$ & $-0,94$ & 0,00 & $-0,59$ & 7,93 & $-0,84$ & $-6,81$ & 0,00 & 0,00 & 19,60 \\
\hline
\end{tabular}


APÊNDICE 15. Produção de frutos $\left(\mathrm{t} \mathrm{ha}^{-1}\right)$ e índices DRIS obtidos pelo método Elwali \& Gascho (1984) utilizando o critério de escolha da razão entre nutrientes "Valor R" em 70 pomares de macieira no Rio Grande do Sul e Santa Catarina. (Safra 2002)

\begin{tabular}{|c|c|c|c|c|c|c|c|c|c|c|c|c|}
\hline \multirow{2}{*}{ Amostra } & \multirow{2}{*}{$\frac{\text { Produção }}{\text { t ha }^{-1}}$} & \multicolumn{10}{|c|}{ Índices DRIS } & \multirow{2}{*}{ IBN } \\
\hline & & $\mathbf{N}$ & $\bar{P}$ & $\mathbf{K}$ & $\mathbf{C a}$ & Mg & Fe & Mn & $\mathbf{Z n}$ & $\mathbf{C u}$ & B & \\
\hline 36 & 43,0 & $-0,88$ & 0,00 & $-0,60$ & 0,00 & 0,00 & 0,00 & 2,99 & 0,00 & $-0,68$ & $-0,82$ & 5,98 \\
\hline 37 & 28,0 & 1,85 & $-1,13$ & 1,56 & 0,00 & $-1,32$ & 11,59 & $-0,30$ & $-15,02$ & 0,00 & 2,77 & 35,53 \\
\hline 38 & 51,0 & $-1,39$ & 2,54 & 0,78 & $-0,86$ & $-0,97$ & 0,00 & 1,40 & 0,00 & 0,00 & $-1,50$ & 9,43 \\
\hline 39 & 52,0 & 0,00 & 0,00 & 0,00 & 0,00 & $-0,70$ & 1,28 & $-0,57$ & 0,00 & 0,00 & 0,00 & 2,55 \\
\hline 40 & 39,0 & $-3,90$ & 1,88 & 2,29 & $-5,08$ & $-4,29$ & 10,27 & $-2,80$ & 2,61 & 1,67 & $-2,66$ & 37,44 \\
\hline 41 & 34,0 & $-2,31$ & 1,35 & $-5,66$ & $-3,48$ & $-2,27$ & 15,74 & $-1,75$ & 0,00 & 1,01 & $-2,63$ & 36,20 \\
\hline 42 & 47,0 & $-0,90$ & 0,02 & $-2,68$ & 0,00 & 0,00 & 6,57 & 0,78 & $-4,62$ & 0,83 & 0,00 & 16,40 \\
\hline 43 & 41,0 & $-0,63$ & $-0,26$ & $-11,13$ & 1,54 & 1,04 & 5,92 & $-0,91$ & 0,00 & 2,82 & 1,62 & 25,88 \\
\hline 44 & 54,0 & $-6,51$ & $-5,87$ & $-7,20$ & $-1,01$ & $-6,76$ & $-4,25$ & $-13,94$ & 58,35 & $-4,33$ & $-8,49$ & 116,70 \\
\hline 45 & 63,0 & $-2,78$ & $-2,92$ & $-4,48$ & 1,69 & $-3,92$ & $-0,22$ & $-7,44$ & 28,25 & $-2,16$ & $-6,00$ & 59,86 \\
\hline 46 & 61,0 & $-5,75$ & $-5,30$ & $-6,63$ & $-6,80$ & $-11,88$ & $-4,02$ & 25,32 & 28,54 & $-5,49$ & $-7,99$ & 107,72 \\
\hline 47 & 82,0 & $-6,45$ & $-7,23$ & $-4,04$ & $-6,30$ & $-18,41$ & $-2,29$ & 22,24 & 36,02 & $-3,68$ & $-9,86$ & 116,51 \\
\hline 48 & 60,0 & $-9,13$ & $-10,21$ & $-8,16$ & $-1,00$ & $-10,35$ & $-8,70$ & 19,37 & 44,08 & $-5,93$ & $-9,99$ & 126,91 \\
\hline 49 & 54,0 & $-3,14$ & $-3,11$ & $-3,49$ & 2,45 & $-3,87$ & $-2,45$ & $-4,82$ & 28,20 & $-3,23$ & $-6,54$ & 61,30 \\
\hline 50 & 41,0 & $-8,87$ & $-8,82$ & $-9,59$ & $-3,09$ & $-11,27$ & $-7,76$ & 25,19 & 45,04 & $-7,96$ & $-12,87$ & 140,46 \\
\hline 51 & 55,0 & $-6,08$ & $-4,29$ & $-7,37$ & $-3,65$ & $-10,16$ & $-7,24$ & 17,10 & 40,27 & $-6,55$ & $-12,03$ & 114,73 \\
\hline 52 & 53,0 & $-11,24$ & $-8,18$ & $-9,76$ & $-4,35$ & $-10,96$ & 42,84 & $-8,50$ & 29,37 & $-5,60$ & $-13,62$ & 144,42 \\
\hline 53 & 4 & $-0,19$ & $-1,44$ & 1,93 & $-0,13$ & $-1,14$ & 4,79 & $-43,31$ & 41,27 & $-0,11$ & $-1,67$ & 95,97 \\
\hline 54 & 75,8 & $-3,01$ & $-16,05$ & $-4,12$ & $-4,98$ & $-34,94$ & $-0,10$ & $-126,59$ & 200,90 & $-5,01$ & $-6,11$ & 401,81 \\
\hline 55 & 97,5 & 3,90 & 2,93 & 5,52 & 3,18 & $-4,17$ & 5,48 & $-22,01$ & $-0,85$ & 2,44 & 3,58 & 54,05 \\
\hline 56 & 38,1 & $-1,09$ & 2,46 & 4,05 & 1,39 & $-5,55$ & 2,84 & $-53,95$ & 47,31 & 1,00 & 1,55 & 121,19 \\
\hline 57 & 15,9 & $-7,46$ & $-7,37$ & $-6,44$ & $-6,34$ & $-32,35$ & $-4,74$ & $-157,47$ & 236,63 & $-6,20$ & $-8,28$ & 473,27 \\
\hline 58 & 15,9 & $-7,26$ & $-10,30$ & $-5,45$ & $-4,01$ & $-14,43$ & 1,06 & $-122,03$ & 174,53 & $-5,45$ & $-6,66$ & 351,18 \\
\hline 59 & 46,9 & 2,41 & $-0,09$ & 3,75 & 1,90 & $-20,32$ & 7,88 & $-68,31$ & 68,23 & 1,78 & 2,78 & 177,44 \\
\hline 60 & 15,9 & $-2,59$ & $-6,21$ & $-4,21$ & $-4,24$ & $-7,04$ & 0,50 & $-148,25$ & 179,19 & $-2,47$ & $-4,69$ & 359,38 \\
\hline 61 & 46,9 & $-0,41$ & $-3,49$ & $-6,18$ & 0,78 & $-6,26$ & 9,43 & $-28,24$ & 40,19 & $-1,66$ & $-4,16$ & 100,82 \\
\hline 62 & 46,9 & $-1,58$ & 2,66 & $-1,61$ & $-7,13$ & $-5,28$ & 0,00 & 7,98 & 4,20 & 4,06 & $-3,29$ & 37,79 \\
\hline 63 & 37,4 & $-0,11$ & 0,00 & $-0,61$ & $-2,72$ & $-1,99$ & 0,00 & 7,28 & 0,00 & $-0,83$ & $-1,03$ & 14,56 \\
\hline 64 & 50,1 & $-4,27$ & $-1,49$ & $-1,63$ & $-1,49$ & $-3,04$ & 9,28 & 5,37 & 2,25 & 1,31 & $-6,27$ & 36,39 \\
\hline 65 & 46,8 & 2,37 & 2,27 & 1,57 & $-5,89$ & $-6,76$ & 0,63 & $-1,95$ & 3,71 & 2,46 & 1,60 & 29,20 \\
\hline 66 & 43,0 & 1,84 & 3,84 & 2,94 & $-4,06$ & $-3,50$ & 2,02 & $-5,97$ & 2,20 & 0,68 & 0,00 & 27,04 \\
\hline 67 & 43,0 & $-2,29$ & $-1,66$ & $-1,74$ & $-3,83$ & $-3,42$ & $-2,24$ & 11,82 & 6,61 & $-0,95$ & $-2,32$ & 36,87 \\
\hline 68 & 36,8 & $-0,32$ & $-5,64$ & 1,20 & $-0,67$ & $-2,62$ & $-2,19$ & 8,38 & 4,39 & $-0,82$ & $-1,70$ & 27,93 \\
\hline 69 & 70,1 & 0,93 & 0,00 & $-0,65$ & $-1,37$ & $-3,11$ & 0,00 & 3,55 & 2,61 & $-0,73$ & $-1,24$ & 14,20 \\
\hline 70 & 78,3 & 2,20 & $-2,36$ & $-0,89$ & $-3,83$ & $-5,20$ & 3,69 & 0,43 & 6,77 & 0,59 & $-1,42$ & 27,37 \\
\hline
\end{tabular}


APÊNDICE 16. Produção de frutos ( $\mathrm{t} \mathrm{ha}^{-1}$ ) e índices DRIS obtidos pelo método Elwali \& Gascho (1984) utilizando o critério de escolha da razão entre nutrientes "Valor R” em 70 pomares de macieira no Rio Grande do Sul e Santa Catarina. (Safra 2003)

\begin{tabular}{|c|c|c|c|c|c|c|c|c|c|c|c|c|}
\hline \multirow{2}{*}{ Amostra } & \multirow{2}{*}{$\begin{array}{c}\text { Produção } \\
\text { t ha }^{-1}\end{array}$} & \multicolumn{10}{|c|}{ Índices DRIS } & \multirow{2}{*}{ IBN } \\
\hline & & $\mathbf{N}$ & $\mathbf{P}$ & $\mathbf{K}$ & $\mathbf{C a}$ & Mg & $\mathbf{F e}$ & Mn & Zn & $\mathbf{C u}$ & B & \\
\hline 1 & 44,5 & $-1,29$ & 2,60 & 5,10 & 1,31 & $-0,27$ & $-10,30$ & 10,34 & 5,45 & $-13,46$ & 0,51 & 50,64 \\
\hline 2 & 43,2 & 0,11 & 2,19 & 0,09 & $-0,89$ & 1,74 & $-6,17$ & 6,92 & 3,39 & $-6,65$ & $-0,71$ & 28,87 \\
\hline 3 & 40,2 & $-3,37$ & 0,28 & $-3,66$ & 6,47 & 4,93 & $-4,66$ & $-1,32$ & 0,00 & $-2,52$ & 3,84 & 31,05 \\
\hline 4 & 33,8 & $-0,70$ & 0,53 & $-11,48$ & 9,58 & 11,51 & $-7,42$ & $-1,76$ & 0,00 & $-3,51$ & 3,26 & 49,77 \\
\hline 5 & 40,6 & 0,06 & 9,85 & 3,43 & 3,26 & $-0,88$ & $-8,33$ & $-0,86$ & 0,00 & $-7,21$ & 0,68 & 34,57 \\
\hline 6 & 40,7 & $-4,28$ & 10,95 & 11,00 & 5,83 & $-3,48$ & $-8,79$ & 3,75 & 0,82 & $-9,00$ & $-6,80$ & 64,72 \\
\hline 7 & 19,5 & $-0,80$ & 0,00 & 1,92 & $-1,61$ & 2,34 & $-4,70$ & 3,44 & 0,00 & $-0,61$ & 0,00 & 15,41 \\
\hline 8 & 28,3 & 0,56 & 0,00 & 0,00 & $-0,56$ & 0,00 & $-1,52$ & 2,13 & 0,00 & $-0,61$ & 0,00 & 5,39 \\
\hline 9 & 28,0 & $-2,50$ & $-3,07$ & $-1,01$ & $-1,84$ & 3,56 & $-4,85$ & 12,83 & 1,41 & $-3,36$ & $-1,17$ & 35,59 \\
\hline 10 & 33,6 & 1,50 & $-0,09$ & 10,72 & $-3,20$ & 1,92 & $-14,35$ & 3,32 & 0,77 & $-1,16$ & 0,58 & 37,61 \\
\hline 11 & 52,2 & $-0,49$ & $-1,42$ & $-9,76$ & $-0,20$ & 0,92 & $-6,13$ & 16,26 & 1,60 & $-0,99$ & 0,20 & 37,97 \\
\hline 12 & 58,7 & $-3,42$ & $-5,49$ & $-5,41$ & $-1,75$ & 0,53 & $-2,10$ & 20,83 & 0,63 & $-2,86$ & $-0,97$ & 43,99 \\
\hline 13 & 18,0 & $-3,59$ & $-1,61$ & 2,89 & $-1,57$ & $-0,68$ & 0,00 & 0,74 & 0,00 & 0,00 & 3,82 & 14,90 \\
\hline 14 & 15,0 & $-2,09$ & 0,00 & 2,54 & $-0,59$ & $-1,45$ & 0,00 & 0,00 & 0,00 & $-2,02$ & 3,61 & 12,29 \\
\hline 15 & 22,0 & $-4,26$ & $-2,13$ & 6,43 & $-1,38$ & $-0,65$ & $-4,47$ & 3,10 & 0,00 & $-2,55$ & 5,91 & 30,88 \\
\hline 16 & 30,0 & $-4,82$ & $-3,92$ & $-2,45$ & $-0,46$ & $-3,64$ & $-2,20$ & 17,02 & $-0,64$ & $-3,37$ & 4,48 & 43,00 \\
\hline 17 & 35,0 & $-2,99$ & $-0,88$ & 1,60 & $-0,75$ & 0,00 & 0,00 & 1,32 & 0,00 & $-2,50$ & 4,20 & 14,23 \\
\hline 18 & 25,0 & $-6,12$ & $-4,79$ & 2,14 & 0,74 & $-2,89$ & 2,56 & 10,19 & 0,00 & $-4,31$ & 2,48 & 36,22 \\
\hline 19 & 12,0 & $-1,45$ & $-1,38$ & 1,55 & $-0,75$ & $-0,77$ & 2,47 & 0,77 & 0,00 & $-4,49$ & 4,04 & 17,68 \\
\hline 20 & 35,0 & $-2,84$ & $-1,75$ & 3,85 & 0,07 & 5,47 & $-7,33$ & 9,39 & 2,06 & $-14,67$ & 5,76 & 53,18 \\
\hline 21 & 75,0 & $-2,97$ & 0,79 & $-1,56$ & 0,00 & 0,00 & 0,00 & 2,98 & 0,00 & $-2,10$ & 2,86 & 13,26 \\
\hline 22 & 30,0 & $-3,86$ & 0,79 & 1,55 & 0,00 & 0,00 & 0,00 & 1,97 & 0,00 & $-2,88$ & 2,43 & 13,47 \\
\hline 23 & 18,0 & $-2,92$ & $-0,60$ & 3,26 & $-2,83$ & 3,67 & 0,00 & 1,98 & 0,00 & $-5,58$ & 3,03 & 23,87 \\
\hline 24 & 70,0 & $-3,04$ & $-0,90$ & 0,00 & $-1,19$ & 6,74 & $-4,77$ & 3,09 & 0,56 & $-2,45$ & 1,96 & 24,71 \\
\hline 25 & 22,0 & $-0,60$ & $-2,14$ & 6,95 & $-2,58$ & 2,69 & $-8,89$ & 4,48 & 1,03 & $-5,52$ & 4,58 & 39,46 \\
\hline 26 & 18,0 & $-1,87$ & $-5,90$ & 6,56 & $-1,30$ & 2,10 & $-5,39$ & 5,62 & 0,00 & $-3,51$ & 3,69 & 35,93 \\
\hline 27 & 25,0 & $-5,65$ & $-6,32$ & 4,26 & 2,55 & 5,33 & $-6,54$ & 10,22 & 0,00 & $-6,84$ & 2,99 & 50,71 \\
\hline 28 & 52,0 & $-5,34$ & $-5,10$ & $-1,02$ & $-3,11$ & 4,00 & 2,02 & 10,54 & 1,86 & $-3,31$ & $-0,55$ & 36,85 \\
\hline 29 & 40,0 & $-0,27$ & $-1,11$ & $-2,25$ & $-0,87$ & 4,96 & 0,00 & 0,00 & 0,00 & $-2,07$ & 1,62 & 13,14 \\
\hline 30 & 57,0 & $-3,65$ & $-6,10$ & $-0,51$ & $-2,78$ & 5,27 & 1,85 & 12,32 & 6,74 & $-12,14$ & $-1,00$ & 52,36 \\
\hline 31 & 46,0 & $-0,03$ & $-1,04$ & $-3,11$ & $-0,04$ & 5,53 & 0,57 & 0,00 & 0,00 & $-4,19$ & 2,33 & 16,84 \\
\hline 32 & 49,0 & 0,65 & $-1,32$ & 0,00 & 0,00 & 0,67 & 0,56 & $-0,56$ & 0,00 & 0,00 & 0,00 & 3,77 \\
\hline 33 & 63,0 & $-3,48$ & $-4,36$ & $-1,87$ & $-2,75$ & 3,52 & $-2,55$ & 12,84 & 4,47 & $-3,60$ & $-2,22$ & 41,66 \\
\hline 34 & 40,0 & $-1,97$ & $-2,79$ & 0,79 & $-3,54$ & $-2,44$ & $-1,47$ & 12,51 & 4,03 & $-3,39$ & $-1,73$ & 34,67 \\
\hline 35 & 33,0 & 2,08 & $-0,73$ & 0,00 & $-2,09$ & 0,77 & 0,00 & 0,63 & 0,00 & $-1,24$ & 0,58 & 8,12 \\
\hline
\end{tabular}


APÊNDICE 16. Produção de frutos $\left(\mathrm{t} \mathrm{ha}^{-1}\right)$ e índices DRIS obtidos pelo método Elwali \& Gascho (1984) utilizando o critério de escolha da razão entre nutrientes "Valor R" em 70 pomares de macieira no Rio Grande do Sul e Santa Catarina. (Safra 2003)

\begin{tabular}{|c|c|c|c|c|c|c|c|c|c|c|c|c|}
\hline \multirow{2}{*}{ Amostra } & \multirow{2}{*}{$\frac{\text { Produção }}{\text { t ha }^{-1}}$} & \multicolumn{10}{|c|}{ Índices DRIS } & \multirow{2}{*}{ IBN } \\
\hline & & $\mathbf{N}$ & $\mathbf{P}$ & $\mathbf{K}$ & Ca & Mg & $\mathbf{F e}$ & Mn & n & $\mathbf{C u}$ & B & \\
\hline 36 & 32,0 & $-4,10$ & $-4,98$ & $-3,44$ & $-3,46$ & $-4,31$ & 3,41 & 15,37 & 7,70 & $-4,41$ & $-1,79$ & 52,96 \\
\hline 37 & & 0,80 & 0,00 & 0,00 & 0,00 & & 0,00 & 00 & 0,00 & $-1,62$ & 0,83 & 3,25 \\
\hline 38 & 55,0 & $-2,99$ & $-5,57$ & 1,21 & $-1,51$ & $-3,62$ & $-3,17$ & 17,37 & 8,83 & $-8,80$ & $-1,74$ & 54,80 \\
\hline 39 & 60,0 & 0,77 & 0,00 & 0,00 & 0,00 & 0,00 & 0,00 & 0,00 & 0,00 & $-0,77$ & 0,00 & 1,55 \\
\hline 40 & 25,0 & $-2,36$ & $-3,78$ & 7,25 & $-5,58$ & $-2,61$ & $-2,73$ & $-19,31$ & 34,87 & $-3,90$ & $-1,85$ & 84,24 \\
\hline 41 & 29,0 & 0,87 & $-1,69$ & $-2,93$ & $-1,92$ & 4,07 & $-1,97$ & $-46,37$ & 54,26 & $-4,10$ & $-0,22$ & 118,40 \\
\hline 42 & 34,0 & $-0,92$ & $-1,68$ & $-2,57$ & $-0,67$ & 8,08 & $-3,63$ & $-8,33$ & 25,35 & $-13,42$ & $-2,21$ & 66,86 \\
\hline 43 & 31,0 & $-0,82$ & $-2,58$ & $-6,42$ & $-3,28$ & 5,29 & $-2,18$ & $-12,68$ & 28,64 & $-5,64$ & $-0,32$ & 67,86 \\
\hline 44 & 25,0 & $-11,43$ & $-13,78$ & 0,16 & $-4,30$ & $-3,38$ & $-17,22$ & $-47,76$ & 99,17 & 3,39 & $-4,85$ & 205,44 \\
\hline 45 & 41,0 & $-1,78$ & $-9,96$ & $-0,72$ & $-0,41$ & $-0,09$ & $-13,46$ & $-23,31$ & 42,11 & 10,25 & $-2,63$ & 104,73 \\
\hline 46 & 31,0 & $-11,00$ & $-11,88$ & 0,23 & $-6,10$ & $-7,59$ & $-13,47$ & $-21,24$ & 76,41 & $-1,71$ & $-3,66$ & 153,28 \\
\hline 47 & 29,0 & $-12,26$ & $-19,80$ & 8,27 & $-8,34$ & $-10,03$ & $-15,46$ & $-18,39$ & 64,32 & 12,74 & $-1,05$ & 170,66 \\
\hline 48 & 19,0 & $-12,39$ & $-13,22$ & 3,53 & $-5,08$ & $-7,71$ & $-15,83$ & $-37,76$ & 83,53 & 7,01 & $-2,07$ & 188,13 \\
\hline 49 & & & $-10,42$ & 0,95 & & & $-11,86$ & $-18,14$ & 36,87 & 17,07 & $-1,81$ & 109,76 \\
\hline 50 & 19,0 & $-8,44$ & $-13,67$ & 2,91 & $-7,40$ & $-7,32$ & $-13,99$ & $-41,82$ & 86,34 & 9,34 & $-5,97$ & 197,20 \\
\hline 51 & 21,0 & $-10,13$ & $-13,54$ & 2,09 & $-9,79$ & $-4,51$ & $-16,11$ & $-43,92$ & 91,27 & 8,18 & $-3,54$ & 203,08 \\
\hline 52 & 38,0 & $-7,03$ & $-8,40$ & 4,06 & $-5,21$ & $-4,21$ & $-7,71$ & $-24,39$ & 37,14 & 17,03 & $-1,29$ & 116,46 \\
\hline 53 & 28,8 & $-0,03$ & $-8,61$ & 12,62 & 1,06 & $-16,96$ & $-6,66$ & $-45,41$ & 60,93 & $-5,97$ & 9,03 & 167,27 \\
\hline 54 & 21,1 & $-1,51$ & $-11,47$ & 12,72 & $-9,62$ & $-13,39$ & $-5,79$ & $-57,29$ & 89,00 & $-8,01$ & 5,36 & 214,17 \\
\hline 55 & 28,8 & 1,02 & $-7,68$ & 7,99 & 0,19 & $-9,62$ & $-1,52$ & $-41,74$ & 52,17 & $-6,19$ & 5,37 & 133,48 \\
\hline 56 & 21,1 & $-4,68$ & $-6,15$ & 9,61 & $-5,74$ & $-14,10$ & $-4,01$ & $-85,44$ & 116,82 & $-9,18$ & 2,87 & 258,61 \\
\hline 57 & 21,1 & $-4,69$ & $-13,71$ & 13,68 & $-4,62$ & $-15,78$ & $-2,57$ & $-101,83$ & 130,74 & $-8,28$ & $7,04:$ & 302,95 \\
\hline 58 & 21,1 & $-6,67$ & $-3,52$ & 6,22 & $-6,35$ & $-13,69$ & $-9,30$ & $-71,67$ & 110,08 & $-9,57$ & 4,47 & 241,54 \\
\hline 59 & 28,8 & $-1,72$ & $-10,26$ & 14,22 & $-1,82$ & $-23,48$ & $-1,24$ & $-74,41$ & 99,01 & $-11,34$ & 11,05 & 248,55 \\
\hline 60 & 21,1 & $-3,14$ & $-9,42$ & 7,75 & $-2,59$ & $-5,50$ & $-2,32$ & $-91,35$ & 101,21 & $-2,72$ & 8,08 & 234,09 \\
\hline 61 & 28,8 & $-2,04$ & $-11,43$ & 3,34 & $-1,16$ & $-8,53$ & $-3,86$ & $-25,90$ & 44,94 & $-5,43$ & 10,06 & 116,67 \\
\hline 62 & 53,3 & $-3,03$ & $-7,99$ & 7,29 & $-8,01$ & $-6,52$ & $-6,79$ & 15,69 & 10,27 & $-4,03$ & 3,12 & 72,72 \\
\hline 63 & 46,6 & 0,85 & $-7,35$ & 9,17 & $-7,88$ & $-6,67$ & $-6,31$ & 9,27 & 9,72 & $-5,85$ & 5,07 & 68,14 \\
\hline 64 & 41,7 & $-5,45$ & $-9,06$ & 2,28 & $-7,70$ & $-4,93$ & $-11,05$ & 21,65 & 20,61 & $-7,08$ & 0,75 & 90,57 \\
\hline 65 & 38,1 & 1,55 & $-6,43$ & 4,46 & $-5,40$ & $-4,02$ & 5,43 & 0,58 & 0,00 & $-2,21$ & 6,05 & 36,13 \\
\hline 66 & 37,1 & 2,15 & $-4,50$ & 4,51 & $-3,41$ & $-4,15$ & 1,28 & 0,00 & 0,00 & $-1,70$ & 5,83 & 27,52 \\
\hline 67 & 45,6 & $-4,10$ & $-7,73$ & 1,90 & $-9,29$ & $-12,17$ & $-7,64$ & 30,63 & 16,92 & $-6,48$ & $-2,05$ & 98,91 \\
\hline 68 & 46,6 & $-3,02$ & $-6,15$ & 3,06 & $-12,15$ & $-13,17$ & $-6,33$ & 26,95 & 17,16 & $-6,05$ & $-0,31$ & 94,37 \\
\hline 69 & 17,1 & $-1,72$ & $-6,36$ & 2,97 & $-3,28$ & $-3,87$ & 1,55 & $-3,55$ & 10,22 & $-3,31$ & 7,33 & 44,15 \\
\hline 70 & 21,6 & 0,25 & $-6,00$ & 3,11 & $-4,56$ & $-4,33$ & $-1,05$ & $-2,19$ & 12,39 & $-4,31$ & 6,71 & 44,89 \\
\hline
\end{tabular}


APÊNDICE 17. Produção de frutos ( $\mathrm{t} \mathrm{ha}^{-1}$ ) e índices DRIS obtidos pelo método Elwali \& Gascho (1984) utilizando o critério de escolha da razão entre nutrientes "Valor F” em 70 pomares de macieira no Rio Grande do Sul e Santa Catarina. (Safra 2002)

\begin{tabular}{|c|c|c|c|c|c|c|c|c|c|c|c|c|}
\hline \multirow{2}{*}{ Amostra } & \multirow{2}{*}{$\begin{array}{c}\text { Produção } \\
\text { t ha }^{-1}\end{array}$} & \multicolumn{10}{|c|}{ Índices DRIS } & \multirow{2}{*}{ IBN } \\
\hline & & $\mathbf{N}$ & $\mathbf{P}$ & K & $\mathbf{C a}$ & Mg & $\mathbf{F e}$ & Mn & $\mathbf{Z n}$ & $\mathbf{C u}$ & B & \\
\hline 1 & 33,0 & $-4,76$ & 6,77 & $-0,76$ & $-4,70$ & 2,92 & 0,77 & 1,70 & 0,00 & 2,34 & $-4,29$ & 29,00 \\
\hline 2 & 35,0 & $-4,84$ & 5,91 & $-2,99$ & $-4,17$ & $-1,95$ & 11,01 & 0,00 & 0,00 & 0,00 & $-2,97$ & 33,85 \\
\hline 3 & 35,0 & $-8,23$ & $-1,60$ & $-7,69$ & $-3,96$ & $-6,54$ & 64,12 & $-24,71$ & 2,53 & $-2,70$ & $-4,27$ & 126,34 \\
\hline 4 & 33,0 & $-5,83$ & $-2,88$ & $-4,29$ & $-3,63$ & $-3,48$ & 27,51 & $-4,40$ & 4,60 & $-2,48$ & $-4,35$ & 63,45 \\
\hline 5 & 39,0 & $-2,51$ & 10,86 & 8,21 & 1,60 & 0,86 & $-10,44$ & 0,68 & 0,00 & $-7,00$ & $-2,26$ & 44,43 \\
\hline 6 & 68,0 & 3,19 & 5,09 & 5,99 & 7,64 & 0,82 & $-14,67$ & $-9,18$ & $-5,26$ & 0,49 & 4,04 & 56,36 \\
\hline 7 & 18,1 & $-0,29$ & $-0,07$ & $-5,09$ & $-2,39$ & 6,11 & 0,00 & 6,38 & 1,18 & 0,00 & $-5,25$ & 26,77 \\
\hline 8 & 11,4 & $-3,31$ & $-3,16$ & $-5,28$ & $-2,76$ & $-1,34$ & 7,06 & 9,94 & 1,93 & 0,66 & $-2,77$ & 38,19 \\
\hline 9 & 24,3 & $-4,17$ & $-3,71$ & $-4,75$ & $-2,81$ & 3,90 & 7,74 & 5,50 & 0,00 & 2,30 & $-4,01$ & 38,89 \\
\hline 10 & 29,9 & $-1,27$ & $-0,05$ & 9,13 & $-0,17$ & 0,94 & 0,00 & 0,93 & $-12,04$ & 0,00 & $-1,73$ & 26,25 \\
\hline 11 & 81,7 & $-0,95$ & $-0,16$ & $-8,58$ & 5,60 & $-1,69$ & $-0,66$ & 6,73 & 0,00 & 0,91 & $-1,21$ & 26,48 \\
\hline 12 & 38,6 & 0,96 & 0,65 & $-5,40$ & 1,93 & $-0,82$ & $-1,73$ & 13,73 & $-0,77$ & $-2,93$ & $-5,63$ & 34,52 \\
\hline 13 & 85,0 & $-0,17$ & 3,83 & $-0,67$ & $-0,93$ & 0,00 & 0,00 & 0,00 & $-0,64$ & 0,00 & $-1,42$ & 7,66 \\
\hline 14 & 98,0 & $-1,30$ & 4,28 & 0,00 & $-0,08$ & $-2,17$ & 0,00 & 0,00 & 0,00 & 0,00 & $-0,73$ & 8,56 \\
\hline 15 & 80,0 & $-1,56$ & 0,88 & 0,00 & 0,68 & 0,00 & 0,00 & 0,00 & 0,00 & 0,00 & 0,00 & 3,12 \\
\hline 16 & 87,0 & $-0,58$ & 1,64 & $-3,19$ & 4,61 & $-3,39$ & 0,00 & 5,51 & $-3,09$ & 0,00 & $-1,51$ & 23,52 \\
\hline 17 & 80,0 & $-2,35$ & 0,33 & $-2,77$ & $-1,32$ & $-1,53$ & $-0,99$ & 11,82 & $-1,65$ & 0,00 & $-1,55$ & 24,31 \\
\hline 18 & 76,0 & 0,11 & 3,22 & $-5,21$ & 1,50 & $-1,62$ & 2,06 & 0,69 & 0,00 & 0,83 & $-1,57$ & 16,80 \\
\hline 19 & 104,0 & 1,04 & 1,06 & $-6,85$ & 0,70 & 0,87 & 0,91 & 0,00 & 0,00 & 1,17 & 1,10 & 13,70 \\
\hline 20 & 90,0 & $-3,85$ & 1,18 & $-3,82$ & 1,21 & 1,50 & 0,00 & 7,20 & 0,00 & 0,00 & $-3,41$ & 22,17 \\
\hline 21 & 62,0 & 5,21 & 2,97 & $-3,29$ & 2,74 & 2,23 & 4,37 & 1,56 & $-24,55$ & 5,38 & 5,22 & 57,53 \\
\hline 22 & 82,0 & $-1,72$ & 2,84 & $-1,24$ & 0,78 & $-2,59$ & 0,00 & 2,67 & $-0,74$ & 0,00 & 0,00 & 12,57 \\
\hline 23 & 79,0 & 0,58 & 0,64 & $-1,23$ & 0,00 & 0,00 & 0,00 & 0,00 & 0,00 & 0,00 & 0,00 & 2,45 \\
\hline 24 & 54,0 & $-3,59$ & 3,13 & $-1,43$ & 0,82 & 2,59 & 0,00 & 0,00 & 0,00 & 0,00 & $-1,53$ & 13,10 \\
\hline 25 & 78,0 & 0,00 & 0,00 & 0,00 & 0,00 & 0,00 & 0,00 & 0,00 & 0,00 & 0,00 & 0,00 & 0,00 \\
\hline 26 & 53,0 & 0,00 & 0,00 & 1,92 & 0,66 & 0,59 & 0,00 & 0,57 & $-5,66$ & 0,00 & 0,00 & 9,40 \\
\hline 27 & 52,0 & 2,00 & 1,47 & $-5,65$ & 0,61 & 1,79 & 1,77 & 0,64 & 0,00 & 0,70 & $-3,33$ & 17,96 \\
\hline 28 & 45,0 & $-0,56$ & $-1,20$ & 0,00 & $-1,71$ & 2,77 & 0,00 & 1,28 & 0,00 & 0,00 & $-0,58$ & 8,11 \\
\hline 29 & 40,0 & 3,95 & 1,54 & 2,45 & 0,96 & 3,34 & 11,53 & $-1,19$ & $-24,48$ & 4,77 & 1,30 & 55,51 \\
\hline 30 & 48,0 & 1,32 & 1,50 & $-5,47$ & $-1,62$ & 3,19 & 2,31 & 3,32 & 0,00 & 0,64 & $-5,19$ & 24,55 \\
\hline 31 & 44,0 & 2,74 & 5,15 & 1,57 & $-0,37$ & 3,00 & 11,21 & $-2,69$ & $-18,02$ & 0,00 & 1,04 & 45,79 \\
\hline 32 & 42,0 & 2,91 & 1,80 & $-2,46$ & 2,85 & 3,97 & 8,26 & $-1,95$ & $-13,32$ & 0,68 & $-0,07$ & 38,27 \\
\hline 33 & 60,0 & $-0,56$ & $-0,69$ & $-2,38$ & 0,10 & 2,51 & 1,94 & 3,85 & 0,00 & 0,63 & $-5,40$ & 18,06 \\
\hline 34 & 57,0 & $-0,04$ & 0,05 & 0,00 & $-1,59$ & $-0,67$ & 0,00 & 3,73 & 0,00 & 0,00 & $-1,47$ & 7,56 \\
\hline 35 & 38,0 & 3,14 & 0,82 & $-1,57$ & 0,74 & 0,84 & 6,01 & 0,00 & $-4,91$ & 0,00 & $-0,78$ & 18,81 \\
\hline
\end{tabular}


APÊNDICE 17. Produção de frutos $\left(\mathrm{t} \mathrm{ha}^{-1}\right)$ e índices DRIS obtidos pelo método Elwali \& Gascho (1984) utilizando o critério de escolha da razão entre nutrientes "Valor F" em 70 pomares de macieira no Rio Grande do Sul e Santa Catarina. (Safra 2002)

\begin{tabular}{|c|c|c|c|c|c|c|c|c|c|c|c|c|}
\hline \multirow{2}{*}{ Amostra } & \multirow{2}{*}{$\begin{array}{c}\text { Produção } \\
\text { t ha }^{-1}\end{array}$} & \multicolumn{10}{|c|}{ Índices DRIS } & \multirow{2}{*}{ IBN } \\
\hline & & $\mathbf{N}$ & $\mathbf{P}$ & $\mathbf{K}$ & $\mathbf{C a}$ & Mg & $\mathbf{F e}$ & Mn & 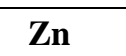 & $\mathbf{C u}$ & B & \\
\hline 36 & 43,0 & $-0,88$ & $-1,00$ & $-0,60$ & $-0,82$ & $-0,94$ & 0,00 & 5,07 & 0,00 & 0,00 & $-0,82$ & 10,13 \\
\hline 37 & 28,0 & 1,69 & 0,92 & 1,56 & 1,06 & $-0,70$ & 10,72 & 0,70 & $-14,26$ & 0,00 & 1,84 & 33,45 \\
\hline 38 & 51,0 & $-1,39$ & 2,54 & 0,98 & $-1,58$ & $-1,95$ & 0,00 & 3,10 & 0,00 & 0,00 & $-1,70$ & 13,24 \\
\hline 39 & 52,0 & 0,00 & 0,00 & 0,00 & $-0,82$ & 0,00 & 0,00 & 0,00 & 0,00 & 0,82 & 0,00 & 1,64 \\
\hline 40 & 39,0 & $-4,33$ & 1,80 & 3,65 & $-5,97$ & $-4,31$ & 9,56 & $-2,03$ & 2,03 & 2,13 & $-2,52$ & 38,33 \\
\hline 41 & 34,0 & $-2,61$ & 1,92 & $-6,12$ & $-3,48$ & $-2,44$ & 16,29 & $-2,34$ & 0,00 & 1,01 & $-2,23$ & 38,43 \\
\hline 42 & 47,0 & 0,56 & 1,34 & $-3,92$ & 0,56 & 2,06 & 5,95 & 0,78 & $-2,76$ & 0,83 & $-1,58$ & 20,35 \\
\hline 43 & 41,0 & $-0,92$ & $-0,34$ & $-10,32$ & 1,34 & 1,34 & 5,59 & 0,00 & 0,00 & 3,44 & $-0,12$ & 23,41 \\
\hline 44 & 54,0 & $-5,87$ & $-11,43$ & $-7,20$ & $-5,37$ & $-13,61$ & $-4,25$ & $-13,38$ & 77,29 & $-4,33$ & $-8,90$ & 151,64 \\
\hline 45 & 63,0 & $-2,74$ & $-5,74$ & $-5,11$ & 4,05 & $-6,58$ & $-0,04$ & $-7,44$ & 34,91 & $-2,16$ & $-6,62$ & 75,40 \\
\hline 46 & 61,0 & $-4,89$ & $-8,00$ & $-6,63$ & $-9,55$ & $-14,63$ & $-3,89$ & 23,11 & 41,35 & $-6,48$ & $-8,64$ & 127,17 \\
\hline 47 & 82,0 & $-6,19$ & $-10,51$ & $-3,32$ & $-9,52$ & $-24,51$ & $-1,40$ & 19,94 & 52,41 & $-4,49$ & $-10,75$ & 143,03 \\
\hline 48 & 60,0 & $-9,06$ & $-15,12$ & $-8,16$ & $-4,08$ & $-15,17$ & $-7,67$ & 17,22 & 59,32 & $-6,77$ & $-9,84$ & 152,41 \\
\hline 49 & 54,0 & $-3,11$ & $-5,96$ & $-3,49$ & 4,92 & $-8,12$ & $-2,45$ & $-4,79$ & 33,69 & $-3,30$ & $-6,36$ & 76,19 \\
\hline 50 & 41,0 & $-8,83$ & $-13,12$ & $-9,59$ & $-6,41$ & $-16,08$ & $-6,76$ & 23,07 & 61,63 & $-9,07$ & $-12,69$ & 167,24 \\
\hline 51 & 55,0 & $-6,10$ & $-7,92$ & $-7,37$ & $-6,68$ & $-14,60$ & $-6,36$ & 15,33 & 53,88 & $-7,46$ & $-11,74$ & 137,44 \\
\hline 52 & 53,0 & $-11,36$ & $-10,57$ & $-9,76$ & $-6,99$ & $-15,71$ & 42,98 & $-8,56$ & 43,12 & $-4,91$ & $-13,89$ & 167,83 \\
\hline 53 & 46,8 & 1,03 & 1,94 & 2,14 & 2,34 & 1,98 & 4,52 & $-45,69$ & 37,09 & $-1,01$ & $-3,32$ & 101,05 \\
\hline 54 & 75,8 & $-2,52$ & $-28,80$ & $-3,36$ & $-12,99$ & $-57,11$ & $-0,12$ & $-126,55$ & 246,21 & $-5,98$ & $-5,09$ & 488,73 \\
\hline 55 & 97,5 & 4,16 & 4,52 & 5,52 & 5,56 & $-4,76$ & 6,73 & $-24,64$ & $-4,55$ & 1,23 & 3,94 & 65,62 \\
\hline 56 & 38,1 & $-1,37$ & 5,06 & 5,54 & 4,35 & $-8,31$ & 3,03 & $-56,49$ & 47,70 & $-0,25$ & 1,15 & 133,23 \\
\hline 57 & 15,9 & $-7,08$ & $-17,32$ & $-5,77$ & $-14,71$ & $-54,07$ & $-3,81$ & $-158,98$ & 279,22 & $-7,30$ & $-7,68$ & 555,93 \\
\hline 58 & 15,9 & $-6,45$ & $-18,50$ & $-5,03$ & $-10,13$ & $-27,62$ & 0,71 & $-122,77$ & 206,60 & $-6,48$ & $-6,32$ & 410,62 \\
\hline 59 & 46,9 & 3,44 & $-1,56$ & 4,52 & 0,81 & $-28,83$ & 7,79 & $-70,39$ & 81,42 & 0,48 & 3,51 & 202,75 \\
\hline 60 & 15,9 & $-2,59$ & $-12,93$ & $-4,21$ & $-9,54$ & $-13,64$ & 1,00 & $-150,99$ & 205,19 & $-4,04$ & $-4,69$ & 408,83 \\
\hline 61 & 46,9 & $-0,48$ & $-1,97$ & $-6,74$ & 4,12 & $-10,18$ & 10,39 & $-29,76$ & 42,82 & $-1,10$ & $-3,84$ & 111,41 \\
\hline 62 & 46,9 & $-1,37$ & 1,65 & $-1,61$ & $-6,45$ & $-3,76$ & 0,00 & 7,88 & 3,07 & 4,44 & $-3,11$ & 33,34 \\
\hline 63 & 37,4 & 0,08 & $-1,28$ & $-0,61$ & $-2,46$ & $-1,45$ & 0,00 & 6,74 & 0,00 & 0,00 & $-1,03$ & 13,64 \\
\hline 64 & 50,1 & $-4,43$ & $-2,64$ & $-1,44$ & $-2,43$ & $-2,75$ & 9,28 & 6,37 & 2,86 & 1,69 & $-5,90$ & 39,78 \\
\hline 65 & 46,8 & 2,89 & 2,27 & 2,50 & $-7,40$ & $-7,28$ & 0,00 & $-0,22$ & 1,95 & 3,00 & 2,29 & 29,80 \\
\hline 66 & 43,0 & 2,30 & 4,40 & 3,80 & $-5,10$ & $-4,30$ & 1,82 & $-7,64$ & 2,20 & 1,72 & 0,81 & 34,09 \\
\hline 67 & 43,0 & $-2,29$ & $-0,54$ & $-1,74$ & $-2,35$ & $-1,71$ & $-1,70$ & 8,91 & 3,84 & 0,00 & $-2,32$ & 25,40 \\
\hline 68 & 36,8 & $-0,32$ & $-4,26$ & 1,20 & $-1,29$ & $-1,35$ & $-1,64$ & 7,36 & 1,32 & 0,00 & $-1,70$ & 20,46 \\
\hline 69 & 70,1 & 1,35 & $-0,81$ & $-0,65$ & $-1,90$ & $-2,10$ & 0,00 & 4,10 & 1,90 & 0,00 & $-1,24$ & 14,05 \\
\hline 70 & 78,3 & 2,68 & $-1,48$ & $-0,89$ & $-4,52$ & $-4,06$ & 3,58 & 1,70 & 4,98 & 0,98 & $-2,10$ & 26,97 \\
\hline
\end{tabular}


APÊNDICE 18. Produção de frutos ( $\mathrm{t} \mathrm{ha}^{-1}$ ) e índices DRIS obtidos pelo método Elwali \& Gascho (1984) utilizando o critério de escolha da razão entre nutrientes "Valor F” em 70 pomares de macieira no Rio Grande do Sul e Santa Catarina. (Safra 2003)

\begin{tabular}{|c|c|c|c|c|c|c|c|c|c|c|c|c|}
\hline \multirow{2}{*}{ Amostra } & \multirow{2}{*}{$\begin{array}{c}\text { Produção } \\
\text { t ha }^{-1}\end{array}$} & \multicolumn{10}{|c|}{ Índices DRIS } & \multirow{2}{*}{ IBN } \\
\hline & & $\mathbf{N}$ & $\mathbf{P}$ & K & $\mathbf{C a}$ & Mg & $\mathbf{F e}$ & Mn & $\mathbf{Z n}$ & $\mathrm{Cu}$ & B & \\
\hline 1 & 44,5 & $-0,91$ & 1,00 & 5,39 & 0,49 & 0,36 & $-9,58$ & 12,32 & 2,75 & $-14,99$ & 1,64 & 49,42 \\
\hline 2 & 43,2 & 0,74 & 0,97 & 0,09 & $-1,32$ & 0,44 & $-5,11$ & 9,60 & 2,68 & $-8,52$ & $-0,28$ & 29,76 \\
\hline 3 & 40,2 & $-3,44$ & $-0,13$ & $-3,04$ & 5,46 & 3,26 & $-4,22$ & 0,00 & 0,00 & $-2,83$ & 4,94 & 27,31 \\
\hline 4 & 33,8 & $-1,71$ & 0,06 & $-10,56$ & 8,50 & 11,08 & $-6,28$ & $-1,55$ & $-0,56$ & $-3,83$ & 4,86 & 49,01 \\
\hline 5 & 40,6 & $-0,28$ & 9,56 & 3,43 & 3,33 & $-1,54$ & $-7,25$ & $-1,45$ & 0,00 & $-7,60$ & 1,79 & 36,25 \\
\hline 6 & 40,7 & $-3,48$ & 10,11 & 12,38 & 5,84 & $-4,90$ & $-8,04$ & 2,49 & 0,00 & $-7,70$ & $-7,54$ & 62,46 \\
\hline 7 & 19,5 & $-1,58$ & $-0,90$ & 3,09 & $-2,89$ & 1,74 & $-3,52$ & 4,04 & 0,00 & 0,00 & 0,00 & 17,76 \\
\hline 8 & 28,3 & 1,32 & $-0,67$ & 0,00 & $-1,98$ & 1,20 & $-2,18$ & 2,31 & 0,00 & 0,00 & 0,00 & 9,65 \\
\hline 9 & 28,0 & $-2,37$ & $-2,65$ & $-1,01$ & $-1,97$ & 2,60 & $-3,51$ & 12,84 & 0,57 & $-4,17$ & $-1,17$ & 32,85 \\
\hline 10 & 33,6 & 0,80 & $-1,33$ & 12,42 & $-5,16$ & 0,75 & $-12,51$ & 3,59 & 0,00 & $-0,60$ & 1,27 & 38,44 \\
\hline 11 & 52,2 & $-0,62$ & $-1,02$ & $-8,98$ & 0,04 & 0,60 & $-4,59$ & 14,55 & 1,77 & $-1,67$ & 0,08 & 33,91 \\
\hline 12 & 58,7 & $-3,29$ & $-4,93$ & $-4,99$ & $-1,21$ & 0,70 & $-1,40$ & 19,42 & 1,25 & $-3,84$ & $-1,10$ & 42,13 \\
\hline 13 & 18,0 & $-4,33$ & $-2,54$ & 4,63 & $-2,94$ & $-2,61$ & 0,00 & 2,62 & 0,00 & 0,00 & 5,18 & 24,85 \\
\hline 14 & 15,0 & $-2,71$ & 0,00 & 3,25 & $-0,84$ & $-2,29$ & 0,00 & 0,00 & 0,00 & $-2,48$ & 5,07 & 16,64 \\
\hline 15 & 22,0 & $-5,10$ & $-3,20$ & 8,21 & $-2,08$ & $-2,52$ & $-4,51$ & 3,13 & 0,00 & $-2,33$ & 8,39 & 39,46 \\
\hline 16 & 30,0 & $-5,14$ & $-3,83$ & $-2,32$ & 0,52 & $-3,37$ & $-1,48$ & 15,58 & $-0,64$ & $-5,35$ & 6,02 & 44,24 \\
\hline 17 & 35,0 & $-3,65$ & $-1,88$ & 1,88 & $-1,03$ & 0,00 & 0,00 & 1,25 & 0,00 & $-2,28$ & 5,71 & 17,69 \\
\hline 18 & 25,0 & $-5,75$ & $-3,82$ & 2,45 & $-0,69$ & $-2,48$ & 0,00 & 11,36 & 0,00 & $-5,63$ & 4,56 & 36,74 \\
\hline 19 & 12,0 & $-1,65$ & $-0,88$ & 2,32 & $-0,38$ & $-0,88$ & 0,00 & 0,00 & 0,00 & $-5,01$ & 6,46 & 17,57 \\
\hline 20 & 35,0 & $-3,30$ & $-1,71$ & 4,12 & $-1,36$ & 3,99 & $-6,53$ & 11,07 & 1,11 & $-16,47$ & 8,13 & 57,78 \\
\hline 21 & 75,0 & $-3,27$ & 0,08 & $-1,43$ & $-0,81$ & $-0,76$ & 0,00 & 3,98 & 0,00 & $-1,29$ & 3,50 & 15,13 \\
\hline 22 & 30,0 & $-4,48$ & 0,16 & 1,81 & $-0,61$ & $-1,50$ & $-0,58$ & 3,42 & 0,00 & $-2,30$ & 4,07 & 18,93 \\
\hline 23 & 18,0 & $-3,36$ & $-1,31$ & 3,99 & $-4,33$ & 3,44 & $-0,77$ & 3,05 & 0,00 & $-4,88$ & 4,15 & 29,29 \\
\hline 24 & 70,0 & $-3,13$ & $-0,30$ & 0,00 & $-1,10$ & 6,44 & $-3,48$ & 1,66 & 0,00 & $-1,98$ & 1,32 & 19,41 \\
\hline 25 & 22,0 & $-1,52$ & $-3,57$ & 7,74 & $-4,28$ & 1,48 & $-7,87$ & 5,04 & 0,00 & $-4,68$ & 6,63 & 42,82 \\
\hline 26 & 18,0 & $-2,43$ & $-5,92$ & 7,32 & $-3,46$ & 2,25 & $-4,78$ & 4,29 & 0,00 & $-2,75$ & 5,49 & 38,69 \\
\hline 27 & 25,0 & $-6,04$ & $-6,25$ & 4,56 & 0,63 & 4,58 & $-5,60$ & 11,50 & 0,00 & $-8,07$ & 4,68 & 51,92 \\
\hline 28 & 52,0 & $-4,43$ & $-3,01$ & $-1,02$ & $-2,54$ & 2,87 & 0,00 & 11,32 & 1,26 & $-4,10$ & $-0,34$ & 30,90 \\
\hline 29 & 40,0 & $-0,14$ & $-1,11$ & $-1,82$ & $-0,76$ & 4,41 & 0,00 & 0,00 & 0,00 & $-2,46$ & 1,88 & 12,57 \\
\hline 30 & 57,0 & $-2,72$ & $-3,47$ & $-0,51$ & $-1,48$ & 4,18 & 0,00 & 13,36 & 5,78 & $-13,71$ & $-0,43$ & 45,63 \\
\hline 31 & 46,0 & 0,10 & $-1,04$ & $-2,67$ & $-0,06$ & 4,98 & 0,57 & 0,00 & 0,00 & $-4,59$ & 2,72 & 16,75 \\
\hline 32 & 49,0 & 0,65 & $-1,32$ & 0,00 & $-0,56$ & 1,23 & 0,00 & 0,00 & 0,00 & 0,00 & 0,00 & 3,77 \\
\hline 33 & 63,0 & $-3,35$ & $-3,12$ & $-1,87$ & $-2,19$ & 2,94 & $-1,90$ & 13,06 & 3,74 & $-4,41$ & $-2,84$ & 39,42 \\
\hline 34 & 40,0 & $-1,26$ & $-1,68$ & 1,18 & $-3,38$ & $-1,34$ & $-0,93$ & 11,28 & 1,99 & $-4,12$ & $-1,73$ & 28,89 \\
\hline 35 & 33,0 & 2,26 & $-1,30$ & 0,00 & $-2,42$ & 0,66 & 0,00 & 0,57 & 0,00 & $-1,50$ & 1,73 & 10,42 \\
\hline
\end{tabular}


APÊNDICE 18. Produção de frutos $\left(\mathrm{t} \mathrm{ha}^{-1}\right)$ e índices DRIS obtidos pelo método Elwali \& Gascho (1984) utilizando o critério de escolha da razão entre nutrientes "Valor F" em 70 pomares de macieira no Rio Grande do Sul e Santa Catarina. (Safra 2003)

\begin{tabular}{|c|c|c|c|c|c|c|c|c|c|c|c|c|}
\hline \multirow{2}{*}{ Amostra } & \multirow{2}{*}{$\frac{\text { Produção }}{\text { t ha }^{-1}}$} & \multicolumn{10}{|c|}{ Índices DRIS } & \multirow{2}{*}{ IBN } \\
\hline & & $\mathbf{N}$ & $\mathbf{P}$ & $\mathbf{K}$ & $\mathrm{Ca}$ & Mg & $\mathbf{F e}$ & Mn & nn & $\mathrm{Cu}$ & $\mathbf{B}$ & \\
\hline 36 & 32,0 & $-3,85$ & $-2,30$ & $-3,44$ & $-1,96$ & $-1,88$ & 0,58 & 14,66 & 5,91 & $-5,71$ & $-0,73$ & 41,01 \\
\hline 37 & - & 0,80 & 0,00 & 0,00 & $-0,79$ & $-0,84$ & 0,00 & 0,00 & 0,00 & 2,09 & 2,92 & 7,44 \\
\hline 38 & 55,0 & $-3,25$ & $-3,86$ & 1,47 & $-0,29$ & $-1,93$ & $-2,46$ & 16,07 & 5,55 & $-10,16$ & $-1,29$ & 46,34 \\
\hline 39 & 60,0 & 0,77 & 0,00 & 0,00 & 0,00 & 0,00 & 0,00 & 0,00 & 0,00 & $-1,66$ & 0,89 & 3,32 \\
\hline 40 & 25,0 & $-2,50$ & $-6,64$ & 8,78 & $-10,37$ & $-0,41$ & $-2,73$ & $-19,31$ & 37,47 & $-4,78$ & $-0,85$ & 93,84 \\
\hline 41 & 29,0 & 0,87 & $-3,73$ & $-2,64$ & $-3,66$ & 6,72 & $-2,12$ & $-50,02$ & 58,89 & $-3,48$ & $-0,22$ & 132,35 \\
\hline 42 & 34,0 & $-0,78$ & 0,07 & $-2,27$ & 0,80 & 7,87 & $-3,14$ & $-8,90$ & 21,60 & $-13,32$ & $-1,60$ & 60,36 \\
\hline 43 & 31,0 & $-0,82$ & $-0,83$ & $-5,84$ & $-5,62$ & 5,81 & $-2,18$ & $-12,05$ & 29,39 & $-6,08$ & $-0,67$ & 69,29 \\
\hline 44 & 25,0 & $-12,56$ & $-22,63$ & 1,23 & $-10,01$ & $-9,51$ & $-17,23$ & $-46,82$ & 113,33 & 3,54 & $-5,23$ & 242,09 \\
\hline 45 & 41,0 & $-2,24$ & $-14,12$ & $-0,72$ & $-3,42$ & 0,87 & $-12,99$ & $-21,53$ & 43,58 & 9,39 & $-1,60$ & 110,44 \\
\hline 46 & 31,0 & $-11,61$ & $-20,52$ & 1,40 & $-12,95$ & $-14,92$ & $-13,97$ & $-21,24$ & 92,91 & $-1,71$ & $-2,54$ & 193,75 \\
\hline 47 & 29,0 & $-13,09$ & $-29,73$ & 10,19 & $-15,93$ & $-17,22$ & $-16,67$ & $-17,12$ & 78,55 & 13,46 & 1,13 & 213,09 \\
\hline 48 & 19,0 & $-13,09$ & $-21,51$ & 4,73 & $-11,59$ & $-13,39$ & $-17,04$ & $-36,84$ & 96,72 & 7,30 & $-1,43$ & 223,64 \\
\hline 49 & 36,0 & $-6,18$ & $-14,76$ & 1,23 & $-5,67$ & $-8,35$ & $-12,06$ & $-16,96$ & 43,81 & 16,50 & $-0,48$ & 125,99 \\
\hline 50 & 19,0 & $-8,15$ & $-21,91$ & 3,84 & $-14,68$ & $-13,18$ & $-15,11$ & $-40,72$ & 100,93 & 8,75 & $-5,10$ & 232,36 \\
\hline 51 & 21,0 & $-10,10$ & $-22,01$ & 2,88 & $-18,15$ & $-10,48$ & $-16,78$ & $-42,87$ & 106,00 & 7,65 & $-1,93$ & 238,85 \\
\hline 52 & 38,0 & $-7,58$ & $-12,30$ & 4,80 & $-10,18$ & $-1,98$ & $-8,20$ & $-22,83$ & 39,27 & 16,20 & 0,78 & 124,12 \\
\hline 53 & 28,8 & $-0,26$ & $-14,02$ & 14,40 & $-1,20$ & $-25,92$ & $-7,92$ & $-44,99$ & 71,51 & $-6,48$ & 12,17 & 198,86 \\
\hline 54 & 21,1 & $-1,62$ & $-18,42$ & 14,86 & $-16,10$ & $-23,65$ & $-6,78$ & $-56,31$ & 106,45 & $-8,50$ & 7,57 & 260,26 \\
\hline 55 & 28,8 & 0,81 & $-12,49$ & 9,36 & $-2,66$ & $-15,87$ & $-1,03$ & $-42,36$ & 62,03 & $-6,68$ & 7,95 & 161,24 \\
\hline 56 & 21,1 & $-5,02$ & $-11,96$ & 11,49 & $-11,49$ & $-24,99$ & $-3,44$ & $-87,52$ & 135,33 & $-9,05$ & 4,65 & 304,94 \\
\hline 57 & 21,1 & $-5,19$ & $-21,76$ & 15,81 & $-10,26$ & $-27,20$ & $-2,49$ & $-102,45$ & 151,90 & $-9,74$ & 9,42 & 356,23 \\
\hline 58 & 21,1 & $-7,11$ & $-8,23$ & 7,66 & $-12,41$ & $-23,44$ & $-10,60$ & $-72,28$ & 126,18 & $-10,12$ & 6,84 & 284,86 \\
\hline 59 & 28,8 & $-2,10$ & $-16,47$ & 16,38 & $-5,16$ & $-36,31$ & $-0,45$ & $-76,52$ & 117,50 & $-12,75$ & 14,26 & 297,91 \\
\hline 60 & 21,1 & $-3,81$ & $-14,93$ & 8,99 & $-6,38$ & $-10,89$ & $-1,64$ & $-93,34$ & 114,84 & $-4,44$ & 10,20 & 269,48 \\
\hline 61 & 28,8 & $-2,17$ & $-16,62$ & 3,86 & $-4,14$ & $-14,43$ & $-4,37$ & $-25,90$ & 55,59 & $-6,04$ & 13,39 & 146,50 \\
\hline 62 & 53,3 & $-3,41$ & $-6,38$ & 8,79 & $-7,04$ & $-5,25$ & $-5,28$ & 13,75 & 4,45 & $-5,62$ & 4,85 & 64,82 \\
\hline 63 & 46,6 & 0,84 & $-6,12$ & 10,76 & $-7,37$ & $-6,09$ & $-6,10$ & 7,74 & 4,20 & $-6,98$ & 7,53 & 63,72 \\
\hline 64 & 41,7 & $-5,38$ & $-11,95$ & 2,99 & $-10,73$ & $-1,70$ & $-11,32$ & 19,29 & 22,71 & $-8,49$ & 2,63 & 97,20 \\
\hline 65 & 38,1 & 2,48 & $-8,09$ & 5,46 & $-7,47$ & $-6,26$ & 4,91 & 2,82 & 0,00 & $-2,05$ & 8,21 & 47,75 \\
\hline 66 & 37,1 & 1,58 & $-4,39$ & 6,34 & $-4,53$ & $-4,85$ & 0,00 & 0,00 & 0,00 & $-2,12$ & 7,96 & 31,77 \\
\hline 67 & 45,6 & $-3,94$ & $-5,79$ & 3,24 & $-12,19$ & $-15,43$ & $-6,23$ & 27,62 & 19,57 & $-7,60$ & $-0,45$ & 102,06 \\
\hline 68 & 46,6 & $-3,53$ & $-3,75$ & 4,58 & $-15,69$ & $-16,79$ & $-5,18$ & 24,22 & 20,57 & $-7,07$ & 1,64 & 103,03 \\
\hline 69 & 17,1 & $-2,88$ & $-5,28$ & 4,61 & $-2,96$ & $-2,93$ & 0,00 & $-2,89$ & 7,17 & $-3,86$ & 9,77 & 42,35 \\
\hline 70 & 21,6 & 0,33 & $-6,00$ & 4,00 & $-5,07$ & $-4,98$ & $-1,05$ & $-0,20$ & 7,69 & $-4,06$ & 9,17 & 42,55 \\
\hline
\end{tabular}

